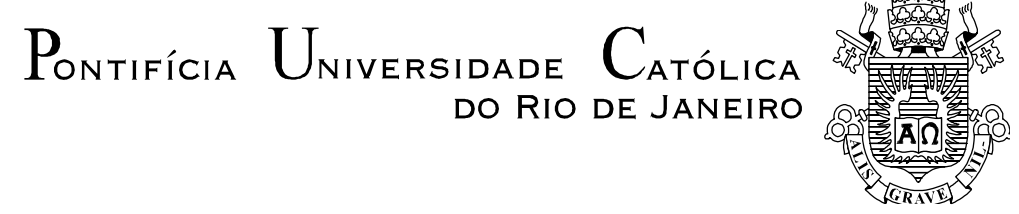

Dayana Enríquez Burbano

\title{
Mobilidade eficiente para cidades compactas e menos segregadas: O Plano Urbanístico do Centro Ampliado de Bogotá
}

\author{
Dissertação de Mestrado
}

Dissertação apresentada ao Programa de Pósgraduação em Engenharia Urbana e Ambiental da PUC-Rio como requisito parcial para obtenção do grau de Mestre em Engenharia Urbana e Ambiental.

Orientador: Prof. Hugo Miguel Varela Repolho Co-orientador: Prof. Rafael da Silva Nunes 

Pontifícia Universidade $_{\text {do Rio de Janeiro }}$

Dayana Enríquez Burbano

Mobilidade eficiente para cidades compactas e menos segregadas: O Plano Urbanístico do Centro Ampliado de Bogotá

Dissertação apresentada como requisito parcial para obtenção do grau de Mestre pelo Programa de Pós-Graduação em Engenharia Urbana e Ambiental da PUC-Rio. Aprovada pela Comissão Examinadora abaixo assinada.

Prof. Hugo Miguel Varela Repolho Orientador Departamento de Engenharia Industrial - PUC-Rio

Prof. Nélio Domingues Pizzolato Departamento de Engenharia Industrial - PUC-Rio

Prof. Annibal Parracho Sant'Anna UFF

Prof. Márcio da Silveira Carvalho Coordenador Setorial do Centro Técnico Científico - PUC-Rio

Rio de Janeiro, 07 de agosto de 2017 
Todos os direitos reservados. É proibida a reprodução total ou parcial do trabalho sem a autorização da universidade, do autor e do orientador.

\section{Dayana Enríquez Burbano}

Graduou-se em Engenharia Civil pela Universidade de Nariño - UDENAR, em 2008. Título revalidado na Universidade de Brasília UnB, em 2014.

Ficha Catalográfica

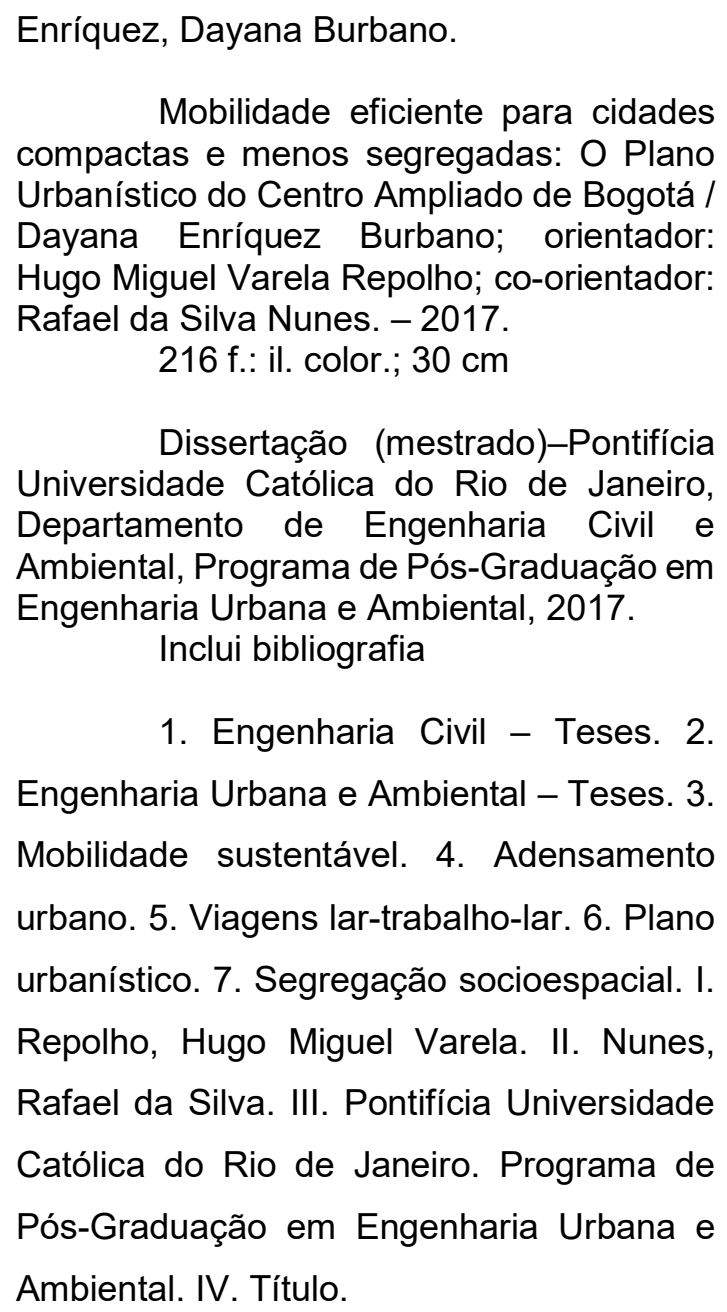




\section{Agradecimentos}

Agradeço aos meus pais Hernando Enríquez e Alicia Burbano pelo apoio recebido.

Agradeço ao meu orientador Hugo Repolho, co-orientador Rafael Nunes

Agradeço aos Doutores Nélio Pizzolato e Jean de Faria pela dedicada ajuda.

Agradeço aos Professores, Diretores e Colegas do Mestrado em Engenharia Urbana e Ambiental pela agradável companhia na minha estadia no Rio de Janeiro. 


\section{Resumo}

Enríquez, Dayana Burbano; Varela, Hugo Miguel Repolho (Orientador); Da Silva, Rafael Nunes (co-orientador). Mobilidade eficiente para cidades compactas e menos segregadas: O Plano Urbanístico do Centro Ampliado de Bogotá. Rio de Janeiro, 2017. 216p. Dissertação de Mestrado. Departamento de Engenharia Civil e Ambiental, Pontifícia Universidade Católica do Rio de Janeiro.

A Prefeitura de Bogotá, publicou em 2015 o Plano Urbanístico do Centro Ampliado de Bogotá (PUCAB) cujo objetivo principal era diminuir a segregação socioespacial evidente nos limites geográficos da cidade, onde nas periferias habita a classe socioeconômica baixa, e no centro da cidade habitam as classes média e alta, ao mesmo tempo em que é almejado o adensamento da cidade, alocando pessoas num número equivalente ao aumento populacional para o ano 2020 no setor analisado e delimitado geograficamente sob condições de mobilidade de tempos de chegada aos polos de emprego em máximo 20 minutos nos transportes públicos e 10 minutos a pé até as estações dos sistemas coletivos, isso desde qualquer ponto dentro do setor do Centro Ampliado. A partir do objetivo geral de alocar pessoas de classe socioeconômica baixa no centro da cidade e, das variáveis de delimitação geográfica, deduz-se a intensão de alocar à população adensada em zonas em que são permitidos os percursos curtos lar-trabalho-lar, de onde surge a hipótese de tese do não cumprimento de tempos máximos de 20 minutos nos transportes públicos ainda submetidos ao transito veicular no setor do PUCAB; comprovação feita com base nas pesquisas da Secretaria Distrital de Mobilidade (2015). Avalia-se o limite geográfico do setor do PUCAB e se apresentam metodologias de priorização de adensamento em zonas em que são permitidos os deslocamentos curtos das casas à maior oferta de emprego e, outras atividades habituais dos cidadãos.

\section{Palavras-chave}

Otimização no tempo de percurso; mobilidade sustentável; adensamento urbano; segregação socioespacial. 


\section{Extended Abstract}

Enríquez, Dayana Burbano; Varela, Hugo Miguel Repolho (Advisor); Da Silva, Rafael Nunes (Co-Advisor). Efficient mobility for compact and less segregated cities: the urban plan of expanded center from Bogotá. Rio de Janeiro, 2017. 216p. Dissertação de Mestrado. Departamento de Engenharia Civil e Ambiental, Pontifícia Universidade Católica do Rio de Janeiro.

The Bogota Humana series (2015) published a book entitled Urbanistic Plan for the Enlarged Bogota's Downtown (PUCAB in Spanish) aimed at turning Bogota into a more egalitarian and environmentally friendly city, with spaces where sustainable mobility is promoted. Among other objectives, the book proposes a structured densification of the historical downtown and nearby sectors of Bogotá, the Colombian capital city. The project intended to mitigate the existing sociospatial segregation characterized by low class people living towards the city periphery and middle-high classes living in the so-called Enlarged Downtown. The search for social inclusion should be promoted in Bogota by forcing spatial inclusion, i.e., by dislocating low class population to central areas equipped with better public facilities (TORRES et al. 2009). The dislocated population will benefit from subsidies programs similar to the ones they now receive.

The advantages of concentrating low class residences close to high employment areas are obvious as most of these people have precarious labor conditions and commute long distances (ALCALDÍA DE BOGOTÁ, 2015). The economy of Bogota is mostly based in factories and sales, which employ low class employers (GUTIÉRREZ, 2011). This fact underscores the convenience of dislocating these people who presently commute mostly from the periphery, so that they can get better access to jobs with shorter commutes, and eventually to other job offers. The densification initiative is understood as an activity that precedes economic growth for the city and the country, while improving urban mobility through decreasing pendulum-like tides, originated by people who live in the periphery and work downtown.

Though urban zoning is coherent with the Urban Plan main goal regarding socio-spatial segregation, it is not part of the land zoning variables defined in the same document. Because of this, there is a discussion about the environmental and socio viability of densifying the enlarged Bogota downtown. The discussion is mentioned but scarcely analyzed in the Urban Plan.

The Enlarged Bogota's Downtown has a great amount of urban facilities and a housing deficit. The boundaries of the area were set such that

"public transport commutes of less than 20 minutes to the zones generating the greatest amount of employment in the city, and access to the integrated transportation system by less than 10 minutes walking" (ALCALDÍA DE BOGOTÁ, 2015). 
The research highlights mobility as the main variable for geographical markup of the urban and zoning plans, as it depends on the occupation of land under such documents. When analyzing the geographical mark-up of the PUCAB and the mobility restrictions that were used as bounding rules, one may question whether the area defined by the document accomplishes them. In fact, the 20 minutes maximum commute using public transportation it is not possible between all $\mathrm{O} / \mathrm{D}$ pairs, due to traffic jam conditions present in Bogota city (GIZ; BMZ, 2017). Discussions about the Enlarged Bogota's Downtown boundaries are then necessary.

This context shows a dynamic city that depends on the citizen's criterion for its transformation through the transmission of knowledge and philosophies that, together, enrich the urban policies needed to generate law proposals that answer social needs (regarding land use) possible when communication is allowed between people from different social and economic levels in public spaces such as parks, bike lanes, massive public transportation, walk ways even for long walks in the city.

Spaces that promote social integration have multiple functions, among them allowing efficient mobility (understood in this text as the optimization of homework commuting time). There is an urban perception that citizen's happiness regarding urban environment is inversely proportional to commuting time (ONS, 2014) and proportional to the availability and quality of collective sustainable transports. A street may be classified as incomplete when it is made only for the traditional goal of allowing the efficient motion of motor vehicles. A complete street is a space that allows the efficient motion of cars, bikes, pedestrians. This has to be a place where people can interact and move regardless of owning a motor vehicle; it is about a fair urban connectivity (AGYEMAN \& ZAVETOVSKI, 2015).

From the above concept, the Urban Plan's effort to integrate all urban components as intertwined elements is interpreted as it is possible to affect the citizens' living conditions with improvement policies interventions in any city aspect, achieving a sound mobility, with a regular flow in spaces free of contamination.

This work shows the no-fulfilment of commutes in less than 20 minutes from home to the zones of highest employment generation in public transportation according to the District Mobility Secretary surveys (SDM, 2015), and presents methodologies for prioritizing areas for densification under the conditions of short commutes from home to work, from the case study of PUCAB. A different approach is presented, one with a prioritization of zones to be densified in order to locate homes near to all usual activities, for which people commute in the highest amount from the periphery to Bogota downtown, without overlooking the scenario of placing homes close to jobs, because employment is the greatest attractor of displacement to downtown.

The prioritization of zones to be densified to meet the pretense of PUCAB to allow short commutes from home to work, consults the District Mobility Secretary surveys (SDM, 2015). Bearing in mind that this survey studies the Zones of 
Transportation Analysis (ZAT) to determine mobility patterns according to demographic and socio-economic features of the studied population, corresponding to residents of Bogota and 17 neighboring towns, older than 5 years old.

Priority areas to be densified under conditions of mobility in under 20 minutes in public transportation from home to work are delivered in this same measurement unit ZAT.

Database consultation:

Table 1 - Amount of travels or displacements for each ZAT zone because of employment. Source: Moility survey (SDM, 2015).

\begin{tabular}{|r|r|r|r|}
\hline B & D & E & N \\
\hline 3 & 1 & 1 & 568 \\
\hline 3 & 1 & 1 & 471 \\
\hline 1 & 1 & 1 & 198 \\
\hline 1 & 1 & 1 & 230 \\
\hline
\end{tabular}

"B": amount of people per interview moving to target ZAT zone.

"D": reason of travel, employment $=1(\mathrm{SDM}, 2015)$.

"E": destination town, Bogota $=1\left(\right.$ DANE, 2005) ${ }^{1}$

"N": target ZAT zone.

Before presenting the prioritization methodology of zones to be densified under the Urban Plan commute condition, it is necessary to set-up the OriginDestination (OD) time matrix of public transportation in Bogota and its 17 neighboring towns that form the region of study in the Mobility Survey (SDM, 2015). It is relevant to take the whole set of regions to check up commutes, since the proposal is to densify zones within the enlarged downtown, but being able to cover a perimeter of job offer even outside of this sector, provided that the travel takes less than the 20 minutes of the mobility condition. Like other authors, zones are considered major employment offer ones if they attract the greatest amount of people for that reason. Below it will be clear how the calculations determine the major employment offer zones.

Table 1 consultation, results in the number of people that travel to a certain region or ZAT ("B”), named Travel Number ( $N k)$ for setting-up commute time matrices. In this case there are 365 zones ( $j$ ) making-up the Enlarged Downtown, since the home can be located in any ZAT within the sector boundaries described by PUCAB. If there is at least one travel motivated by employment to any ZAT of the Mobility survey (SDM, 2015), this zone will be placed in row $(k)$.

Calculations cannot be displayed in whole due to the size of the matrix including 365 Origin zones $(j)$ and 790 employment-motivated Destination ZAT.

\footnotetext{
${ }^{1}$ (DANE, 2005): provinces and sub-regions.
} 


\begin{tabular}{|c|c|c|c|c|c|c|c|c|}
\hline \multicolumn{9}{|c|}{ Destination zones $k$} \\
\hline ZAT & 1 & 3 & 4 & 6 & 7 & $\mathrm{Aj}$ & $\mathrm{Zj}$ & $\mathrm{Aj}$ \\
\hline & 18 & 18 & 30 & 9 & 77 & & & \\
\hline 167 & 60,72 & 55,33 & 38,91 & 37,71 & 20,33 & 13,36 & 10662 & 31,56 \\
\hline 168 & 37,87 & 32,75 & 24,9 & 23,7 & 22,05 & 12,56 & 12958 & 38,35 \\
\hline 169 & 49,75 & 38,92 & 37,19 & 35,99 & 26,69 & 13,21 & 15267 & 45,19 \\
\hline 170 & 36,97 & 38,38 & 30,53 & 29,33 & 25,99 & $\Delta 12,47$ & 12873 & 38,10 \\
\hline 171 & 60,72 & 55,33 & 41,79 & 40,59 & 25,57 & 13,18 & 12814 & 37,93 \\
\hline
\end{tabular}

Figure 1 - Matrix of O/D times in public transportation.

Source: Own, based on information from the Mobility Survey (SDM, 2015).

ZAT: ID numbering of ZAT's.

$k$ : row.

$j$ : column.

Origin Zone $j$ : Origin ZAT zone in the first column to the left.

Destination Zone $k$ : Destination ZAT zone in the upper row.

T $j k$ (min): Matrix nucleus of travel times from Origin zones $(j)$ to Destination zones $(k)$ in public transportation.

$N k$ : amount of travels attracted by Destination zone $(k)$

$\triangle$ : Hidden cells between Destination zone ZAT 7 and Pj.

$\mathbf{P} \boldsymbol{j}=$ Mean time in minutes of those travels of less than 20 minutes from each Origin zone to all Destintion zones.

$\mathbf{Z} \mathbf{j}=$ Amount of travels attracted by Destination zones in less than 20 minutes, per Origin zone.

$\mathbf{A} \boldsymbol{j}=$ Percent of Destination zones coverage, due to employment, in commutes under 20 minutes, from each Origin zone.

$\mathbf{N T} \boldsymbol{j}=$ Total amount of $\mathrm{T} j . k \leq 20$ in commutes from each Origin zone $(j)$ to D.

$\mathbf{D}=$ Total amount of Destination zones (Destination zone universe)

Equation 1:

$$
P j=\frac{\sum_{\substack{k=1 \\ T j . k \leq 20}}^{D} T j . k}{\mathrm{NT} j}
$$

Equation 2:

$$
Z j=\sum_{\substack{K=1 \\ T j . k \leq 20}}^{D} N k
$$




$$
A j=\frac{\mathrm{Zj} x 100}{\sum_{k=1}^{D} N k}
$$

After calculating the mean time and the coverage of zones reachable in commutes under 20 minutes from each zone within the enlarged downtown, higher weights are assigned to the ZAT's of PUCAB sectors with a greater coverage $(A j)$ and less mean commute time under the mobility condition. $\mathrm{Aj}$ is greater when attracts more commutes due to employment $(N k)$, guaranteeing a greater priority to areas that can be reached in under 20 minutes and, at the same time, generating the most employment.

This calculation allows singling out areas that shall be densified for citizens to be able to access the greatest amount of job offerings and commute in less than 20 minutes. PUCAB suggests some sectors for densification; nevertheless, these sectors are found in a middle densification priority according to the analysis methodology proposed in this investigation.

On the other hand, there are optimal zones for densification which are not included in the specific proposals of the Urban Plan, but are considered in Decree 562 of 2014 as areas prone to densification.

See Figure 1 with the result for densification of green, yellow and red areas, in priority order. 

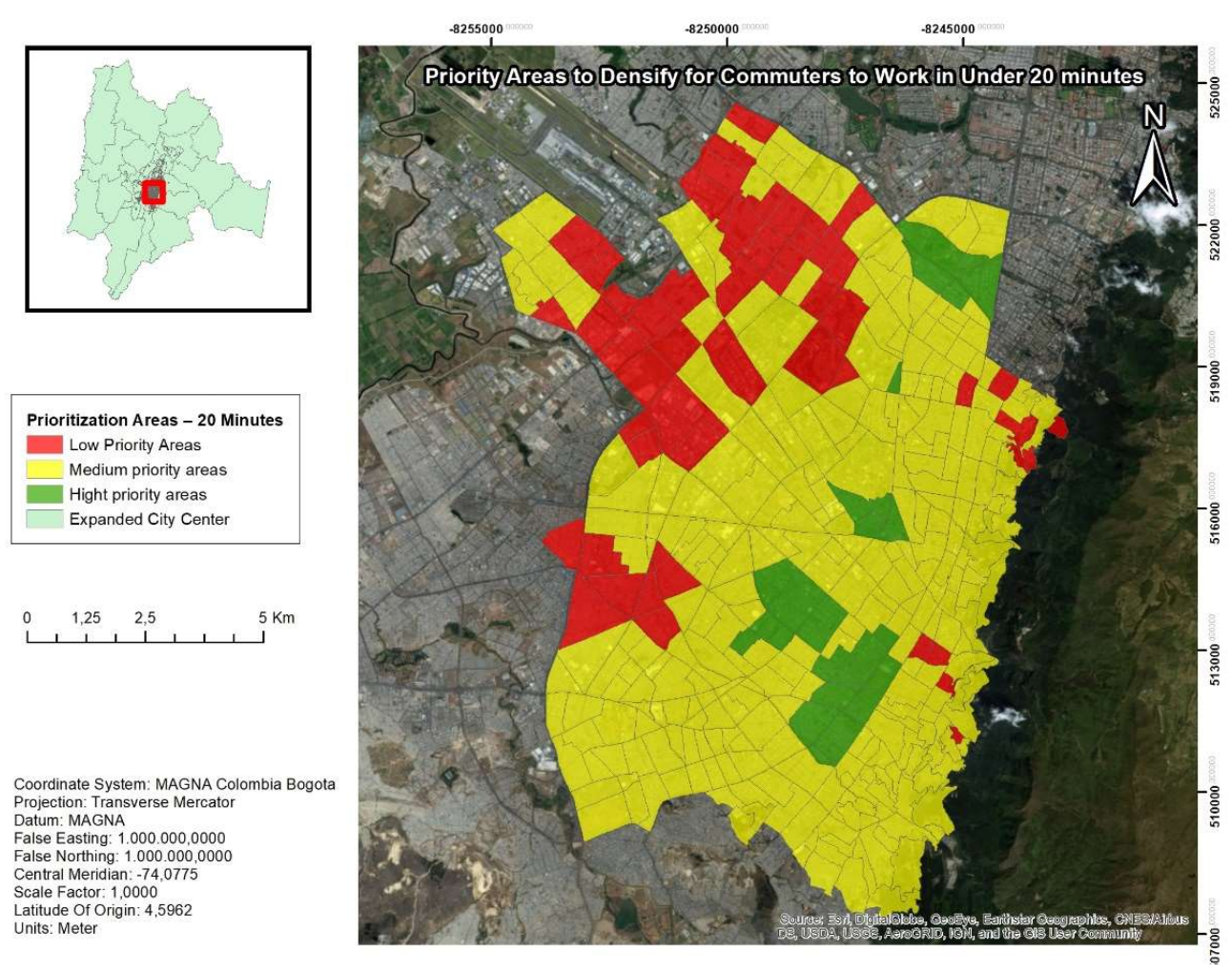

Figure 1 - Prioriy areas to densify for commuters to work in under 20 minutes.

Font: Efficient mobility for compact and less segregated cities: the urban plan of expanded center from Bogotá.

The map represented in Figure 1 can be superposed to the specific proposals of the Urban Plan for comparison of prioritization areas. Lilac stands for high priority, pink for middle priority and orange for low priority. There is a hot pink area because there are 2 areas from the PUCAB specific proposals that ovelap in the same sector, only 1 of there areas is orange or low priority to densify.

It can be noticed in the following map that most of the specific proposals fall within the yellow area which corresponds to middle priority according to the mobility and employment conditions. 


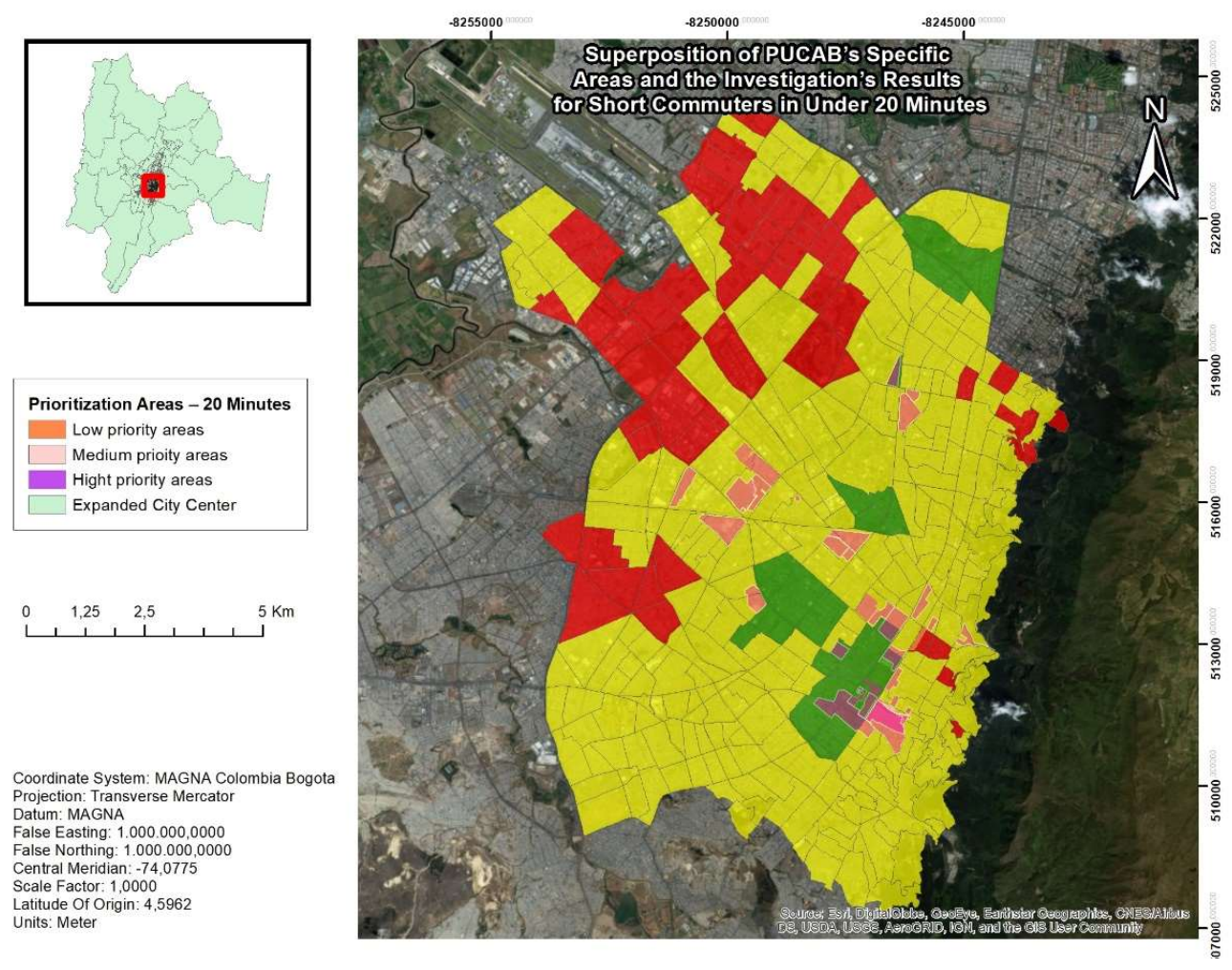

Figure 2 - Superpotition of PUCAB'S especific areas and the investigation's results for short commuters to work in under 20 minutes.

Font: Efficient mobility for compact and less segregated cities: the urban plan of expanded center from Bogotá.

It is possible to apply this method for commutes of under 30 or under 40 minutes in public transportation from home to work, since investigations in ideal and tolerance times for short-duration/long-duration commuters are scarce and arrive at different conclusions. It can also be adapted for different reasons people might have to go to downtown, as a sensibility scenario.

This investigation concludes with the viability to densify the PUCAB's sector, based in the little area available in Bogota for urban expansion (IDECA, 2017) and other reasons like protecting the environmental preservation areas and countering social segregation. But for mobility conditions exist other areas to densify as better options than PUCAB's specific proposals.

\section{Keywords}

Travel time optimization; sustainable mobility; urban density; socio-spatial segregation. 


\section{Sumário}

1 Introdução 22

1.1. Estrutura da dissertação 23

2 Interpretação da relação entre componentes urbanísticos para um consequente fluxo regular da mobilidade urbana 27

2.1. Mobilidade eficiente

3 Ocupação do solo urbano após época da industrialização

3.1. Referências normativas para delimitações e adensamentos geográficos da ocupação do solo urbano em Bogotá D.C.

3.1.1. Referências normativas relevantes para adensamento em Bogotá a partir da lei 388 de 1997, artigo 13 da regulamentação dos Planos Diretores

4 Premissas socioeconômicas: conquistas na inclusão social viabilizadoras da inclusão espacial dentro dos limites geográficos do PUCAB

4.1. Uma comparação entre o Rio de Janeiro e Bogotá na urbanização de favelas

4.2. Uma comparação do Rio de Janeiro e Bogotá sobre as lacunas salariais

5 Premissas ambientais coerentes com os limites geográficos do PUCAB

6.1. Discussão sobre as zonas de maior geração de emprego da cidade de Bogotá: elemento das condições de mobilidade para a delimitação geográfica do PUCAB

6.2. Discussão sobre os tempos de percursos das casas aos empregos: elemento das condições de mobilidade para delimitação geográfica do PUCAB 
7 Generalidades das pesquisas de mobilidade (SDM, 2015)

8 Metodologia

8.1. Comprovação do não cumprimento das condições de mobilidade do PUCAB:

8.2. Priorização de zonas a serem adensadas para percursos curtos das casas aos empregos.

8.3. Priorização de zonas a serem adensadas para percursos curtos das casas às atividades habituais

9 Discussões

102

10 Conclusões

11 Referências bibliográficas

Apêndices

Anexos 


\section{Lista de Figuras}

Figura 01 - Premissas de delimitação geográfica do Plano

Urbanístico do Centro Ampliado de Bogotá, discutidas na pesquisa.

Figura 02 - Interpretação da conexão entre componentes

urbanísticos.

Figura 03 - Representação analógica do tamponamento arterial na cidade de Dhâka, Bangladesh.

Figura 04 - Representação analógica do fluxo fluente para um

correto funcionamento dos órgãos vitais em Houston, Texas dos

Estados Unidos.

Figura 05 - Saturação de modal predominante, veículo particular. $\quad 36$

Figura 06 - Superficie do solo rural, urbano e de expansão urbana de 39 Bogota D.C.

Figura 07 - Zoom de área urbana e de expansão urbana de Bogotá

D.C.

Figura 08 - Localização Geográfica das Localidades.

Figura 09 - Centro Ampliado de Bogotá D.C. 42

Figura 10 - Adensamento populacional por UPZ em Bogotá -

Decreto 562 de 2014.

Figura 11 - Influência da vizinhança - Avaliação 2011.

Figura 12 - Percentagem de assentamentos informais por localidade em Bogotá.

Figura 13 - Proporção da população de comunidade urbanizada sobre a população total das favelas, por área de planejamento Município do Rio de Janeiro (IPP,2012).

Figura 14 - Proporção de favelas por área de planejamento Município do Rio de Janeiro (IPP,2012).

Figura 15 - Percentagem de risco por desmoronamento e alagamento não mitigável

Figura 16 - Nós de Biodiversidade de Bogotá D.C.

Figura 17 - Destinos económicos do Centro Ampliado de Bogotá. 
Figura 18 - Aglomeração de empregos segundo o plano urbanístico do Centro Ampliado.

Figura 19 - Distribuição de adensamento do emprego baseado em 62 pesquisa de mobilidade 2006.

Figura 20 - Distribuição dos limites de tolerância em Kunming China. 64

Figura 21 - Tempo ideal de percurso em Kunming China. 64

Figura 22 - Representação da rede viária. 68

Figura 23 - Representação geral da matriz de tempos Origem 68

Destino nos transportes públicos.

Figura 24 - Universo das pesquisas de mobilidade 2015.

Figura 25 - Matriz de tempos Origem Destino nos transportes 73 públicos da comprovação.

Figura 26 - Matriz de tempos O/D em transportes públicos num universo hipotético.

Figura 27 - Cálculos na Matriz de tempos O/D nos transportes públicos da comprovação.

Figura 28 - Cálculos na Matriz hipotética de tempos O/D nos transportes públicos da proposta 1.

Figura 29 - Matriz de tempos O/D nos transportes públicos da proposta 1.

Figura 30 - Matriz de tempos O/D nos transportes públicos da proposta 2. Estudo. 


\section{Lista de Tabelas}

Tabela 01 - Área de Bogotá e tipo de solo. 38

Tabela 02 - Localidades de Bogotá D.C. 40

Tabela 03 - Localização dos nós de biodiversidade. 56

Tabela 04 - Dados demográficos do universo das pesquisas de 71 mobilidade 2015.

Tabela 05 - Número de viagens ou deslocamentos para cada zona 80 ZAT por motivo de emprego.

Tabela 06 - Asignação de pesos para intervalos de tempos até 20 minutos.

Tabela 07 - Asignação de pesos para intervalos de abrangência até 83 20 minutos.

Tabela 08 - Ranking de um setor hipotético.

84

Tabela 09 - Asignação de pesos para intervalos de tempos até 30

minutos.

Tabela 10 - Asignação de pesos para intervalos de abrangência até

30 minutos.

Tabela 11 - Asignação de pesos para intervalos de tempos até 40 minutos.

Tabela 12 - Asignação de pesos para intervalos de abrangência até 40 minutos.

Tabela 13 - Motivo da viagem.

Tabela 14 - Ponderção de abrangência por motivos para 20

minutos.

Tabela 15 - Viagens por proposito, pesquisa 2015 vérsus pesquisa 2011.

Tabela 16 - Equipamentos por $\mathrm{Km}^{2} / 10.000 \mathrm{hab}$, em localidades de 105 Bogotá D.C.

Tabela 17 - Percentagem de participação das zonas a intervir pelo 109 PUCAB na proposta da pesquisa. 


\section{Lista de Mapas}

Mapa 01 - Viagens de volta a casa - pesquisas de mobilidade 2015.

Mapa 02 - Abrangência nos 20 minutos da zona 433.

77

Mapa 03 - Atração de viagens por emprego da pesquisa de

79

mobilidade 2015.

Mapa 04 - Priorização de adensamento restrito aos 20 minutos 89

Mapa 05 - Priorização de adensamento restrito aos 30 minutos 90

Mapa 06 - Priorização de adensamento restrito aos 40 minutos 91

Mapa 07 - Priorização de adensamento para os 20 minutos do 99

cenário 2.

Mapa 08 - Priorização de adensamento para os 30 minutos do

100 cenário 2.

Mapa 09 - Priorização de adensamento para os 40 minutos do

101

cenário 2.

Mapa 10 - Priorização de adensamento restrito aos 20 minutos das intervenções do plano na proposta 1 da pesquisa. 


\section{Apêndices}

01- Tabela de demonstração do não cumprimento das condições de mobilidade do PUCAB.

02 - Ranking ZAT de adensamento da proposta para cumprir os percursos lar-trabalho-lar nos 20,30 e 40 minutos.

03 - Ranking ZAT de adensamento no Cenário 2 de sensibilidade aos outros motivos de viagem para o Centro Ampliado.

04 - Mapa anexo, Localização zonas ZAT. 


\section{Anexos}

01 - Endereços dos limites geográficos do centro ampliado de Bogotá

02 - Listas UPZ

03 - Equipamentos por setor, população e equipamentos por cada

10.000 habitantes 2011.

04 - Figura Proximidade aos equipamentos 2015. 


\section{Lista de abreviaturas e siglas}

PUCAB - Plano Urbanístico do Cetro Ampliado de Bogotá

PD - Plano Diretor.

GIZ - Agência Alemã de cooperação técnica

SUTP - Projeto de Transporte Urbano Sustentável

(BR) - Brasil.

(COL) - Colômbia.

IPC - Índice de Preços ao Consumidor

FMI - Fundo Monetário Internacional

SDP - Secretaria Distrital de Planejamento

SDA - Secretaria Distrital de Ambiente

SDH - Secretaria Distrital de Hábitat.

DANE - Departamento Administrativo Nacional de Estatística

UPZ - Unidade de Planejamento Zonal

ZAT - Zona de Análise de Transportes

IDECA - Unidade Administrativa Especial de Cadastro Distrital

POT - Plano de Ordenamento Territorial (plano diretor da cidade)

DCN - Distrito Central de Negócios

ONS - Órgão Nacional de Estatísticas (UK)

SDM - Secretaria Distrital de Mobilidade

EODH - Pesquisas Origem Destino Lares

EODI - Pesquisas Origem Destino Intercepções

O/D - Origem Destino

IDPC - Instituto Distrital do Patrimônio Cultural

PMM - Plano Mestre de Mobilidade de Bogotá

OLE - Observatório Laboral para a Educação

IPP - Instituto municipal de urbanismo Pereira Passos

IBGE - Instituto Brasileiro de Geografia e Estatística

INPC - Índice Nacional de Preços ao Consumidor

ONG - Organização não governamental

DNP - Departamento Nacional de Planejamento. 


\section{1 Introdução}

O Plano Urbanístico do Centro Ampliado de Bogotá (PUCAB) é um livro da série Bogotá Humana publicado pela prefeitura da capital colombiana no ano 2015. O livro é nomeado conforme a pretensão de revitalizar e adensar um setor que compreende o centro tradicional da cidade e mais os setores adjacentes.

O setor do PUCAB foi delimitado geograficamente até as áreas onde se conta com atraente oferta de emprego, privilegiado número de equipamentos urbanos, onde moram majoritariamente as classes socioeconômicas médias e altas em déficit residencial e, onde se encontra às condições de mobilidade em que são permitidos os deslocamentos no tempo máximo de 20 minutos nos transportes públicos coletivos desde os lares às áreas de maior geração de emprego da cidade e, tempo máximo de 10 minutos a pé desde qualquer ponto do Centro Ampliado até às estações dos sistemas coletivos.

As zonas periféricas são mais adensadas, menos dotadas de equipamentos urbanos e majoritariamente habitadas por classes socioeconômicas baixas.

O objetivo do referido Plano Urbanístico é atrair moradores das camadas socioeconômicas baixas para dentro das áreas centrais da cidade, para garantir equidade, melhor aproveitamento dos serviços, equilibrar as condições socioeconômicas, e melhorar a mobilidade por localizar os lares perto dos empregos dessas pessoas, que se deslocam ao trabalho em maior quantidade desde as periferias para o centro da cidade.

Analisam-se as pretensões do PUCAB com respeito à mobilidade urbana, sobre a importância da participação cidadã para criar políticas de ocupação do solo, o como essa ocupação atinge ou melhora a mobilidade, e se parte da hipótese do não cumprimento das condições de mobilidade em que são permitidos os deslocamentos em transportes públicos nos 20 minutos dos lares aos empregos no Centro Ampliado, setor apto para o adensamento segundo o Plano.

Entrega-se a priorização de áreas a serem adensadas sob as condições de mobilidade, onde as pessoas possam morar em lugares perto da maior oferta de emprego e, num outro cenário, dos equipamentos urbanos da cidade de Bogotá considerando também a localização próxima ao emprego. 


\section{1.}

\section{Estrutura da dissertação}

No Capítulo 2, será interpretada a relação entre componentes urbanísticos para um consequente fluxo regular da mobilidade urbana e o como a inclusão socioespacial acaba beneficiando-a. A Seção 2.1 introduz o conceito de mobilidade eficiente e a sua dependência com o entorno urbano para analisar os desafios desde a ocupação do solo nas cidades ocidentais.

No Capítulo 3, será feito um levantamento histórico da ocupação do solo após a época da industrialização, onde se apresenta a cidade atual como um espaço desconectado nos componentes urbanísticos com o imperante protagonismo do carro particular; relata-se o nascimento das classes sociais e as tendências expansivas das camadas socioeconômicas baixas para as periferias de forma adensada e desorganizada, trazendo verdadeiros desafios de mobilidade.

Na Seção 3.1, se contextualiza a geografia de Bogotá nas normas que regem o espaço e adensamentos planejados por lei, entendendo a necessidade dos adensamentos devido ao pouco espaço disponível para a expansão urbana. As normas definem até onde essas zonas podem ser adensadas sob as condições de aproveitamento do terreno e usos dos solos contidos no Plano Diretor (PD).

Considere-se a nomeação do Plano Diretor como PD com atenção para não confundir os termos de "Plano" e "Plano Urbanístico", os quais são usados em referência ao Plano Urbanístico do Centro Ampliado de Bogotá (PUCAB). O PD é o equivalente na Colômbia ao Plano de Ordenamento Territorial (POT).

Perante a possibilidade da comprovação da hipótese de não ser possível garantir o tempo de 20 minutos nos deslocamentos das casas aos trabalhos sob as próprias premissas de mobilidade do Plano, surgem os seguintes questionamentos sobre manter os limites do Centro Ampliado de Bogotá ou propor novos limites geográficos que cumpram com as condições de mobilidade. Por outro lado, é essencial discutir cada elemento da premissa de mobilidade nos tempos de deslocamentos em até 20 minutos nos transportes públicos e identificar quais são as zonas de maior geração de emprego em Bogotá.

O Capítulo 4, trata sobre condições socioeconômicas da cidade como uma das premissas coerente com os limites propostos pelo PUCAB, premissas de onde surge o objetivo geral do Plano Urbanístico na diminuição da segregação 
socioespacial. Expõe as conquistas de inclusão social em Bogotá que viabilizam a inclusão espacial.

Nas Seções 5.1 e 5.2, serão comparadas as circunstâncias contrárias encontradas no Rio de Janeiro, Brasil, onde evidencia-se a inclusão espacial, porém, existe uma situação de conflito quanto às conquistas da inclusão social que viabilizam a mistura das classes sociais em Bogotá.

A comparação é relevante para quando surge a desconfiança na inclusão espacial com camadas socioeconômicas baixas ao comparar cidades de outros países onde, apesar de existir a mistura de classes socioeconômicas, não se evidenciam as garantias oferecidas pela inclusão social.

O Capítulo 5 discute ainda sobre as condições ambientais da cidade capital na Colômbia, devido a ser esta mais uma das premissas não discutidas como uma das variáveis para delimitação geográfica do PUCAB, porém, guarda coerência com esses limites escolhidos.

As premissas socioeconômicas e ambientais são discutidas por concordarem com a delimitação geográfica do território em análise, e também porque ao encontrar diferenças nas condições de mobilidade com a realidade das condições da cidade, é necessário entrar a verificar as outras premissas que afetam a delimitação do espaço e o objetivo do Plano que nas próprias palavras do PUCAB (2015) orientará políticas públicas urbanas para uma cidade integrada e igualitária; saber se for viável apresentar uma priorização de adensamento dentro dos limites geográficos do PUCAB (como conclui a pesquisa), mudar esses limites ou até desvirtuar as premissas motivacionais de fundo das quais nasceu o Plano Urbanístico do Centro Ampliado de Bogotá, caso no qual a pesquisa acabaria sem apresentação de propostas de mobilidade para um Plano sem sustento teórico na filosofia da sua criação fundamental.

Tanto as premissas socioeconômicas, ambientais, de déficit habitacional no Centro Ampliado e, o atraente número de equipamentos desse setor são sustentados como verdadeiros neste trabalho.

Uma vez encontrada a coerência entre os limites territoriais do PUCAB e as premissas socioeconômicas e ambientais que viabilizam a proposta para uma priorização de adensamento por zonas, respeitando os limites geográficos escolhidos. Parte-se das premissas de mobilidade de onde surge a hipótese de tese: O não cumprimento nas condições de mobilidade do referido Plano Urbanístico 
para os percursos de máximo 20 minutos nos transportes públicos, das casas aos empregos. Segue a representação na Figura 1 que mostra quais serão as premissas discutidas do PUCAB; onde pode-se interpretar a existência de três grandes premissas das quais se argumentam para apoio teórico, as premissas socioeconômicas e ambientais que fundamentam os limites geográficos do setor do Centro Ampliado e, apresenta o surgimento da hipótese de tese a partir das premissas de mobilidade.

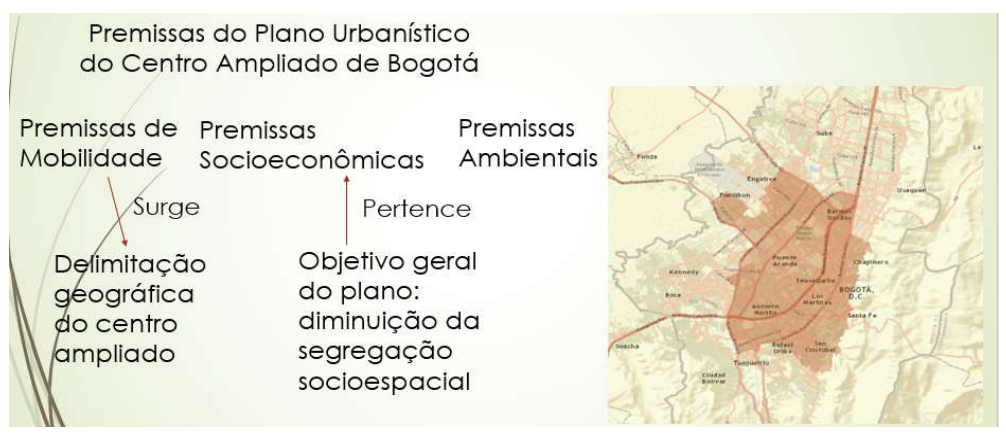

Figura 1 - Premissas de delimitação geográfica do Plano Urbanístico do Centro Ampliado de Bogotá, discutidas na pesquisa.

Fonte: Desenho próprio.

O Capítulo 6, Apresenta os questionamentos da dissertação a respeito das premissas de mobilidade, onde o PUCAB parte de haver delimitado geograficamente o setor do Centro Ampliado pelas condições de mobilidade em que são permitidos os deslocamentos de 20 minutos nos transportes públicos das casas às zonas de maior geração de emprego da cidade, o que faz imperante a análise de cada componente dessa premissa, chegando à Seção 6.1 que discute sobre quais são as zonas de maior geração de emprego em Bogotá e, 6.2, onde discute-se os tempos de percurso de 20 minutos nos transportes públicos das casas aos empregos.

Os tempos a pé até as estações dos sistemas coletivos não são discutidos, levando em conta as pretensões de adensar o Centro Ampliado com camadas socioeconómicas baixas das periferias para ficarem perto dos polos de emprego, onde o maior tempo desses deslocamentos lar-trabalho-lar são os empregados nos transportes públicos submetidos ao transito veicular.

O Capítulo 7, trata sobre as generalidades das pesquisas de mobilidade (SDM, 2015) para o entendimento dos dados abstraídos, necessários para o desenvolvimento da metodologia.

O Capítulo 8, apresenta as metodologias, para a comprovação do não 
cumprimento das condições de mobilidade que delimitaram o Centro Ampliado na Seção 8.1 e, as metodologias para adensamento sob condições de mobilidade, nas Seções 8.2 e 8.3, onde se entregam as propostas para a priorização de adensamento no PUCAB em zonas em que são possíveis os percursos curtos das casas aos empregos e se apresenta um cenário de sensibilidade em que é considerado, a priorização de adensamento em zonas do PUCAB em que é possível localizar os lares por perto de todas as atividades habituais dos cidadãos, considerando também o cenário onde é pretendido localizar os lares por perto do trabalho.

O Capítulo 9 relaciona as discussões finais de todos os Capítulos anteriores.

O Capítulo 10 encerra a dissertação com as conclusões do trabalho de pesquisa aqui apresentado. 


\section{2 Interpretação da relação entre componentes urbanísticos para um consequente fluxo regular da mobilidade urbana}

$\mathrm{Na}$ leitura do Plano Urbanístico pode-se interpretar os esforços pela integração de todos os componentes urbanos como elementos entrelaçados em que é possível afetar as condições de vida dos cidadãos ao intervir com políticas de melhorias em qualquer um dos âmbitos da cidade, chegando a uma consequente mobilidade, de fluxo regular em espaços despoluídos.

Devido à consequente mobilidade pela conexão entre os componentes urbanísticos, é possível estabelecer comprovações de caráter demográfico, socioeconômico, entre outros a partir da análise da caraterização urbana por meio das pesquisas de mobilidade da Secretaria Distrital de Mobilidade (SDM, 2015) como, por exemplo, a condição adensada de residências na periferia e o déficit residencial no centro da cidade (componente urbanístico demográfico), ou a comprovação de zonas com maior atração de viagens por motivo de emprego (componente urbanístico socioeconômico).

Por outro lado, e como discutido posteriormente; o tempo de percurso entre as casas e os trabalhos afeta diretamente a satisfação do ser humano com o entorno, encontrando cidadãos satisfeitos e felizes quando existem curtas distâncias e, portanto, menores tempos de percursos entre as casas e os empregos das pessoas.

A mobilidade urbana conecta os propósitos do ser humano na cidade e o planejamento dos espaços deve ser analisado a consciência pelo cidadão, já que as políticas urbanas surgem a partir das necessidades expressas da sociedade em espaços em que é permitida a interação humana. A consciência para o planejamento da cidade nasce da comunicação entre pessoas que criam políticas para a construção de projetos de lei a serem implementados pelos governantes em resposta às necessidades.

A criação de espaços para mobilidade sustentável são também espaços de convívio diário dos cidadãos onde são promovidas essas práticas sociais para construir a cidade.

Lara et al (2004) da universidade católica Andrés Bello na Venezuela, partem da análise da situação política atual nessa região, que chamam de "caótica" e fazem referência aos transportes massivos de tecnologias limpas como um meio 
de transporte despoluidor, mas principalmente como um "ambiente de aprendizado" social, onde se impulsiona o desenvolvimento de competências cidadãs, se consolida a democracia, se criam leis, valores cidadãos e se aprende a prática desses valores nos espaços públicos, associando a integração social com a criação de espaços em que é promovida a comunicação e o aprendizado.

O Plano Urbanístico do Centro Ampliado de Bogotá prioriza a mobilidade sustentável para a delimitação do setor, em que os percursos nos transportes públicos não superam o tempo de 20 minutos, e as distâncias a pé, são de máximo 10 minutos entre estações dos sistemas coletivos. A finalidade é chegar a ter uma cidade despoluída com pessoas saudáveis e satisfeitas com o meio urbano.

A análise crítica é feita nesta pesquisa com o propósito de ainda ressaltar a mobilidade como variável prioritária nos Planos Urbanísticos e Diretores dentro dos critérios acertados que permitam uma implementação de metodologias com o propósito de capturar a interpretação de mobilidade eficiente como a consequência de um planejamento consciencioso da ocupação do solo; situação que acaba melhorando a qualidade de vida das pessoas pela redução dos tempos de percursos além dos benefícios ambientais do descongestionamento veicular.

A conectividade entre componentes urbanísticos para um consequente fluxo regular da mobilidade é representada na Figura 2.

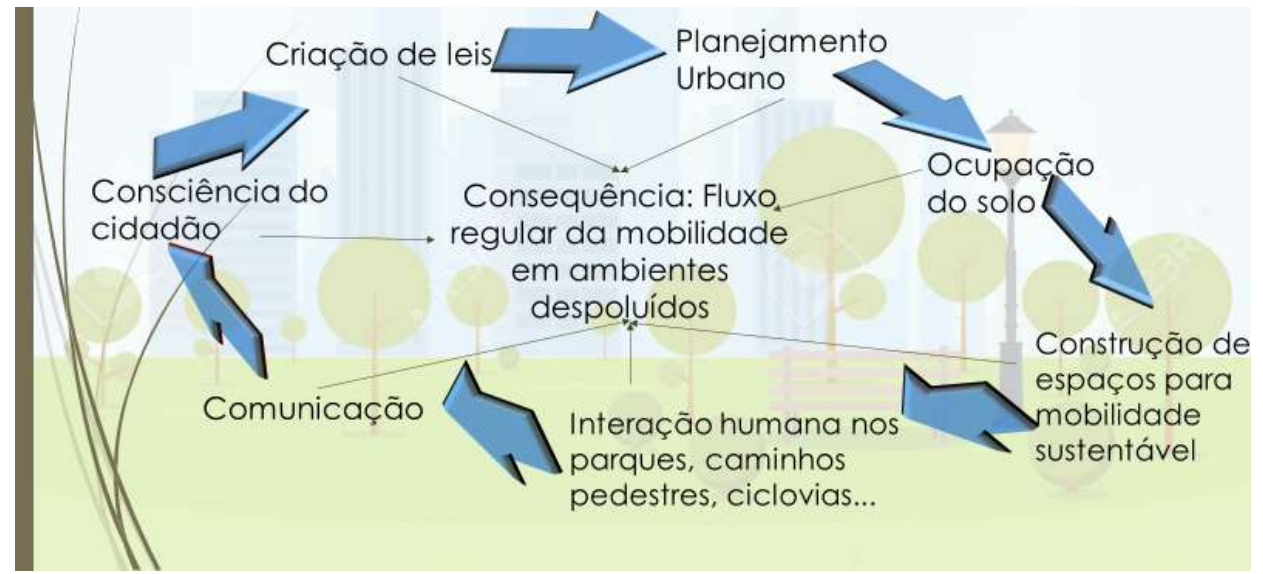

Figura 2 - Interpretação da conexão entre componentes urbanísticos.

Fonte: Desenho próprio.

Em teoria, ao atrair pessoas de camadas socioeconômicas mais baixas moradoras da periferia para dentro dos limites do Centro Ampliado, será possível reduzir a segregação socioespacial e melhorará a mobilidade, devido à reversão dos 
fluxos atuais típicos de trabalhar no centro e morar na periferia.

Além do mais, tende-se a pensar na redução volumétrica de carros particulares e melhor mobilidade porque, dependendo da camada socioeconómica, as pessoas mais pobres tendem à maior tolerância e empatia com políticas relacionadas à mudança de modais particulares motorizados, por outros como os transportes públicos massivos e meios de transportes não motorizados (mobilidade sustentável). (MUÑOZ et al, 2013).

O Plano Urbanístico do Centro Ampliado de Bogotá contempla adensar e revitalizar o setor com parques, ciclovias, vias pedestres que permitem a livre escolha das pessoas para se mobilizar em meios de transportes não motorizados pela oferta de equipamentos e a facilidade de morar perto das atividades habituais, em distâncias passíveis de se locomover a pé com as implicações de descongestionamento veicular, portanto, menor emissão de gases tóxicos e maior saúde dos residentes do setor além da economia nos transportes públicos, promovendo assim a mobilidade sustentável num ambiente cívico e equitativo (PREFEITURA DE BOGOTÁ et al, 2015).

Uma rua é incompleta quando está feita só para o objetivo tradicional de permitir o movimento dos automóveis de forma eficiente. Uma rua completa é um espaço onde cabe o movimento eficiente para ciclistas, pedestres, motoristas. Este deve ser um lugar onde as pessoas possam interagir e se movimentar independente de contar com automóvel; trata-se de uma conectividade urbana justa. As ruas e os setores que estas ligam são espaços físicos e simbólicos com grande potencial. Eles podem refletir e reproduzir as estruturas sociais, desigualdades e injustiças que continuam a moldar e definir muitas vidas urbanas. Mas eles também podem capacitar e engajar, construir capital cívico social e, criar oportunidades. (AGYEMAN \& ZAVETOVSKI, 2015)

...nas políticas, planos e esforços das ruas planejadas e implementadas podem ser sistematicamente reproduzidas e até ampliadas muitas das desigualdades e injustiças espaciais e sociais urbanas que caracterizaram as cidades durante o último século ou mais ${ }^{2}$.

\footnotetext{
${ }^{2}$ Agyeman \& Zavetovski, 2015, p.7.
} 


\section{1. Mobilidade eficiente}

$\mathrm{Na}$ linguagem dos transportes, a mobilidade eficiente ("Conducción eficiente") refere-se ao baixo consumo de combustível (energia) e menores emissões de gases tóxicos $\mathrm{CO}_{2}$ para a atmosfera, emitidos pelos veículos automotores. Tenta-se economizar combustível com processos de otimização dos tempos por meio de estratégias como, controle preditivo graças ao uso de Mapas digitais que informam rotas e possíveis engarrafamentos para escolhas seguras das vias a serem transitadas após sugestões dos meios digitais. Para este tipo de análises capturam-se resultados a partir da lógica Barrosa capaz de abranger condutas imprecisas como as atitudes dos motoristas (VILLETA et al, 2012).

Mobilidade eficiente apresenta-se como um dos benefícios da mobilidade inteligente das cidades (smart urban mobility) e explica junto às outras vantagens o como os passageiros podem usar as tecnologias emergentes como celulares com aplicativos, em que os passageiros dos veículos automotores possam adquirir conselhos em tempo real para escolhas que minimizem o movimento (LYONS, 2016).

Para Villeta (2012), a otimização do tempo denota-se de forma direta na interpretação da mobilidade eficiente. Entretanto para Lyons (2016), a mobilidade eficiente se dá por entendida no contexto em que junto às outras vantagens consegue-se minimizar o movimento, porém, os dois autores estariam coincidindo em minimizar o movimento levando em conta que, ao otimizar o tempo dos percursos, o movimento será menos prolongado. Assim, Lyons (2012) não discorda da otimização do tempo como interpretação da mobilidade eficiente.

Uma interpretação particular a aplicar para a compreensão do critério da mobilidade eficiente, se faz a partir de uma analogia da cidade com o corpo humano onde a infraestrutura viária representa as veias e as artérias com fluxo sanguíneo fluente (mobilidade), para o correto funcionamento dos órgãos vitais que no caso das cidades são todos aqueles lugares que dão vida à urbe, política e economicamente, como os lugares de emprego e de equipamentos de saúde, estudo e recreação. (Sangue $=$ cidadãos $)$.

Esta analogia explica a importância do fluente sanguíneo para o corpo humano, em que é necessária a chegada do sangue ininterruptamente através das 
veias e as artérias aos órgãos vitais para o corpo funcionar corretamente, assim mesmo é a cidade, esta precisa do regular fluxo das pessoas até os polos de emprego e equipamentos urbanos para o seu ótimo funcionamento.

$\mathrm{Na}$ Figura 3. Observa-se a cidade de Dhâka em Bangladesh como uma representação da obstrução arterial em que o fluxo sanguíneo não consegue chegar de forma fluida e ininterrupta até os órgãos vitais da cidade.

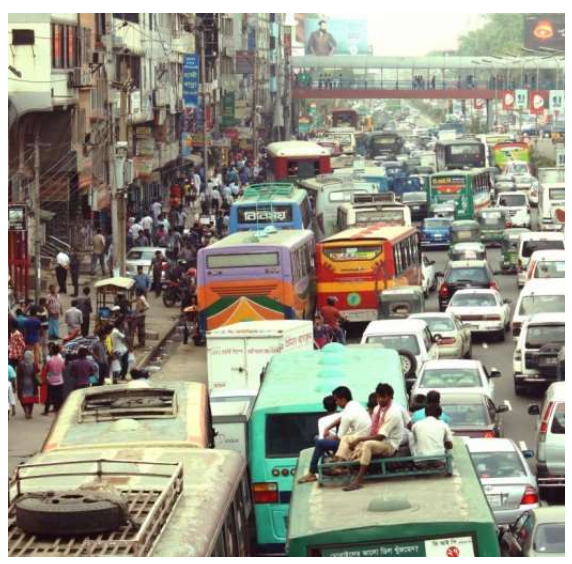

Figura 3 - Representação analógica da obstrução arterial na cidade de Dhâka, Bangladesh. Fonte: Agence Française De Developpement AFD, 2017.

$\mathrm{Na}$ Fig. 4, representa-se a analogia no caso contrário ao representado na Fig. 3.

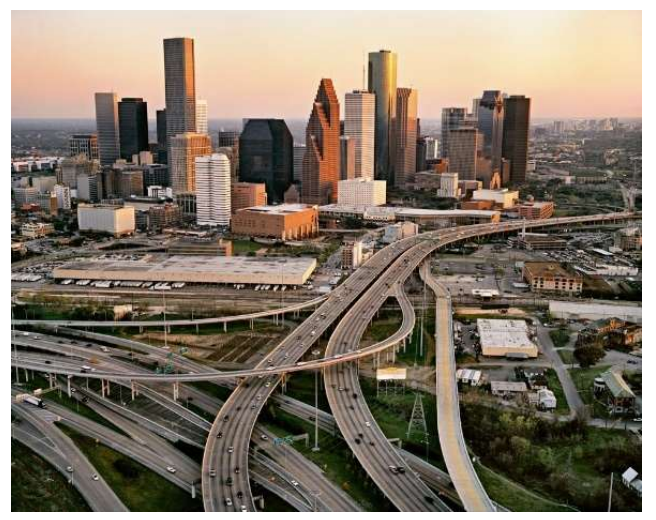

Figura 4 - Representação analógica do fluxo fluente para um correto funcionamento dos órgãos vitais em Houston, Texas dos Estados Unidos.

Fonte: Joel Rodríguez Díaz, 2017.

Todas as interpretações para mobilidade eficiente são coerentes entre si, colocando ao tempo como elemento a ser otimizado, porém, a analogia é feita entre o corpo humano e a cidade porque este trabalho de pesquisa pretende enfatizar a 
conectividade com fluxo fluido entre propósitos como parte da necessidade vital urbana, assim como é necessária a conectividade dos órgãos vitais no corpo humano para mantê-lo vivo. A mobilidade assim interpretada permite a integração de vários componentes urbanísticos, age como rede entre propósitos e o fluxo ininterrupto nesta rede será interpretado como a otimização do tempo para minimizar o movimento e a energia desnecessários que causam os esforços dos engarrafamentos.

Este conceito excluí o aumento da velocidade dos transportes motorizados graças às implementações de vias rápidas, como foi concebida antigamente a otimização dos tempos de percursos dentro das cidades. Agora, destaca-se o papel fundamental da fluidez de qualquer um dos transportes motorizados e não motorizados.

Independentemente dos transportes, o cidadão deve poder contar com um tempo aproximado de chegada ao seu destino, segundo ofereça a velocidade média dos transportes da sua escolha. É possível para cada cidadão planejar o tempo dos percursos se o fluxo for ininterrupto, pelas vias rápidas para os veículos, vias pedestres e ciclovias, o que permite ao cidadão organizar o seu tempo para dedicar às suas atividades diárias e seus deslocamentos, sem as incertezas devido aos imprevistos dos engarrafamentos no trânsito.

O PUCAB oferece a oportunidade de melhorar a mobilidade por meio das estratégias de adensamento das zonas em que são possíveis os percursos curtos das casas aos lugares das atividades habituais dos cidadãos. Isso com a possibilidade ainda de transitar os espaços em meios de transportes não motorizados, facilitando assim, as múltiplas escolhas da população para se locomover, com o benefício de poder programar o seu tempo graças aos fluxos ininterruptos. 


\title{
3 Ocupação do solo urbano após época da industrialização
}

A evolução das sociedades no século XIX foi diferentemente interpretada da noção atual. A noção de avance era constituída pelo conceito do "modernismo", totalmente desapropriado da integração da sociedade ao meio ambiente. Nesse tempo onde começou a industrialização e a valorização do dinheiro como pertencente aos burgueses: "Quando a industrialização começa, quando nasce o capitalismo concorrencial [...]" 3 (LEFEBVRE, 2008).

A partir da metade do século XIX nasceram as classes sociais, depois da industrialização. A burguesia com os ricos e donos das empresas e o proletariado com os trabalhadores empregados pelas empresas e os camponeses. A humanidade com a chegada da industrialização começa um sentido separatista entre espaço, pessoas e meio ambiente.

\begin{abstract}
Divide a cidade do campo, o trabalho conforme os sexos e as idades (divisão biológica do trabalho), a organização do trabalho segundo os instrumentos e as habilidades (divisão técnica), a divisão social do trabalho entre o campo e cidade corresponde à separação entre o trabalho material e o trabalho intelectual, e, por conseguinte entre o natural e o espiritual. À cidade incumbe o trabalho intelectual: funções de organização e de direção, atividades políticas e militares, elaboração do conhecimento teórico (Filosofia e ciência). A totalidade se divide; instauram-se separações, inclusive a separação entre physis e o logos, entre a teoria e a prática e, na prática a separação entre práxis (ação sobre grupos humanos), poésis (criação de obras), techné (atividade armada com técnicas e orientada para os produtos) ${ }^{4}$. (LEFEBVRE, 2008)
\end{abstract}

A urbanização europeia foi replicada também nos países do continente Americano: Norte, Centro e Sul. Residentes de periferias que trabalham nas cidades são os pobres mais relegados dos serviços dos transportes. "La exclusión social implica la negación del acceso - a un individuo o grupo - a las oportunidades de

\footnotetext{
${ }^{3}$ Lefebvre, 2008, p.4

${ }^{4}$ Lefebvre, 2008, p.28-29
} 
participar en la vida social y politica de la comunidad." (KENYON, LYONS \& RAFFERTY ${ }^{5}$ apud LIZARRGA $\left.{ }^{6}, 2012\right)$.

As zonas urbanas - que deveriam ter serviços públicos garantidos para os cidadãos como eficiência na oferta da infraestrutura, uso eficiente da terra, geração de receitas, vitalidade humana, maior controle social, acesso aos transportes públicos de baixo custo, manutenção da infraestrutura, onde se encontram economias de escala, facilidade de acesso aos consumidores e maior acessibilidade a emprego, maior quantidade de equipamentos como hospitais, postos de saúde e clinicas que permitissem um ambiente seguro de gente saudável e despoluído de doenças, assim como outros equipamentos de tratamentos de lixo com facilidade para reciclagem massiva mais eficiente que garantisse um meio ambiente preservado e cuidado pelos agentes governamentais - atraem as multidões em busca de emprego que se iludem com a ideia de rápida prosperidade, como descreve Eduardo Galeano (2000).

É multitudinária a invasão dos braços provenientes das zonas mais pobres de cada país; as cidades excitam e golpeiam as expectativas de trabalho de famílias inteiras, atraídas pela esperança de elevar seu nível de vida e conseguir um lugar no grande circo mágico da civilização urbana. Uma escada mecânica é a revelação do Paraíso, porém o deslumbramento não se come: a cidade torna ainda mais pobres os pobres, porque cruelmente exibe miragens de riquezas às quais nunca terão acesso - automóveis, mansões, máquinas poderosas como Deus e como o Diabo - e, em compensação, lhes nega uma ocupação segura e um teto decente, pratos cheios para cada meio-dia. ${ }^{7}$ (GALEANO, 2000)

Com os centros urbanos supervalorizados, quem trabalha na cidade é compelido a se deslocar para a periferia e morar distante de seus objetos ilusórios de riqueza, havendo a tendência de as cidades crescerem para as periferias. Este movimento pode ser interpretado como a busca de algumas das pessoas que privilegiam as condições naturais oferecidas pelo campo, como a possibilidade de obter saneamento básico barato, aquisição de terra a baixo custo, maior silêncio e tranquilidade e menor poluição que nas cidades densas.

\footnotetext{
${ }^{5}$ Kenyon, Lyons \& Rafferty, J. (2002). Transport and social exclusion. Investigating the possibility of promoting inclusion through virtual mobility. Journal of Transport Geography, 10(3), 207-209.

${ }^{6}$ Lizarrga, 2012, p. 102.

${ }^{7}$ Galeano, 2000, p. 176.
} 
As condições descritas como vantagens para o campo são, pelo contrário, as desvantagens das cidades mais inseguras, com ecossistemas e paisagens mais degradadas e associadas a espaços mais congestionados e saturados.

O presente século requer a necessidade de integrar a paisagem da cidade como um todo, de construir espaços em busca de um equilíbrio relacionando a natureza com o ser humano na cidade, bem como entre seres humanos. A consciência é gerada a partir de uma inconformidade comum sempre comunicada entre as pessoas que realizam mudanças na sociedade; comunicação inclusive física espacial na interação dos espaços urbanos e rurais, ou seja, priorizando a comunicação com a natureza e comunicação entre pessoas. Devemos ser cientes que da comunicação surge o conhecimento das necessidades em uma sociedade.

As políticas mudam a partir das necessidades expressas da sociedade. Existem diversas perspectivas teóricas, que são apresentadas como pano de fundo para interpretação da influência da comunicação sobre os indivíduos, sociedade e cultura (DEFLEUR \& BALL- ROKEACH, 1993). A comunicação é interpretada como o interagir das pessoas e dos meios que as une. Daí a importância da comunicação física de espaços e, por conseguinte, da mobilidade.

Geralmente as mudanças partem da classe média que tem o conhecimento do seu rol de direitos e deveres ao contrário da classe baixa com pouco acesso ao conhecimento dos seus direitos e deveres. E, por outro lado, a classe alta, que pouco interesse tem em mudar as condições mais conservadoras que garantem a sua cômoda posição.

A importância do convívio diário entre as pessoas nos espaços e nos transportes públicos em um ambiente onde existe a integração é relevante, aumenta o interesse por participar das preocupações dos outros e dar a conhecer as próprias opiniões sem importar as diferenças socioeconômicas.

$\mathrm{O}$ uso de carros particulares incentiva posturas individuais, onde pouco se empresta para o convívio com as pessoas de pensamentos diversos que possam contribuir ao debate necessário para geração de consciência, além dos interesses pessoais ou marcados por uma mesma tendência.

As infraestruturas viárias para carros particulares são representativas nas paisagens das cidades, incentivando o uso desses veículos, encarando verdadeiros problemas de congestão veicular que leva a entender a necessidade do estimulo pelo uso dos transportes públicos massivos e o uso dos transportes não motorizados. 
O incentivo pelo uso dos transportes não motorizados está acompanhado dos espaços criados para essas práticas de mobilidade sustentável, onde se apresentam paisagens com parques de cidades mais acessíveis, caminháveis e de interação humana no espaço público. Permite-se assim a livre escolha do cidadão de fazer parte da solução para o descongestionamento veicular ao optar por se mobilizar em transportes sustentáveis graças às curtas distâncias, ou até mesmo longas distâncias, mas, por caminhos atrativos a serem percorridos como pretendido na construção de vias pedestres das proposições específicas do Plano Urbanístico em discussão.

Uma abordagem da concepção da mobilidade é vista na Colômbia pelo político Peñalosa (2015): "uma cidade é mais civilizada, não quando tem estradas e sim, quando uma criança no seu triciclo consegue se deslocar por todo lado com facilidade e segurança"

Quando se fala de mobilidade sustentável, existe uma tendência associativa imperante na sociedade colombiana que relaciona as boas práticas de mobilidade sustentável com espaços públicos de convívio humano e segurança de caminhar entre pessoas, ao invés do risco proporcionado pelas vias rápidas para carros particulares.

Um exemplo da paisagem saturada de carros particulares é apresentado pelo ex-prefeito da cidade de Bogotá, Gustavo Petro (2015) na Figura 5.

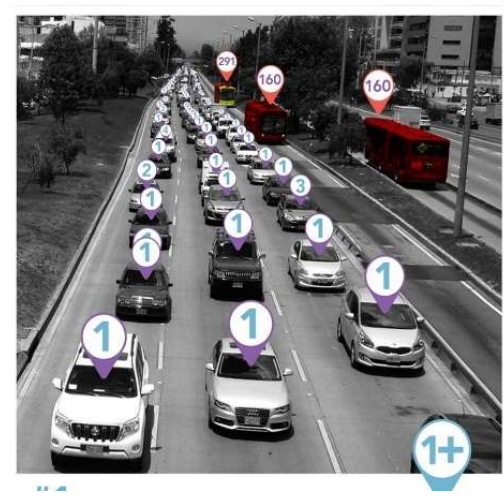

Figura 5 - Saturação de modal predominante, veículo particular. Fonte: Gustavo Petro 13/04/2015

A Fig.5. Apresenta o modal predominante e explica o protagonismo que o veículo particular ganhou ao longo do tempo, a enorme infraestrutura construída para o carro com sua desnecessária ocupação volumétrica, para transportar 
geralmente uma pessoa.

$\mathrm{Na}$ atualidade existem desafios de mobilidade para todos, devido a ser conveniente tanto para o proletariado reduzir custos dos transportes e ganhar tempo de lazer junto às suas famílias, quanto para a burguesia que cada vez precisa mais da chegada a tempo dos trabalhadores.

Percorrer longas e cansativas distâncias implica atrasos na chegada, e cada vez mais, um menor rendimento no serviço devido ao desgaste das pessoas para se locomover; empregando maiores tempos no trânsito que poderia ser aproveitado na produção laboral.

Estes desafios dependem de estratégias como moradias próximas aos locais de trabalho e eficiente transporte massivo acessível em custo e infraestrutura que permita aos usuários se locomoverem de forma rápida e segura (PREFEITURA DE BOGOTÁ et al, 2015).

É necessário construir, adequar e melhorar ambientes onde se promova a integração social dentro do cenário cidadão para criar políticas de bem-estar, de forma a permitir a evolução do cidadão tanto de forma individual como em sociedade a partir da comunicação de entendimentos, conhecimentos e filosofias que, em conjunto, enriqueçam as políticas sociais, ambientais e, por conseguinte, de boas práticas de mobilidade sustentável, desconstruindo as antigas ideias formadas em séculos passados que promoviam a segregação socioambiental na zona urbana.

O princípio de mobilidade que delimitou o "Centro Ampliado de Bogotá", até às zonas de maior geração de emprego da cidade, encontra-se submetido ao trânsito que dificulta garantir tempos ótimos de percurso. É importante salientar que esta condição de transportes está contra os princípios de transportes sustentáveis da cidade, segundo agência alemã de cooperação técnica - (GIZ; BMZ, 2017) que apoia o Projeto de Transportes Urbanos Sustentáveis (SUTP), de Bogotá.

Para o cumprimento das práticas de mobilidade sustentável deve-se promover o uso dos transportes públicos coletivos existentes, alimentados pelos transportes não motorizados (PMM, 2017). 


\section{1. \\ Referências normativas para delimitações e adensamentos geográficos da ocupação do solo urbano em Bogotá D.C.}

Nesta Seção, são contextualizadas as normas e o espaço geográfico da cidade de Bogotá e o setor do Centro Ampliado. As normas aqui relacionadas entregam as diretrizes para os adensamentos e as consequências na mobilidade.

As referências geográficas podem estar mencionadas por localidades, unidades de planejamento zonal (UPZ) ou ZAT, dependendo do grau de detalhe, sendo localidades as maiores áreas de referência geográfica seguida das UPZ e por último as ZAT especificas para a mobilidade, desde as pesquisas de mobilidade de 2011, mas as pesquisas de mobilidade de 2006 foram apresentadas por UPZ.

As áreas de análise geográfica variam segundo o grau de detalhe necessário para estudos diversos de meio ambiente, mobilidade, economia, entre outros.

Bogotá é a capital da Colômbia com adensamento populacional de 8.363.782 habitantes, segundo as projeções populacionais do Departamento Administrativo Nacional de Estadísticas (DANE, 2005).

Pela Tabela 1 nota-se pouca área de expasão urbana, fazendo necessário o adensamento da cidade.

Os decretos são apresemtdos na Tabela 1, como o marco legal para limitar no espaço as possíveis açoes a partir das proposições da pesquisa.

Área total de Bogotá D.C.: $1.636,36 \mathrm{Km}^{2}$.

Tabela 1. Áreas de Bogotá e tipo de solo.

\begin{tabular}{|l|l|l|}
\hline Tipo de solo & Área $\left(\mathrm{Km}^{2}\right)$ & $\begin{array}{l}\text { Decreto normativo de } \\
\text { delimitação geográfica }\end{array}$ \\
\hline Solo rural & 1227,17 & $\begin{array}{l}\text { Decreto 190 de 2004 e } \\
\text { Ajuste limite Município } \\
\text { Calera. Resolução } \\
\text { normativa 1751 de 2016. }\end{array}$ \\
\hline Solo Urbano & 379,45 & $\begin{array}{l}\text { Resolução normativa 228 } \\
\text { de 04-03-2015 }\end{array}$ \\
\hline $\begin{array}{l}\text { Solo de expansão } \\
\text { urbana }\end{array}$ & 29,74 & $\begin{array}{l}\text { Decreto 190 de 22-06- } \\
2004\end{array}$ \\
\hline
\end{tabular}

Fonte: IDECA, https://www.ideca.gov.co/es/documentos 
Segue a representação geográfica da Tabela 1 nas Figuras 6 e 7, de áreas de Bogotá e, do tipo de solos nesses setores, onde também se evidencia o pouco espaço de expansão urbana que obriga o adensamento na cidade de Bogotá:

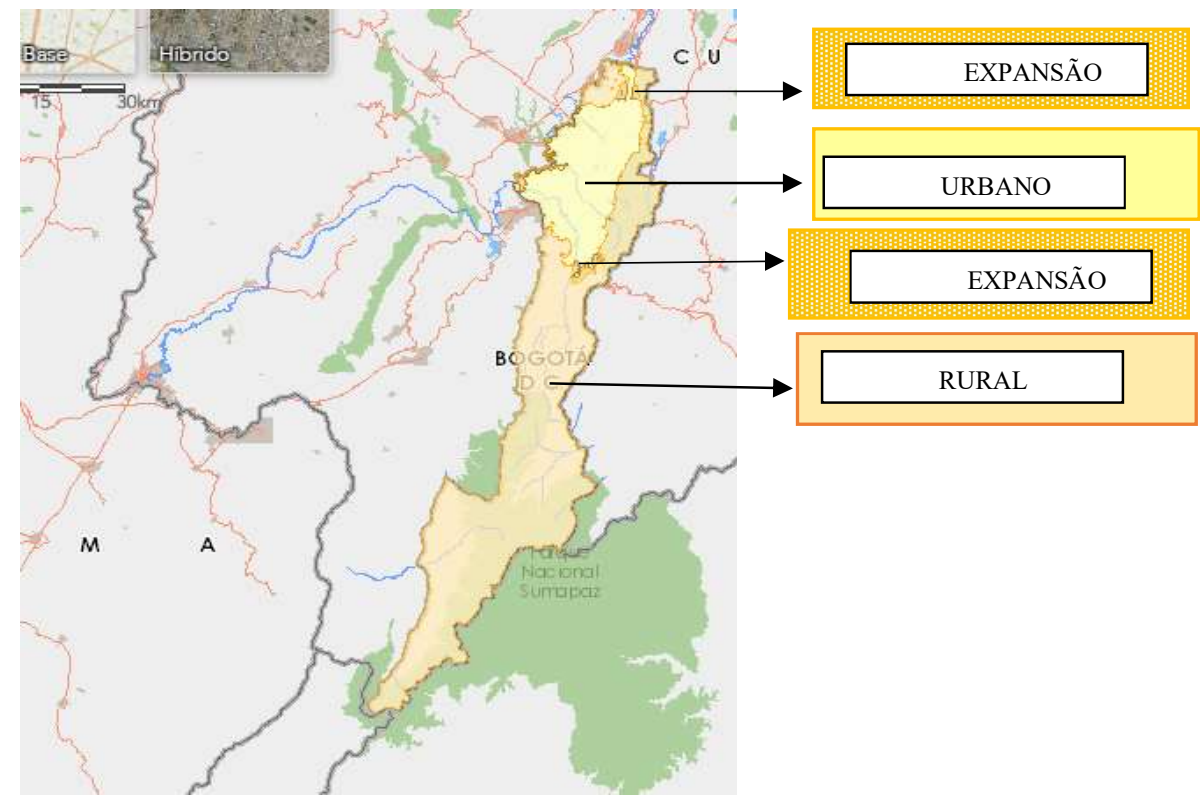

Figura 6 - Superficie do solo rural, urnano e de expansão urbana de Bogota D.C. Fonte: UNIDAD ADMINSTRATIVA ESPECIAL DE CATASTRO DISTRITAL https://www.ideca.gov.co/es/documentos

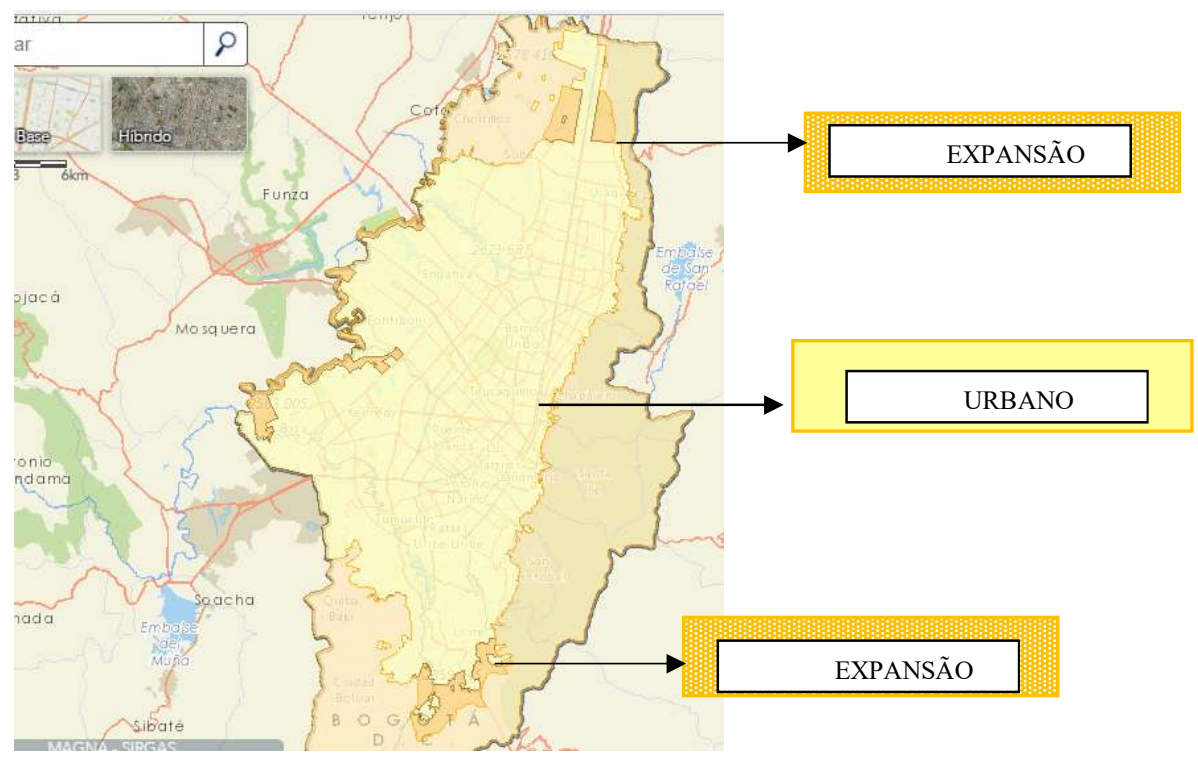

Figura 7 - Zoom de área urbana e de expansão urbana de Bogotá D.C. Fonte: UNIDAD ADMINSTRATIVA ESPECIAL DE CATASTRO DISTRITAL https://www.ideca.gov.co/es/documentos 
O planejamento da cidade pelo Plano Diretor (POT), divide Bogotá em localidades da Tabela 2 e Figura 8, segundo a Infraestrutura de Dados Espaciais para o distrito Capital (IDECA, 2017):

Tabela 2 - Localidades de Bogotá D.C.

\begin{tabular}{|c|c|c|c|}
\hline $\begin{array}{l}\text { Numeração } \\
\text { segundo } \\
\text { pesquisa de } \\
\text { mobilidade } \\
2015 \\
\end{array}$ & Localidade & Área $\left(\mathrm{Km}^{2}\right)$ & $\begin{array}{l}\text { Ato } \\
\text { administrativo da } \\
\text { localidade. }\end{array}$ \\
\hline 1 & Usaquén & 65,20 & $\begin{array}{l}\text { Acordo } 8 \text { de } \\
\text { 1977. Resolução } \\
1751 \text { de } 2016\end{array}$ \\
\hline 2 & Chapinero & 38,00 & $\begin{array}{l}\text { Acordo } 8 \text { de } \\
\text { 1977. Resolução } \\
1751 \text { de } 2016\end{array}$ \\
\hline 3 & Santa Fe & 45,17 & $\begin{array}{lll}\text { Acordo } 117 & \text { de } \\
2003 & & \\
\end{array}$ \\
\hline 4 & San Cristobal & 49,10 & $\begin{array}{lll}\text { Acordo } 117 & \text { de } \\
2003 & & \\
\end{array}$ \\
\hline 5 & Usme & 215,07 & $\begin{array}{lll}\begin{array}{l}\text { Acordo } \\
1993\end{array} & 15 & \mathrm{de} \\
\end{array}$ \\
\hline 6 & Tunjuelito & 9,91 & $\begin{array}{l}\text { Acordo } 117 \text { de } \\
2003 \text {. }\end{array}$ \\
\hline 7 & Bosa & 23,93 & $\begin{array}{lll}\text { Acordo } 14 & \text { de } \\
1983\end{array}$ \\
\hline 8 & Kennedy & 38,59 & Acordo 8 de 1977 \\
\hline 9 & Fontibón & 33,28 & Acordo 8 de 1977 \\
\hline 10 & Engativá & 35,88 & Acordo 8 de 1977 \\
\hline 11 & Suba & 100,56 & Acordo 8 de 1977 \\
\hline 12 & Barrios Unidos & 11,90 & Acordo 8 de 1977 \\
\hline 13 & Teusaquillo & 14,19 & Acordo 8 de 1977 \\
\hline 14 & Los Martires & 6,52 & Acordo 8 de 1977 \\
\hline 15 & Antonio Nariño & 4,88 & $\begin{array}{l}\text { Acordo } 117 \text { de } \\
2003 \text {. }\end{array}$ \\
\hline 16 & Puente Aranda & 17,31 & Acordo 8 de 1977 \\
\hline 17 & Candelaria & 2,06 & $\begin{array}{l}\text { Acordo } 117 \text { de } \\
2003 \text {. }\end{array}$ \\
\hline 18 & Rafael Uribe Uribe & 13,83 & $\begin{array}{l}\text { Acordo } 117 \text { de } \\
2003 \text {. }\end{array}$ \\
\hline 19 & Ciudad Bolivar & 130,00 & $\begin{array}{lll}\text { Acordo } & 14 & \mathrm{de} \\
1983 & & \\
\end{array}$ \\
\hline 20 & Sumapaz & 780,98 & Acordo 9 de 1986 \\
\hline
\end{tabular}

Fonte: Própria. Informações do IDECA. 


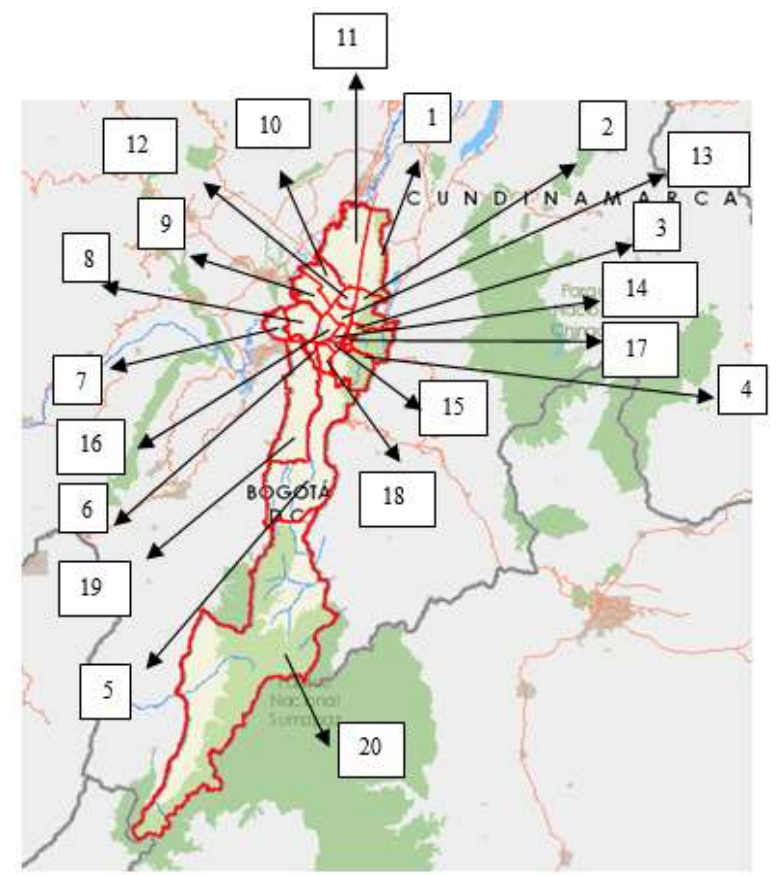

Figura 8 - Localização Geográfica das Localidades. Fonte: http://idecabogota.maps.arcgis.com.

As localidades são referências espaciais para cálculos de redes sanitárias, aquedutos, malha viária e indicadores ambientais que devem entrar em análise para os adensamentos da cidade.

Para o controle de adensamento das zonas urbanas de Bogotá existem os índices de construção equivalentes aos Índices de Aproveitamento do Terreno (IAT) do Brasil, mas, esses índices estão em análise para novas implementações no PD, segundo a Secretaria de Planejamento Distrital de Bogotá (SDP), portanto, esses dados não foram entregues e estão parcialmente disponíveis nos portais das entidades governamentais da cidade, pela internet.

O setor do PUCAB a ser analisado no presente estudo, contem quatorze (14), das vinte (20) localidades: Chapinero, Santafe, San cristóbal, Tunjulito, Kennedy, Fontibón, Engativá, Barrios unidos, Teusaquillo, Los martires, Antonio Nariño, Puente aranda, Candelaria, Rafael Uribe Uribe.

A Figura 9 mostra os limites geográficos do Centro Ampliado de Bogotá segundo os endereços descritos no Anexo 1, e também algumas localidades de Bogotá são parciamente abrangidas pelo setor do Centro Ampliado $\left(125,76 \mathrm{Km}^{2}\right)$ : 


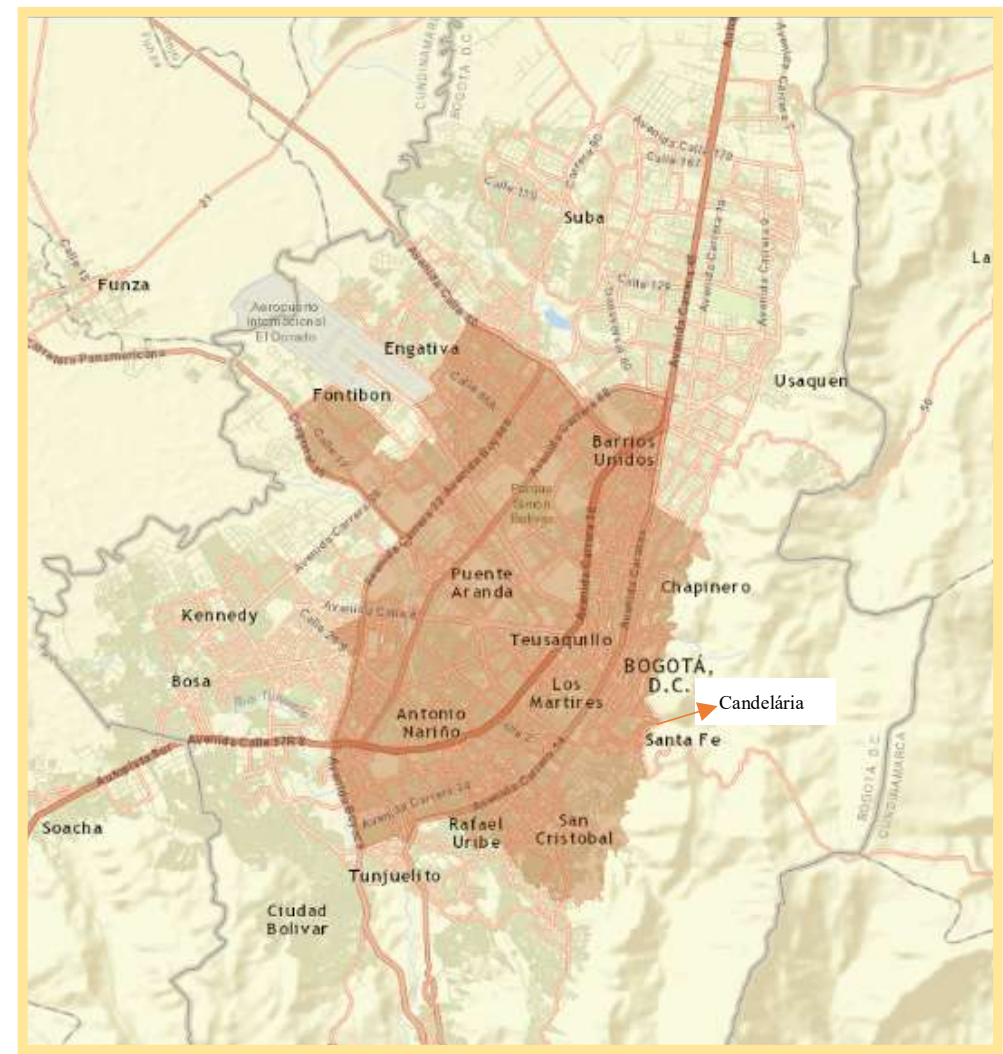

Figura 9 - Centro Ampliado de Bogotá D.C. Fonte: Desenho próprio.

A Figura 9 deixa ver o espaço ocupado pelo setor do Centro Ampliado, proposto pelo PUCAB para ser modificado com adensamentos populacionais, abrangendo uma grande quantidade de localidades da cidade capital da Colômbia.

\subsection{1.}

Referências normativas relevantes para adensamento em Bogotá a partir da lei 388 de 1997, artigo 13 da regulamentação dos Planos Diretores

Os Planos de Ordenamento Territorial (POT) ou seu equivalente brasileiro do PD, contêm um componente urbano em que são previstas normas urbanisticas gerais, estruturais e complementárias; das quais é inerente a esta pesquisa para adensamentos em Bogotá, o Decreto 190 de 2004 e o Decreto complementario 562 de 2014 (COLOMBIA, 1997). 


\subsubsection{1.}

Decreto $n^{\circ} 190$ de junho de 2004

Controla os processos de expansão urbana, estipula a diversificação de usos do solo e especifica ações de equidade territorial para diminuir fatores de pobreza e exclusão social (COLOMBIA, 2004).

O artigo 19 do decreto, associa o território das centralidades com a mobilidade que terá interdependência descrita no Plano Mestre de Mobilidade PMM.

Os eixos da mobilidade que integram as centralidades são: "Avenida Caracas - Paseo de los libertadores, Avenida Centenario - Corredor Férreo de Occidente - Calle 26, Autopista al Llano - Avenida Boyacá, NQS - Autopista Sur, calle $80 "$.

As ruas anteriores são os principais eixos que integram a mobilidade regional e internacional.

\subsubsection{2.}

Decreto $n^{\circ} 562$ de dezembro de 2014

Regulamenta a renovação urbana de Bogotá, estimulando a habitabilidade no centro da cidade e as centralidades.

A finalidade do decreto já estava estipulada no decreto 619 do POT 2000, mas não existiam os mecanismos para exercer dita regulamentação (COLOMBIA, 2014).

A Figura 10 de adensamento populacional por UPZ 2015 estabelece a média populacional na área urbana como 214 hab./hectare.

$\mathrm{O}$ decreto estabelece as áreas a serem adensadas em unidade de planejamento zonal (UPZ), que são áreas de intervenções menores do que as localidades, já que a ocupação precisa de maior detalhe no espaço. (Ver Anexo 2. Lista de UPZ, Bogotá). O decreto apresenta uma intervenção de áreas a serem adensadas de bordas roxas (“Renovación”), sem priorização e partindo do déficit populacional no centro da cidade como o explica a Figura 10. 


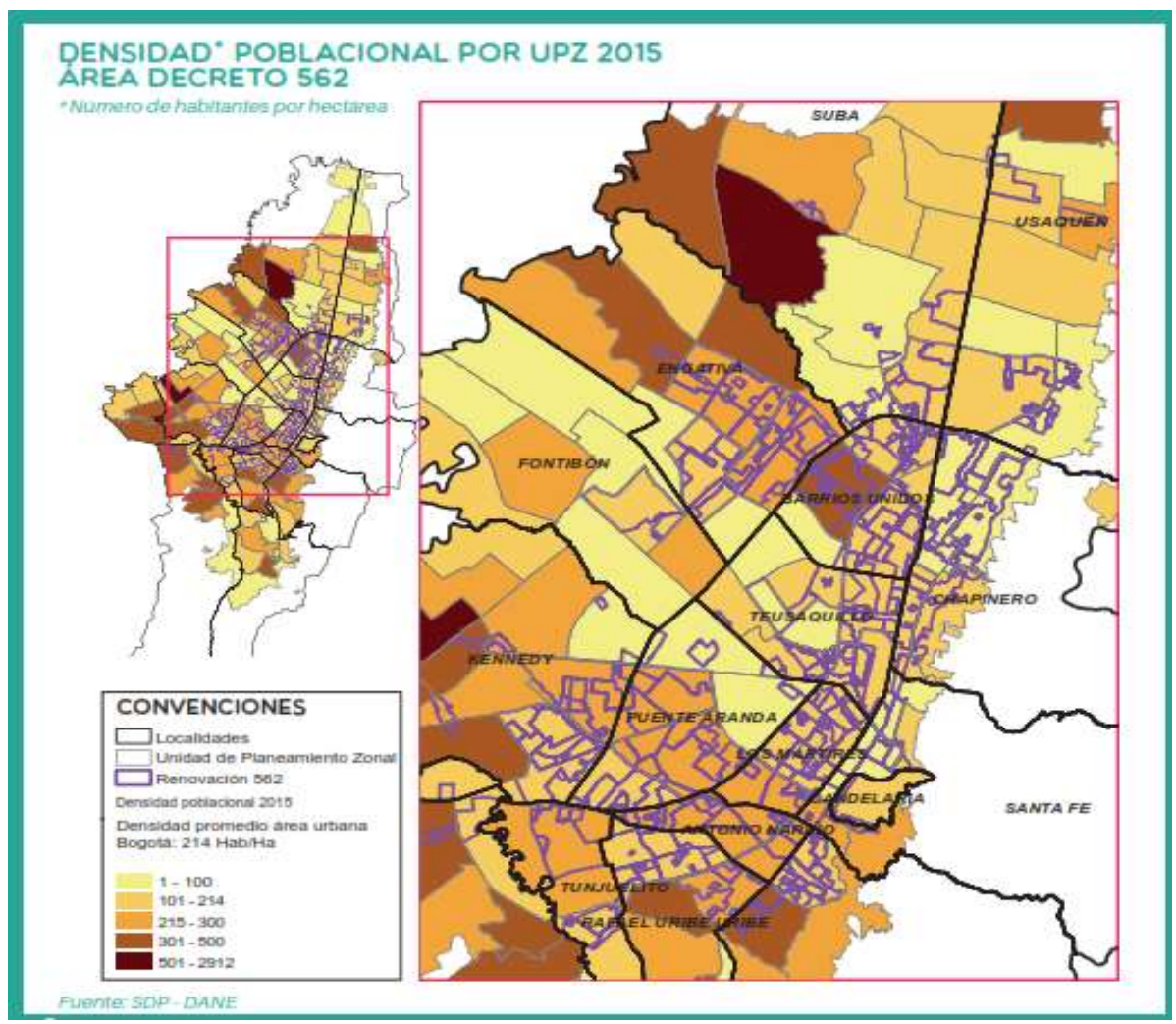

Figura 10 - Adensamento populacional por UPZ em Bogotá - Decreto 562 de 2014. Fonte: SECRETARIA DISTRITAL DE PLANEACIÓN DE BOGOTÁ: SDP. http://www.sdp.gov.co/portal/page/portal/PortalSDP/OrdenamientoTerritorial/Decreto_562/Broc hure-562-web-21092015.pdf

O Mapa 1 (Página 45), numa consulta própria nas pesquisas de mobilidade (SDM, 2015), ratifica o déficit de lares no centro da cidade.

As cores beige, rosa e o amarelo, representam o menor número de viagens de volta a casa desde os empregos das pessoas em Bogotá, a cor verde representa a maior quantidade de viagens por esse mesmo motivo, comprovando assim, os setores das periferias são majoritariamente adensados pelas residências dos trabalhadores do centro da cidade capital da Colômbia.

O Capítulo seguinte discutirá as premissas socioeconômicas do PUCAB, sobre as periferias serem majoritariamente adensadas pelas camadas socioeconômicas baixas, no intuito de serem atraídas para morarem por perto dos seus trabalhos.

O déficit residencial do Centro Ampliado é uma das variáveis de delimitação do espaço do PUCAB, assumido por esta pesquisa, como paradigma de fácil comprovação por meio da consulta nas pesquisas de mobilidade (SDM, 2015). 

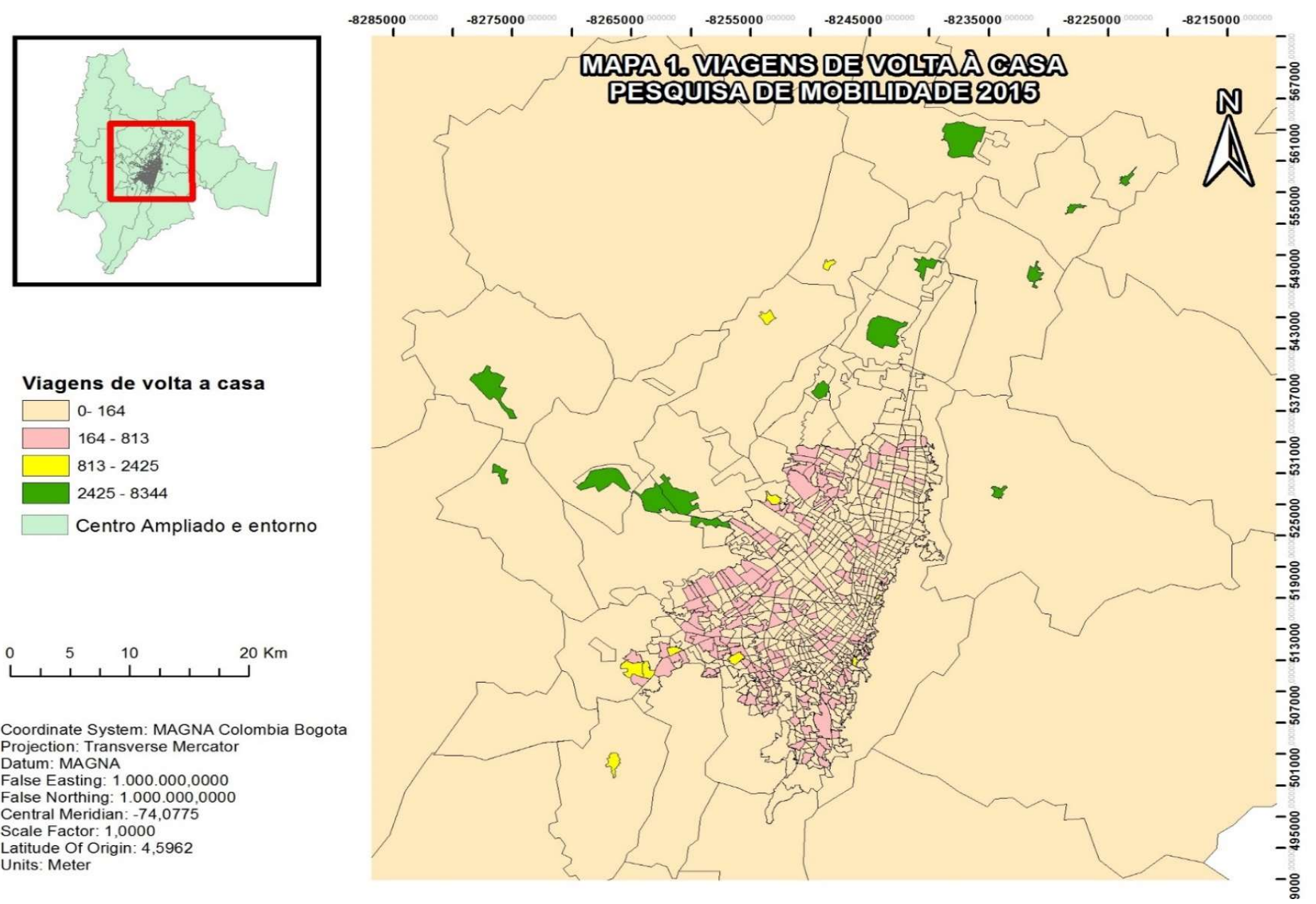

Viagens de volta a casa

$\square$ 0- 164

$164-813$

$813-2425$

$2425-8344$

Centro Ampliado e entorno

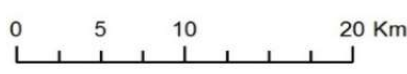

Coordinate System: MAGNA Colombia Bogot Projection: Transverse Mercator Datum: MAGNA

False Easting: $1.000 .000,0000$

False Northing: $1.000 .000,0000$

Scale Factor: 1,0000

Latitude Of Origin: 4,5962

$20 \mathrm{Km}$

Mapa 1. Viagens de volta à casa, pesquisa de mobilidade 2015

Fonte: Própria 


\section{4 \\ Premissas socioeconômicas: conquistas na inclusão social viabilizadoras da inclusão espacial dentro dos limites geográficos do PUCAB}

No Capítulo anterior foram discutidas as normas que promovem o adensamento no centro de Bogotá, devido a encontrar maior número de lares nas periferias. Essas periferias são majoritariamente ocupadas por camadas socioeconômicas baixas, motivo pelo qual o PUCAB propõe atrair a população mais pobre para dentro do Centro Ampliado e garantir a inclusão espacial graças a sua contribuição com avanços na inclusão social.

Os esforços pela inclusão social e melhoramento de vida dos cidadãos que viabilizam a inclusão espacial em Bogotá datam desde 1972, com ação das entidades governamentais na criação de programas de melhoria integral de bairros, colocando a cidade de Bogotá sobre estandes internacionais em cobertura de redes de serviços públicos como aqueduto, esgoto, eletricidade, telefonia e coleta de lixo. Estes esforços obtiveram o resultado de conseguir que $76 \%$ dos colombianos, more em assentamentos urbanizados, condição que garante acesso aos serviços públicos para quase todos os cidadãos (TORRES et al, 2009).

O cenário anteriormente descrito é um dos motivos pelos quais se viabiliza a integração socioespacial, porque o cidadão das periferias, mesmo sendo de uma camada socioeconômica baixa, contribui à tributação e fortalece a estrutura do mercado do solo urbano, razão pela qual pode ser atraído com programas de subsídios similares aos que já se possui na periferia, sem que os custos da tributação impliquem em um conflito na hora da escolha do setor de moradia.

Os bens e serviços habituais dos consumidores colombianos são acessíveis para qualquer um dos níveis salariais e garantido em qualquer setor da cidade, devido à existência do Índice de Preços ao Consumidor (IPC).

O Índice de Preços ao Consumidor (IPC) é um índice baseado numa pesquisa estatística que mede a variação percentual a partir dos preços de um conjunto de bens e serviços habituais dos consumidores. Este índice é usado como fator de ajuste na determinação do salário mínimo.

O cálculo do IPC é feito por cidade na Colômbia, incluindo na metodologia famílias de camadas socioeconômicas médias e baixas (DANE, 2017). 
A lacuna salarial não é significativa na Colômbia entre operários, assistentes, técnicos, profissionais analistas e chefes/coordenadores, os quais constituem os cargos laborais na média dos salários colombianos. As lacunas salariais mais significativas encontram-se ao passar para os cargos gerenciais e primeiro executivo com ingressos econômicos altos (ACRIP, 2017).

Na metodologia para os cálculos do IPC foram excluídas as famílias com chefe de família de classe socioeconômica alta, para não atingir aqueles com menores ingressos familiares (DANE, 2017). Pode-se concluir que, independentemente da localização, uma família de salário mínimo tem acesso aos bens e serviços básicos em Bogotá. Portanto, uma inclusão espacial não aumentará os custos do sustento familiar.

A redução na segregação espacial é mais uma estratégia para conseguir equidade socioeconômica na Colômbia, como reconhece o FMI (Fundo Monetário Internacional / International Monetary Fund) no conselho executivo de primeiro de maio de 2017, onde foi concluído que a Colômbia em 2016 avançou notavelmente em crescimento econômico superando os pares regionais e logrando reduzir a pobreza e a desigualdade (IMF, 2017).

A Figura 11 representa a cidade de Bogotá num panorama da divisão socioespacial. Mostra assim uma das premissas do plano: a classe socioeconômica baixa está localizada na periferia, e, segundo a mesma figura, a condição socioeconômica influencia a vizinhança aglomerando as classes socioeconômicas em setores geográficos que permitem evidenciar a segregação socioespacial. Segundo o índice integrado de segregação, as localidades identificadas como problemas são: Bosa, Usme e ciudad Bolivar (periferia) (SDP, 2013). 


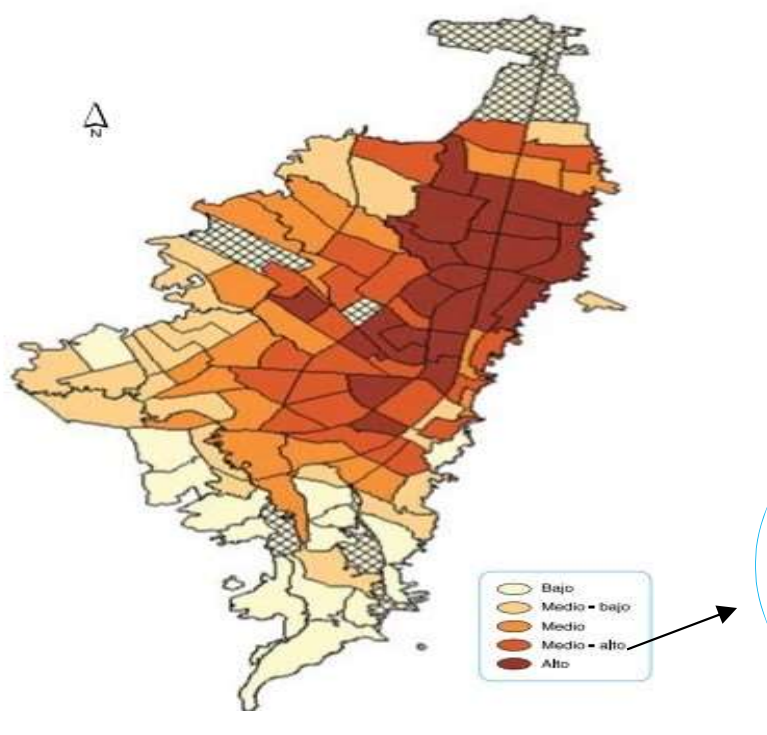

Figura 11 - Influência da vizinhança - Avaliação 2011.

Fonte: Segregação no espaço urbano de Bogotá, (SDP, 2013)

Baixo

Médio baixo

Médio

Médio alto

Alto

Observa-se a concentração das classes socioeconômicas médias e altas dentro dos limites do Centro Ampliado de Bogotá.

Existem cidades como o Rio de Janeiro no Brasil onde existe a inclusão espacial, porém, não se evidenciam as garantias no equilíbrio socioeconômico pretendidos com a inclusão em Bogotá, Colômbia.

Para quando surge a dúvida, se esclarecem as principais diferenças que viabilizam a inclusão espacial em Bogotá e o por que não se garantem as vantagens da inclusão espacial no Rio de Janeiro que, em resumo, se deve à falta de inclusão social, o que ainda dificulta o equilíbrio socioeconômico nessa cidade do Brasil.

As conquistas de inclusão social na Colômbia neste documento discutidas bem poderiam implicar um mínimo tema dentro do desenvolvimento de assuntos em referência à inclusão social, cuja importância abrange outros aspectos relevantes a serem comparados com o Brasil, porém, este trabalho considera apenas dois assuntos da inclusão social que viabilizam a inclusão espacial: primeiro a legalização da ocupação do solo e a dotação dos serviços públicos; e em seguida o acesso aos principais bens e serviços para qualquer um dos níveis salariais. 


\section{1.}

Uma comparação entre o Rio de Janeiro e Bogotá na urbanização de favelas

Evoca-se a dotação dos serviços públicos domiciliários e a legalização das ocupações irregulares do solo na Colômbia, não só como um mecanismo de cobrança pelos serviços e para o fortalecimento do solo urbano e sim, como estratégia "urbanizadora" de inclusão social dos setores ocupados irregularmente. Situação que garante dignificação aos moradores, ao fornecê-los dos serviços públicos e estabelecer o domínio legal com títulos de propriedade do terreno habitável invadido, entendendo que o lugar é ambientalmente seguro e não pertence a solos protegidos por lei, em cujo caso, a população deve ser conscientizada para obedecer aos delineamentos da lei n 388 de 1997 e demais normas complementares (CONPES, 2009). As ações de urbanização na Colômbia implicam garantir a dotação dos serviços públicos pelo estado (COLOMBIA, 1994), com segurança oferecida na instalação dos serviços sob critérios técnicos da construção civil, sem improviso das conexões dos serviços públicos com fugas que desestabilizam a estrutura das edificações no solo e, colocam em risco a vida humana.

Os assuntos aqui discutidos como conquistas viabilizadoras da inclusão espacial na Colômbia, parte dos avanços conseguidos com a educação das pessoas que habitavam solos irregularmente ocupados em cujo caso, gerou-se uma consciência na interpretação de inclusão social que envolve os direitos dos cidadãos, mas também os deveres das pessoas para aportarem como principais motores do desenvolvimento econômico da cidade, incluindo programas de capacitação e conscientizado coletivo para criar soluções econômicas sustentáveis em que devia-se basear às ocupações produtivas dos habitantes nas comunidades "urbanizadas". Esta visão da inclusão social garantiu avanços nos processos da urbanização, ao ponto da Colômbia chegar a ser um referencial na América do sul em assuntos da inclusão social. (TORRES et al, 2009).

Para Colômbia o termo de "Área urbana", é sempre caraterizada como um conjunto de edificações, e estruturas contiguas e agrupadas por quarteirões, delimitadas por ruas e/ou avenidas, cujos domicílios encontram-se geralmente dotados por serviços públicos essenciais tais como aqueduto, esgoto, energia elétrica, hospitais e escolas (DANE,2017), associando intrinsicamente o território urbano à dotação dos serviços públicos. 
Para 2015 em Bogotá na Colômbia foram registrados 55.450 lares (230.456 habitantes) em 125 assentamentos informais (favelas), equivalente acerca de 2,9\% do total da população da cidade, que, no ano 2015 chegava aos 7.883.075. Os assentamentos informais localizam-se em 11 localidades com maior concentração (59\%) nas localidades periféricas de Usme e Ciudad Bolivar ao Sul de Bogotá, como representa a Figura 12. (ONG-TECHO,2015).

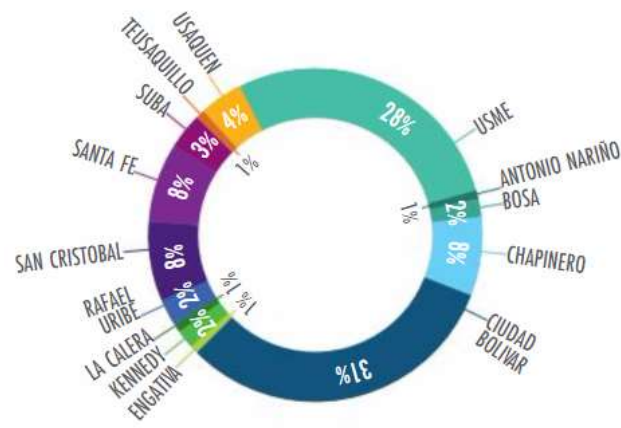

Figura 12 - Percentagem de assentamentos informais por localidade em Bogotá. Fonte: Derecho a Bogotá, (ONG-TECHO,2015).

No Brasil a interpretação de "áreas urbanizadas” adotado pelo documento com esse mesmo nome criado pelo IBGE no ano 2015, identifica as áreas urbanizadas sub aspectos morfológicos das imagens de satélite. As texturas investigadas consideram a proximidade entre residências e edificações, bem como os padrões de arruamento que caracterizam o modo de vida urbano. Este modo de vida urbano se entende pelas caraterísticas de relação entre os vizinhos, medida pela proximidade das residências e demais construções presentes no tecido urbano, além de fatores como a diversidade nas ocupações laborais da população. $\mathrm{O}$ resultado desse estudo para a cidade do Rio de Janeiro obteve 1.505,55 Km2 de área urbanizada com população acima dos 300.000 habitantes (IBGE, 2017).

No volume 35 das informações demográficas e socioeconômicas dos estudos e pesquisas do IBGE do ano 2015 - apresenta-se um panorama das condições de vida dos brasileiros numa síntese dos indicadores sociais resultantes da Pesquisa Nacional por Amostra de Domicílios do ano 2014; informações combinadas com outras pesquisas de outras das instituições e o Censo Demográfico 2010. Nos documentos de apoio para representação dos indicadores sociodemográficos, encontra-se $97,3 \%$ da população do Rio de Janeiro como moradora em áreas urbanas segundo a síntese dos indicadores sociais de 2015. Dito 
valor da população concentrada em área urbana, utiliza o conceito da localização geográfica dentro dos limites do perímetro que divide o setor rural do setor urbano municipal (IBGE, 2015).

O Censo Demográfico (2010) descreve: na região metropolitana do Rio de Janeiro moram 11.793.174 pessoas das quais 1.702 .073 pertencem aos moradores em domicílios particulares ocupados em aglomerados subnormais, representando aproximadamente $14,4 \%$ da população total da região metropolitana; sendo o $85,6 \%$ o restante dos moradores que ocupam áreas urbanizadas dentro dos padrões vigentes. Levando em conta a identificação das áreas subnormais como urbanização fora dos padrões vigentes - refletido por vias de circulação estreitas e de alinhamento irregular, lotes de tamanhos e formas desiguais e construções não regularizadas por órgãos públicos e precariedade de serviços públicos essenciais. Esta mesma identificação de aglomerações subnormais exclui aquelas aglomerações que contêm menos de 51 unidades habitacionais. Na cidade do Rio de Janeiro (cidade núcleo) especificamente, encontram-se $82,1 \%$ do total dos aglomerados subnormais da região metropolitana. Sendo o $17,9 \%$ a percentagem correspondente à participação dos aglomerados subnormais no restante dos municípios. (IBGE, 2011).

Por outro lado, existe a interpretação do Instituto Municipal de Urbanismo Pereira Passos (IPP) que considera a urbanização das favelas como as melhorias associadas à implementação dos serviços de infraestrutura sanitária, sistemas de circulação, equipamentos sociais, educacionais, de lazer e de esportes (PREFEITURA DA CIDADE DO RIO DE JANEIRO \& IPP, 2012). Interpretação similar para o termo "Urbanizado" da Colômbia.

Para o município do Rio de Janeiro, os dados do IPP- RIO em 2012 resulta em um acréscimo de 4\% da população em aglomerados subnormais com respeito aos dados do Censo Demográfico de 2010 do IBGE que propõe um número de 51 domicílios para considerar um conjunto como aglomerado subnormal. Devido a isso, algumas outras poucas áreas, apontadas como favelas pelo IPP-RIO, não foram assim consideradas pelo IBGE.

Os critérios do termo "urbanizado" da prefeitura do Rio de Janeiro e IPP-RIO no estudo de favelas 2012 são mais parecidos com os critérios da Colômbia, por isso, os resultados da cidade de Bogotá na Colômbia são comparados com aqueles entregues nos últimos documentos sobre favelas do ano 2012, mesmo existindo 
resultados mais recentes sobre indicadores sociodemográficos do IBGE, publicados no mesmo ano das últimas informações de aglomerados subnormais em Bogotá, porém, os critérios são inaplicáveis nas finalidades comparativas Bogotá-Rio, pelas diferenças de conceitos nos termos de "urbanização" e "área urbana".

Seguem as Figuras 13 e 14 de onde se fazem as análises do Rio para depois comparar os dados do Rio e Bogotá.

\begin{tabular}{|l|r|r|c|}
\hline \multicolumn{1}{|c|}{ Area de Planejamento } & Total (A) & $\begin{array}{c}\text { Comunidades } \\
\text { Urbanizadas (B) }\end{array}$ & Proporção B/A \\
\hline Total & 1.443 .773 & 283.058 & $20 \%$ \\
AP1 - Central & 103.296 & 28.060 & $27 \%$ \\
AP2 - Zona Sul & 174.149 & 58.305 & $33 \%$ \\
AP3 - Zona Norte & 654.755 & 149.014 & $23 \%$ \\
AP4 - Barra/Jacarepaguá & 236.834 & 13.310 & $6 \%$ \\
AP5 - Zona Oeste & 274.739 & 34.369 & $13 \%$ \\
\hline
\end{tabular}

Figura 13 Proporção da população de comunidade urbanizada sobre a população total das favelas, por área de planejamento - Município do Rio de Janeiro (IPP,2012).

Fonte: Estimativa IPP (2012) sobre IBGE. Censo 2010

\begin{tabular}{|l|r|r|c|}
\hline \multicolumn{1}{|c|}{ Área de Planejamento } & \multicolumn{1}{c|}{ Cidade (A) } & Favela (B) & (B) / (A) \\
\hline Total & 6.320 .446 & 1.443 .773 & $23 \%$ \\
AP1 - Central & 297.976 & 103.296 & $35 \%$ \\
AP2 - Zona Sul & 1.009 .170 & 174.149 & $17 \%$ \\
AP3 - Zona Norte & 2.399 .159 & 654.755 & $27 \%$ \\
AP4 - Barra/Jacarepaguá & 909.368 & 236.834 & $26 \%$ \\
AP5 - Zona Oeste & 1.704 .773 & 274.739 & $16 \%$ \\
\hline
\end{tabular}

Figura 14 Proporção de favelas por área de planejamento - Município do Rio de Janeiro (IPP, 2012).

Fonte: Estimativa IPP (2012) sobre IBGE. Censo 2010.

Segundo as informações das Figuras 13 e 14, conclui-se uma participação da população moradora em aglomerados subnormais para o município do Rio de Janeiro de $23 \%$ da população total da cidade (PREFEITURA DO RIO DE JANEIRO \& IPP-RIO, 2012). Entretanto, a participação da população moradora em aglomerados subnormais na cidade de Bogotá é de 2,9\% (ONG-TECHO, 2015). Esta é uma análise de sensibilidade pela diferença de anos em que foram publicados os dados, mas, que ainda assim, permite ver o panorama, sabendo que é pouco factível terem sido superadas as condições de urbanização da Colômbia nesse tempo diferencial em que foram feitas as publicações dos dados, das duas cidades comparadas. 


\section{2. Uma comparação do Rio de Janeiro e Bogotá sobre as lacunas salariais}

Um dos mecanismos de inclusão social é conseguir um custo dos preços no comércio ao alcance de qualquer um dos níveis salariais.

O Índice de Preços ao Consumidor é considerado na Colômbia e no Brasil para reajustar o salário mínimo segundo os custos da cesta familiar (serviços e produtos com maiores demandas do mercado).

O Índice de Preços ao Consumidor (IPC) colombiano não pode ser diretamente comparado com o seu equivalente brasileiro do índice Nacional de Preços ao Consumidor (INPC). O INPC tem como população objetivo às pessoas com ingressos dentre 1 e 5 salários mínimos por mês segundo o IBGE (2017).

O IPC colombiano não considera os ingressos econômicos na sua metodologia de cálculo que inclui famílias das classes socioeconômicas médias e baixas, cujo critério para classificação das camadas socioeconômicas baseia-se na Lei $n^{\circ} 142$ de 11 de julho de 1994 (COLOMBIA, 1994): dos serviços públicos domiciliários e se ditam outras disposições em que a classificação socioeconômica é feita, segundo a qualidade de vida que oferecem as residências e seu entorno, para cada lar e seus moradores classificados; sendo claro que as pessoas de camadas socioeconômicas altas adquirem residências conforme é permitido pelos seus altos ingressos salariais.

A pesar de não ser possível comparar os dois índices de preços ao consumidor de forma direta, pode-se comparar, sim, os tetos salariais para analisar a lacuna socioeconômica perceptível majoritariamente no Brasil e que atinge o custo do mercado para as pessoas com ingressos do salário mínimo.

O intervalo do INPC para a população objetivo com ingressos mensais dentre 1 e 5 salários mínimos, parece ainda um intervalo muito amplo para garantir custos ao alcance do salário mínimo, levando em conta que os cálculos dos índices de preços são resultantes de uma ponderação de bens e serviços consumidos por um conjunto de pessoas dentro de um intervalo de ingressos econômicos e, quanto menor for o intervalo da ponderação, maior é a garantia dos custos serem mais equitativos para a população objetivo.

Segundo o Ministério de Educação da Colômbia (MINEDUCACIÓN, 2016), baseado nas pesquisas do Observatório Laboral para a Educação (OLE), um 
profissional universitário, tecnólogo, técnico ou técnico profissional formado em 2014 e vinculado ao exercício profissional em 2015, percebe uma média aproximada de 2,35 salários mínimos e, para especialistas, mestres e doutores, a média é de 5,23 salários mínimos. Este último valor aproxima-se ao máximo dos valores do intervalo de ingressos da população objetivo do INPC brasileiro.

No Brasil, incluem-se aos profissionais nas ocupações típicas das classes socioeconômicas altas, entretanto os trabalhadores com ocupações como auxiliares, empregados domésticos e operários (ocupações do salário mínimo), em geral, são classificados dentro das camadas socioeconômicas baixas. (RUESGA et al, 2014). Existindo uma ampla lacuna socioeconômica entre profissionais e obreiros.

A média econômica do Colombiano encontra-se nos cargos operários, assistentes, técnicos, profissionais analistas e chefes/coordenadores. A lacuna salarial encontra-se ao passar aos cargos gerenciais e altos executivos (ACRIP,2017).

Lembre-se, na metodologia do cálculo do IPC da Colômbia existe uma exclusão das famílias das camadas socioeconômicas altas para não atingir a média do comércio, garantindo assim a inclusão social das pessoas de salário mínimo ao conseguir custos acessíveis no mercado.

Especificamente na cidade do Rio de Janeiro no Brasil é perceptível um custo de vida bastante alto em qualquer um dos bens, produtos e serviços do mercado para o salário mínimo desse país.

Nesta Seção destaca-se a coerência do objetivo geral do Plano Urbanístico na diminuição da segregação socioespacial, com os limites do Centro Ampliado.

No próximo Capítulo, será discutida a premissa ambiental de existir zonas de preservação nas periferias a partir dos limites do Centro Ampliado; mais uma razão para não propor novos limites de zonas a serem adensadas e, sim, apresentar um ranking de priorização de adensamento nas zonas do setor do PUCAB que cumpram com as condições de mobilidade para percursos curtos dos lares aos empregos. 


\section{5 \\ Premissas ambientais coerentes com os limites geográficos do PUCAB}

O Plano do Centro Ampliado de Bogotá declarou vulneráveis as pessoas das classes socioeconômicas baixas que se aglomeram majoritariamente nas periferias da cidade sem infraestrutura adequadamente construída, por causa de carecerem de segurança estrutural e também pela condição de expansão no espaço de preservação ambiental, com risco de alagamentos (periferia Ocidental) e desmoronamento (colinas do Leste) como representado na Figura 15 (SDP, 2011).

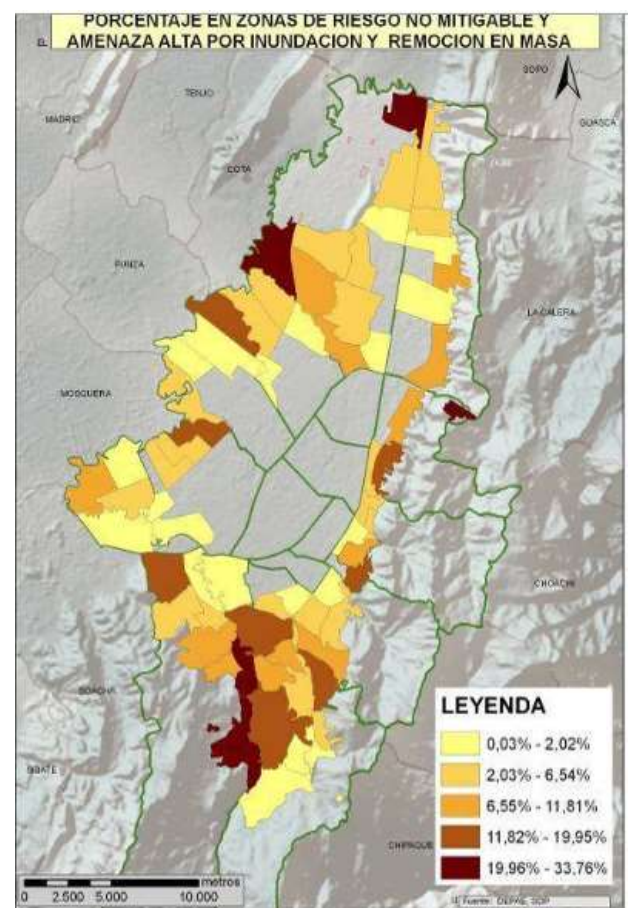

Figura 15 - Percentagem de risco por desmoronamento e alagamento não mitigável.

Fonte: SDP http://www.sdp.gov.co/portal/page/portal/PortalSDP/POT/QueEs/DTS.pdf

A Figura 16 e Tabela 3 localizam os nós de biodiversidade de preservação ambiental, localizados na periferia à exceção do Jardim Botânico (SDA, 2017); sabendo da aglomeração de residências nesses setores que devem ser protegidos por lei. 


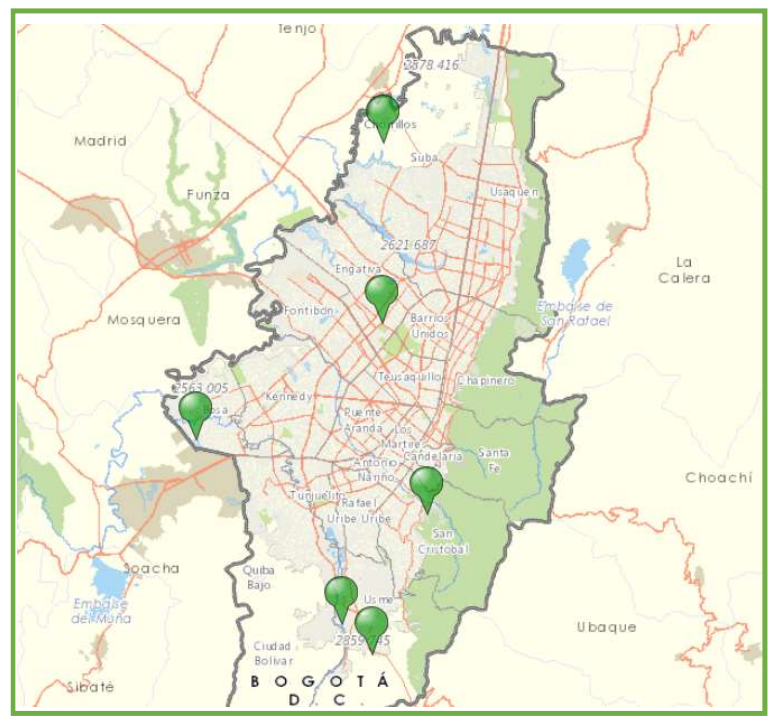

Figura 16 - Nós de Biodiversidade de Bogotá D.C.

Fonte: SDA http://www.secretariadeambiente.gov.co/visorgeo/\#submenu-jbb

Tabela 3. Localização dos nós de biodiversidade.

\begin{tabular}{|l|l|l|}
\hline Nome do nó & Localização localidade & Observação \\
\hline Las Mercedes & Engativá & Presença de pantanais \\
\hline Tibanica & Bosa & Presença de pantanais \\
\hline Cantarrana & Usme & Presença de pantanais \\
\hline $\begin{array}{l}\text { Agrodiversidad de } \\
\text { usme }\end{array}$ & Usme & Agrícola \\
\hline Cerros Orientales & San Cristóbal & \\
\hline Jardim Botánico & Engativá & Ecológica urbana \\
\hline
\end{tabular}

Fonte: SDA http://www.secretariadeambiente.gov.co/visorgeo/\#submenu-jbb

O Plano Urbanístico em discussão pretende partir das necessidades e satisfações do ser humano a nível ambiental, social, econômico e cultural como o centro das preocupações do desenvolvimento da cidade e, melhorar a estética do setor do Centro Ampliado acompanhando-o de políticas de integração das funções e habitantes que aí residem originalmente. Inclui-se aos moradores de rua que residem no setor do centro urbano $(0,005 \%$ do total da população da cidade), para formar parte das soluções de revitalização do setor. Permitindo que os moradores de rua permaneçam participando do espaço público que ocupam. (PREFEITURA DE BOGOTÁ et al, 2015).

Os componentes urbanísticos e moradores do centro, continuarão a ocupar 
o espaço após a renovação urbanística, integrando-os aos benefícios e melhorias; com o desafio de adensar o centro ampliado em 808.506 ${ }^{12}$ (DANE, 2005) habitantes a mais que espera a cidade de Bogotá para ano 2020.

As melhorias inerentes ao adensamento irão da mão dos atores públicos, privados e mistos, no nível do governo central e distrital, descritos e nomeados no Capítulo 4. "Descrição dos atores" no Plano; para ser integrados na procura de revitalizar o setor.

No PUCAB, mostra-se algumas áreas a serem intervindas para ocupação nos setores dos Mártires, o centro tradicional, cidade saúde da zona industrial e Campín.

A revitalização de cada zona apresenta a intervenção com parques, ciclovias, bem como maior aproveitamento do terreno construído.

O adensamento com a participação do ser humano na criação de soluções e espaços de convívio e mobilidade sustentável significa uma integração do ser humano e a cidade com o meio ambiente.

As Figuras 15 (Página 55) e 16 (Página 56), permitem ver os limites do Centro Ampliado de Bogotá como os limites das áreas seguras quanto aos riscos ambientais que, não atingem as zonas de preservação ambiental.

Até este Capítulo, se argumenta respeitar os limites propostos pelo PUCAB para propor soluções de mobilidade por meio do adensamento nos setores em que é possível garantir tempos de mobilidade eficiente nos percursos dos lares aos empregos, devido a existir diversas razões pelas quais a cidade de Bogotá pode crescer dentro desses limites; mesmo que essas razões não pertençam às variáveis de delimitação geográfica do setor do Centro Ampliado de Bogotá.

No próximo Capítulo entra-se a análise de cada elemento das condições de mobilidade do PUCAB, de onde surge a hipótese de tese, de não ser possível garantir os 20 minutos das casas às zonas de maior geração de emprego nos transportes públicos e, de onde se desprendem as propostas de mobilidade para cumprir com as pretensões do Plano para localizar os lares por perto da maior oferta de emprego na cidade de Bogotá.

\footnotetext{
12 Projeções populacionais DANE 2005-2020.
} 


\section{6 \\ Premissa de mobilidade do PUCAB}

As condições de mobilidade são as principais variáveis para a delimitação do Centro Ampliado de Bogotá; descreve-se o setor como um território passível de se locomover a pé até as estações dos transportes públicos em 10 minutos e percorrer em máximo 20 minutos nos transportes coletivos desde qualquer ponto dentro dos limites do setor do PUCAB até os polos de emprego, porém, parte-se da hipótese do não cumprimento destas condições.

Do objetivo de alocar pessoas das classes socioeconômicas baixas, em zonas ambientalmente seguras, perto da maior oferta laboral oferecida no Centro Ampliado segundo o PUCAB, e das condições de mobilidade que delimitaram geograficamente esse território, se questiona o tempo nos percursos dos lares ao trabalho nos transportes públicos, devido a serem submetidos ao transito veicular, o que dificulta garantir tempos de até 20 minutos nos percursos desde qualquer ponto do Centro Ampliado até os polos de emprego, como deverá ser comprovado na metodologia desta pesquisa.

Para desvirtuar as condições de mobilidade lar-trabalho-lar, basta desvirtuar a mobilidade nos transportes públicos, levando em conta que, os lares podem se localizar em qualquer um dos pontos dentro dos limites do território em questão.

\section{1. Discussão sobre as zonas de maior geração de emprego da cidade de Bogotá: elemento das condições de mobilidade para a delimitação geográfica do PUCAB}

Será analisado o conceito das áreas de maior geração de emprego segundo o Plano Urbanístico do Centro Ampliado de Bogotá (2015) e a tese de Gutiérrez (2011).

O Plano Urbanístico do Centro Ampliado de Bogotá, no Capítulo 1 descreve as zonas de maiores indicadores de emprego e atividade económica, localizadas desde o centro histórico para o norte de Bogotá, percorrendo um corredor alongado e limitado pelas ruas "Carrera 7 e 30 NQS", formando um "J" geográfico ao prolongar a atividade econômica para o aeroporto. Projetam-se zonas de maior atividade econômica também na influência ao norte e sul da "calle 26" como 
representado na Figura 17, onde a maior aglomeração de pontos roxos, lilás e vermelhos; reconhecem a indústria e o comércio como as principais atividades econômicas da cidade, a partir da consulta das pesquisas de mobilidade (SDM, 2011).

Os endereços descritos no Plano Urbanístico ao mencionar a “calle 26”, não identifica os limites geográficos da influência norte-sul para saber exatamente as zonas de maior geração de emprego que tenta definir nesse espaço e, igualmente no caso da projeção do braço da "J" até o aeroporto. Portanto, a Figura 17 apresenta uma aproximação das descrições das zonas de maior geração de emprego do Plano Urbanístico do Centro Ampliado de Bogotá, segundo a descrição do Capítulo 1 desse documento.

\section{CONVENÇÕES:}

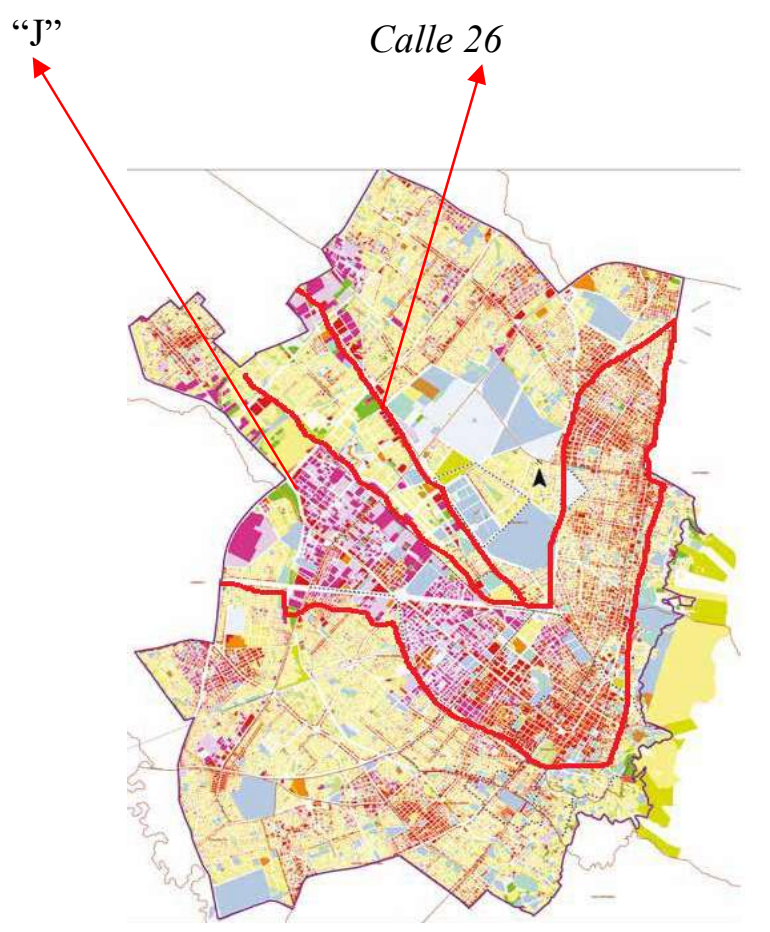

Centro Ampliado
Localidades
Intervenções
Sem destıno
01 Residencial
03 Industrial
04 Dotações públicas
05 Recreações públicas
06 Dotações Privada
07 Mineiros
08 Recreações Privadas
21 Comércios em corredor comercial.
22 Comércios em Centro comercial
23 Comércios pontoais
24 Estacionamento
61 Urbanizado não edificado
62 Urbanizável, não urbanizado.
63 Não urbanizável e solo protegido.
64 Terrenos estaduais
65 Vias
66 Espaços públicos
67 Edifícios com melhorias alheias
81 Agropecuário
85 Florestal

Figura 17 - Destinos económicos do Centro Ampliado de Bogotá.

Fonte: Plano Urbano do Centro ampliado de Bogotá-Bogotá Humana.

Segue a Figura 18, da aglomeração de empregos representado pelo Plano Urbanístico do Centro Ampliado de Bogotá no Capítulo 4 desse documento, notando maior aglomeração de emprego em cor vermelho, além das descrições das zonas de maior geração de emprego descritas no Capítulo 1 do PUCAB. 


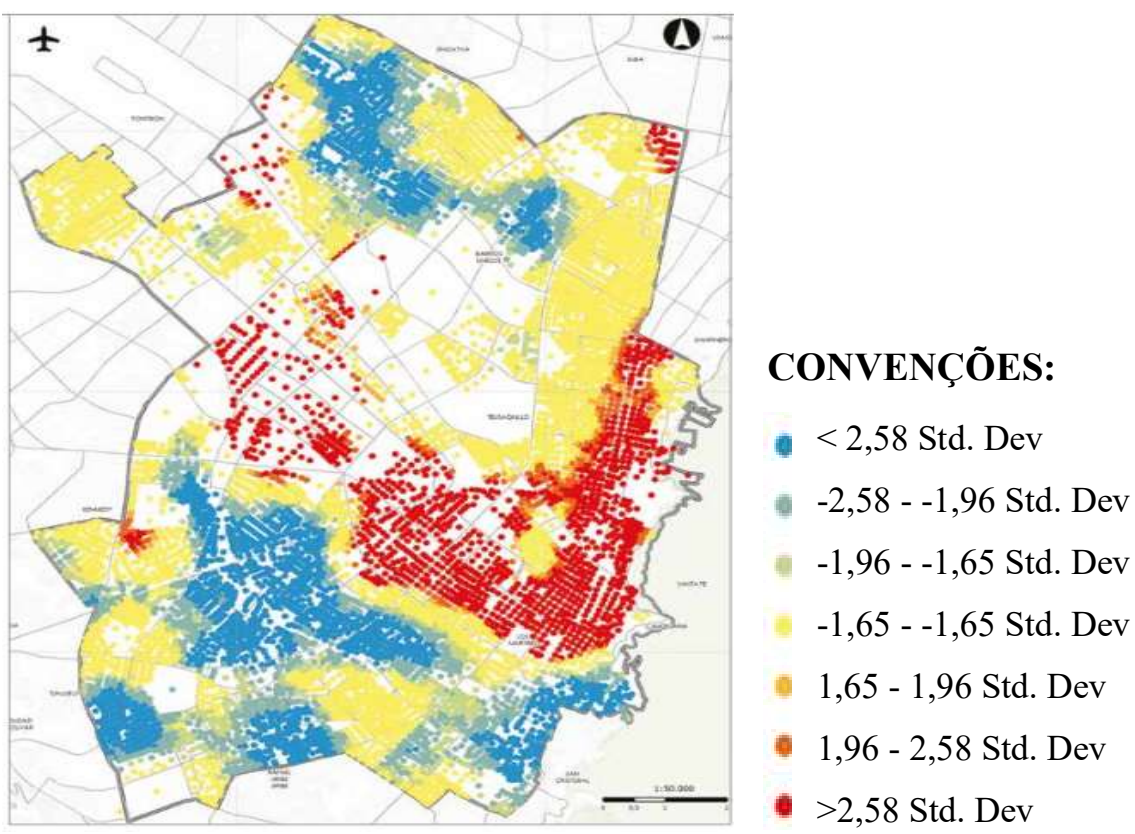

Figura 18 - Aglomeração de empregos segundo o plano urbanístico do Centro Ampliado. Fonte: Plano Urbano do Centro ampliado de Bogotá-Bogotá Humana.

Segundo Gutiérrez (2011), a cidade tem sido estudada por economistas, identificando uma organização física e aglomerações comerciais em Bogotá: Distrito Central de Negócios (DCN).

O DCN é o setor com mais alta concentração de serviços e funções comerciais pelo conceito monocêntrico de Von Thunen em 1826 em que, discute sobre um ponto no espaço chamado centro onde começa a cidade. A conformação do setor industrial, residencial e agropecuário situam-se em forma de anéis concêntricos ao redor daquele ponto.

Para a descentralização das atividades e comércio urbano, foram tratados os modelos exógenos que não explicam as origens do DCN, mas, reconhece a sua existência. Este modelo foca a oferta de trabalho em sub - centros de empregos que descentralizam a mão de obra.

Por outro lado, o modelo endógeno explica a aparição do DCN pela minimização de custos no transporte. À medida que o centro se vê congestionado, se vê descentralizada também a mão de obra, aumentando os salários. Novamente este modelo explica a localização do DCN pelas economias de aglomeração e transportes.

Finalmente, o modelo da nova geografia econômica reconhece o rendimento 
crescente da economia central interna. Considera dois agentes básicos: os consumidores e as empresas. Baseia-se na competência monopolística DixitStiglitz e usa como ferramenta de consulta as pesquisas de mobilidade de 2006, de onde extrai a variável de emprego, do módulo $\mathrm{C}$, caraterísticas socioeconômicas.

O trabalho destaca-se como ferramenta para implementação de instrumentos de planejamento urbanístico, devido à criação das centralidades do Decreto 190 de 2004 que complementa o Decreto 619 de 2000. O decreto 190 de 2004 do Plano Diretor de Bogotá define e regulamenta a conformação de "centralidades" como focos de geração de emprego em lugares de assentamento urbanizado e, a urbanizar, para geração de sustentabilidade econômica ${ }^{13}$ (COLOMBIA, 2004).

Gutiérrez (2011) concluiu que, as atividades de maior geração de emprego são o comércio e a terceirização de mão de obra para o setor da indústria.

As zonas de maior geração de emprego da Figura 19 estão dadas por UPZ. Estas áreas são menores que as localidades da cidade, maiores do que as ZAT e servem como unidades territoriais para planificar o desenvolvimento urbanístico da cidade. (Ver Anexo 2, lista UPZ).

${ }^{13}$ Decreto 190 de 2004 


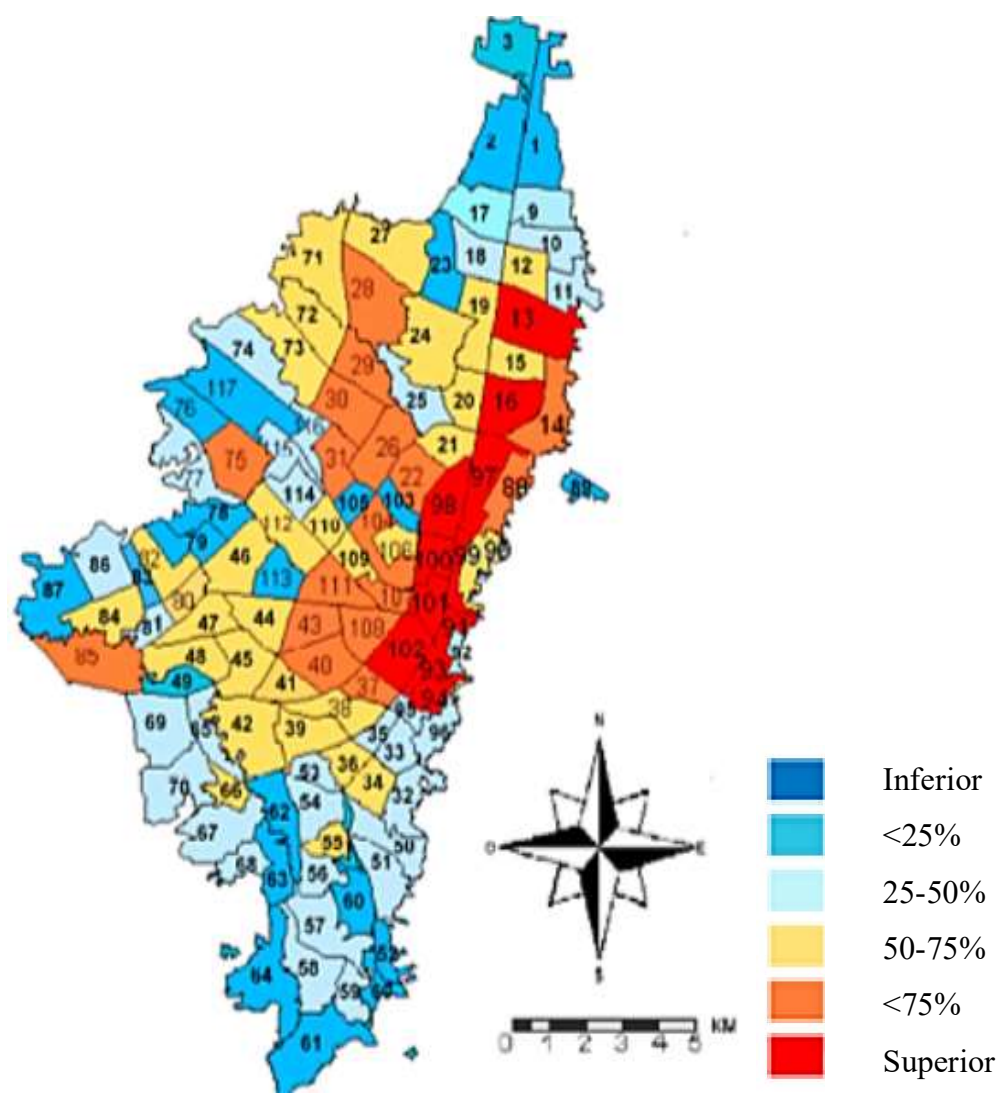

Figura 19 - Distribuição de adensamento do emprego baseado em pesquisa de mobilidade 2006.

Fonte: Gutiérrez (2011).

Destacam-se as diferenças na distribuição de emprego do PUCAB e Gutiérrez, devido à criação das centralidades do Decreto 190 de 2004, que muda a conduta das viagens por emprego consultadas para a definição das zonas de maior geração de emprego que dependem da atração de viagens na mobilidade segundo as consultas de 2011 do PUCAB e 2006 de Gutiérrez.

\section{2.}

Discussão sobre os tempos de percursos das casas aos empregos: elemento das condições de mobilidade para delimitação geográfica do PUCAB

O Plano Urbanístico na condição de mobilidade determina um tempo não maior que vinte (20) minutos, em transportes públicos como tempo eficiente de percurso desde os lares até o trabalho, porém, não há bibliografia que defina esse topo de tempo como ideal para que se considere tal condição dentro do Plano Urbanístico do Centro Ampliado de Bogotá. 
Existem pesquisas sobre o bem-estar das pessoas associadas ao tempo de percursos desde as casas até os trabalhos que concluem uma relação inversa entre tempo da viagem ao trabalho e a satisfação humana para com a vida.

O órgão nacional de estatísticas (ONS, 2014) do Reino Unido avalia níveis de felicidade e ansiedade das pessoas relacionadas ao tempo de percurso até os seus trabalhos.

Especificamente, comparam as pessoas que se deslocam para o trabalho com aquelas outras pessoas que não se deslocam (Homeworkers); tempos usuais de deslocamento e, modais de viagem.

Em termos gerais, mostra-se maior satisfação e bem-estar naquelas pessoas que não se deslocam para o trabalho (Homeworkers).

Ao passar das três horas de percurso, os efeitos negativos desaparecem para todos os casos da pesquisa.

Nos percursos em carro particular e transportes públicos, o pior cenário se apresenta ao passar dos trinta minutos para viagens desde os lares ao trabalho em que o passageiro se sente ansioso. Sendo os trinta minutos (30 minutos), um parâmetro de referência máximo do lar ao trabalho em transportes públicos no Reino Unido.

Em Kunming, China (HE \& ZHAO, 2017), se procura por meio de outra pesquisa: encontrar tempos máximos de tolerância nos percursos para qualquer atividade, destacando a importância do tempo de percurso do trabalho às casas para planejamentos urbanísticos em que se tomam decisões para localização do emprego nas cidades.

Os quarenta minutos (40 minutos) dividem aos passageiros de curto e longo percurso de viagem em que é classificada pela pesquisa na Figura 20 representa-se os resultados. Note-se que para a maioria dos passageiros $(37,3 \%)$, de percursos maiores que quarenta minutos, a tolerância máxima está entre 50 e 60 minutos e, para a maioria dos passageiros $(30,6 \%)$, de percursos curtos, a tolerância é máxima no intervalo dos 30 aos 40 minutos. 


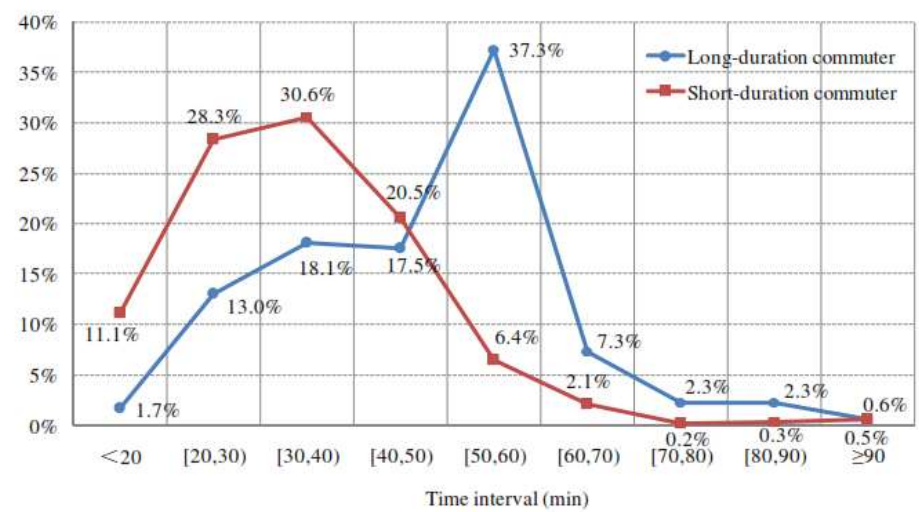

Figura 20 - Distribuição dos limites de tolerância em Kunming China. Fonte: (HE \& ZHAO, 2017)

$\mathrm{Na}$ mesma pesquisa para tempo ideal de percurso das casas aos trabalhos, na Figura 21, note-se que para a maioria dos passageiros $(40,7 \%)$, de percursos maiores aos quarenta minutos, o tempo ideal de viagem está entre os 20 e 30 minutos e, para a maioria dos passageiros $(47,7 \%)$, de percursos curtos, o tempo ideal de viagem é de 10 a 20 minutos.

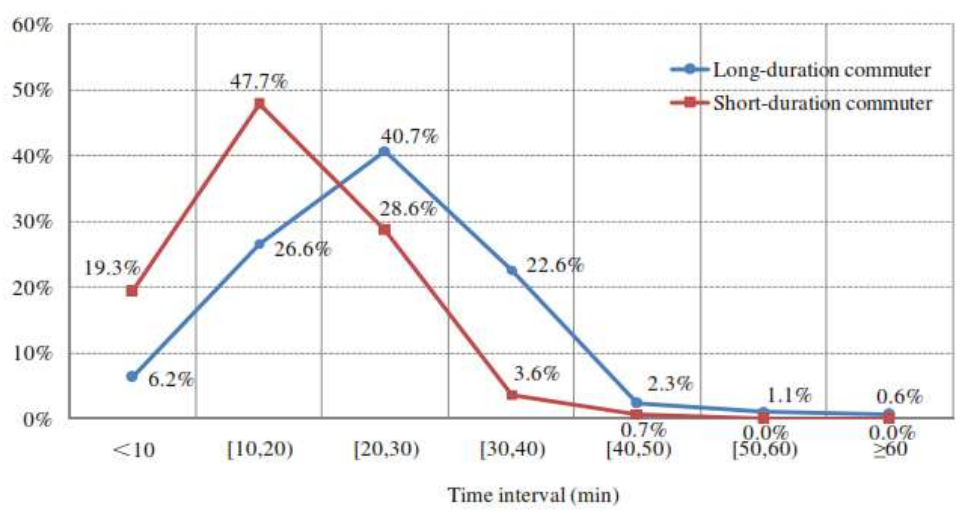

Figura 21 - Tempo ideal de percurso em Kunming China. Fonte: (HE \& ZHAO, 2017)

Deve ser salientada a importância da pesquisa com a sociedade colombiana, toda vez que o tempo ideal e de tolerância apresenta diferenças entre as duas pesquisas neste Capítulo discutidas.

O próximo Capítulo introduz as generalidades da pesquisa de mobilidade (SDM, 2015), de onde se abstraem os dados da metodologia para a comprovação da hipótese de tese e, as propostas de mobilidade nos tempos eficientes de tolerância e ideais dos lares aos empregos nos transportes públicos 


\section{7 Generalidades das pesquisas de mobilidade (SDM, 2015)}

Esta pesquisa de mobilidade foi feita entre janeiro e dezembro de 2015 pelo consorcio Transconsult - Informétika, com fiscalização da firma TPD engenharia e, supervisão da entidade contratante.

A entidade contratante é a Secretaria Distrital de Mobilidade SDM, pertencente à administração pública de Bogotá, com autonomia administrativa e financeira para orientar e liderar a formulação de políticas na mobilidade da cidade.

A SDM é a única entidade com autoridade na entrega, distribuição e permissão no uso das informações das pesquisas, portanto, as informações the pertencem e são de caráter oficial.

A pesquisa de mobilidade consta de entrevistas Origem Destino nos lares (EODH), e nas interceptações ou estações de trabalho da cidade (EODI).

No caso desta pesquisa para a mobilidade do PUCAB são consultadas as EODH devido a serem precisas as informações dos tempos de percursos das viagens desde as zonas Origem dos lares até as zonas Destino de maior geração de emprego, da proposta de adensamento prioritário sub condições de mobilidade.

As informações das entrevistas nos lares servem para apreciar os fluxos na mobilidade sub algumas condições socioeconômicas da população que se desloca de um setor a outro (Origem/Destino), por vários motivos a serem determinados na sua quantidade após as ânforas.

Segundo as pesquisas de mobilidade, estas atendem às regulamentações da lei 1083 de 2006, formulada com base na lei 388 de 1997 das diretrizes dos Planos Diretores em que se concebe a finalidade de formular planos de mobilidade, para melhorar a qualidade de vida dos cidadãos nos distritos e munícipios onde deverão ser planejados modos alternativos dos transportes.

A pesquisa de mobilidade (SDM, 2015) foi realizada como fonte de informações para o planejamento dos transportes pelo modelo das quatro etapas em que, como todo modelo de transporte, permite estimar o padrão de fluxos das viagens de pessoas e veículos com a finalidade de avaliar possíveis investimentos nas malhas viárias ou, nos sistemas dos transportes públicos coletivos, de forma a atender às demandas futuras na cidade de Bogotá. 
O modelo de transportes das quatro etapas consta de quatro módulos: 1. Módulo de geração, 2. Módulo de distribuição, 3. Módulo de repartição e 4. Modulo de atribuição.

No primeiro módulo se estima o número total de produção e atração de viagens de cada área em estudo; no segundo módulo se distribuem as viagens Origem/ Destino, gerando uma matriz futura das viagens; o terceiro módulo envolve a escolha dos modos de transportes (veículos, transporte público, bicicletas, etc.); no quarto módulo se realiza a alocação das viagens de cada modo na rede viária.

Para este modelo dos transportes é necessário contar com as informações socioeconômicas das pessoas entrevistadas nas áreas de estudo e o uso dos solos contidos nas legislações e o PD da cidade.

Para efeitos da presente pesquisa de mobilidade eficiente para cidades compactas e menos segregadas se parte do conhecimento prévio de um estudo de caso do Plano Urbanístico do Centro Ampliado de Bogotá em que é pretendido realocar as residências de 808.506 (hab) - moradores das periferias de Bogotá para dentro dos limites adotados pelo PUCAB (adensamento) - que deverão cumprir com tempos menores ou iguais aos 20 minutos nos percursos dos lares aos empregos nos transportes públicos coletivos existentes na cidade.

Os moradores das periferias a serem realocados já fazem uso da malha viária do setor do PUCAB pelos fluxos que majoritariamente são provenientes das periferias para as zonas de emprego numa conduta monocêntrica até as áreas do Centro Ampliado.

O problema a resolver é o cumprimento do tempo dos percursos no setor do PUCAB que conta com déficit residencial e encontra-se subutilizado na sua infraestrutura, como foi anteriormente explicado.

Após a determinação de áreas a serem adensadas podem ser estudados novos comportamentos das viagens desses cidadãos e fica aberta a possibilidade de uma análise para aplicação de modelos de transportes com a finalidade de estabelecer a demanda futura dos transportes públicos coletivos, mas, isso após este tipo de análises e discussões no marco da escolha ainda para adensamento das zonas dentro do Centro Ampliado onde a população conseguirá morar perto das atividades habituais. 
Dito de outra forma: para essas zonas prioritárias a serem adensadas e aqui escolhidas, será viável o estudo do comportamento das viagens futuras para as implementações no marco das demandas dos transportes públicos de Bogotá.

Cabe anotar a prudente análise que merece cada zona a ser adensada por condições de mobilidade, mas que deverão ser estudadas as possíveis maiores demandas não só para os transportes públicos e sim, também, para todos os demais serviços públicos.

Revisar à infraestrutura viária e de urbanismo; serviços a serem adaptados nas suas capacidades, às novas condições de ocupação adensada em cada zona. Isso se for necessário, sabendo da existência da condição de infraestrutura subutilizada pelo déficit residencial do Centro Ampliado.

A matriz de tempos das zonas Origem/Destino (OD) dos transportes públicos foi fornecida com os tempos da matriz modelada que é calibrada para ser idealmente igual à matriz pesquisada obtida da simulação num software tipo EMME, na rede viária como representado na Figura 22 (centroides, intersecções, zonas e eixos).

Nas pesquisas de mobilidade de Bogotá, as zonas de Origem/Destino são nomeadas como Zonas de Análise dos Transportes ZAT. Estas zonas são divisões geográficas particulares por incluírem variáveis que representam a dinâmica da cidade desde o âmbito econômico, social, de acessibilidade dos transportes, classificação das camadas socioeconômicas e usos dos solos. Estas ZAT existem desde a sua criação para efeitos da análise dos transportes nas pesquisas de mobilidade de 2011.

Na Figura 22 visualizam-se as divisões das zonas ZAT internas de um setor ainda maior como é o PUCAB com os atributos e propriedades concentrados num ponto chamado centroide. Pode-se ver também como o centroide se localiza num ponto geográfico de cada zona onde se concentram todas as caraterísticas da região seccionada, é assim como são representados os centroides e os deslocamentos no espaço pelos nós e eixos até os outros centroides que caracterizam outras zonas ZAT: 
Nós (ou zonas ou centroides) - Zonas de origem e/ou destino de viagens e intersecções.

ARCOS (ou eixos, ou segmentos) - possibilidades de ligação direta entre nós.

Zonas ZAT

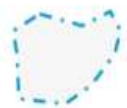

Nós

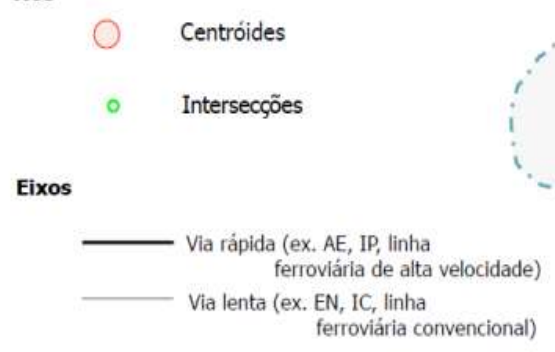

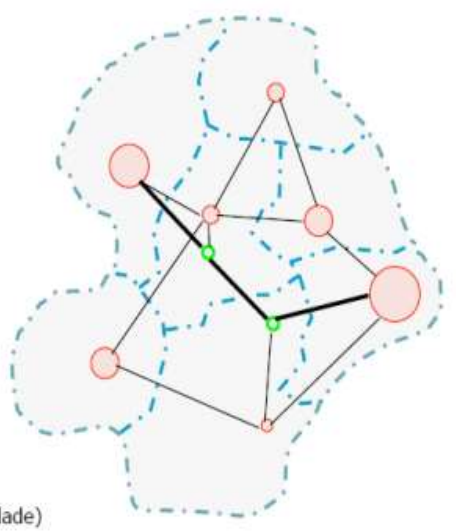

Figura 22 - Representação da rede viária Fonte: Hugo Repolho, 2015

Na Figura 23 se representam os tempos de zero (0) minutos das zonas ZAT Origem para as mesmas ZAT Destino por se tratar de um percurso desde um ponto até o mesmo ponto geográfico.

A matriz OD dos tempos se representa em termos gerais da seguinte maneira:

Zonas Destino $k$

\begin{tabular}{|c|c|c|c|c|c|}
\hline ZAT & 1 & 2 & 3 & 4 & 5 \\
\hline 1 & 0 & $(\mathrm{Tmin})$ & $(\operatorname{Tmin})$ & $(\operatorname{Tmin})$ & (Tmin \\
\hline 2 & (Tmin) & 0 & (Tmin) & (Tmin) & (Tmin) \\
\hline 3 & (Tmin) & (Tmin) & 0 & $(\operatorname{Tmin})$ & (Tmin) \\
\hline 4 & (Tmin) & (Tmin) & $(\operatorname{Tmin})$ & 0 & $(\mathrm{Tmin})$ \\
\hline 5 & (Tmin) & (Tmin) & $(\operatorname{Tmin})$ & (Tmin) & 0 \\
\hline
\end{tabular}

Miolo da matriz: $\mathrm{T} j k(\mathrm{~min})$

Figura 23 - Representação geral da matriz de tempos Origem Destino nos transportes públicos. Fonte: Desenho próprio baseado nas informações das pesquisas de mobilidade (SDM, 2015).

ZAT: numeração de identificação das Zonas de Análises dos Transportes.

$\boldsymbol{k}:$ linha

j: coluna

Zona Origem j: zonas ZAT Origem na primeira coluna à esquerda da matriz.

Zona Destino k: zonas ZAT Destino na linha superior da matriz. 
Tjk (min): Miolo da matriz dos tempos em minutos (Tmin) de percursos em transportes públicos desde as zonas Origem $(j)$ até as zonas Destino $(k)$.

O miolo da matriz Tj.k ( $\min )$ da matriz Origem/Destino, é entregue pela consulta de mobilidade (SDM, 2015). São os tempos das zonas Origem às zonas Destino.

A hipótese desta pesquisa parte do não cumprimento de percursos de até 20 minutos nos transportes públicos desde qualquer ponto geográfico do setor do PUCAB até os polos de emprego.

Note-se às condições de mobilidade podem ser representadas numa matriz de tempos das zonas Origem (lares) até as zonas Destino (zonas de maior geração de emprego).

Deveria se representar uma matriz de todas as zonas Origem do PUCAB (localização dos lares), e, as zonas Destino deveriam ser as zonas descritas no Plano como as zonas de maior geração de emprego, mas, essas descrições são diferentes em dois dos Capítulos desse documento, mesmo que estas são descritas dentro do mesmo setor do PUCAB, como foi discutido no Capítulo 6. Devido às diferenças das descrições do Plano, para a comprovação da hipótese, se apresentará uma mobilidade interna no Centro Ampliado, em que estão contidas às zonas de maior geração de emprego e os lares. A matriz de tempos OD representa-se simétrica com os tempos de todas as zonas ZAT Origem até todas as zonas ZAT Destino do PUCAB.

As zonas de maior geração de emprego contidas no Centro Ampliado, deveriam cumprir com uma abrangência nos 20 minutos do $100 \%$ do setor do PUCAB, para garantir as condições de mobilidade lembrando que os lares podem se localizar em qualquer uma das zonas dentro desse setor e, se nenhuma zona consegue cumprir com uma abrangência do $100 \%$ da região, então, ficará demonstrado o não cumprimento nos percursos de 20 minutos, nos transportes públicos das casas aos polos de emprego e vice-versa (hipótese).

Para a proposta de cumprir as pretensões de mobilidade do Plano, a representação matricial será conformada com zonas origem $\mathrm{j}$ : todas as zonas do PUCAB (lares) e zonas destino k: todas as zonas que contem pelo menos com uma viagem por motivo de emprego, segundo todo o universo das pesquisas de mobilidade (SDM, 2015). 
Para o cenário de sensibilidade para uma mobilidade dos lares até todos os demais motivos. O universo destino serão as zonas ZAT com pelo menos uma viagem numa mobilidade interna no Centro Ampliado por causa de os equipamentos, poder ser escolhidos pela população nos lugares perto dos lares, sendo o setor do PUCAB, a região com maior número de equipamentos urbanos da cidade de Bogotá D.C. (PREFEITURA DE BOGOTÁ et al, 2015).

Entenda-se o universo como o número total de zonas que intervêm num território em análise e, neste caso das pesquisas de mobilidade de 2015, na caraterização da mobilidade urbana de Bogotá e os 17 municípios vizinhos da Figura 24 e a Tabela 4.

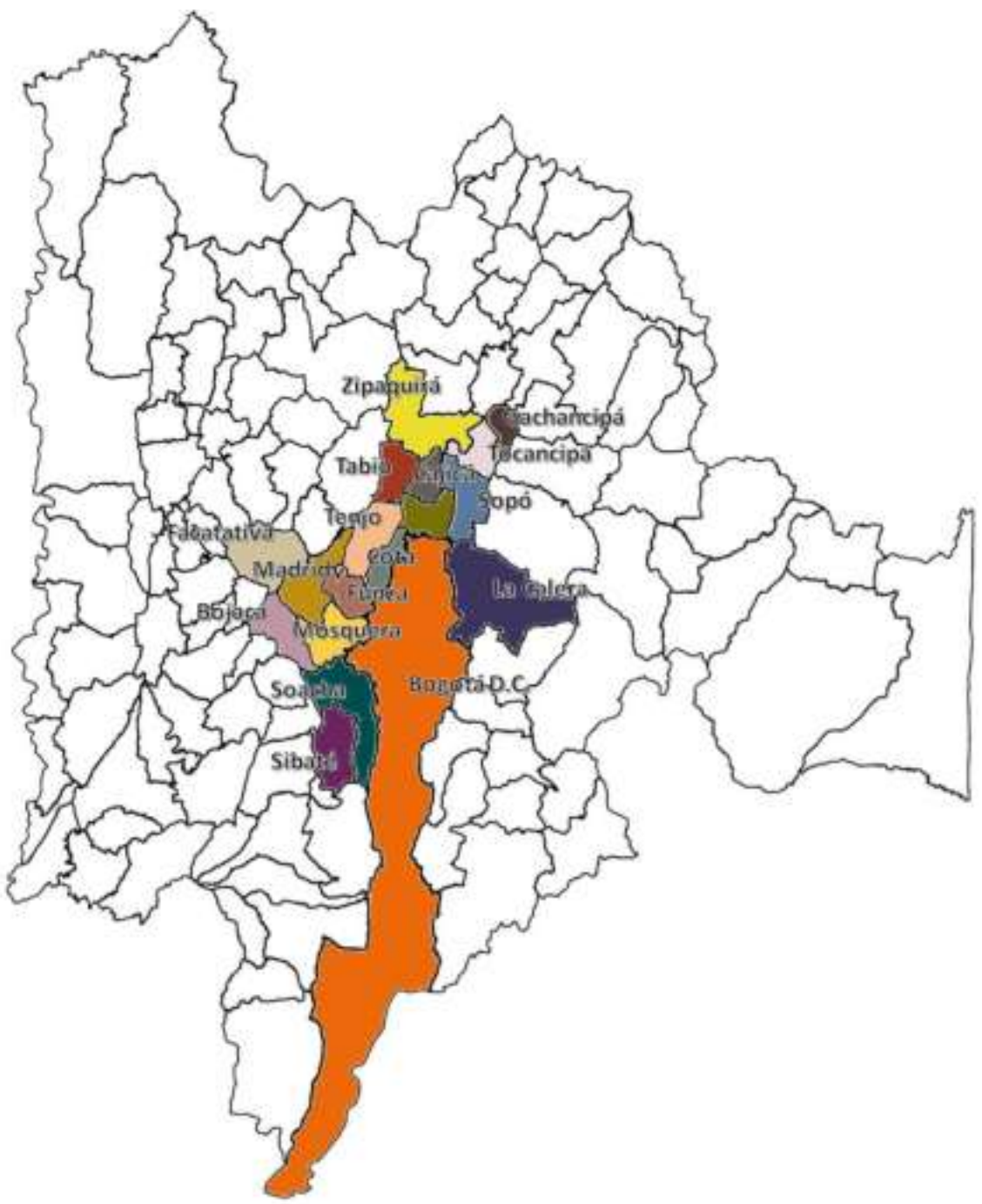

Figura 24 - Universo das pesquisas de mobilidade 2015.

Fonte: Consorcio Transconsult - Informétika. 
Tabela 4. Dados demográficos do universo das pesquisas de mobilidade 2015.

\begin{tabular}{|c|c|c|c|}
\hline Município & População & Lares & Pessoas por lar \\
\hline Bogotá, D.C. & 7872323 & 2428377 & 3,24 \\
\hline Usaquén & 494066 & 176067 & 2,81 \\
\hline Chapinero & 137870 & 60034 & 2,30 \\
\hline Santa Fe & 110053 & 38966 & 2,82 \\
\hline San Cristobal & 406025 & 123680 & 3,28 \\
\hline Usme & 432724 & 127024 & 3,41 \\
\hline Tunjuelito & 200048 & 63633 & 3,14 \\
\hline Bosa & 646833 & 190522 & 3,40 \\
\hline Quennedy & 1069469 & 322446 & 3,32 \\
\hline Fontibon & 380453 & 120996 & 3,14 \\
\hline Engativá & 874755 & 265406 & 3,30 \\
\hline Suba & 1174736 & 331074 & 3,55 \\
\hline Barrios Unidos & 240960 & 71931 & 3,35 \\
\hline Teusaquillo & 151092 & 59886 & 2,52 \\
\hline Los Marires & 98758 & 31818 & 3,10 \\
\hline Antonio Nriño & 108941 & 31893 & 3,42 \\
\hline Puente aranda & 258414 & 82251 & 3,14 \\
\hline La candelaria & 24096 & 8279 & 2,91 \\
\hline Rafael Uribe Uribe & 375107 & 115982 & 3,23 \\
\hline Ciudad Bolivar & 687923 & 206489 & 3,33 \\
\hline Bojacá & 9256 & 2436 & 3,80 \\
\hline Cajicá & 35700 & 9395 & 3,80 \\
\hline Chía & 99226 & 26112 & 3,80 \\
\hline Cota & 14354 & 3777 & 3,80 \\
\hline Facatativá & 119294 & 31393 & 3,80 \\
\hline Funza & 70622 & 18585 & 3,80 \\
\hline Gachancipá & 8365 & 2201 & 3,80 \\
\hline La Calera & 11849 & 3118 & 3,80 \\
\hline Madrid & 67527 & 17770 & 3,80 \\
\hline Mosquera & 79316 & 20873 & 3,80 \\
\hline Sibaté & 25903 & 6817 & 3,80 \\
\hline Soacha & 505319 & 132979 & 3,80 \\
\hline Sopó & 17151 & 4513 & 3,80 \\
\hline Tabio & 13145 & 3459 & 3,80 \\
\hline Tenjo & 9421 & 2479 & 3,80 \\
\hline Tocancipá & 13618 & 3584 & 3,80 \\
\hline Zipaquirá & 107278 & 28231 & 3,80 \\
\hline Total & 9079667 & 2746099 & 3,30 \\
\hline
\end{tabular}

Fonte: Consorcio Transconsult-Informetika

Desse universo geográfico foram entrevistados 33.000 lares com o objetivo de fazer as projeções da caraterização urbana de mobilidade, cuja população objetivo é toda pessoa com mais dos 5 anos de idade. 


\section{8 Metodologia}

Neste Capítulo serão sujeitos à comprovação, o não cumprimento das condições de mobilidade dos lares aos polos de emprego nos transportes públicos e, entregam-se metodologias de priorização de adensamento em zonas em que serão possíveis os percursos curtos dos lares aos polos de emprego e, num outro cenário se apresentará a priorização de adensamento em zonas em que serão possíveis os deslocamentos em percursos curtos dos lares às atividades habituais dos cidadãos, sem desestimar os percursos curtos dos lares às zonas de maior oferta de emprego.

\section{1. \\ Comprovação do não cumprimento das condições de mobilidade do PUCAB:}

As condições de mobilidade para a delimitação geográfica do PUCAB partem da premissa de serem possíveis os percursos dos lares às zonas de maior geração de emprego em 20 minutos nos transportes públicos e 10 minutos nos percursos a pé até as estações desde qualquer ponto da região delimitada. Para desvirtuar as condições de mobilidade sob as próprias premissas do Plano, basta comprovar a impossibilidade de abranger o PUCAB numa matriz de tempos OD desde qualquer uma das zonas contidas nesse setor nos percursos dos transportes públicos coletivos em tempos de até 20 minutos. (Hipótese), por ser o tempo nos transportes os de maior relevância de acordo com as pretensões de povoar o Centro Ampliado para alocar às pessoas por perto dos empregos.

Analisa-se a matriz de tempos para a mobilidade interna desde todas as zonas Origem onde é possível localizar os lares, até todas as zonas Destino do setor do PUCAB onde são contidas também as zonas de maior geração de emprego, descritas de forma imprecisa no Plano Urbanístico como foi visto no Capítulo 6.

Em teoria e contra a hipótese desta pesquisa, as zonas de maior geração de emprego deveriam abranger 100\% do território nos 20 minutos se percorridos nos transportes públicos coletivos para garantir o tempo de percursos das casas aos polos de emprego.

Na base de dados da consulta em Excel encontra-se que, o deslocamento desde e até a mesma zona é de zero minutos e, os números “9999999999” da matriz 
OD, significam um valor infinito por não existir conexão em transportes públicos entre algumas dessas zonas, segundo o explicado pela prefeitura na Secretaria Distrital de Mobilidade da cidade de Bogotá.

Originalmente a matriz identifica como zero aqueles números de valor “infinito”, mas, para efeitos dos cálculos foram substituidos por números nove consecutivos, devido a ser preciso contar o número de zonas com tempos menores que 20 minutos e, ter zeros por dois motivos diferentes é contra a avaliação dos cálculos.

A Matriz da comprovação do não cumprimento dos percursos das casas aos polos de emprego se representa como na Figura 25 que em termos gerais deve ser empregada no exercício como uma matriz simétrica de 365 zonas ZAT Origem vs 365 zonas ZAT Destino das zonas totais do setor do PUCAB. Pelo tamanho da matriz se ilustram reticências para a continuidade nas zonas Origem e Destino.

Zonas Destino $k$

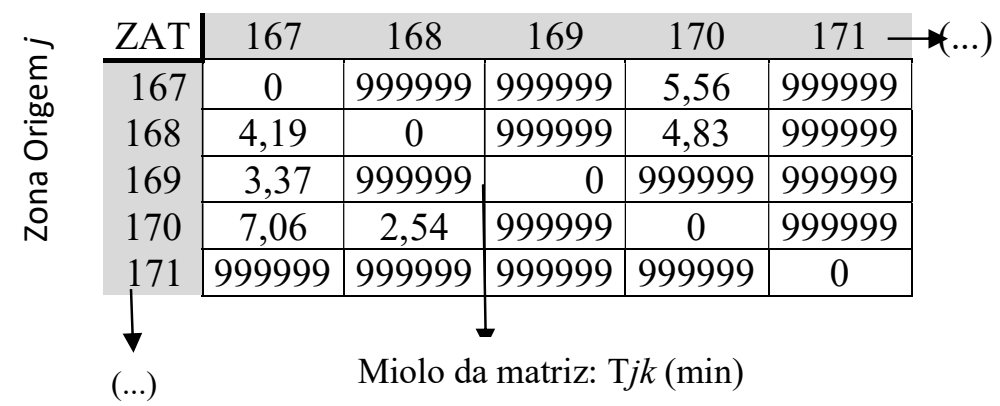

Figura 25 - Matriz de tempos Origem Destino nos transportes públicos da comprovação. Fonte: Desenho próprio baseado nas informações das Pesquisas de Mobilidade (2015).

ZAT: numeração de identificação das Zonas de Análises dos Transportes.

$k$ : linha

j: coluna

Zona Origem j: zonas ZAT Origem na primeira coluna à esquerda.

Zona Destino k: zonas ZAT Destino na linha superior.

Tjk (min): Miolo da matriz dos tempos em minutos dos percursos desde as zonas Origem $(j)$ até as zonas Destino $(k)$ nos Transportes públicos coletivos.

As zonas contidas no Centro Ampliado começam em 167 da numeração assignada como identificação de cada zona ZAT (SDM, 2015).

A Figura 25 é a representação da matriz empregada pela Secretaria Distrital de Mobilidade dos transportes públicos coletivos em Bogotá, com ela serão feitas 
as comprovações para calcular o quanto abrange cada zona ZAT com respeito do universo total do setor do PUCAB.

Devido ao tamanho da matriz, será feito inicialmente um exemplo com uma matriz hipotética completa como representada na Figura 26, com a mesma estrutura geral apresentada na Figura 25 (Página 73) para a melhor compreensão das expressões, depois, será realizado o cálculo com a matriz real para a consequente comprovação.

Calcula-se $\mathrm{Nj}$ como a contagem de uma a uma das zonas Destino que cumpram com os percursos em tempos menores ou iguais aos 20 minutos desde cada zona Origem $(j)$ :

Expressão 1:

$$
N j=\sum_{\substack{K=1 \\ T j . k \leq 20}}^{D} 1
$$

$\leq$ Menor ou igual a

D: Universo das zonas Destino $(k)$ (número total das zonas Destino contidas na matriz).

Zonas Destino $k$

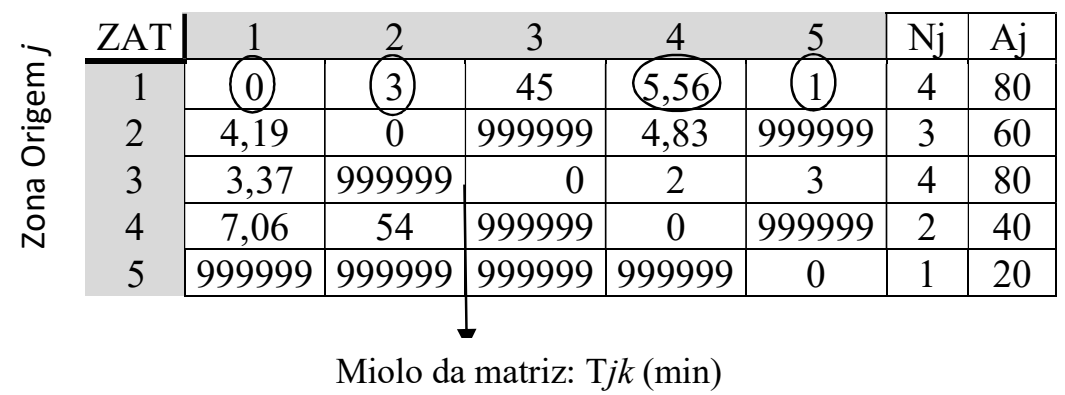

Figura 26 - Matriz de tempos O/D em transportes públicos num universo hipotético. Fonte: Desenho próprio.

Calcula-se Aj como a percentagem de abrangência de cada zona Origem com respeito ao universo das zonas Destino $(D=5)$, nos percursos menores ou iguais aos 20 minutos (porção de espaço abrangido nos 20 minutos).

Expressão 2:

$$
A j=\frac{N j \times 100}{\mathrm{D}}
$$


Encontrando assim os valores para Aj da Figura 26 em que está representada a porção de espaço do universo das zonas Destino $(k)$ abrangidas nos percursos de tempos menores ou iguais aos 20 minutos desde cada zona Origem $(j)$.

No caso do exemplo hipotético com a matriz de um universo completo da Figura 26, se conclui que nenhuma zona Origem $(j)$ consegue abranger o total das zonas Destinos $(k)$ em 20 minutos.

Essa mesma conclusão é à qual se deve chegar na matriz dos tempos OD para o setor do PUCAB e assim comprovar o não cumprimento das condições de mobilidade do Plano Urbanístico do Centro Ampliado.

Se alguma das zonas do Centro Ampliado abrangesse a totalidade do setor no tempo estabelecido, $\mathrm{Nj}$ seria 365 e Aj seria 100\%, nesse caso deveria-se analisar se a zona corresponde às de maior geração de emprego; informação contida tanto no Capítulo 1 do PUCAB, como em seu Capítulo 4, porém, a hipótese sugere que nenhuma das zonas poderá abranger 100\% do setor do Centro Ampliado.

Cálculos a partir da consulta na mastriz OD dos tempos para o PUCAB da Figura 27:

\begin{tabular}{|c|c|c|c|c|c|c|c|}
\hline \multicolumn{5}{|c|}{ Zonas Destino $k$} & \multicolumn{3}{|c|}{$\mathrm{T}_{167.170}=5,56 \mathrm{mi}$} \\
\hline ZAT & 167 & 168 & 169 & $170 /$ & 171 & $\Delta \mathrm{Nj}$ & $\mathrm{Aj}$ \\
\hline 167 & 0 & 999999 & 999999 & 5,56 & 999999 & 79 & 21,64 \\
\hline 168 & 4,19 & 0 & 999999 & 4,83 & 999999 & 97 & 26,57 \\
\hline 169 & 3,37 & 999999 & 0 & 999999 & 999999 & 132 & 36,16 \\
\hline 170 & 7,06 & 2,54 & 999999 & \begin{tabular}{|l|}
0 \\
\end{tabular} & 999999 & $\Delta 130$ & 35,61 \\
\hline 171 & 999999 & 999999 & 999999 & 999999 & 0 & 104 & 28,49 \\
\hline
\end{tabular}

Figura 27 - Cálculos na Matriz de tempos O/D nos transportes públicos da comprovação. Fonte: Desenho próprio baseado nas informações das Pesquisas de Mobilidade (2015).

$\triangle$ : Células ocultas entre a zona ZAT Destino 171 e $\mathrm{Nj}$.

A estrutura geral da matriz continua a ser como na Figura 25 (página 73), mas, o elemento das celulas ocultas se faz necessário em razão das reticências para indicar a totalidade das 365 zonas Destino $(k)(\mathrm{D}=365)$ que não são representados na matriz dos cálculos devido ao número extenso de zonas do universo Destino.

Para a zona Origem $(j)$ 167, resultaram 79 zonas Destino $(k)$ com tempos menores ou iguais aos 20 minutos e, a abrangêcia é de 21,64\% (79*100/365). 
Segue Mapa 2 da comprovação do não cumprimento dos percursos em 20 minutos desde os lares aos polos de emprego; a zona 433 tem a maior abrangência $(77,53 \%)$. As zonas sem conexão com os transportes públicos são as zonas de fundo cinza. As Tabelas totais resultantes encontram-se no Apêndice 1. 

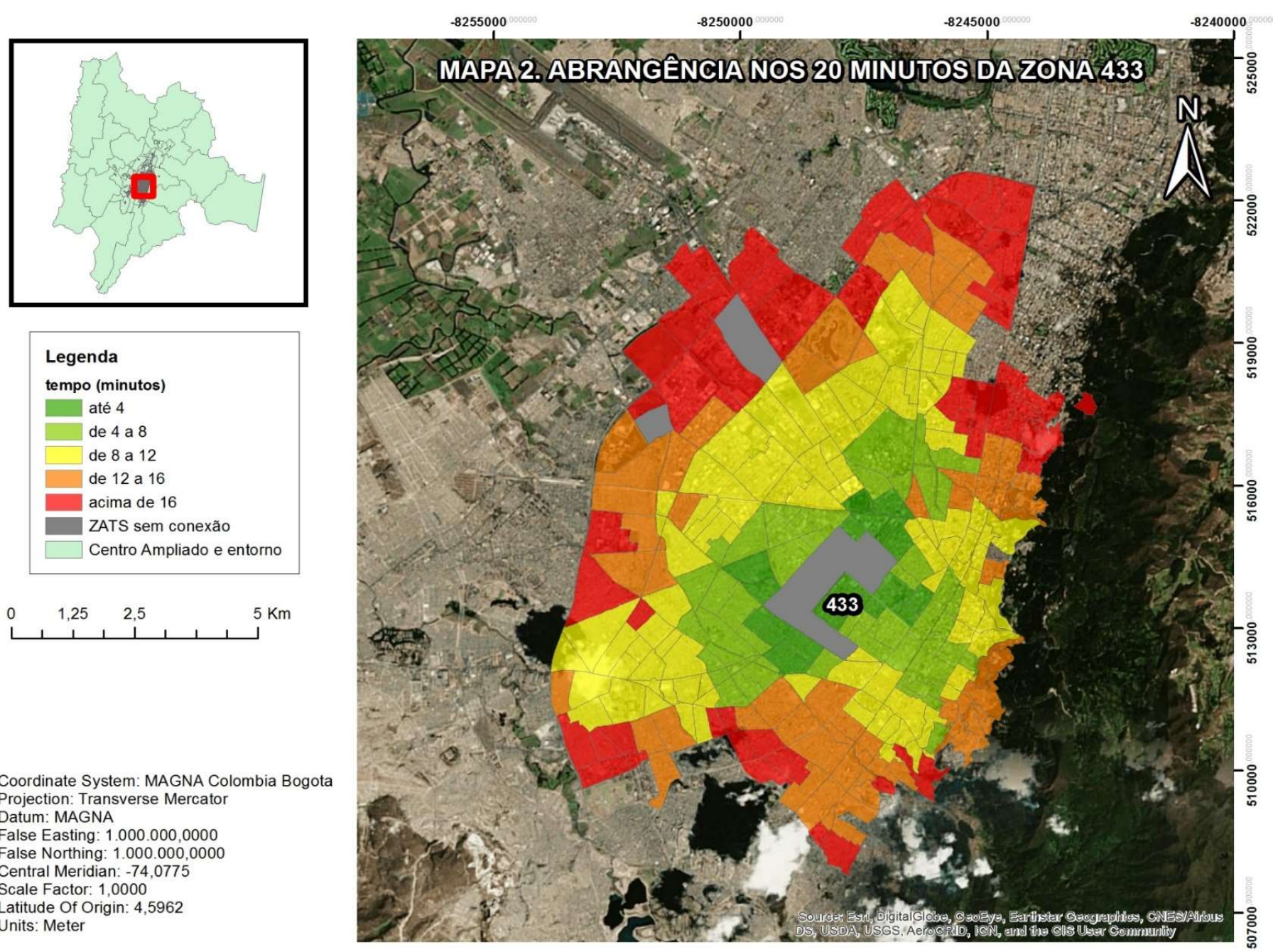

Coordinate System: MAGNA Colombia Bogota Projection. Transverse Mercator Datum: MAGNA

False Easting: $1.000 .000,0000$

False Northing: 1.000.000,0000

Scale Factor: 1,0000

Latitude Of Origin: 4,5962

Units: Meter

Mapa 2. Abrangência nos 20 minutos da zona 433

Fonte: Própria 


\section{2. \\ Priorização de zonas a serem adensadas para percursos curtos das casas aos empregos.}

Ao longo do texto se justificaram os limites geográficos escolhidos para o adensamento populacional urbano no setor do PUCAB pelas razões de segurança quanto aos riscos ambientais e, também pelas razões de caráter proposital do Plano Urbanístico quanto à diminuição da segregação socioespacial, no território em que é evidenciado o déficit residencial e onde os moradores são majoritariamente das classes socioeconômicas médias e altas.

Os limites do PUCAB serão respeitados ao apresentar uma metodologia de adensamento que prioriza as zonas que permitem deslocamentos curtos dos lares aos empregos, sem excluir o restante do setor por considerar, que ainda nas piores posições do Ranking de adensamento por condições de mobilidade eficiente, este setor ainda continua a ser uma melhor opção para alocar aos moradores se comparado com as periferias.

Nesta proposta será o cálculo que definirá quais são as zonas de maior geração de emprego segundo as pesquisas de mobilidade (SDM, 2015).

Será priorizado o adensamento naqueles setores dentro dos limites geográficos do PUCAB de maior abrangência das zonas com mais número de viagens por motivo de emprego, abrangência inclusive além do Centro Ampliado, nos deslocamentos dos transportes públicos até o tempo preestabelecido como eficiente.

A determinação assim colocada é devido a encontrar a zona com mais deslocamentos das pessoas por motivo de emprego (26), além das descrições do Plano (Ver Mapa 3) segundo as pesquisas de mobilidade (SDM, 2015), consultadas por ter sido escolhida a variável de geração de emprego no PUCAB pelo maior número de viagens até as zonas do trabalho dos cidadãos, consultadas nesse caso nas pesquisas de mobilidade (SDM, 2011). 

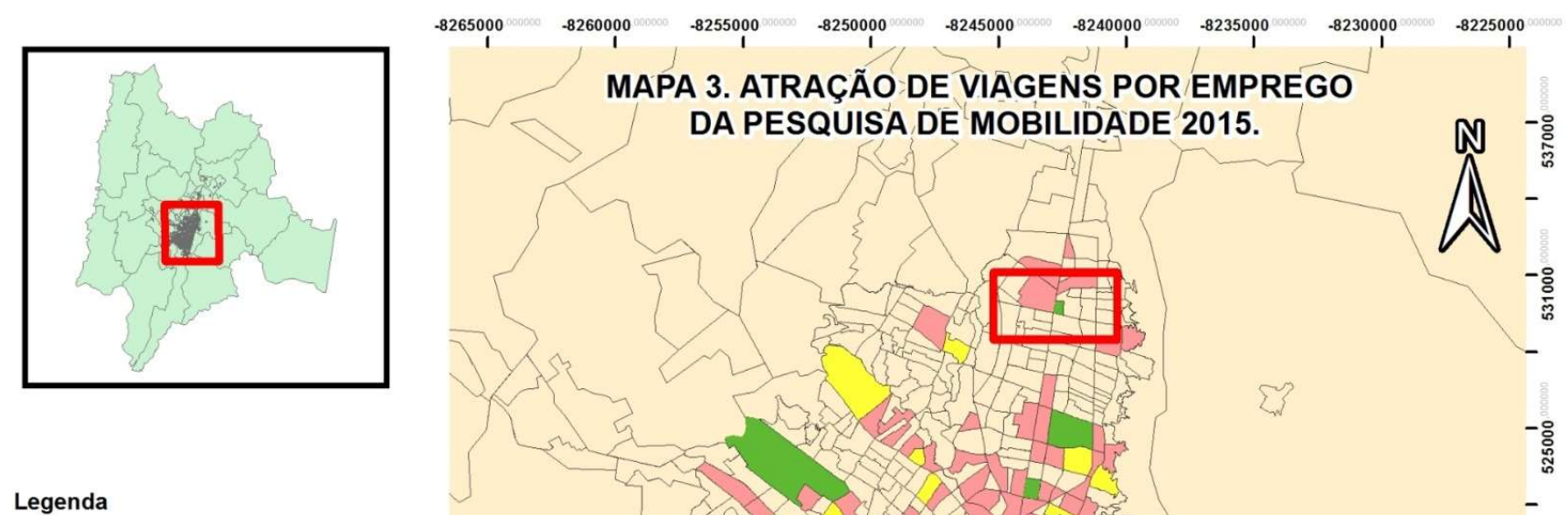

Legenda

ATRAÇÃO DE VIAGENS POR EMPREGO Viagens
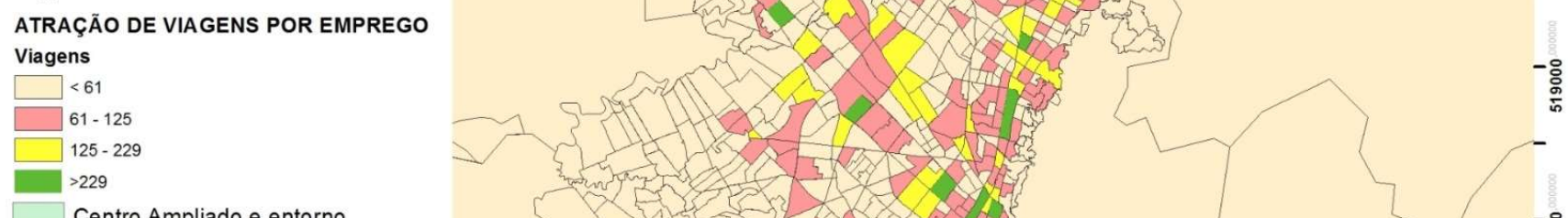

Centro Ampliado e entorno

Coordinate System: MAGNA Colombia Bogota Projection: Transverse Mercator Datum: MAGNA

False Easting: $1.000 .000,0000$ Forthing: $1.000 .000,0000$

Central Meridian: $-74,077$

Scale Factor. 1,0000

Units: Meter

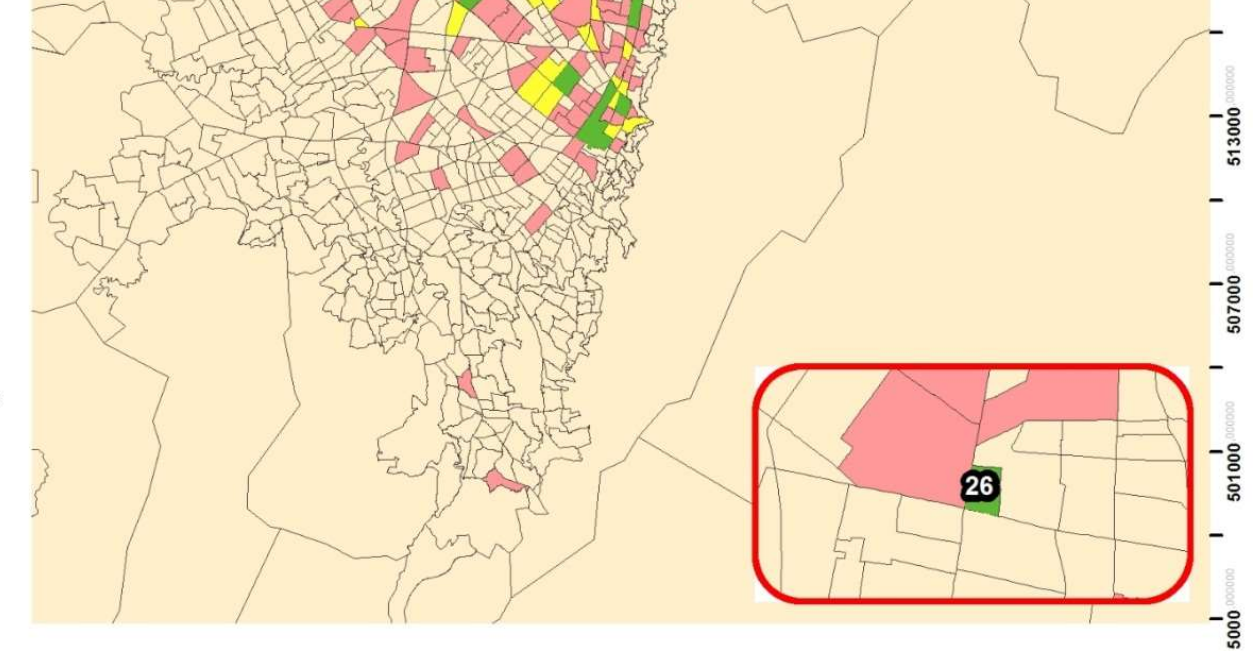

Mapa 3. Atração de viagens por emprego da pesquisa de mobilidade 2015

Fonte: Própria. 
$\mathrm{Na}$ Seção 6.2 foram discutidos os tempos ideias e de tolerância nos percursos das casas aos empregos das pesquisas do Reino Unido (UK) e Kunming, China, de forma comparativa, por não existir uma pesquisa similar na Colômbia e, pelas condições adensadas dos centros dessas cidades que, segundo o PUCAB, são condições de cidades "modernas".

Esta pesquisa de mobilidade eficiente para cidades compactas, assume a restrição dos vinte (20), trinta (30) e quarenta (40) minutos, dos lares aos empregos.

Os tempos determinados correspondem à proposta do Plano de vinte minutos (20 minutos); trinta minutos (30 minutos) é o tempo em que, se superado, começam a aparecer efeitos negativos na percepção dos passageiros dos transportes públicos nas cidades do Reino Unido; quarenta minutos (40 minutos) é o tempo de tolerância nos percursos curtos em Kunming, China. O PUCAB pretende adensar as zonas em que é possível morar perto dos empregos, devido a isso, se acolhem os tempos de tolerância nos percursos curtos.

Com a definição dos tempos e das zonas de maior geração de emprego para os objetivos propositais desta pesquisa, pode-se passar à conformação da matriz OD dos transportes públicos com todas as zonas Origem ( $j$ ) do PUCAB a adensar e as zonas Destino $(k)$ que no mínimo contem com uma viagem por motivo de emprego no universo total da pesquisa de mobilidade (SDM, 2015).

Para saber quais das zonas do universo da pesquisa de mobilidade (SDM, 2015) contam com pelo menos uma viagem por motivo de emprego, se faz a seguinte consulta na base de dados EODH da Tabela 5:

Tabela 5. Número de viagens ou deslocamentos para cada zona ZAT por motivo de emprego

\begin{tabular}{|c|c|c|c|}
\hline $\mathbf{B}$ & $\mathbf{D}$ & $\mathbf{E}$ & $\mathbf{N}$ \\
\hline 3 & 1 & 1 & 568 \\
\hline 3 & 1 & 1 & 471 \\
\hline 1 & 1 & 1 & 198 \\
\hline 1 & 1 & 1 & 230 \\
\hline
\end{tabular}

Fonte: Pesquisas de mobilidade (SDM, 2015)

"B": número de pessoas por entrevista que se deslocam a uma zona ZAT Destino.

"D": motivo da viagem, emprego = $1($ SDM, 2015).

"E": município destino, Bogotá = $1\left(\right.$ DANE, 2005) ${ }^{14}$

"N": Zona ZAT Destino.

14 (DANE, 2005): províncias e sub-regiões. 
Para saber quantas pessoas viajam para um setor de Bogotá por motivo de emprego, se faz um filtro na base de dados pelo "motivo da viagem" $($ emprego $=1)$ para o município de Bogotá (município destino $=1$ ), obtendo como resposta de consulta a "Zona ZAT Destino" e "número de pessoas por entrevista que se deslocam até à zona ZAT Destino”.

A matriz OD se conforma pelas 365 zonas ZAT Origem (setor do PUCAB) até às 790 zonas ZAT Destino por motivo de emprego.

Segundo a pesquisa de mobilidade (SDM, 2015), as 790 zonas Destino $(k)$ são as que recebem pelo menos uma viagem - desde qualquer zona de Bogotá e os 17 munícipios vizinhos - que se deslocam para qualquer uma das zonas de Bogotá por motivo de emprego.

Os cálculos priorizarão as zonas com maior atração de viagens por trabalho e a maior abrangência dessas zonas em tempos menores ou até os 20 minutos percorridos desde qualquer ponto do PUCAB.

Para maior entendimento dos cálculos será feita uma matriz hipotética na Figura 28, menor à matriz real e depois, serão entregues os cálculos sobre a matriz real de difícil apresentação na sua extensão total.

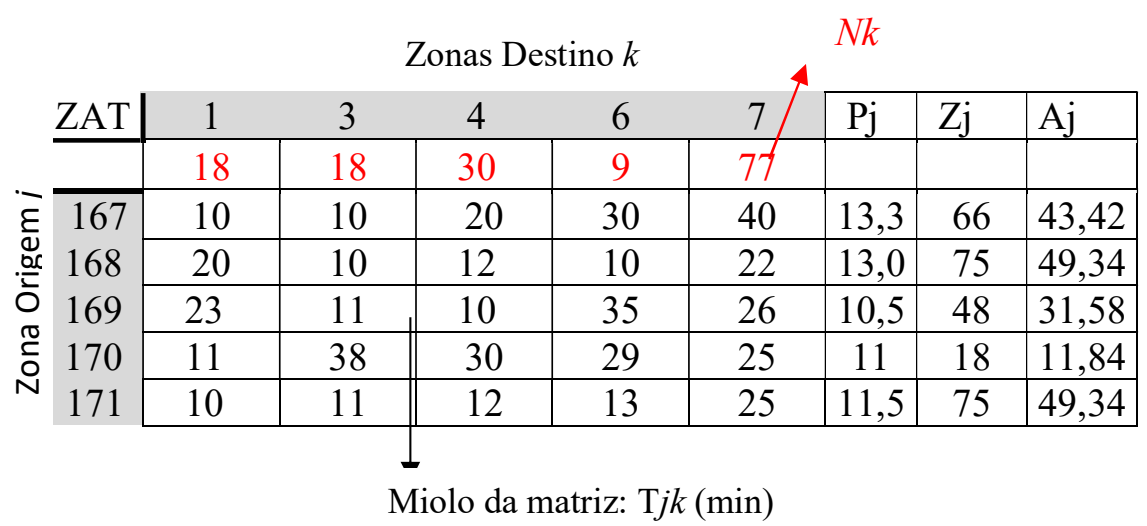

Figura 28 - Cálculos na Matriz hipotética de tempos O/D nos transportes públicos da proposta 1. Fonte: Desenho próprio.

ZAT: numeração de identificação das Zonas de Análises dos Transportes.

$k$ : linha

$\mathrm{j}$ : coluna

Zona Origem j: zonas ZAT Origem na primeira coluna à esquerda.

Zona Destino k: zonas ZAT Destino na linha superior.

Tjk (min): Miolo da matriz dos tempos em minutos dos percursos desde as zonas Origem $(j)$ até as zonas Destino $(k)$ nos Transportes públicos coletivos.

$N k$ : número de viagens atraidas por cada zona Destino $(k)$, por motivo de emprego. 
Os cálculos são para obter $\mathrm{P} j, \mathrm{Z} j$ e $\mathrm{Aj}$ com base na mariz de tempos dos percursos das zonas Origem até as zonas Destino:

$\mathbf{P} \boldsymbol{j}=\mathrm{O}$ tempo médio em minutos dentre aqueles menores ou iguais aos 20 minutos desde cada zona Origem até o número total das zonas destino.

$\mathbf{Z} \mathbf{j}=$ As viagens atraidas pelas zonas Destino abrangidas nos 20 minutos por cada zona Origem.

$\mathbf{A} \boldsymbol{j}=$ Percentagem de abrangência de zonas Destino, contidas as suas atrações de viagens por emprego em percursos de até os 20 minutos, desde cada zona Origem.

$\mathbf{N T} \boldsymbol{j}=$ Número total de T $j . k \leq 20$ nos percursos desde cada zona Origem $(j)$ até D.

D = Número total das zonas Destino (Universo das zonas Destino).

Expressão 1:

$$
P j=\frac{\sum_{\substack{k=1 \\ T j . k \leq 20}}^{D} T j . k}{\mathrm{NT} j}
$$

Expressão 2:

$$
\begin{gathered}
Z j=\sum_{\substack{K=1 \\
T j . k \leq 20}}^{D} N k \\
A j=\frac{Z j x 100}{\sum_{k=1}^{D} N k}
\end{gathered}
$$

Expressão 3:

No exemplo da Figura 28 (Página 81) para a zona Origem (j) 167:

$\mathrm{Pj}=\left(\mathrm{T}_{167.1}+\mathrm{T}_{167.3}+\mathrm{T}_{167.4}\right) / 3$

$\mathrm{Pj}=(10+10+20) / 3=13,3$ minutos

$\mathrm{Zj}=(18+18+30)=66$ viagens

$\mathrm{Aj}=(66 \times 100) /(18+18+30+9+77)=43,42 \%$

Para a zona Origem (j) 168:

$\mathrm{Pj}=(20+10+12+10) / 4=13$ minutos

$\mathrm{Zj}=(18+18+30+9)=75$ viagens

$A j=(75 \times 100) /(18+18+30+9+77)=7500 / 152=49,34 \%$

Conforme o proposito deste Capítulo, interessa agora priorizar o adensamento dentro do Centro Ampliado, naquelas zonas com maior abrangência dos setores com maior oferta de emprego e, menores tempos médios até 20 minutos conforme as pretensões do PUCAB. 
Para o propósito anteriormente mencionado serão assignados pesos para as zonas de maior abrangência e menores tempos médios na Tabela 6, assim:

Atribuição de pesos para intervalos em função do tempo para 20 minutos como é o caso do exemplo na Figura 28 (Página 81):

Tabela 6: Asignação de pesos para intervalos de tempos até 20 minutos.

\begin{tabular}{|l|l|l|}
\hline Intervalo & $\begin{array}{l}\text { Tempo em } \\
\text { minutos }\end{array}$ & $\begin{array}{l}\text { Peso para cada } \\
\text { intervalo }\end{array}$ \\
\hline I1 & Até 11 & 5 \\
\hline I2 & $11-12$ & 4 \\
\hline I3 & $12-13$ & 3 \\
\hline I4 & $13-14$ & 2 \\
\hline I5 & $>14$ & 1 \\
\hline
\end{tabular}

Fonte: Própria

Atribuição de pesos para intervalos em função de percentagem de abrangência para os 20 minutos na Tabela 7 :

Tabela 7: Asignação de pesos para intervalos de abrangência até 20 minutos.

\begin{tabular}{|l|l|l|}
\hline Intervalo & $\begin{array}{l}\text { Abrangência em } \\
\text { percentagem. }\end{array}$ & $\begin{array}{l}\text { Peso para cada } \\
\text { intervalo }\end{array}$ \\
\hline I1 & Até 15 & 1 \\
\hline I2 & $15-25$ & 2 \\
\hline I3 & $25-35$ & 3 \\
\hline I4 & $35-45$ & 4 \\
\hline I5 & $>45$ & 5 \\
\hline
\end{tabular}

Fonte: Própria

As asignações das Tabelas 6 e 7 mostram maiores pesos para os menores intervalos de tempos e, maiores abragências.

Para o exemplo da Figura 28 (Página 81): Zona ZAT 167: Pj está no Intervalo dos 13 aos 14 minutos, portanto, o peso do tempo médio para essa zona ZAT é de 2; a abrangência está no intervalo de $35 \%$ a $45 \%$, portanto, o peso da abrangência é de 4

O peso total da Zona ZAT $167=6$ 
Zona ZAT 168: Pj está no intervalo dos 13 aos 14 minutos, portanto, o peso do tempo médio para essa zona ZAT é de 2; a abrangência é maior ao $45 \%$, portanto, o peso da abrangência é de 5

\section{O peso total da Zona ZAT $168=7$}

Zona ZAT 169: Pj está no tempo de até 11 minutos, portanto, o peso do tempo médio para essa zona ZAT é de 5; a abrangência está entre 25 e 35\%, portanto, o peso da abrangência é de 3

\section{O peso total da Zona ZAT $169=8$}

Zona ZAT 170: Pj está no tempo de até 11 minutos, portanto, o peso do tempo médio para essa zona ZAT é de 5; a abrangência está num valor inferior ao $15 \%$, portnto, o peso da abrangência é de 1

\section{$O$ peso total da Zona ZAT $170=6$}

Zona ZAT 171: Pj está no intervalo de 11 aos 12 minutos, portanto, o peso do tempo médio para essa zona ZAT é de 4; a abrangência é maior ao $45 \%$, portanto, o peso da abrangência é de 5

\section{O peso total da Zona ZAT $171=9$}

Se priorizado o adensamento nas zonas contidas no setor hipotético da Figura 28 (Página 81) zonas priorizadas com maior abrangência na oferta de emprego e menores tempos médios nos percursos desde os lares até essas zonas abrangidas em até 20 minutos. Se obtêm o Ranking da Tabela 8:

Tabela 8. Ranking de um setor hipotético.

\begin{tabular}{|l|l|}
\hline Ranking & Zona ZAT \\
\hline 1 & 171 \\
\hline 2 & 169 \\
\hline 3 & 168 \\
\hline 4 & 167 \\
\hline 5 & 170 \\
\hline
\end{tabular}

Fonte: Cálculo próprio.

O exemplo hipotético da Figura 28 (Página 81) desenvolveu-se num cenário de priorização de zonas a serem adensadas para abrangência de maior oferta de emprego no tempo de até 20 minutos como sugere o PUCAB, as formulações estão também condicionadas a esse tempo. Para os cenários de priorização em áreas sub os 30 e 40 minutos, basta trocar nas formulações a condição "T $j . k \leq 20$ " pelas 
condições "T $j . k \leq 30$ " para os trinta mnutos ou "T $j . k \leq 40$ " para os quaretna minutos, como corresponda.

Deve ser levado em conta uma asignação de pesos diferente para os intervalos de tempos médios e abrangência em cenários parar percursos lartrabalho-lar em 30 e 40 minutos. Pesos para intervalos adotados segundo as Tabelas $9,10,11 \mathrm{e} 12$.

Tabela 9. Asignação de pesos para intervalos de tempos até 30 minutos.

\begin{tabular}{|l|l|l|}
\hline Intervalo & $\begin{array}{l}\text { Tempo em } \\
\text { minutos }\end{array}$ & $\begin{array}{l}\text { Peso para cada } \\
\text { intervalo }\end{array}$ \\
\hline I1 & Até 17 & 5 \\
\hline I2 & $17-18$ & 4 \\
\hline I3 & $18-19$ & 3 \\
\hline I4 & $19-20$ & 2 \\
\hline I5 & $>20$ & 1 \\
\hline
\end{tabular}

Fonte: Própria

Tabela 10: Asignação de pesos para intervalos de abrangência até 30 minutos.

\begin{tabular}{|l|l|l|}
\hline Intervalo & $\begin{array}{l}\text { Abrangência em } \\
\text { percentagem. }\end{array}$ & $\begin{array}{l}\text { Peso para cada } \\
\text { intervalo }\end{array}$ \\
\hline I1 & Até 30 & 1 \\
\hline I2 & $30-40$ & 2 \\
\hline I3 & $40-50$ & 3 \\
\hline I4 & $50-60$ & 4 \\
\hline I5 & $>60$ & 5 \\
\hline
\end{tabular}

Fonte: Própria

Tabela 11. Asignação de pesos para intervalos de tempos até 40 minutos.

\begin{tabular}{|l|l|l|}
\hline Intervalo & $\begin{array}{l}\text { Tempo em } \\
\text { minutos }\end{array}$ & $\begin{array}{l}\text { Peso para cada } \\
\text { intervalo }\end{array}$ \\
\hline I1 & Até 22 & 5 \\
\hline I2 & $22-24$ & 4 \\
\hline I3 & $24-26$ & 3 \\
\hline I4 & $26-28$ & 2 \\
\hline I5 & $>28$ & 1 \\
\hline
\end{tabular}

Fonte: Própria 
Tabela 12: Asignação de pesos para intervalos de abrangência até 40 minutos.

\begin{tabular}{|l|l|l|}
\hline Intervalo & $\begin{array}{l}\text { Abrangência em } \\
\text { percentagem. }\end{array}$ & $\begin{array}{l}\text { Peso para cada } \\
\text { intervalo }\end{array}$ \\
\hline I1 & Até 45 & 1 \\
\hline I2 & $45-55$ & 2 \\
\hline I3 & $55-65$ & 3 \\
\hline I4 & $65-75$ & 4 \\
\hline I5 & $>75$ & 5 \\
\hline
\end{tabular}

Fonte: Própria

A seguinte matriz de tempos OD da Figura 29 representa parcialmente a matriz total devido ao tamanho das 365 zonas Origem (lares) e 760 zonas Destino (emprego).

Segue a representação parcial da matriz OD nos transportes públicos segundo as pesquisas de mobilidade (SDM, 2015):

\begin{tabular}{|c|c|c|c|c|c|c|c|c|}
\hline \multirow[b]{2}{*}{ ZAT } & \multicolumn{5}{|c|}{ Zonas Destino $k$} & \multicolumn{3}{|l|}{$N k$} \\
\hline & 1 & 3 & 4 & 6 & 7 & $\mathrm{Pj}$ & $\mathrm{Zj}$ & $\mathrm{Aj}$ \\
\hline & 18 & 18 & 30 & 9 & 77 & & & \\
\hline 167 & 60,72 & 55,33 & 38,91 & 37,71 & 20,33 & 13,36 & 10662 & 31,56 \\
\hline 168 & 37,87 & 32,75 & 24,9 & 23,7 & 22,05 & 12,56 & 12958 & 38,35 \\
\hline 气 169 & 49,75 & 38,92 & 37,19 & 35,99 & 26,69 & 13,21 & 15267 & 45,19 \\
\hline ¿ 170 & 36,97 & 38,38 & 30,53 & 29,33 & 25,99 & 12,47 & 12873 & 38,10 \\
\hline v 171 & 60,72 & 55,33 & 41,79 & 40,59 & 25,57 & 13,18 & 12814 & 37,93 \\
\hline
\end{tabular}

Figura 29 - Matriz de tempos O/D nos transportes públicos da proposta 1.

Fonte: Desenho próprio baseado nas informações das Pesquisas de Mobilidade (SDM, 2015).

ZAT: numeração de identificação das Zonas de Análises dos Transportes.

$k$ : linha

$\mathrm{j}$ : coluna

Zona Origem j: zonas ZAT Origem na primeira coluna à esquerda.

Zona Destino k: zonas ZAT Destino na linha superior.

Tjk (min): Miolo da matriz dos tempos em minutos dos percursos desde as zonas Origem $(j)$ até as zonas Destino $(k)$ nos Transportes públicos coletivos.

$N k$ : número de viagens atraidas por cada zona Destino $(k)$ 
$\triangle$ : Células ocultas entre a zona ZAT Destino 7 e Pj.

$\mathbf{P} \boldsymbol{j}=\mathrm{O}$ tempo médio em minutos dentre aqueles menores ou iguais aos 20 minutos desde cada zona Origem até o número total das zonas destino.

$\mathbf{Z} \boldsymbol{j}=$ As viagens atraidas pelas zonas Destino abrangidas nos 20 minutos por cada zona Origem.

$\mathbf{A} \boldsymbol{j}=$ Percentagem de abrangência de zonas Destino, contidas as suas atrações de viagens por emprego em percursos de até os 20 minutos, desde cada zona Origem

Neste caso a matriz OD dos transportes públicos está dentro do cenário dos 20 minutos; sendo apenas uma fracção da matriz real de tempos totais para todas as zonas do PUCAB, pode-se calcular os pesos das ZAT na Figura 29 representadas e entre elas assignar a ordem do rankig de priorização de adensamento, levando em conta que, existem 365 zonas do PUCAB a serem priorizadas e aqui será entregue apenas uma ordem entre elas por practicidade dos clalculos.

Após a aplicação das expressões 1,2,3 desta proposta que no presente caso não podem ser totalmente visualizadas por causa das células ocultas $(k)$ ou em reticências $(j)$, que não permitem conhecer todos os valores, porém, pode-se ver os resultados totais de $\mathrm{Pj}$ e Aj para algumas zonas ZAT.

Aplicando as Tabelas de assignação de pesos 6 e 7 se obtêm:

Zona ZAT 167: Pj está no Intervalo dos 13 aos 14 minutos, portanto, o peso do tempo médio para essa zona ZAT é de 2; a abrangência está no intervalo do 25 ao $35 \%$, portanto, o peso da abrangência é de 3

\section{O peso total da Zona ZAT $167=5$}

Zona ZAT 168: Pj está no intervalo dos 12 aos 13 minutos, portanto, o peso do tempo médio para essa zona ZAT é de 3; a abrangência está no intervalo de 35 aos $45 \%$, portanto, o peso da abrangência é de 4

\section{O peso total da Zona ZAT $168=7$}

Zona ZAT 169: Pj está no intervalo dos 13 aos 14 minutos, portanto, o peso do tempo médio para essa zona ZAT é de 2; a abrangência é maior ao $45 \%$, portanto, o peso da abrangência é de 5

\section{O peso total da Zona ZAT $169=7$}

Zona ZAT 170: Pj está no intervalo dos 12 aos 13 minutos, portanto, o peso do tempo médio para essa zona ZAT é de 3; a abrangência está no intervalo de 35 os $45 \%$, portnto, o peso da abrangência é de 4

\section{O peso total da Zona ZAT $170=7$}


Zona ZAT 171: Pj está no intervalo de 13 aos 14 minutos, portanto, o peso do tempo médio para essa zona ZAT é de 2; a abrangência está no intervalo de 35 ao $45 \%$, portanto, o peso da abrangência é de 4

\section{O peso total da Zona ZAT $171=6$}

Desta análise pode-se concluir que as zonas 168, 169 e 170 têm o mesmo grau de priorização sem importar a sua ordem, seguem 171 e por ultimo, a zona 167.

O peso dessas 5 zonas ZAT é real devido a serem abstraídas das pesquisas de mobilidade (SDM, 2015), porém, a priorização das zonas a serem adensadas neste exemplo descrito, mudam as suas posições no Ranking final (Apêndice 2), ao organizar os resultados das 365 zonas ZAT que conformam o PUCAB, entrando zonas ZAT, no meio do Ranking destas descritas.

Seguem Mapas 4,5 e 6 da priorização de zonas do PUCAB a serem adensadas sob condições de abranger a maior oferta de emprego em menores percursos lar-trabalho-lar para os 20, 30 e 40 minutos respectivamente. (Ver Mapa de localização das ZAT no Apêndice 4). 

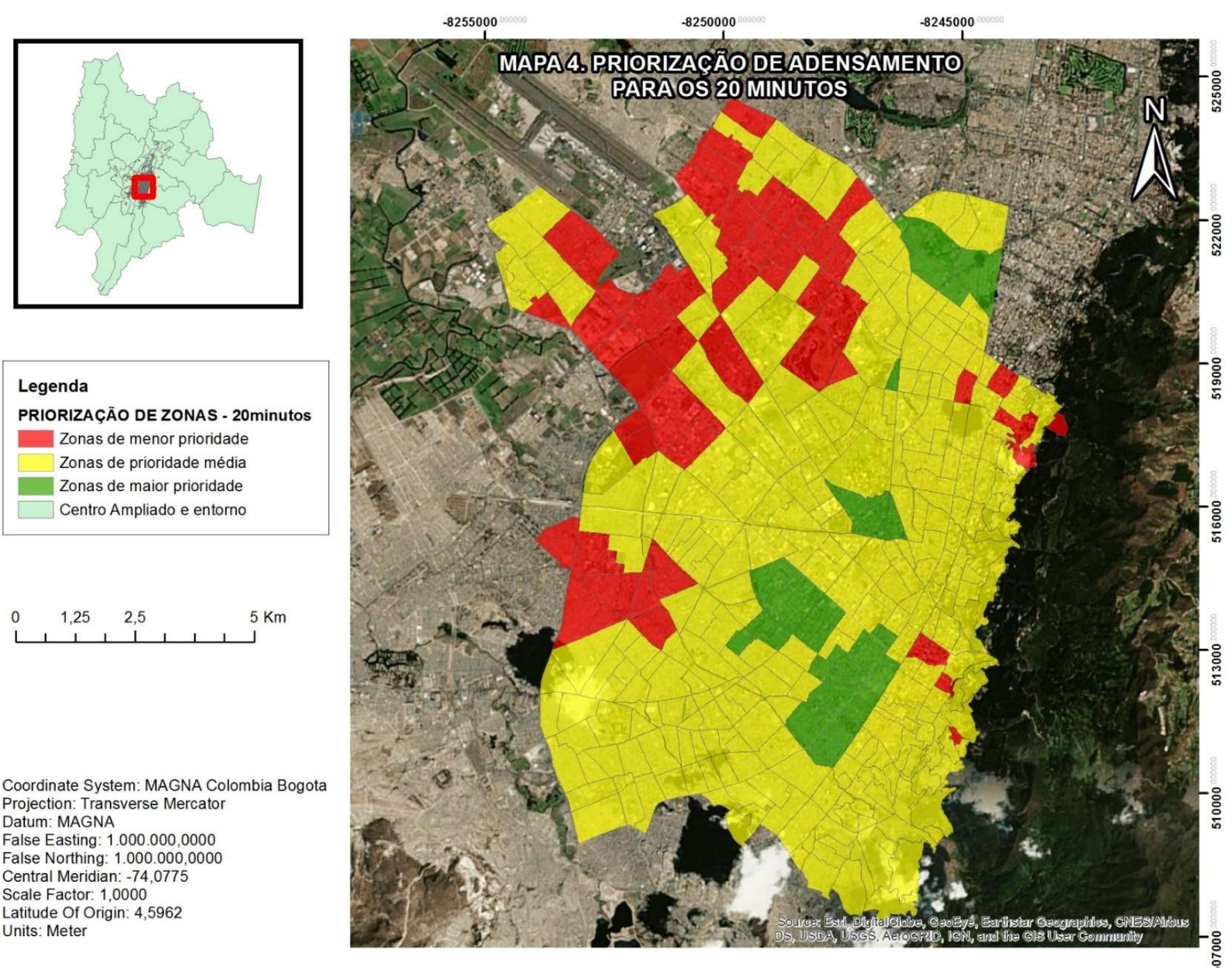

Coordinate System: MAGNA Colombia Bogota Projection: Transverse Mercator

Datum. MAGNA

False Easting: 1.000.000,0000

Celse Norhing. 1.000.000,0000

Scale Factor: 1,0000

atitude Of Origin: 4,5962

Units: Meter

Mapa 4: Priorização de adensamento para os 20 minutos

Fonte: própria. 


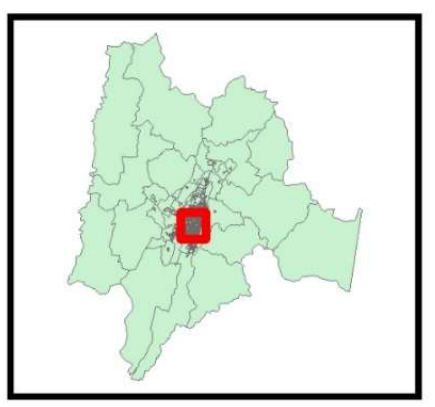

Legenda

PRIORIZAÇÃO DE ZONAS - 30minutos

Zonas de menor prioridade

Zonas de prioridade média

Zonas de maior prioridade

Centro Ampliado e entorno

$1,25 \quad 2,5$ $5 \mathrm{Km}$

Coordinate System: MAGNA Colombia Bogota Projection: Transverse Mercator Datum: MAGNA

False Easting: $1.000 .000,0000$

False Northing: $1.000 .000,0000$

Scale Factor: 1,0000

Latitude of Origin: 4,5962

Units: Meter

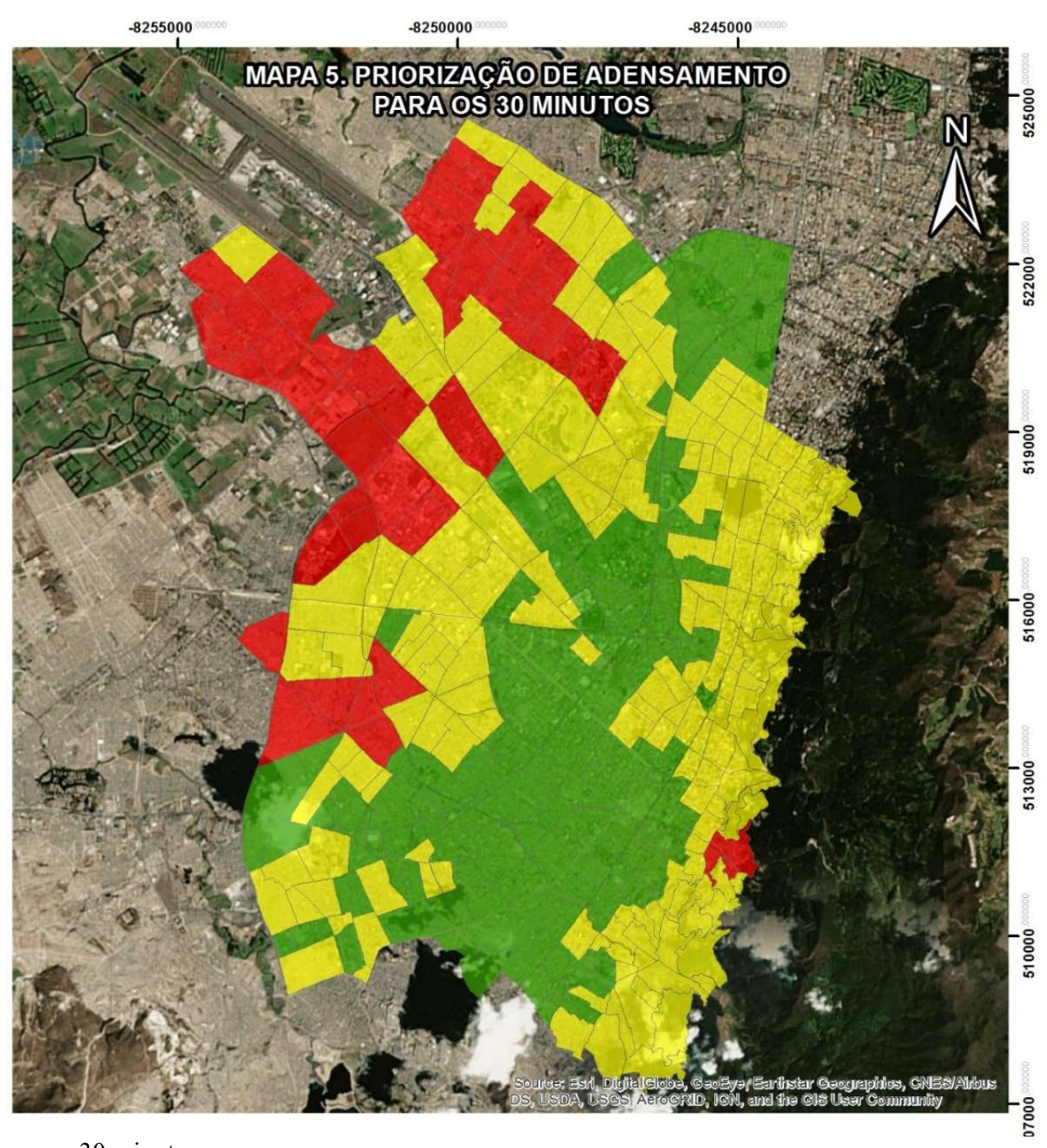

Mapa 5: Priorização de adensamento para os 30 minutos

Fonte: própria. 

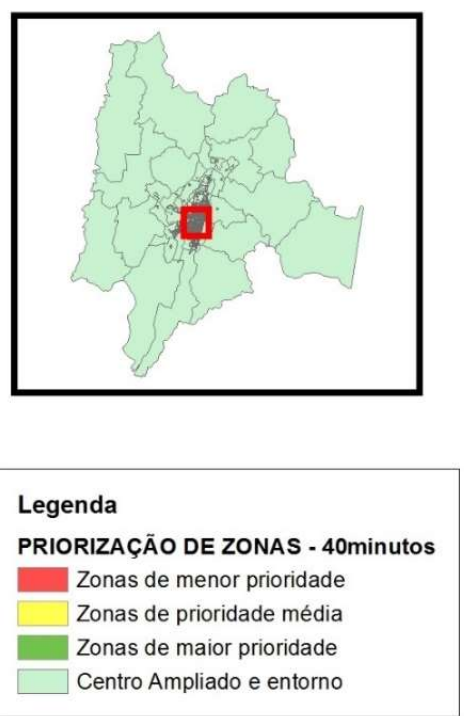

$\begin{array}{lll}0 & 1,25 & 2,5\end{array}$ $5 \mathrm{Km}$

Coordinate System: MAGNA Colombia Bogota Projection: Transverse Mercator Datum: MAGNA

False Easting: $1.000 .000,0000$ Central Meridian: - 74 .0775

Scale Factor: 1,0000

Latitude Of Origin: 4,5962 Units: Meter

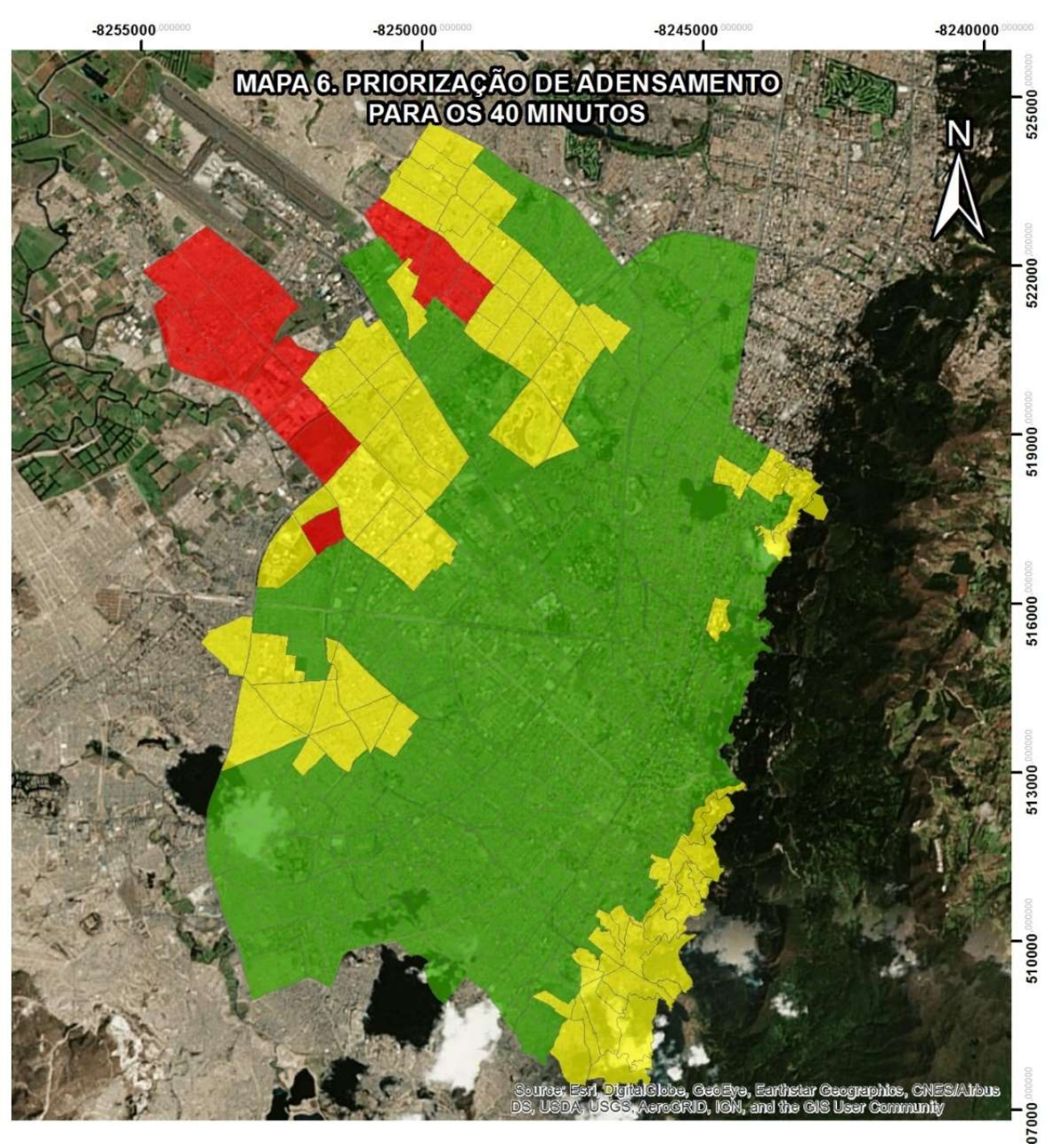

Mapa 6: Priorização de adensamento para os 40 minutos Fonte: própria. 


\section{3. Priorização de zonas a serem adensadas para percursos curtos das casas às atividades habituais}

Este é um cenário de sensibilidade por se tratar de uma priorização de adensamento em áreas dentro do Centro Ampliado, em que é possível a maior abrangência de zonas com maior atração de viagens por emprego, estudo, saúde e recreação. Essas zonas priorizadas sem o cálculo do "Pj" por assumir tempos absolutos de 20, 30 e 40 minutos, como tempos eficientes. Lembre-se que nesses intervalos de tempo, no cenário dentro da Seção 8.2, se assigna um maior peso a aquelas zonas abrangidas em menores tempos médios até chegar ao tempo preestabelecido nas expressões.

Em termos gerais, pode ser tomado o exemplo hipotético da Seção 8.2 para o entendimento na dinâmica dos cálculos com as duas variantes já mencionadas de ser calculada só a abrangência e, incluir os outros motivos pelos quais as pessoas se deslocam para às áreas centrais da cidade de Bogotá, conformando as suas respectivas matrizes de tempos OD.

A abrangência é um valor percentual devido a ser mais fácil representar nos Mapas, as porções do espaço em que se consegue a chegada nos transportes públicos coletivos, nos tempos de 20,30 ou 40 minutos.

Por motivo de emprego são avaliadas todas as zonas de atração de viagens para Zonas Destino contidas na totalidade da cidade de Bogotá e os 17 municípios vizinhos das pesquisas de mobilidade (SDM, 2015). Cálculo assim realizado também no cenário proposital da Seção 8.2. Isso com a finalidade de adensar as zonas contidas no setor do PUCAB que possam abranger a oferta de emprego, mesmo se essas áreas estiverem além do Centro Ampliado, mas, que possam ser abrangidas nos 20, 30 e 40 minutos desde o setor a ser adensado.

Para a análise das viagens por motivos inerentes aos equipamentos, constróise a matriz OD numa mobilidade interna do PUCAB pela razão de entender: a população escolhe os equipamentos de estudo, saúde e recreação por perto das moradias, entanto, para o trabalho, é o cidadão quem deve procurar a oferta segundo condições específicas das suas habilidades, talentos e experiência.

Pelas anteriores afirmações é que se procura localizar as casas por perto da maior oferta de emprego. 
Para definir as viagens por motivos inerentes aos equipamentos devemos comparar os motivos de viagem e as Tabelas de equipamentos de Bogotá.

Observe-se as descrições da Tabela 13 de identificação dos motivos das viagens (deslocamentos) da população, a seguir:

Tabela 13. Motivo da viagem.

\begin{tabular}{|c|l|}
\hline id & Descrição \\
\hline 1 & Trabalhar \\
\hline 2 & Assuntos de trabalho \\
\hline 3 & Estudar \\
\hline 4 & $\begin{array}{l}\text { Receber atenção em } \\
\text { saúde }\end{array}$ \\
\hline 5 & Ir ver alguém \\
\hline 6 & Voltar a casa \\
\hline 7 & $\begin{array}{l}\text { Procurar/Levar alguém } \\
\text { sob seu cuidado }\end{array}$ \\
\hline 8 & $\begin{array}{l}\text { Procurar/Levar alguém } \\
\text { que não está sob seu } \\
\text { cuidado }\end{array}$ \\
\hline 9 & $\begin{array}{l}\text { Procurar/Levar alguma } \\
\text { coisa }\end{array}$ \\
\hline 10 & Comer/Beber \\
\hline 11 & Compras \\
\hline 12 & Tramitar documentos \\
\hline 13 & Recreação \\
\hline 14 & Procurar trabalho \\
\hline 89 & Uma outra coisa \\
\hline
\end{tabular}

Fonte: pesquisas de mobilidade (SDM, 2015).

Comparando-se à Tabela (13) anterior da identificação do motivo das viagens com a Tabela de equipamentos do Anexo 3, se determinam as viagens inerentes aos equipamentos por saúde, estudo e recreação, sendo 3 motivos diretos dos quais existem números de equipamentos representados na Tabela do Anexo mencionado.

Para o cenário da priorização de adensamento em áreas do Centro Ampliado, dentro da Seção 8.2, se consultaram quais das zonas do universo da pesquisa de mobilidade (SDM, 2015) contam com pelo menos uma viagem por motivo de emprego na Tabela 5, assim: 
“Tabela 5 - Número de viagens ou deslocamentos para cada zona ZAT por motivo de emprego"

Fonte: Pesquisas de mobilidade (SDM, 2015).

\begin{tabular}{|r|r|r|r|}
\hline B & D & E & N \\
\hline 3 & 1 & 1 & 568 \\
\hline 3 & 1 & 1 & 471 \\
\hline 1 & 1 & 1 & 198 \\
\hline 1 & 1 & 1 & 230 \\
\hline
\end{tabular}

"B”: número de pessoas por entrevista que se deslocam a uma zona ZAT Destino.

"D": motivo da viagem.

"E": município destino, Bogotá = 1 (DANE, 2005)

"N": Zona ZAT Destino.

Para este cenário, a célula " $\mathrm{D}$ " varia para cada matriz de tempos conformada segundo for o caso do motivo da viagem em emprego, estudo, saúde ou recreação.

A célula " $D$ " será 1 para emprego, 3 para estudo, 4 para saúde e, 13 para recreação. Isso segundo a Tabela. 13, para consultar o motivo da viagem.

Para a conformação da matriz da Figura 30 de tempos OD de emprego, é exatamente igual ao já realizado no cenário da Seção 8.2, sem calcular Pj. Agora para a conformação das matrizes para estudo, saúde e recreação, seguem as principais diferenças representadas no exemplo, numa porção da matriz de estudo, assim:

\begin{tabular}{|c|c|c|c|c|c|c|c|}
\hline \multicolumn{5}{|c|}{ Zonas Destino $k$} & \multicolumn{3}{|l|}{${ }^{N k}$} \\
\hline ZAT & 167 & 168 & 169 & 170 & 171 & $\Lambda \mathrm{Zj}$ & $\mathrm{Aj}$ \\
\hline & 17 & 30 & 3 & 38 & 65 & $\Delta$ & \\
\hline 167 & 0 & 999999 & 999999 & 5,56 & 999999 & $\triangle 13911$ & 88,53 \\
\hline 168 & 4,19 & 0 & 999999 & 4,83 & 999999 & 14001 & 89,11 \\
\hline 169 & 3,37 & 999999 & 0 & 999999 & 9999999 & 14459 & 92,03 \\
\hline 170 & 7,06 & 2,54 & 999999 & \begin{tabular}{|l|}
0 \\
\end{tabular} & 999999 & 14761 & 93,94 \\
\hline 171 & 999999 & 999999 & 999999 & 999999 & 0 & $\Delta 14472$ & 92,10 \\
\hline
\end{tabular}

Figura 30 - Matriz de tempos O/D nos transportes públicos da proposta 2. Estudo.

Fonte: Desenho próprio baseado nas informações das Pesquisas de Mobilidade (2015).

ZAT: numeração de identificação das Zonas de Análises dos Transportes.

$k$ : linha

$\mathrm{j}$ : coluna

Zona Origem j: zonas ZAT Origem na primeira coluna à esquerda.

Zona Destino k: zonas ZAT Destino na linha superior. 
Tjk (min): Miolo da matriz dos tempos em minutos dos percursos desde as zonas Origem $(j)$ até as zonas Destino $(k)$ nos Transportes públicos coletivos para estudo.

$N k$ : Número de viagens atraídas por cada Zona Destino por motivo de estudo.

$\Delta$ : Células ocultas entre a zona ZAT Destino $171 \mathrm{e} \mathrm{Zj.}$

$\mathbf{Z} \boldsymbol{j}=$ As viagens atraidas pelas zonas Destino abrangidas nos 20 minutos por cada zona Origem.

$\mathbf{A} \boldsymbol{j}=$ Percentagem de abrangência de Zonas Destino, contidas as suas atrações de viagens por estudo em percursos de até os 20 minutos, desde cada zona Origem.

Expressão 2:

$$
Z j=\sum_{\substack{K=1 \\ T j . k \leq 20}}^{D} N k
$$

Expressão 3:

$$
A j=\frac{\operatorname{Zj} x 100}{\sum_{k=1}^{D} N k}
$$

Esta é uma porção da matriz de tempos totais para um dos motivos inerentes aos equipamentos, neste caso, para estudo.

Note-se o começo das Zonas Destino em 167 por se tratar da mobilidade interna, e o Centro Ampliado começa nessa numeração de zona. Não se trata de uma matriz simétrica devido a ter 328 Zonas Destino por motivo de estudo e, as 365 Zonas Origem que compõe o setor do PUCAB. As Zonas Origem representam onde pode se localizar as residências e, as Zonas Destino, são todas as zonas que atraem viagens, por motivo de estudo.

No presente exemplo, é uma coincidência que se comece com a Zona Destino 167, igual que começa a primeira Zona Origem. No caso da recreação essa zona não faz parte das Zonas Destino, por não atrair viagens por esse motivo.

Para os outros motivos de viagem como saúde e recreação em que são atraídas as pessoas ao Centro Ampliado; serão avaliados igualmente por abrangência percentual da cobertura no território em que são possíveis os percursos nos tempos das discussões e, capturando de maior a menor número de viagens por motivo.

Cabe lembrar que as expressões são formuladas para 20 minutos. Para tempos de 30 e 40 minutos deverão ser recalculadas com Tj.k de 30 e 40 respectivamente. 
A partir da abrangência das Zonas Destino para cada Zona Origem, no tempo de mobilidade eficiente, obtém-se uma organizção de maior a menor abrangência (Ranking). Porém, na Tabela 14, essas abrangências por motivo de viagem deverão ser colocadas umas do lado das outras de menor a maior abrangência, devido à ponderação final, multiplicar a posição de cada zona ZAT pela atração de viagens por cada motivo, onde não se deve agravar o motivo de viagem com a maior atração da população ao multiplicá-la pelas menores posições, sabendo que o ranking posiciona desde 1 até 365 as zonas de maior a menor abrangência para quando se analisam os motivos das viagens de forma aislada.

Neste caso é a ponderação a que deve cumprir essa organização final das zonas do Ranking organizado de maior a menor ponderação.

Tabela 14. Ponderação de abrangência por motivos para 20 minutos.

\begin{tabular}{|c|c|c|c|c|c|c|c|c|c|c|c|}
\hline \multicolumn{2}{|c|}{$\begin{array}{c}\text { ZATs } \\
\text { PUCAB }\end{array}$} & \multicolumn{2}{|c|}{ Trabalho } & \multicolumn{2}{|c|}{ estudo } & \multicolumn{2}{|c|}{ saude } & \multicolumn{2}{|c|}{ recreação } & \multicolumn{2}{|r|}{$\mathrm{P}$} \\
\hline & & pucab & abrange $\%$ & pucab & abrange $\%$ & pucab & abrange $\%$ & pucab & abrange $\%$ & & \\
\hline 1 & 167 & 311 & 5,04350915 & 311 & 1,71843177 & 311 & 1,46308268 & 311 & 4,12725709 & 433 & 470669184 \\
\hline 2 & 168 & 403 & 5,41348488 & 403 & 2,03029532 & 312 & 2,58591358 & 403 & 4,98710232 & 337 & 468440116 \\
\hline 3 & 169 & 312 & 6,11199905 & 312 & 3,08681263 & 403 & 2,65396393 & 312 & 5,76096303 & 338 & 465621331 \\
\hline 4 & 170 & 399 & 7,02953886 & 315 & 3,53869654 & 315 & 3,57264376 & 397 & 6,62080825 & 445 & 463150255 \\
\hline 5 & 171 & 315 & 7,27224294 & 400 & 3,5959776 & 399 & 3,70874447 & 400 & 7,30868444 & 336 & 462949752 \\
\hline 6 & 172 & 605 & 7,5060676 & 313 & 4,36608961 & 400 & 3,84484519 & 315 & 7,39466896 & 335 & 462604256 \\
\hline 7 & 173 & 400 & 7,51198721 & 399 & 4,69704684 & 313 & 4,08302144 & 313 & 8,34049871 & 446 & 461077844 \\
\hline
\end{tabular}

Fonte: Cálculo próprio.

Para obter um ranking definitivo das zonas em que é possivel uma maior abrangência de todos os motivos de viagem inerentes aos equipamentos e o trabalho em tempo de 20, 30 ou 40 minutos. É necesario uma ponderação e atribuição de pesos por motivo.

Para atribuir os pesos para cada motivo de viagem, basta saber qual é o motivo que mobiliza um maior número de pessoas dentro do universo da pesquisa de mobilidade (SDM, 2015).

Seria correto calcular e consultar os valores de viagens das amostras como pesos, porém, é correto também colocar os dados já fornecidos, após a projeção proporcional dos dados das ânforas para a população toda. 
Segue a Tabela 15 para a atribuição dos pesos por motivo de viagem da Tabela projetada de deslocamentos por propósito de 2015 comparada com a de 2011:

Tabela 15. Viagens por propósito, pesquisa 2015 vérsus pesquisa 2011

\begin{tabular}{|l|l|l|l|l|}
\hline \multirow{2}{*}{ Motivo da viagem } & \multicolumn{2}{c|}{ Pesquisas 2015 } & \multicolumn{2}{c|}{ Pesquisas 2011 } \\
\cline { 2 - 5 } & \multicolumn{1}{|c|}{$\begin{array}{c}\text { Total } \\
\text { viagens }\end{array}$} & Percentagem & $\begin{array}{c}\text { Total } \\
\text { viagens }\end{array}$ & Percentagem \\
\hline Assuntos do Trabalho & 275,032 & $1,80 \%$ & 420,398 & $3,18 \%$ \\
\hline $\begin{array}{l}\text { Procurar/ levar alguém sem vínculo de } \\
\text { cuidado. }\end{array}$ & 52.497 & $0,34 \%$ & 0 & $0,00 \%$ \\
\hline Procurar/ Levar alguém sob seu cuidado. & 273.447 & $1,79 \%$ & 717.844 & $5,43 \%$ \\
\hline Procurar emprego & 28,458 & $0,19 \%$ & 35,28 & $0,27 \%$ \\
\hline Procurar/Levar algum objeto & 75,337 & $0,49 \%$ & 120,801 & $0,91 \%$ \\
\hline Comer/ Tomar algo & 37,285 & $0,24 \%$ & 75,157 & $0,57 \%$ \\
\hline Compras & 396,442 & $2,60 \%$ & 437,109 & $3,31 \%$ \\
\hline Estudar & 1.427 .476 & $9,34 \%$ & 1.342 .323 & $10,16 \%$ \\
\hline Encontro com alguém & 244,361 & $1,60 \%$ & 368,037 & $2,79 \%$ \\
\hline Outra cosa & 708,293 & $4,64 \%$ & 285,133 & $2,16 \%$ \\
\hline Receber atenção de saúde & 485,477 & $3,18 \%$ & 405,174 & $3,07 \%$ \\
\hline Recreação & 132,302 & $0,87 \%$ & 271,385 & $2,05 \%$ \\
\hline Trabalhar & 3.121 .315 & $20,43 \%$ & 2.088 .358 & $15,81 \%$ \\
\hline Documentos & 595,202 & $3,90 \%$ & 653,645 & $4,95 \%$ \\
\hline Voltar ao lar. & 7.422 .388 & $48,59 \%$ & 5.987 .302 & $45,33 \%$ \\
\hline & $\mathbf{1 5 . 2 7 5 . 3 1 2}$ & $\mathbf{1 0 0 , 0 0 \%}$ & $\mathbf{1 3 . 2 0 7 . 9 4 6}$ & $\mathbf{1 0 0 \%}$ \\
\hline
\end{tabular}

Fonte: Consorcio Transconsult-Informetika.

$\mathrm{P}($ ZATs PUCAB $)=$ VPT x ps + VPE x ps + VPS x ps + VPR x ps

$\mathrm{P}=$ Ponderação

ps $=$ posição.

$\mathrm{VPT}=$ viagens por motivo de trabalho.

$\mathrm{VPE}=$ viagens por motivo de estudo.

VPS $=$ viagens por motivo de saúde.

$\mathrm{VPR}=$ viagens por motivo de recreação.

Exemplo:

Para ZAT PUCAB 403:

$P(403)=3{ }^{\prime} 121.315 \times 2+1 ' 427.476 \times 2+485.477 \times 3+132.302 \times 2$

$P(403)=2^{\prime} 704.654,25$ (A posição final é de 364), esta é uma das zonas pior posicionadas dentre as 365 zonas do setor do PUCAB. 
Exemplo:

$P(433)=3^{\prime} 121.315 \times 364+1 ’ 427.476 \times 365+485.477 \times 365+132.302 \times 365$

4

$\mathrm{P}(433)=470$ '669.184 (A posição final é de 1), esta é a melhor posição do Ranking.

Seguem as representações do Ranking nos Mapas 7,8 e 9 para 20, 30 e 40 minutos respectivamente, deste Cenário para percursos dos lares ao trabalho e aos motivos inerentes aos equipamentos urbanos que também atraem viagens ao centro da cidade.

Consulte o Ranking total para 20, 30 e 40 minutos no Apêndice 3. Ver localização das ZAT no Apêndice 4. 


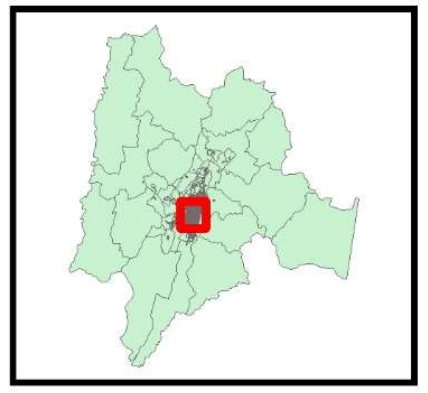

\section{Legenda}

Adensamento alto

Adensamento médio alto

Adensamento médio

Adensamento médio baixo

Adensamento baixo

Centro Ampliado e entorno

$\begin{array}{lll}0 & 1,25 & 2,5\end{array}$ $5 \mathrm{Km}$

Coordinate System: MAGNA Colombia Bogota Projection: Transverse Mercator Datum: MAGNA

False Easting: 1.000.000,0000

False Northing: $1.000 .000,0000$

Central Meridian: $-74,0775$

Scale Factor. 1,0000

Latlude Or Origin: 4,596

255000

$-8245000$

$-8240000$

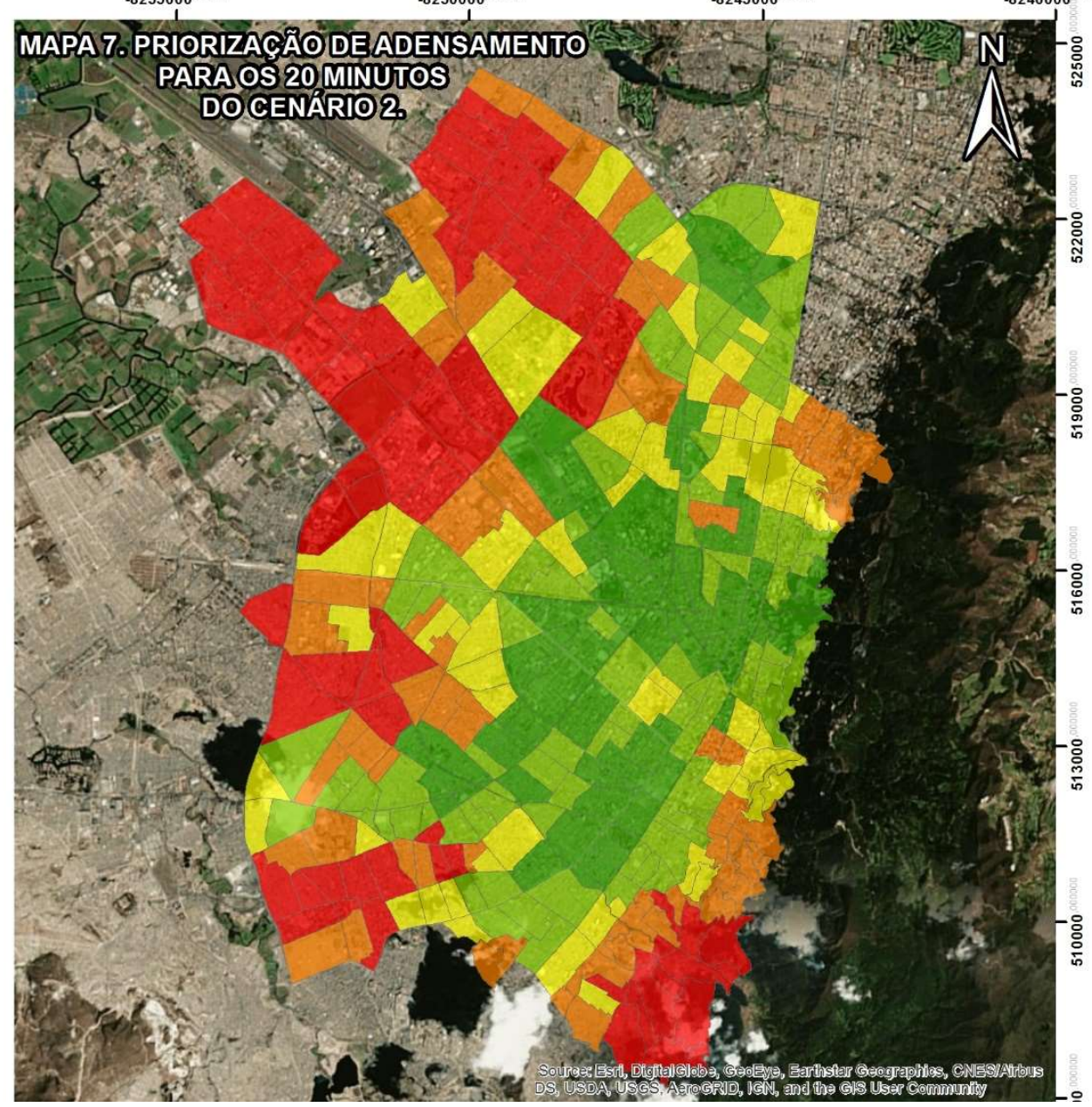

Mapa 7: Priorização de adensamento para os 20 minutos do cenário 2.

Fonte: própria. 


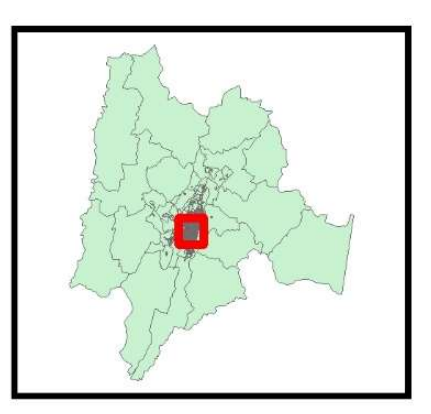

Legenda

Adensamento alto

Adensamento médio alto

Adensamento médio

Adensamento médio baix

Adensamento baixo

Centro Ampliado e entorno

$1,25 \quad 2,5$ $5 \mathrm{Km}$

Coordinate System: MAGNA Colombia Bogota Projection: Transverse Mercator Datum: MAGNA

False Easting: $1000.000,0000$

False Northing: $1.000 .000,0000$

Central Meridian: $-74,0775$

Scale Factor: 1,0000

Latitude Of Origin: 4,596 Units: Meter

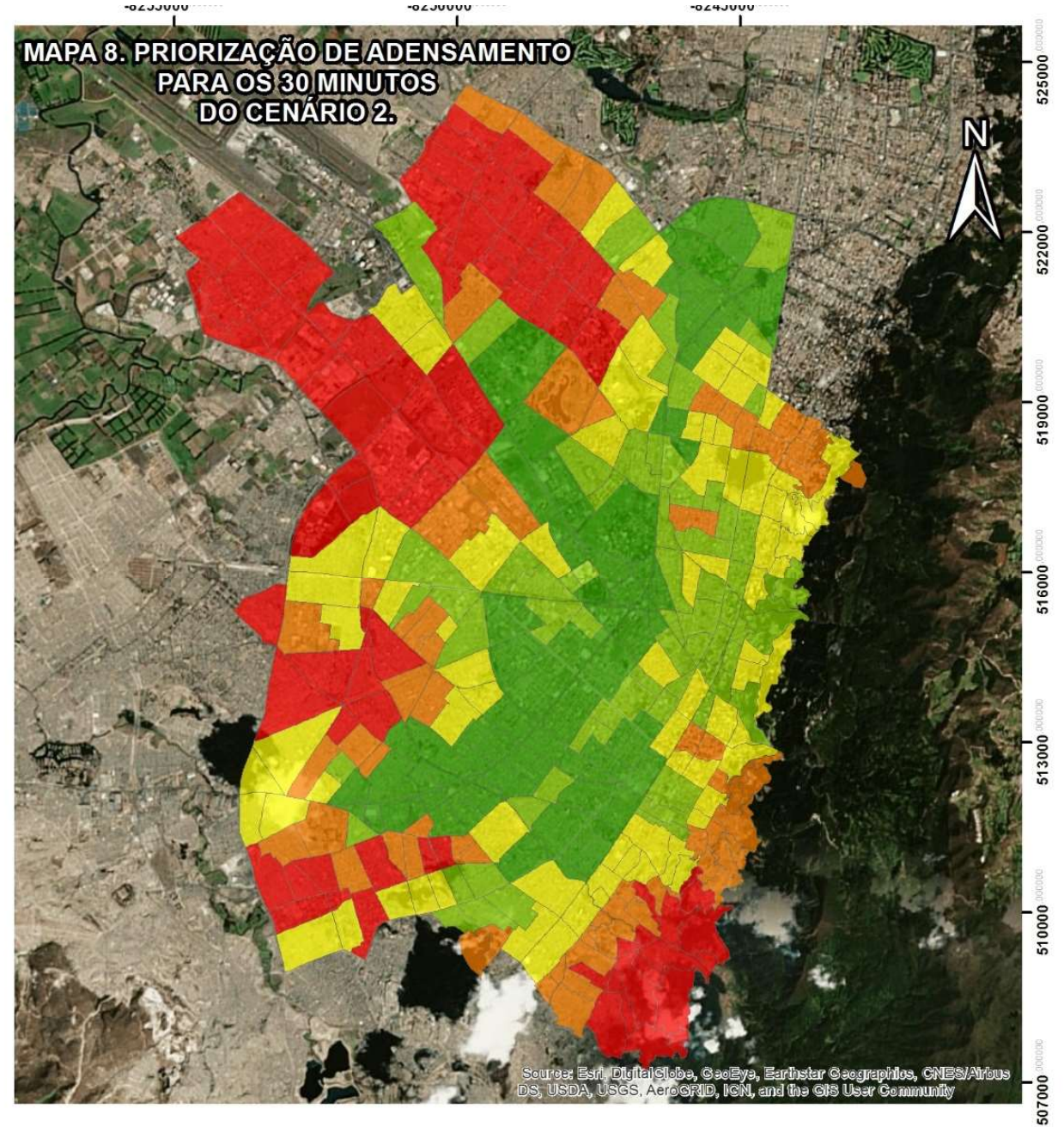

Mapa 8: Priorização de adensamento para os 30 minutos do cenário 2.

Fonte: própria. 


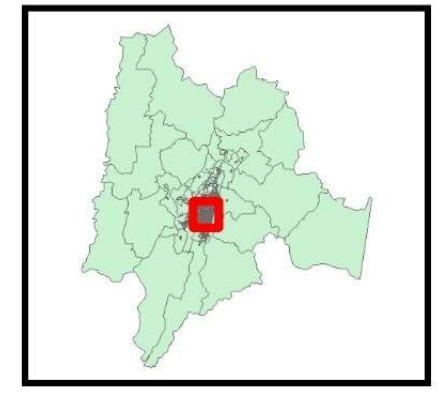

Legenda

Adensamento alto

Adensamento médio alto

Adensamento médio

Adensamento médio baixo

Adensamento baixo

Centro Ampliado e entorno

$\begin{array}{lll}0 & 1,25 & 2,5\end{array}$ $5 \mathrm{Km}$

Coordinate System: MAGNA Colombia Bogota Projection: Transverse Mercator Datum: MAGNA

False Easting: $1.000 .000,0000$ False Northing: $1.000 .000,000$

Central Meridian: $-74,0775$

Scale Factor: 1,0000

Latitude Of Origin: 4,5962
Units: Meter

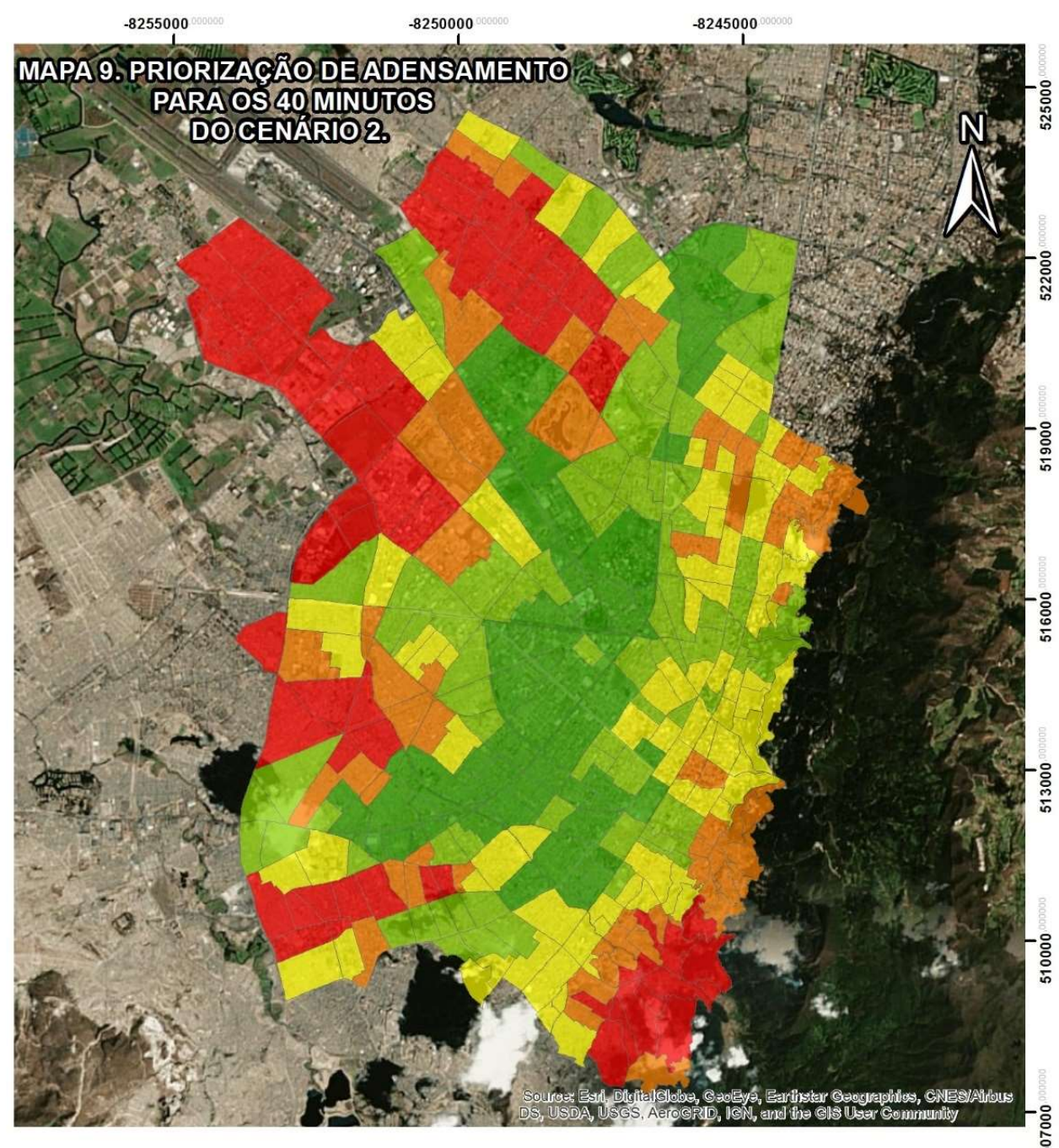

Mapa 9: Priorização de adensamento para os 40 minutos do cenário 2.

Fonte própria. 


\section{9 \\ Discussões}

A Colômbia entende a necesidade do fortalecimento do campo e das zonas rurais nas suas complexas relações urbano-rurais para o desenvolvimento econômico, em que se permite uma relação até onde não se atinja o meio ambiente.

$\mathrm{O}$ estado deve garantir a segurança física e jurídica nas zonas rurais para as pequenas, medianas e grandes empresas, para cumprir a misão na geração de oportunidades econômicas não só subsidiárias que são soluções de curto prazo, mas, sim, reconhecendo nos habitantes rurais como os principais autores do seu próprio desenvolvimento agropecuário, promovendo a criação de empresas, garantindo direitos econômicos, sociais e culturais que dignificam aos seus habitantes. (DNP, 2014)

A situação anteriormente descrita é parte das politicas para saldar a dívida com o campo, permitindo que a população de áreas rurais se sinta segura e digna do espaço que ocupa não só na geografía, mas, também, na sociedade colombiana, motivo pelo qual, a população não se vería atraída às cidades para ganhar um espaço de "dignidade". Daí que se reduz a posibilidade de serem novamente preenchidos os espaços das periferias com pessoas residentes do espaço rural no cenário colombiano.

$\mathrm{O}$ adensamento no setor do $\mathrm{PUCAB}$ responde à necesidade de reduzir os deslocamentos típicos de morar majoritariamente na perifería e trabalhar no centro como demonstrado nos Mapas 1 e 3.

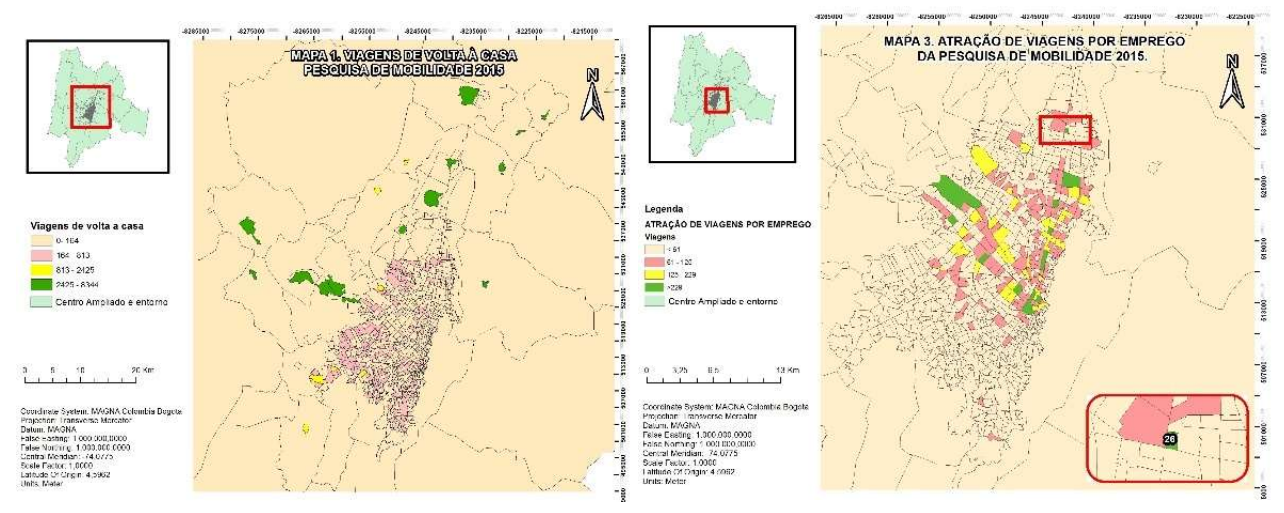

Consulta própria.

O Mapa 3 representa a existência da zona de maior atração de viagens por motivo de emprego (ZAT 26), além dos limites do Centro Ampliado de Bogotá. 
A Tabela 1 da Área de Bogotá e tipo de solo permite ver a cidade de Bogotá conta com limitada área de expansão urbana, sendo necessário um adensamento para controlar a tendência expansiva que teve até agora.

Para adensar a cidade de Bogotá é preciso alocar as pessoas em áreas ainda edificáveis segundo os parâmetros de aproveitamento do terreno.

O Índice de Aproveitamento do Terreno para o Brasil, equivale ao índice de construção na Colômbia, é um valor adimencional resultante de uma divisão de área útil total permitida a ser construída, entre a área total do terreno segundo a metodologia para o cálculo do IAT que facilita on-line, a Prefeitura do Rio de Janeiro (2017) e, na Colômbia se estipula pelo Decreto n. 1788/2004. Com esse valor e da área construida ou com o valor atual da população por região, pode-se chegar a um valor máximo ainda por ser edificado para receber o valor médio de pessoas por hectare da cidade.

A Figura 10 do decreto 562 mostra mais áreas para intervenção urbanística das específicas apresentadas pelo Plano Urbanístico e, uma média populacional de 214 habitantes/hectare. Ditas áreas a serem intervindas segundo o decreto pretendem equilibrar o território no adensamento devido a contar com maior número de habitantes nas periferias e, por ter detectado um déficit no adensamento populacional nesses setores com bordas roxas da Figura 10.

A análise anterior difere do Plano onde é considerado o déficit populacional sob o valor de 175 habitantes/hectare.

Esses valores da definição no déficit habitacional são importantes para quando for definido a média populacional a atingir nos adensamentos das áreas propostas a serem intervindas para alocação das pessoas em área edificada e/ou edificável.

O Decreto n. 190/2004, no setor do centro histórico, designa o uso de solo patrimonial; razão pela qual se restringe o adensamento e, no Decreto 562 de 2014 no Capítulo 1 dos alcances e aplicação da renovação urbana, são restringidos os setores com atividade industrial, por tanto, existirão zonas ZAT de análise da dissertação que podem ser ótimas para serem adensadas por condições de mobilidade, porem, estas são limitadas no adensamento pelo Plano Diretor.

A condição anterior nas restrições para adensamentos deverão ser analisadas após as últimas propostas que forem aceitas nas mudanças do IAT de Bogotá. 
O Plano do Centro Ampliado apresenta propostas ao Índices de Aproveitamento do Terreno não superiores a 5 que no Rio de Janeiro, Brasil, chega até 15 , segundo Decreto n. 322/1976.

Perante às propostas para alterações do IAT em Bogotá, cabe a possibilidade de um estudo de factibilidade aberto a receber propostas desses índices além dos valores contemplados no PUCAB, valores superiores como aqueles aqui mencionados de forma comparativa com cidades adensadas como é o caso do Rio de Janeiro, no Brasil.

Após a análise das áreas prioritárias para serem adensadas, cabe sugerir o estudo das demandas nos serviços públicos e infraestrutura para avaliar as suas capacidades e propor possíveis implementações.

As factibilidades para os adensamentos dependem das condições do solo e demais restrições às que estiver submetida a cidade.

É inviavel apresentar uma simulação de adensamento conforme as normas estabelecidas até agora por existirem propostas para aumentar o Índice de Aproveitamento do Terreno em Bogotá.

Dentre as razões para adensar o setor proposto no PUCAB está, a diminuição da segregação socioespacial.

A Figura 11 de avaliação das condições de moradia das classes socioeconômicas mostra que a camada socioeconômica baixa, mora aglomeradamente nas periferias sendo consideradas as localidades de Bosa, Usme e ciudad Bolivar como as de maiores problemas relacionados à segregação socioespacial.

Das comparações quanto a viabilizar a integração socioespacial se determina que, Bogotá conta com a inclusão social que viabiliza a inclusão espacial. Entretanto, na cidade do Rio de Janeiro, Brasil, já existe inclusão espacial e devese reforçar a inclusão social que garante a dinámica do fortalecimento do solo urbano para o consequênte equilibrio socieconômico da cidade.

De qualquer forma, a inclusão espacial das classes socioeconômicas baixas no Rio de Janeiro, oferecem maiores garantias na oferta de emprego e equipamentos urbanos por perto das moradias dessas pessoas; maiores garantias que as recebidas pelas pessoas das camadas socieconômicas baixas localizadas nas periferias de qualquer uma das duas cidades comparadas. 
Uma das finalidades de adensar a cidade de Bogotá é permitir deslocamentos curtos para as atividades habituais inerentes aos equipamentos.

Comparando a Tabela 2 das áreas por localidade em Bogotá e a Tabela do número de equipamentos por cada 10.000 habitantes (Anexo 3), se obtem os equipamentos $/ \mathrm{Km}^{2} / 10000$ hab, de cada localidade, na Tabela 16 a seguir:

Tabela 16 - Equipamentos por Km2/10000 hab, em localidades de Bogotá D.C.

\begin{tabular}{|c|c|c|c|c|}
\hline No & Localidad & Área & $\begin{array}{l}\text { Equipamentos total } \\
\text { por localidade }\end{array}$ & $\begin{array}{l}\text { Equipamentos/Km2 } \\
\text { por cada } 10000 \text { hab. }\end{array}$ \\
\hline 1 & Usaquen & 65,20 & 835 & 12,81 \\
\hline 2 & Chapinero & 38,00 & 581 & 15,29 \\
\hline 3 & Santa Fe & 45,17 & 600 & 13,28 \\
\hline 4 & San Cristobal & 49,10 & 914 & 18,62 \\
\hline 5 & Usme & 215,07 & 846 & 3,93 \\
\hline 6 & Tunjuelito & 9,91 & 303 & 30,58 \\
\hline 7 & Bosa & 23,93 & 748 & 31,26 \\
\hline 8 & Kennedy & 38,59 & 1116 & 28,92 \\
\hline 9 & Fontibón & 33,28 & 478 & 14,36 \\
\hline 10 & Engativá & 35,88 & 1367 & 38,10 \\
\hline 11 & Suba & 100,56 & 1256 & 12,49 \\
\hline 12 & Barrios Unidos & 11,90 & 641 & 53,86 \\
\hline 13 & Teusaquillo & 14,19 & 543 & 38,27 \\
\hline 14 & Los Martires & 6,52 & 281 & 43,10 \\
\hline 15 & Antonio Nariño & 4,88 & 192 & 39,34 \\
\hline 16 & Puente Aranda & 17,31 & 453 & 26,17 \\
\hline 17 & La Candelaria & 2,06 & 323 & 156,80 \\
\hline 18 & Rafael Uribe Uribe & 13,83 & 868 & 62,76 \\
\hline 19 & Ciudad Bolivar & 130 & 1225 & 9,42 \\
\hline 20 & Sumapaz & 780,98 & 19 & 0,0 \\
\hline
\end{tabular}

Fonte: Cálculo próprio 


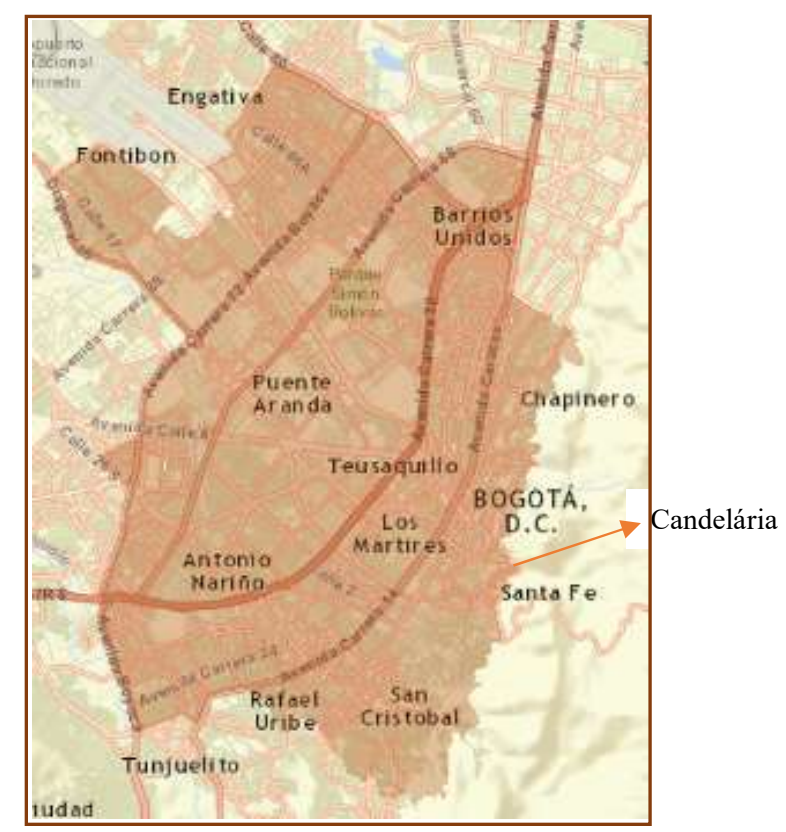

"Figura 9 - Centro Ampliado de Bogotá D.C." Fonte: Desenho próprio.

Note-se o atraente número de equipamentos do Centro Ampliado da Figura 9 segundo a Tabela 16, que apresenta o setor como área vantajosa a ser adensada para permitir maior oferta de equipamentos por perto dos lugares de moradia dos cidadãos. Situação que ainda se representa similiar até 2015 no brouchure do Decreto 562 na proximidade aos equipamentos, na pagina da SDP (Anexo 4).

A Tabela 3 junto às Figuras 15 e 16 mostra a percentagem de risco por alagamento ou desmoronamento, e os nós de Biodiversidade de Bogotá D.C respectivamente, esses cenários em zonas perifericas onde moram as pessoas de baixos recursos econômicos.

A Figura 17 aponta pontos roxos, lilás e vermelhos além das descrições da maior geração de emprego do Plano no Capítulo 1, que são pontos mais atrativos por emprego, segundo a Figura 19 do Hot spot emprego, apresentado pelo mesmo documento no Capítulo 4, encontrando discrepâncias nas descrições do Plano.

As áreas de maior geração de emprego de Gutiérrez (2011) distam da condição atual, comparando as consultas de mobilidade de 2006 em que, baseadas nas pesquisas dessa autora, com as pesquisas do 2015 mais próximas da atualidade. O território vem se modificando progressivamente devido a serem implementadas as centralidades no Plano Diretor em 2004 que distribui o comércio e indústria 
(maior atividade econômica da cidade) no espaço para equilibrá-lo segundo o decreto 190 de 2004.

As pesquisas de mobilidade de 2011 e 2015 são muito similares e de grosso modo, a caraterização urbana ainda tem o mesmo comportamento.

Não se encontrou bibliografia nacional da Colômbia com dados estatísticos de tempos de tolerância e/ou ideais para percursos lar-trabalho-lar. Não se desestimam os 20 minutos fixados pelo Plano devido a ser um tempo ideal para passageiros de percursos curtos em Kunming, China; amplia-se o cenário para percursos de 30 e 40 minutos que são tempos de tolerância nos transportes públicos do Reino Unido e Kunming respectivamente.

Sugere-se a pesquisa de tempos de tolerância e ideais nos percursos lartrabalho-lar, junto às populações de cada região devido a ver que não sempre esses valores são iguais para todas as cidades.

Para a demonstração desta pesquisa se encontrou que, nenhuma das zonas do Centro Ampliado de Bogotá consegue abranger o 100\% do território em que contidas as áreas de maior geração de emprego descritas nos Capítulo 1 e 4 do PUCAB, como consta nas Tabelas do Apêndice 1.

A zona com maior abrangência em vinte minutos é a zona 433 com $\mathrm{Aj}=77,53 \%$, zona pertencente à descrição geográfica de zonas com maior geração de emprego nos Capítulos 1 e 4 do Plano, como representado no Mapa 2.

No Mapa 2, as zonas em cor cinza são aquelas sem conexão de transportes públicos entre centroides, desde e até a zona 433, segundo a explicação da Secretaria Distrital de Mobilidade da cidade de Bogotá; esclarecendo que em veículo particular e moto, essas áreas são abrangidas em tempos menores do que vinte minutos, segundo consulta própria nas pesquisas de mobilidade de 2015.

Segundo as pretensões do Plano, para as pessoas terem acesso à oferta de emprego em curtas distâncias da proposta na Seção 8.2 em que restringida a mobilidade aos 20 minutos lar-trabalho-lar, pode ser observado no Mapa 4, existem zonas ótimas a serem adensadas na zona industrial, no centro tradicional da cidade e ao extremo norte dos limites do Centro Ampliado.

À medida que o tempo for aumentando nas restrições de mobilidade para a proposta da Seção 8.2, as zonas ótimas de adensamento também vão aumentando segundo os Mapas 5 e 6 para 30 e 40 minutos respectivamente. 
No caso da proposta para adensamento em zonas passíveis de se locomover em tempos eficientes e absolutos de 20, 30 e 40 minutos o Mapa não varia notavelmente nos três cenários. Isso devido a ser uma ponderação de todos os motivos das viagens.

A Tabela 17 a seguir, entrega a percentagem de participação das zonas intervindas pelo Plano, na priorização de adensamento sob as condições de mobilidade para deslocamentos em até 20 minutos dos lares aos polos de emprego da proposta desta pesquisa que atende as pretensões do PUCAB.

Tenta-se estabelecer que os adensamentos das zonas propostas no Plano Urbanístico para serem intervindas, não foram bem caraterizadas sob as condições de mobilidade no PUCAB; as condições de mobilidade possuem um maior peso dentre as variáveis para as escolhas de zonas a serem adensadas sob os delineamentos do Plano, porém, essas zonas, na sua maioria, se localizam na mediana priorização de adensamento na pretensão de morar perto da maior oferta de emprego em menores tempos de percursos do Mapa 4.

A análise anterior será representada no Mapa 10 destas discussões.

Segundo o PUCAB, nas zonas a serem redefinidas urbanisticamente se contemplam intervenções além do adensamento populacional como por exemplo, intervenção com criação de parques, janelas paisagísticas, construção de ciclovias e vias pedestres. 
Tabela 17- Percentagem de participação das zonas a intervir pelo PUCAB na proposta 1 da pesquisa.

Fonte: elaboração própria.

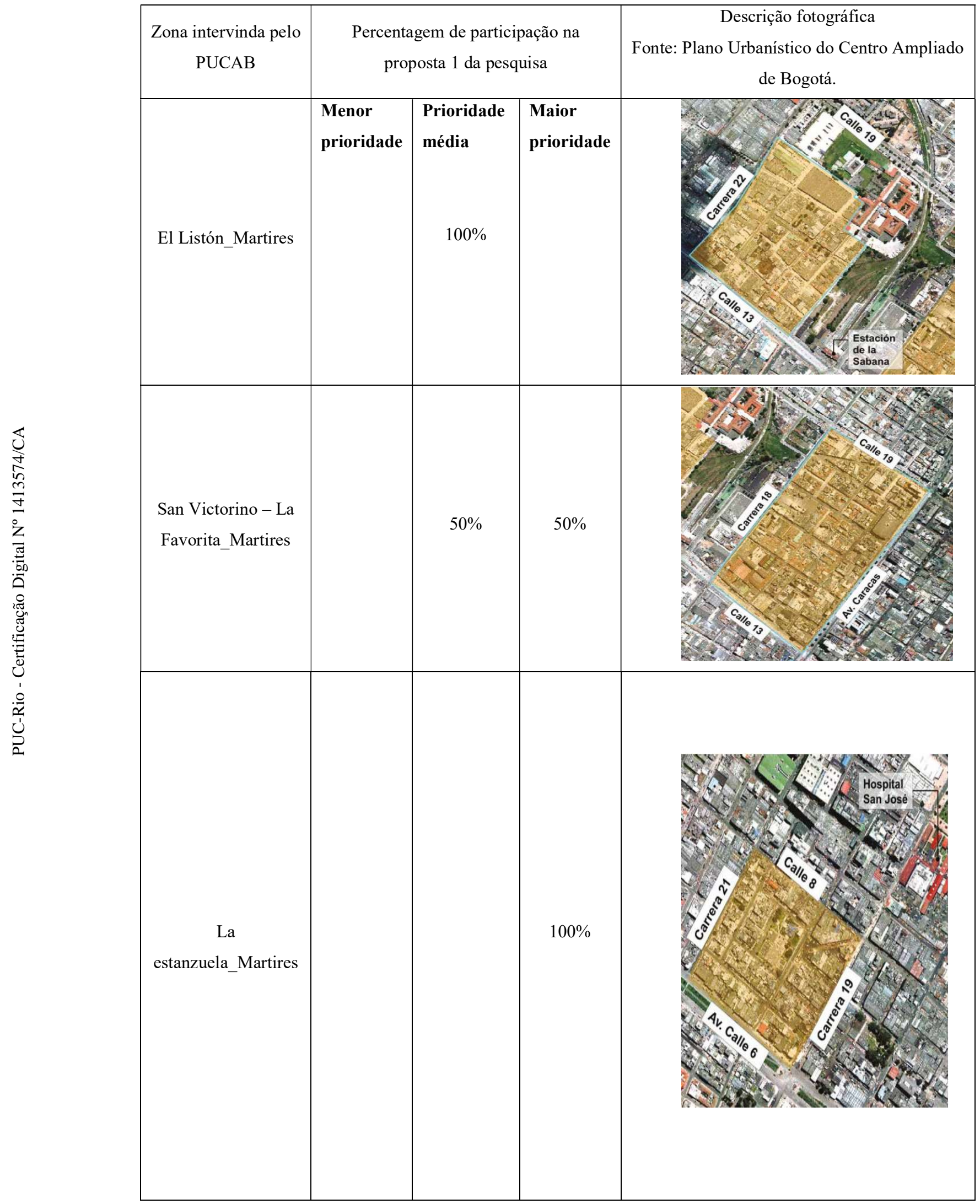




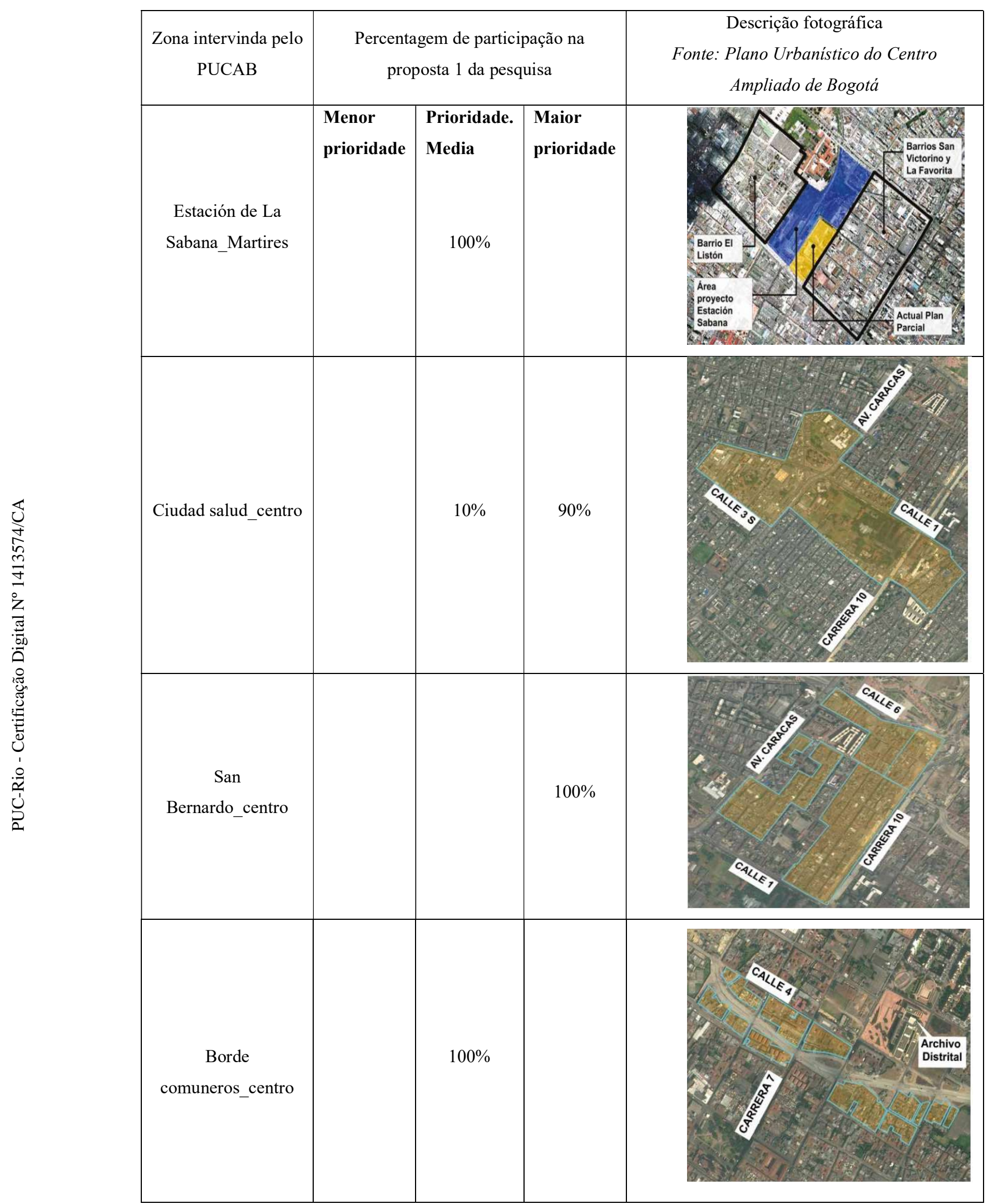




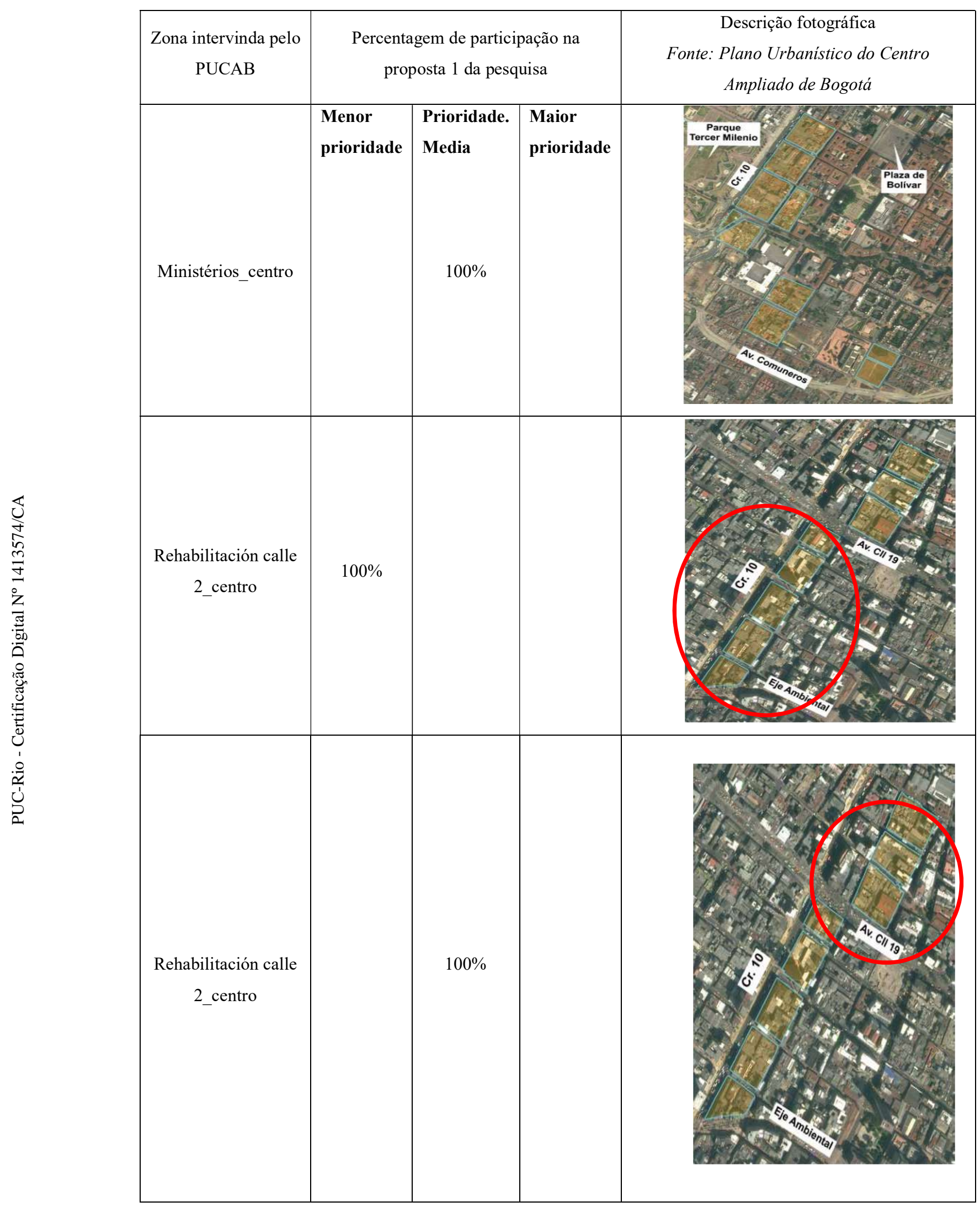




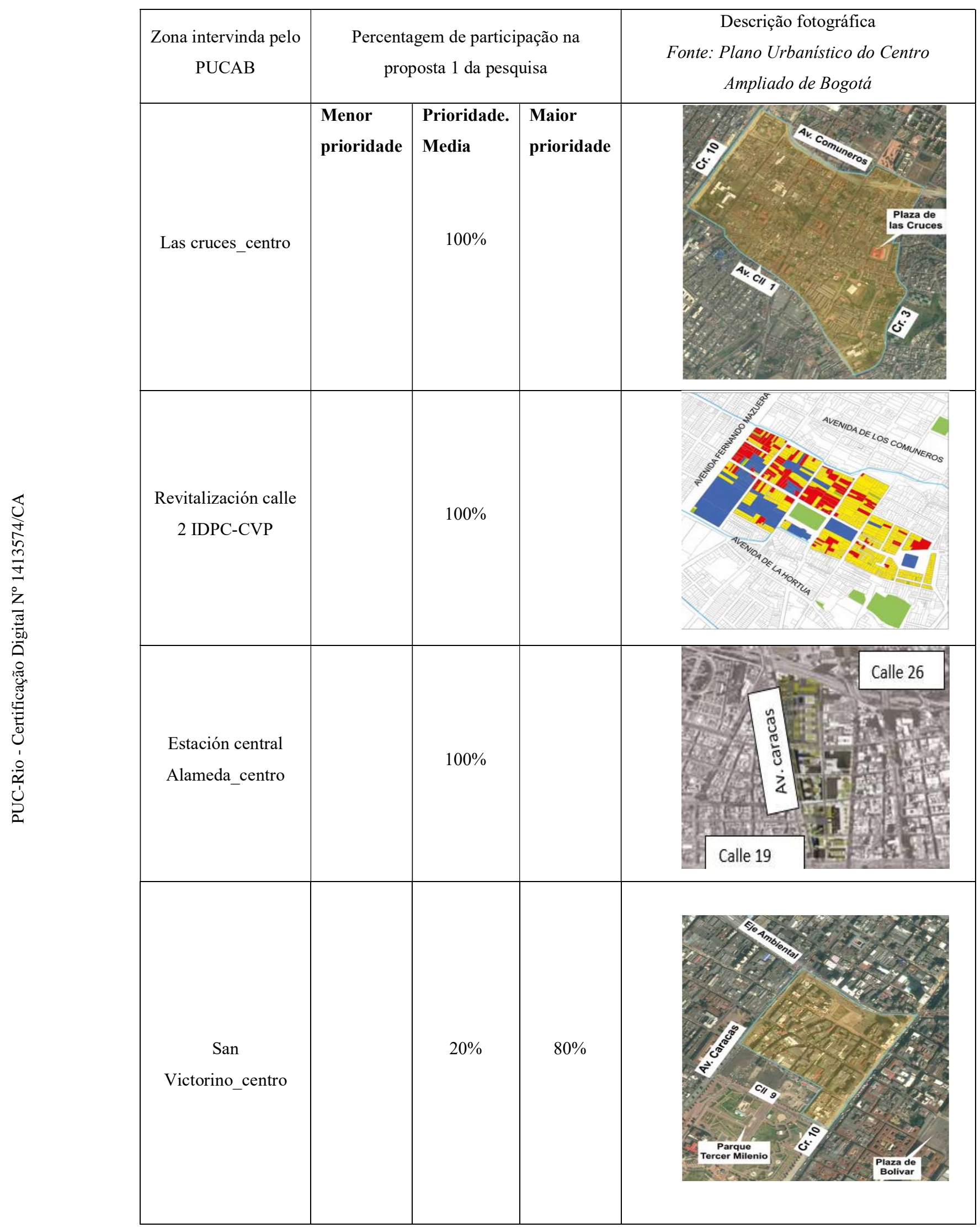




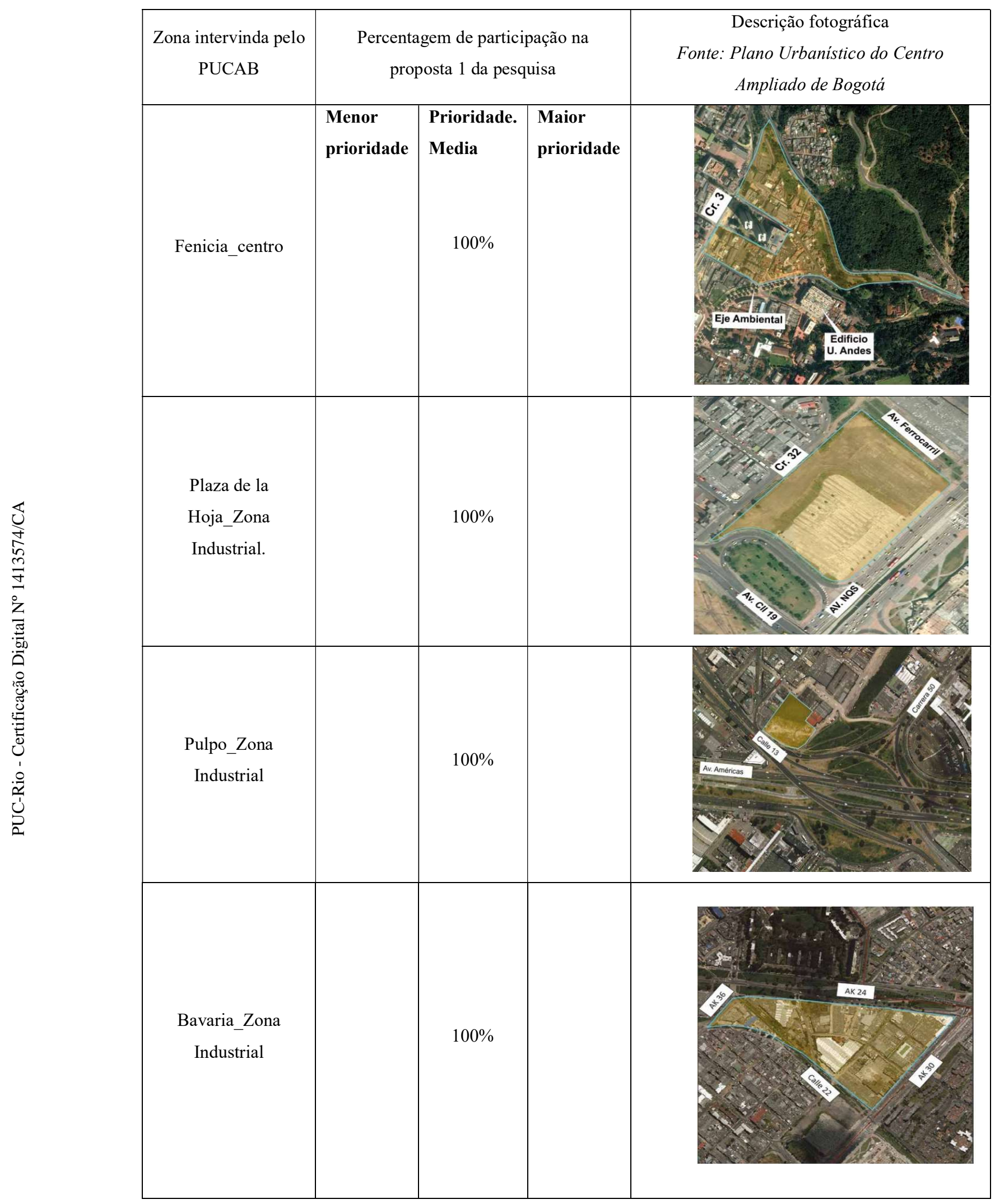




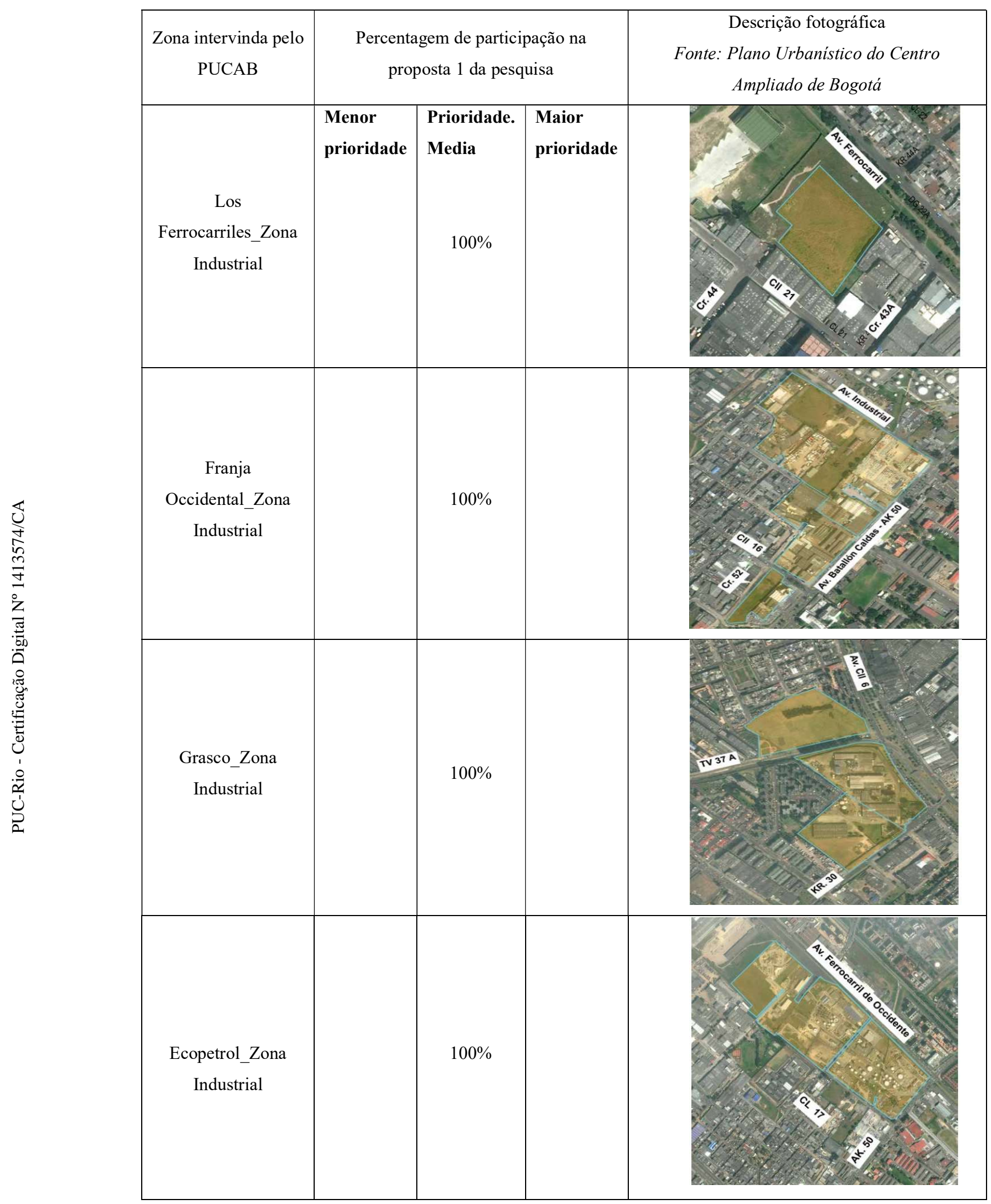




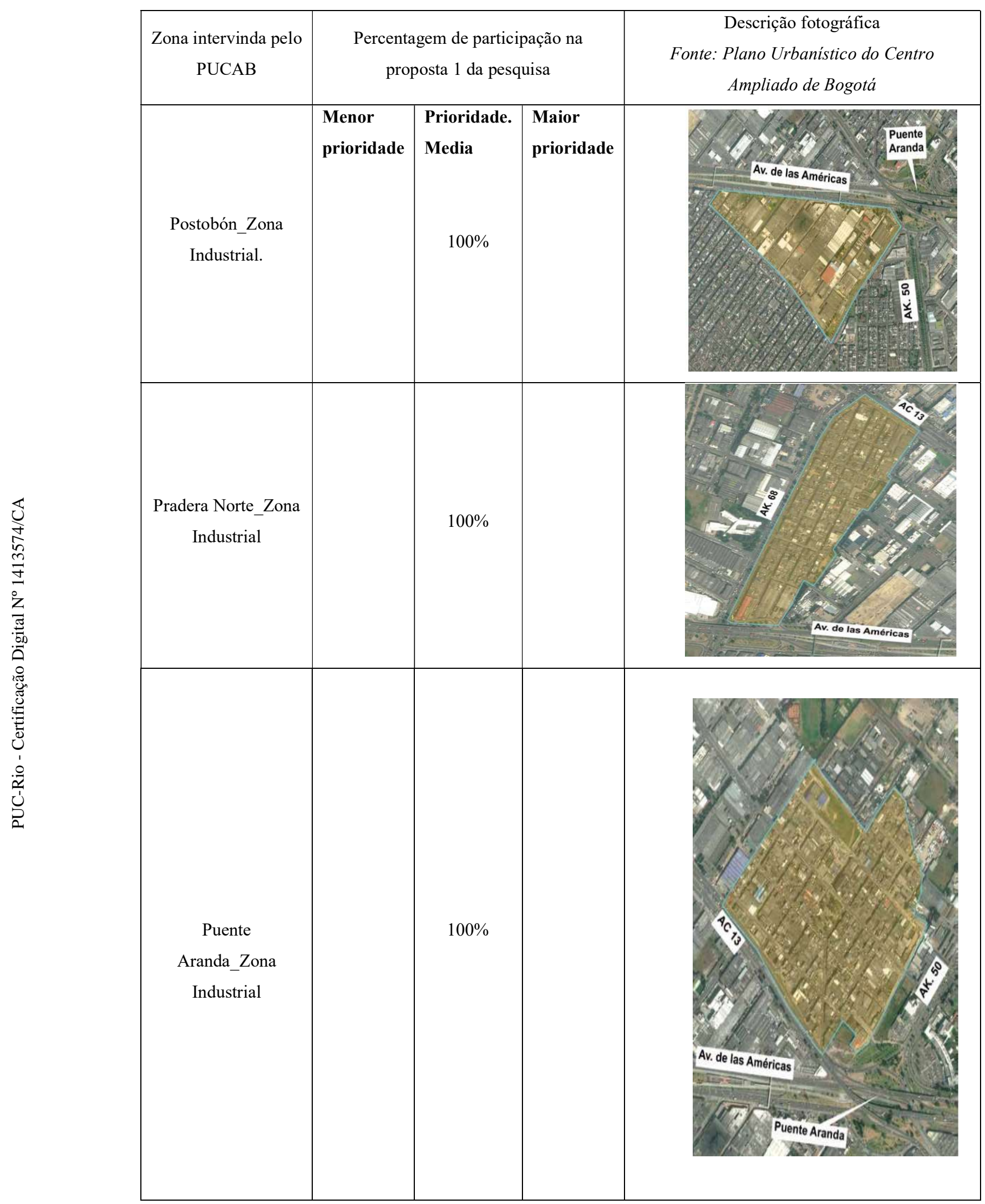




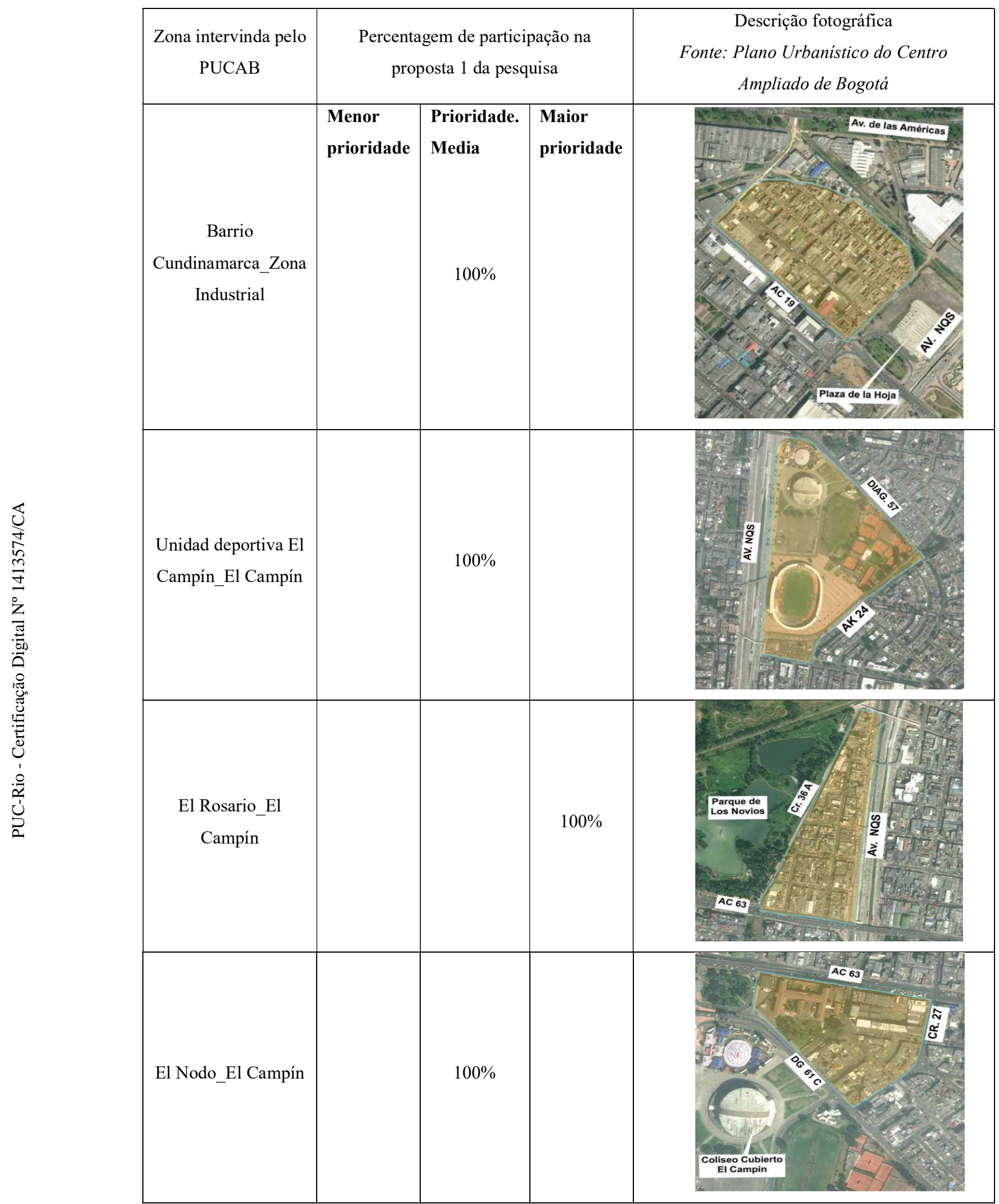


Segue Mapa 10 da sobreposição geográficas das zonas do Plano Urbanístico na proposta 1 da pesquisa que interpreta as pretensões do PUCAB de percursos em até 20 minutos das casas aos empregos.

No Mapa 10 a seguir percebe-se que na borda do bairro comuneros, se traspõem o bairro das cruzes e a revitalização urbana da calle 2 e calle 2_centro (propostas IDPC-CVP e do PUCAB). Essas zonas aparecem numa cor rosa intenso pela transposição de áreas, mas, continuam a serem rosa por causa de estarem em zona de mediana prioridade para adensamento da proposta da Seção 8.2.

Note-se no Mapa 10 e Tabela 17, que a maioria das áreas propostas pelo Plano estão localizadas na mediana priorização por condição de mobilidade.

Uma área proposta pelo plano Rehabilitación calle 2_centro, entra em área de menor priorização de adensamento sob condições de mobilidade da proposta de adensamento desta pesquisa no Cenário 1 para percursos de até 20 minutos nos transportes públicos dos lares aos empregos.

Existem setores de ótimo adensamento da pesquisa na proposta 1 para percursos de até 20 minutos lar-trabalho-lar, ao extremo norte do Centro Ampliado; setor não considerado por esse mesmo Plano para serem intervindos com adensamento populacional, mas esse setor ao norte é sim contemplado para adensamento pelo decreto 562 de 2014.

O Apêndice 4, contém a numeração das zonas ZAT, estas numerações são a identificação desses setores independente do cenário em tempo ou das propostas de priorização de adensamento das Seções 8.2 e 8.3 . 


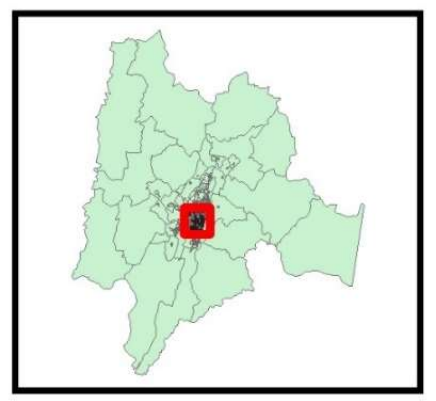

Legenda

PRIORIZAÇÃO DE ZONAS - 20minutos

Zonas de menor prioridade

Zonas de prioridade média

Zonas de maior prioridade

Centro Ampliado e entorno

$\begin{array}{lll}0 & 1,25 & 2,5\end{array}$ $5 \mathrm{Km}$

Coordinate System: MAGNA Colombia Bogota rojection: Transverse Mercator Datum: MAGNA
False Easting: 1.00

Fasting: $1.000 .000,0000$ Central Meridian: $-74,0775$

Scale Factor: 1,0000

atitude Of Origin: 4,5962

Units: Meter

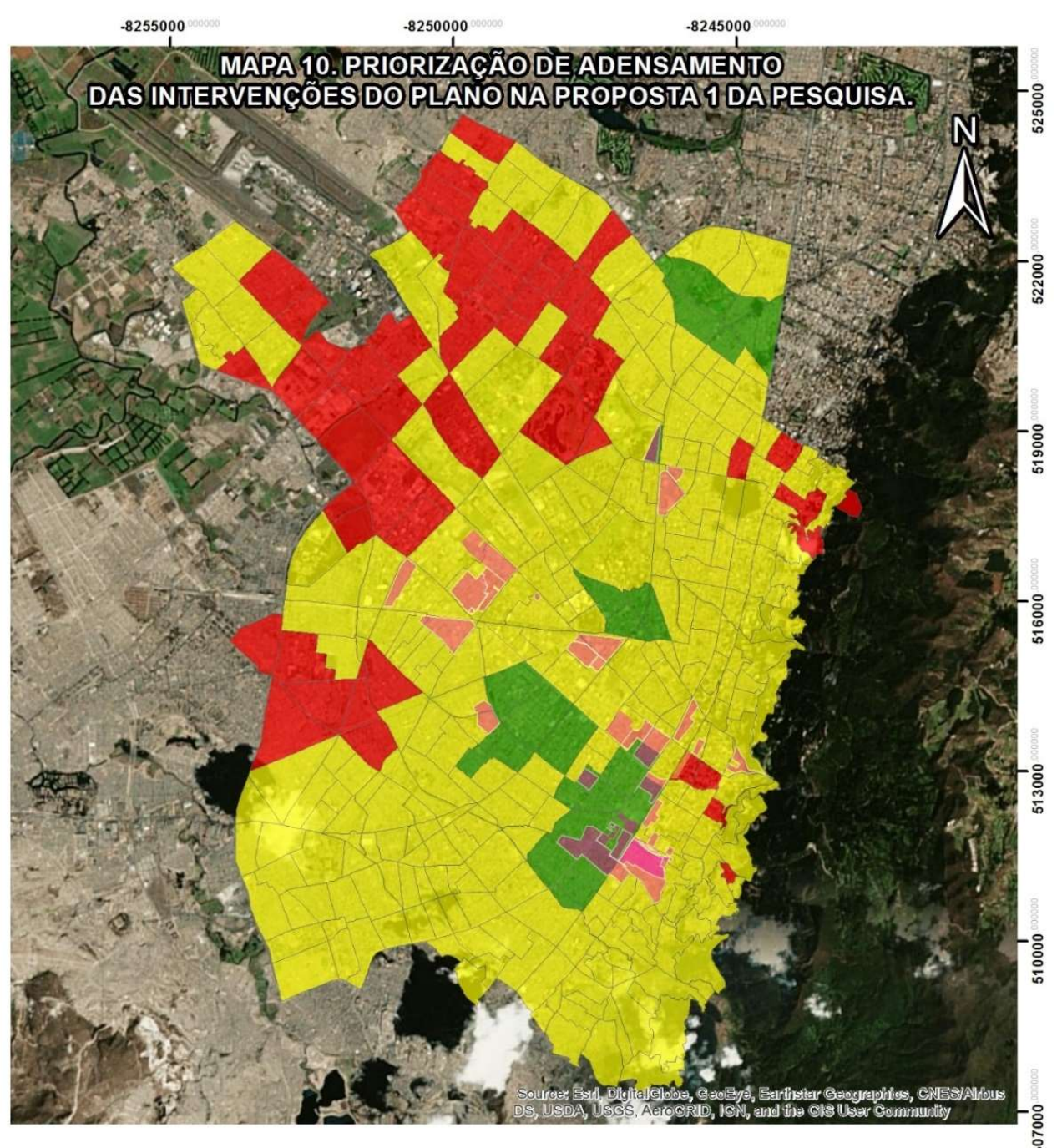

Mapa 10: Priorização de adensamento das intervenções do Plano na proposta 1 da pesquisa. Fonte: própria. 


\section{Conclusões}

Após a comprovação do não cumprimento das condições de mobilidade do PUCAB, foram respondidos os principais questionamentos da pesquisa quanto ao objetivo de corrigir a premissa de mobilidade do Plano, que deu origem aos limites do Centro Ampliado, lembrando os questionamentos:

1. Deveve-se manter os limites do PUCAB ou, propor novos limites que cumpram com as condições de mobilidade?

Conclusão: Sim. Deve-se manter os limites do PUCAB por existirem outros motivos importantes para morar nesse setor como a segurança perante os riscos ambientais de alagamento e desmoronamento, por não atingir às áreas de preservação ambiental das periferias, por ser um setor privilegiado quanto ao número de equipamentos urbanos e por cumprir com o objetivo geral do Plano Urbanístico com respeito à diminuição da segregação socioespacial. Por isso, a proposta de priorização de adensamento se faz num Ranking de maiores a menores vantagens quanto às condições de mobilidade, mas sem excluír nenhuma das zonas contidas no setor do PUCAB.

2. Quais são as zonas de maior geração de emprego em Bogotá?

Conclusão: Assim como outros dos autores nas discussões da Seção 6.1, consultaram as pesquisas de mobilidade e determinaram as zonas de maior geração de emprego, pelo número de viagens atraídos por esse motivo para cada zona; esta pesquisa consultou as pesquisas de mobilidade mais recentes com a mesma finalidade para a determinação das zonas de maior geração de emprego representadas no Mapa 3 e capturadas nos cálculos em que é priorizado o adensamento nas zonas com maior abrangência “Aj”, expressão que implícitamente já contêm um maior peso para as áreas com mais viagens atraídas para cada zona do PUCAB por motivo de emprego.

3. Quais são os tempos ótimos e de tolerância nos percursos lar-trabalho-lar nos transportes públicos, e por que registringir esse tempo aos 20 minutos?

Conclusão: Não foi encontrada uma pesquisa dos percursos dos lares aos trabalhos para os cidadãos da Colômbia, porém, segundo outros estudos analisados na Seção 6.2, o tempo desses percursos das casas aos lugares de trabalho é importante para o bem-estar da população, concluindo que, existe mior satisfação 
do cidadão com o meio urbano qanto menores forem os percursos das casas aos empregos.

Esta pesquisa não subesestima os 20 minutos do Plano por coincidir com tempos ideais para os passageiros de percursos curtos em Kunming, China. Sendo este apenas um cenário, junto aos tempos de tolerância dos percursos nos transportes públicos do Reino Unido de 30 minutos, e os 40 minutos de tolerância para passageiros de percursos curtos em Kunming, China - compõem tres cenários em que é aparesentada a proposta da pesquisa quanto aos tempos sugeridos para percursos dos lares aos empregos e equipamentos.

A metodologia proposital da pesquisa promove os deslocamentos em meios de transportes não motorizados, devido a priorizar os adensamentos em zonas que cumpram com maior abrangência da oferta de emprego em menores tempos de percursos nos transportes públicos, dentro do limite de tempo estabelecido. Isso implica a opção dos cidadãos de se deslocarem sem fazer uso dos transportes motorizados, nas distâncias passiveis de se percorrer a pé, em bicicleta, e demais trasnportes sustentáveis.

Conhece-se do privilegiado número de equipamentos do Centro Ampliado para os que a população pode escolher por perto, o suficiente para chegar inclusive a pé.

A pesar dos limites do PUCAB serem coerentes por outros dos motivos já discutidos e para cumprir com o objetivo geral do Plano. Quanto à diminuição da segregação socioespacial, cabe anotar a relevância nos aportes desta pesquisa - para corrigir a variável de maior peso na delimitação do setor do Centro Ampliado - em resposta à finalidade de ressaltar às condições de mobilidade para conseguir a satisfação dos cidadãos com o meio urbano em espaços despoluidos e equilibrados nas condições socioeconômicas na cidade de Bogotá.

Em resposta aos propósitos motivacionais desta pesquisa para reforçar as afirmações verdadeiras do $\mathrm{PUCAB}$, foram empregadas discussões com os diferentes autores que confirmaram as demais premissas desse Plano. 
11

\section{Referências bibliográficas}

AGYEMAN, Julian; ZAVESTOSKI, Stephen. incomplete streets: Processes, practices, and possibilities. 1.ed. Oxon: Routledge, 2015. 326p.

BRASIL, Rio de Janeiro. Decreto 322 n.1, de 03 de mar. de 1976. Aprova o regulamento de Zoneamento do Município do Rio de Janeiro. Índice de Aproveitamento de Terreno (IAT) Máximo Decreto municipal. Prefeitura do Rio de Janeiro, 190p, mar. 1976. Disponível em:

$<$ http://www.rio.rj.gov.br/dlstatic/10112/5126700/4132731/DECRETO N332.PDF>. Acesso em: 09 mai. 2017.

COLÔMBIA. Decreto 1788, de 03 de jun. de 2004. Dispõe os objetivos parciais da lei 388 de 1997 onde define-se o índice de construção para a ocupação dos solos urbanos. o Ordenamento Territorial do Distrito Capital em perspectiva regional. 3p. Disponível em:

http://www.alcaldiabogota.gov.co/sisjur/normas/Norma1.jsp?i=1382 3>. Acesso em: 18 out. 2016.

COLÔMBIA. Decreto 190, de 22 de jun. de 2004. Dispõe os objetivos para o Ordenamento Territorial do Distrito Capital em perspectiva regional. Alcaldía Mayor de Bogotá - 2004, 230 p. Disponível em: $<$ http://www.alcaldiabogota.gov.co/sisjur/normas/Norma1.jsp?i=139 35>. Acesso em: 18 out. 2016.

COLÔMBIA. Lei n. 142 , de 11 de Julho de 1994. Disciplina os serviços públicos domiciliários e outras disposições: classificação socioeconômica. Bogotá, DC, 11 jul de 1994. Disponível em: $<$ http://www.alcaldiabogota.gov.co/sisjur/normas/Norma1.jsp?i=275 2> Acesso em: 15 set. 2017.

COLÔMBIA. Lei 388 de 18 de julho de 1997. Pela qual se ditam normas sobre Ordenamento Territorial e outras disposições. Bogotá, $\mathrm{DC}$, 18 jul. 1997.Disponível: <http://www.alcaldiabogota.gov.co/sisjur/normas/ Norma1.jsp?i=339>. Acesso em: 02 jan. 2017.

COLÔMBIA. Decreto 562, de 12 de dez de 2014. Regulamenta as condições urbanísticas para a renovação urbana, se incorporam áreas desse tratamento, se adoptam as normatividades dos setores e se ditam outras disposições. Alcaldía Mayor de Bogotá. Bogotá D.C, 25p. Disponível em: <http://www.alcaldiabogota.gov.co/sisjur/normas/Norma1.jsp?i 
$=60137>$. Acesso em: 23 jan. 2015.

CONSEJO NACIONAL DE POLÍTICA ECONÓMICA Y SOCIAL, Conpes. Lineamientos para la consolidación del Mejoramiento Integral de Barrios - MIB. ed. Bogotá: Ministerio de Ambiente, Vivienda y Desarrollo Territorial DNP - DDUPA, 2009. 56p. Disponível em:

http://www.minvivienda.gov.co/Mejoramiento\%20Integral\%20de\%2 0Barrios/Lineamientos\%20para\%20la\%20Consolidaci\%C3\%B3n\% 20de\%20la\%20Pol\%C3\%ADtica\%20de\%20MIB.pdf> Acesso em: 21 out. 2017.

DEPARTAMENTO ADMINISTRATIVO NACIONAL DE ESTADISTICA, DANE. Censo general 2005: Estimaciones y proyecciones de población (2005-2020). Bogotá. Disponível em: $<$ http://www.dane.gov.co/index.php/estadisticas-por-

tema/demografia-y-poblacion>. Acesso em: 07 fev. 2017.

. Censo 2005: províncias y subregiones. Disponível em: $<$ https://www.dane.gov.co/files/censo2005/provincias/subregiones.p df>. Acesso em: 22 mar. 2017.

Disponível

Conceptos básicos: Área urbana, Colombia. $<$ https://www.dane.gov.co/files/inf_geo/4Ge_ConceptosBasicos.pdf >. Acesso em: 06 mar. 2017.

. Metodología de Índice de Precios al Consumidor: IPC, $\quad$ Colombia. Disponível em: <https://www.dane.gov.co/files/investigaciones/fichas/IPC.pdf>. Acesso em: 06 mar. 2017.

DEPARTAMENTO NACIONAL DE PLANEACIÓN, DNP. Misión para la transformación del campo: Saldar la deuda histórica con el campo: Marco conceptual de la misión para la transformación del campo. Bogotá 2014. 47p. Disponivel em: < https://colaboracion.dnp.gov.co/CDT/Prensa/DOCUMENTO\%20MA RCO-MISION.pdf>. Acesso 22 out. 2017.

FEDERACIÓN COLOMBIANA DE GESTIÓN HUMANA, ACRIP. (Org.). $42^{\circ}$ Investigación Nacional de Salarios y Beneficios de ACRIP Nacional 2017 - 2018. Bogotá, Colombia. Disponível em: <http://www.acripnacional.org/Noticias/?sc=42-InvestigacionNacional-de-Salarios-de-ACRIP-Nacional-2017-2018>. Acesso em:21 Out. 2017.

GALEANO, Eduardo. As veias abertas da América Latina. Tradução de Galeno de Freitas. 39a ed. Rio de Janeiro: Paz e Terra, 2000. 307p. Título original: Las venas abiertas de America Latina. (Coleção Estudos Latino-Americanos, v.12). 
GIZ, Deutsche Gesellschaft Für Internationale Zusammenarbeit; BMZ, Federal Ministry for Economic Cooperation and Development. Proyecto de Transporte Urbano Sostenible.: The Sustainable Urban Transport Project. SUTP. Disponível em: <http://sutp.org/es/ >. Acesso em: 21 out. 2017.

GUTIÉRREZ, Diana. Determinantes de la localización del empleo urbano en Bogotá, Colombia. Revista de Economía del Rosario, Bogotá, v.14, n. 1, p. 61 - 98 ene./jun. 2011. Disponível em: < http://www.urosario.edu.co/urosario_files/0a/0a48c3b7-c2db-42bd90f6-16854bda8a41.pdf>. Acesso em: 22 out. 2017.

HE, Mingwei; ZHAO, Schengchuan. Determinants of long duration commuting and long-duration commuters' perceptions and attitudes toward commuting time: evidence from Kunming, China. ScienceDirect, v.41, IATSS, p.22-29 Aug. 2016. Disponível: <http://www.sciencedirect.com/science/article/pii/S0386 111216300279>. Acesso em: 15 jun. 2017.

INSTITUTO BRASILEIRO DE GEOGRAFÍA E ESTATISTICA, IBGE. Áreas urbanizadas do Brasil 2015. ed. Rio de Janeiro: Relatórios metodológicos, ISSN 0101-2843, 2017. 28p. v. 44 Disponível em: <https://biblioteca.ibge.gov.br/visualizacao/livros/liv100639.pdf>. Acesso em: 20 out. 2017.

Censo demográfico 2010: Aglomerações subnormais. Rio de Janeiro: Informações territoriais. ISSN 01043145, 2011. 251p. Disponível em: < https://biblioteca.ibge.gov.br/visualizacao/periodicos/552/cd_2010_ agsn_if.pdf> Acesso em: 20 out. 2017.

Síntese de indicadores sociais: Uma análise das condições de vida da população brasileira. Rio de Janeiro: Estudos e pesquisas. Informações demográficas e socioeconômica. ISSN 1516-3296, 2015. 137p. v.35 Disponível em: <https://biblioteca.ibge.gov.br/visualizacao/livros/liv95011.pdf>. Acesso em: 20 out. 2017.

Sistema Nacional de Índices de Preços ao Consumidor: Índices de Preços ao Consumidor Amplo - IPCA e Índice Nacional de Preços ao Consumidor - INPC. Disponível em: < https://ww2.ibge.gov.br/home/estatistica/indicadores/precos/inpc_ip ca/defaultinpc.shtm > Acesso em: 15 set. 2017. 


\section{INTERNATIONAL MONETARY FUND, IMF. Executive Board Concludes 2017, Article IV Consultation with Colombia. Disponível em:<https://www.imf.org/en/News/Articles/2017/05/04/pr17148- colombia-imf-executive-board-concludes-2017-article-iv- consultation>.Acesso em: 18 abr. 2017.}

L. DEFLEUR, Melvin; BALL- ROKEACH, Sandra. Teorias da comunicação de massa: Zahar, 1993. 400p.

LARA, Jairo.; MORENO, Gustavo. Movilidad urbana en Caracas. Un enfoque desde las tecnologías limpias para la formación de competencias ciudadanas para el desarrollo sostenible. Redalyc.org, Mérida Venezuela, v.31, Universidad de los Andes, p. 11-48 jan. Jun. 2014. Disponível em:< http://www.redalyc.org/pdf/555/55532603002.pdf >. Acesso em: 17 fev. 2015.

LEFEBVRE, Henry. O direito à cidade. São Paulo: Centauro, 2008. $141 \mathrm{p}$.

LIZARRAGA, Carmen. Expansión metropolitana y movilidad: el caso de Caracas. EURE (Santiago), Santiago, v. 38, n. 113, jan. 2012. Disponível em: <http://www.scielo.cl> Acesso em 23 jun. 2015.

LYONS, Glenn. Getting smart about urban mobility - Aligning the paradigms of smart and sustainable. ScienceDirect, England, United Kingdom, Elsevier, 11p. 2016. Disponível em: < http://www.sciencedirect.com/science/article/pii/S09658564163110 28> Acesso: 21 out. 2017.

MINISTERIO DE EDUCAÇÃO DA COLÔMBIA, MINEDUCACIÓN. Salarios de los profesionales: colombianos recién graduados de posgrado ganan 2,2 veces el salario de los recién titulados de pregrado. Disponível em: <http://www.mineducacion.gov.co/1759/w3-article-358827.html>. Acesso em: 20 out. 2017.

MUÑOZ, M. J. P.; DE BLAS, C. S.; JIMÉNEZ, B. I. C. Estudio empírico sobre la utilización del transporte público en la Comunidad de Madrid como factor clave de movilidad sostenible. ScienceDirect, Madrid España, v.37, Elsevier España, p.112-124 mai. I ago. $2014 . \quad$ Disponível em: <http://www.sciencedirect.com/science/article/pii/S0210026613 000435>. Acesso em: 22 jul. 2015. 
OFFICE FOR NATIONAL STATISTICS, ONS. (Org.). Commuting and personal well-being. Reino Unido, 2014, 25p. Disponível em: <http://webarchive.nationalarchives.gov.uk/20160107224314/ht tp://www.ons.gov.uk/ons/dcp171766_351954.pdf>. Acesso em: 16 maio 2017.

PREFEITURA DE BOGOTÁ, 2011; SDP. Equidad, Productividad y Sostenibilidad: Documento técnico de soporte Modificación al plan de ordenamiento territorial. Bogotá Positiva, 2011. 677p. Disponível em:

http://www.sdp.gov.co/portal/page/portal/PortalSDP/POT/QueEs/DT S.pdf>. Acesso em: 13 jun. 2017.

- Monografías de las localidades: Distrito capital $2011 . \quad$ 190p, v.21. Disponível em: <http://www.sdp.gov.co/portal/page/portal/PortalSDP/InformacionTo maDecisiones/Estadisticas/Documentos/An\%E1 lisis/DICE062MonografiaBogota-31122011.pdf>. Acesso em: 23 nov. 2016.

PREFEITURA DE BOGOTÁ, 2015.; SDP.; SDH. el Plan Urbano del Centro Ampliado de Bogotá: Una estrategia para revitalización urbana. ed. Bogotá: Bogotá Humana, 2015. 218p. Disponível em: <http://www.sdp.gov.co/portal/page/portal/PortalSDP/Noticias2014/ SDP_realiza_lanzamiento_de_su_coleccion_de_libros_Bogota_Hu m/01.CENTRO-AMPLIADŌ.pdf>. Acesso em: $2 \overline{3}$ jul. $2 \overline{0} 17$.

Encuesta de movilidad Urbana en Bogotá: EODH EODI, 2015. Alcaldía Mayor de Bogotá. Bogotá, 2011.

Bogotá. Plan Maestro de Movilidad: PMM. Alcaldía Mayor de <http://www.movilidadbogota.gov.co/web/plan-maestro-movilidad>. Acesso em: 06 jan. 2017.

PREFEITURA DO RIO DE JANEIRO, 2012.; IPP - RIO. Favelas na cidade do Rio de Janeiro: o quadro populacional com base no Censo 2010. ISSN 1984-7203 n. 20120501. Coleção de estudos cariocas, 2012 20p. Disponível em: < http://portalgeo.rio.rj.gov.br/estudoscariocas/download/3190_Favel asnacidadedoRiodeJaneiro_Censo_2010.PDF>. Acesso em: 15 set. 2017.

PREFEITURA DO RIO DE JANEIRO, RJ. Metodologia sobre a série de Índices de Aproveitamento do Terreno (IAT). Disponível em:< $\quad$ http://www.rio.rj.gov.br/dlstatic/10112/2041753/DLFE230712.pdf/metodologia_estudo_IAT_v2..pdf>. Acesso em: 07 mar. 2017. 
RUESGA, S.M.; BICHARA, J.S.; MONSUETO, S.E. Movilidad laboral, informalidad y desigualdad salarial en Brasil. ScienceDirect, Madrid, España, vol. LXXIII, no 288, p. 63-86. abr. / jun. 2014. Disponível em: <http://www.sciencedirect.com/science/article/pii/S0185166714709 191>. Acesso em: 15 set. 2017.

Secretaria Distrital de médio Ambiente, SDA. Visor Geográfico Ambiental: Nodos de biodiversidad. Disponível em: <http://www.secretariadeambiente.gov.co/visorgeo/\#submenucapas>. Acesso em: 22 jul. 2017.

SECRETARIA DISTRITAL DE MOVILIDAD, SDM. Encuesta de movilidad Urbana en Bogotá: EODH - EODI, 2015. Alcaldía Mayor de Bogotá. Bogotá, 2015.

Secretaria Distrital de Planeación, SDP; Universidad Nacional de Colombia, UNAL. Segregación Socioeconómica en el Espacio Urbano de Bogotá D.C. ed. Bogotá: Bogotá Humana, 2013. 174p. v.1 Disponível em:<http://www.sdp.gov.co/portal/page/portal/PortalSDP/actualidad -SDP.

home/Segregacion_Socioeconomica_Espacio_Urbano_Bogota_Ju nio_0.pdf> Acesso em: 25 jul. 2017.

TECHO, ONG. Investigación de Asentamientos Informales: derecho a Bogotá. Bogotá, 2015. 166p. Disponível em: <https://issuu.com/techocolombia/docs/derecho_a_bogot__ Acesso em: 10 out. 2017.

TORRES, T.C.A.; RINCÓN, G. J. J.; VARGAS, M. J. E. Pobreza urbana y mejoramiento integral de barrios en Bogotá: Hábitat y vivienda. ed. Universidad Nacional de Colombia: Sede Bogotá: Facultad de Artes, 2009.391p. Disponivel em: < http://www.uneditorial.com/pobreza-urbana-y-mejoramientointegral-de-barrios-en-bogota-habitat-y-vivienda-arquitectura-yurbanismo.html >. Acesso em: 23 out. 2017.

UNIDAD ADMINISTRATIVA ESPECIAL DE CATASTRO DISTRITAL, IDECA: Ordenamiento territorial: Temática: Entidad territorial y planeamiento: Suelo, área urbanística y unidad de planeamiento. Disponível: <http://mapas.bogota.gov.co/portalmapa s/>. Acesso em: 23 mar. 2017.

VILLETA, Miguel. et al. Modelo para la Conducción Eficiente y Sostenible basado en Lógica Borrosa. ScienceDirect, Madrid España, Elsevier España, p. 259-266. 2012. Disponível em: < http://www.sciencedirect.com/science/article/pii/S16977912120003 98 >. Acesso em: 22 jul. 2017. 


\section{Apêndices}

\begin{tabular}{|c|c|c|c|c|c|c|c|c|}
\hline $\begin{array}{l}\text { ZATs } \\
\text { PUCAB }\end{array}$ & $\mathrm{Nj}$ & AJ & $\begin{array}{l}\text { ZATs } \\
\text { PUCAB }\end{array}$ & $\mathrm{Nj}$ & AJ & $\begin{array}{c}\text { ZATs } \\
\text { PUCAB }\end{array}$ & $\mathrm{Nj}$ & AJ \\
\hline 433 & 283 & 77,53424658 & 443 & 218 & 59,7260274 & 395 & 198 & 54,24657534 \\
\hline 445 & 263 & 72,05479452 & 431 & 217 & 59,45205479 & 429 & 198 & 54,24657534 \\
\hline 446 & 255 & 69,8630137 & 436 & 217 & 59,45205479 & 438 & 197 & 53,97260274 \\
\hline 337 & 254 & 69,5890411 & 505 & 216 & 59,17808219 & 506 & 197 & 53,97260274 \\
\hline 338 & 250 & 68,49315068 & 435 & 215 & 58,90410959 & 588 & 197 & 53,97260274 \\
\hline 444 & 248 & 67,94520548 & 508 & 214 & 58,63013699 & 591 & 197 & 53,97260274 \\
\hline 336 & 245 & 67,12328767 & 434 & 213 & 58,35616438 & 504 & 196 & 53,69863014 \\
\hline 447 & 242 & 66,30136986 & 986 & 213 & 58,35616438 & 437 & 195 & 53,42465753 \\
\hline 335 & 237 & 64,93150685 & 439 & 212 & 58,08219178 & 582 & 195 & 53,42465753 \\
\hline 448 & 237 & 64,93150685 & 503 & 212 & 58,08219178 & 589 & 195 & 53,42465753 \\
\hline 449 & 237 & 64,93150685 & 289 & 211 & 57,80821918 & 463 & 194 & 53,15068493 \\
\hline 450 & 234 & 64,10958904 & 430 & 210 & 57,53424658 & 327 & 193 & 52,87671233 \\
\hline 501 & 234 & 64,10958904 & 294 & 207 & 56,71232877 & 457 & 191 & 52,32876712 \\
\hline 452 & 232 & 63,56164384 & 339 & 207 & 56,71232877 & 460 & 191 & 52,32876712 \\
\hline 451 & 231 & 63,28767123 & 442 & 205 & 56,16438356 & 992 & 191 & 52,32876712 \\
\hline 432 & 224 & 61,36986301 & 370 & 204 & 55,89041096 & 340 & 188 & 51,50684932 \\
\hline 453 & 221 & 60,54794521 & 371 & 204 & 55,89041096 & 507 & 186 & 50,95890411 \\
\hline 518 & 221 & 60,54794521 & 364 & 199 & 54,52054795 & 333 & 185 & 50,68493151 \\
\hline
\end{tabular}




\begin{tabular}{|c|c|c|c|c|c|c|c|c|}
\hline $\begin{array}{c}\text { ZATs } \\
\text { PUCAB }\end{array}$ & $\mathbf{N j}$ & AJ & $\begin{array}{c}\text { ZATs } \\
\text { PUCAB }\end{array}$ & $\mathbf{N j}$ & AJ & $\begin{array}{c}\text { ZATs } \\
\text { PUCAB }\end{array}$ & $\mathbf{N j}$ & AJ \\
\hline 461 & 185 & 50,68493151 & 363 & 176 & 48,21917808 & 298 & 164 & 44,93150685 \\
\hline 464 & 185 & 50,68493151 & 440 & 176 & 48,21917808 & 344 & 164 & 44,93150685 \\
\hline 590 & 185 & 50,68493151 & 500 & 176 & 48,21917808 & 350 & 164 & 44,93150685 \\
\hline 984 & 185 & 50,68493151 & 511 & 176 & 48,21917808 & 587 & 164 & 44,93150685 \\
\hline 462 & 184 & 50,4109589 & 579 & 176 & 48,21917808 & 612 & 164 & 44,93150685 \\
\hline 580 & 184 & 50,4109589 & 368 & 175 & 47,94520548 & 613 & 164 & 44,93150685 \\
\hline 985 & 184 & 50,4109589 & 459 & 175 & 47,94520548 & 352 & 163 & 44,65753425 \\
\hline 993 & 184 & 50,4109589 & 220 & 172 & 47,12328767 & 348 & 162 & 44,38356164 \\
\hline 454 & 183 & 50,1369863 & 351 & 172 & 47,12328767 & 356 & 162 & 44,38356164 \\
\hline 331 & 182 & 49,8630137 & 512 & 172 & 47,12328767 & 372 & 162 & 44,38356164 \\
\hline 345 & 182 & 49,8630137 & 952 & 172 & 47,12328767 & 846 & 162 & 44,38356164 \\
\hline 360 & 182 & 49,8630137 & 367 & 171 & 46,84931507 & 293 & 161 & 44,10958904 \\
\hline 365 & 182 & 49,8630137 & 592 & 171 & 46,84931507 & 369 & 161 & 44,10958904 \\
\hline 509 & 182 & 49,8630137 & 458 & 170 & 46,57534247 & 441 & 160 & 43,83561644 \\
\hline 466 & 181 & 49,5890411 & 575 & 170 & 46,57534247 & 593 & 160 & 43,83561644 \\
\hline 502 & 181 & 49,5890411 & 285 & 169 & 46,30136986 & 349 & 156 & 42,73972603 \\
\hline 467 & 180 & 49,31506849 & 517 & 168 & 46,02739726 & 981 & 156 & 42,73972603 \\
\hline 514 & 179 & 49,04109589 & 334 & 166 & 45,47945205 & 982 & 155 & 42,46575342 \\
\hline 465 & 178 & 48,76712329 & 357 & 165 & 45,20547945 & 329 & 154 & 42,19178082 \\
\hline 279 & 177 & 48,49315068 & 499 & 165 & 45,20547945 & 278 & 153 & 41,91780822 \\
\hline 358 & 177 & 48,49315068 & 280 & 164 & 44,93150685 & 366 & 153 & 41,91780822 \\
\hline
\end{tabular}




\begin{tabular}{|c|c|c|c|c|c|c|c|c|}
\hline $\begin{array}{c}\text { ZATs } \\
\text { PUCAB }\end{array}$ & $\mathbf{N j}$ & AJ & $\begin{array}{c}\text { ZATs } \\
\text { PUCAB }\end{array}$ & $\mathbf{N j}$ & AJ & $\begin{array}{c}\text { ZATs } \\
\text { PUCAB }\end{array}$ & $\mathbf{N j}$ & AJ \\
\hline 469 & 153 & 41,91780822 & 384 & 142 & 38,90410959 & 342 & 134 & 36,71232877 \\
\hline 295 & 152 & 41,64383562 & 361 & 141 & 38,63013699 & 354 & 134 & 36,71232877 \\
\hline 341 & 152 & 41,64383562 & 380 & 141 & 38,63013699 & 359 & 134 & 36,71232877 \\
\hline 455 & 152 & 41,64383562 & 283 & 140 & 38,35616438 & 385 & 134 & 36,71232877 \\
\hline 578 & 152 & 41,64383562 & 539 & 140 & 38,35616438 & 376 & 133 & 36,43835616 \\
\hline 343 & 151 & 41,36986301 & 286 & 139 & 38,08219178 & 169 & 132 & 36,16438356 \\
\hline 375 & 151 & 41,36986301 & 288 & 139 & 38,08219178 & 510 & 132 & 36,16438356 \\
\hline 228 & 150 & 41,09589041 & 332 & 139 & 38,08219178 & 610 & 132 & 36,16438356 \\
\hline 268 & 150 & 41,09589041 & 347 & 139 & 38,08219178 & 975 & 132 & 36,16438356 \\
\hline 355 & 147 & 40,2739726 & 173 & 138 & 37,80821918 & 374 & 131 & 35,89041096 \\
\hline 346 & 146 & 40 & 475 & 138 & 37,80821918 & 515 & 131 & 35,89041096 \\
\hline 362 & 146 & 40 & 291 & 137 & 37,53424658 & 170 & 130 & 35,61643836 \\
\hline 966 & 146 & 40 & 328 & 137 & 37,53424658 & 468 & 130 & 35,61643836 \\
\hline 381 & 145 & 39,7260274 & 373 & 137 & 37,53424658 & 330 & 128 & 35,06849315 \\
\hline 456 & 145 & 39,7260274 & 497 & 137 & 37,53424658 & 577 & 127 & 34,79452055 \\
\hline 586 & 145 & 39,7260274 & 472 & 136 & 37,26027397 & 595 & 127 & 34,79452055 \\
\hline 844 & 145 & 39,7260274 & 474 & 136 & 37,26027397 & 997 & 127 & 34,79452055 \\
\hline 488 & 144 & 39,45205479 & 513 & 136 & 37,26027397 & 581 & 126 & 34,52054795 \\
\hline 270 & 143 & 39,17808219 & 290 & 135 & 36,98630137 & 583 & 126 & 34,52054795 \\
\hline 428 & 143 & 39,17808219 & 277 & 134 & 36,71232877 & 584 & 126 & 34,52054795 \\
\hline 845 & 143 & 39,17808219 & 292 & 134 & 36,71232877 & 496 & 125 & 34,24657534 \\
\hline
\end{tabular}




\begin{tabular}{|c|c|c|c|c|c|c|c|c|}
\hline $\begin{array}{c}\text { ZATs } \\
\text { PUCAB }\end{array}$ & $\mathbf{N j}$ & AJ & $\begin{array}{c}\text { ZATs } \\
\text { PUCAB }\end{array}$ & $\mathbf{N j}$ & AJ & $\begin{array}{c}\text { ZATs } \\
\text { PUCAB }\end{array}$ & $\mathbf{N j}$ & AJ \\
\hline 498 & 125 & 34,24657534 & 594 & 120 & 32,87671233 & 377 & 112 & 30,68493151 \\
\hline 477 & 124 & 33,97260274 & 597 & 120 & 32,87671233 & 495 & 112 & 30,68493151 \\
\hline 971 & 124 & 33,97260274 & 226 & 118 & 32,32876712 & 235 & 111 & 30,4109589 \\
\hline 219 & 123 & 33,69863014 & 606 & 118 & 32,32876712 & 238 & 111 & 30,4109589 \\
\hline 378 & 123 & 33,69863014 & 983 & 118 & 32,32876712 & 273 & 110 & 30,1369863 \\
\hline 386 & 123 & 33,69863014 & 221 & 117 & 32,05479452 & 427 & 110 & 30,1369863 \\
\hline 991 & 123 & 33,69863014 & 225 & 117 & 32,05479452 & 229 & 109 & 29,8630137 \\
\hline 353 & 122 & 33,42465753 & 426 & 117 & 32,05479452 & 269 & 109 & 29,8630137 \\
\hline 379 & 122 & 33,42465753 & 574 & 117 & 32,05479452 & 281 & 109 & 29,8630137 \\
\hline 422 & 122 & 33,42465753 & 240 & 116 & 31,78082192 & 485 & 109 & 29,8630137 \\
\hline 473 & 122 & 33,42465753 & 471 & 116 & 31,78082192 & 486 & 109 & 29,8630137 \\
\hline 174 & 121 & 33,15068493 & 478 & 116 & 31,78082192 & 487 & 109 & 29,8630137 \\
\hline 222 & 121 & 33,15068493 & 479 & 116 & 31,78082192 & 218 & 108 & 29,5890411 \\
\hline 223 & 121 & 33,15068493 & 480 & 116 & 31,78082192 & 287 & 108 & 29,5890411 \\
\hline 282 & 121 & 33,15068493 & 585 & 116 & 31,78082192 & 383 & 108 & 29,5890411 \\
\hline 476 & 121 & 33,15068493 & 632 & 116 & 31,78082192 & 482 & 106 & 29,04109589 \\
\hline 576 & 121 & 33,15068493 & 300 & 115 & 31,50684932 & 484 & 106 & 29,04109589 \\
\hline 633 & 121 & 33,15068493 & 491 & 113 & 30,95890411 & 516 & 106 & 29,04109589 \\
\hline 843 & 121 & 33,15068493 & 172 & 112 & 30,68493151 & 176 & 105 & 28,76712329 \\
\hline 299 & 120 & 32,87671233 & 217 & 112 & 30,68493151 & 267 & 105 & 28,76712329 \\
\hline 494 & 120 & 32,87671233 & 276 & 112 & 30,68493151 & 271 & 105 & 28,76712329 \\
\hline
\end{tabular}




\begin{tabular}{|c|c|c|c|c|c|c|c|c|}
\hline $\begin{array}{c}\text { ZATs } \\
\text { PUCAB }\end{array}$ & $\mathbf{N j}$ & AJ & $\begin{array}{c}\text { ZATs } \\
\text { PUCAB }\end{array}$ & $\mathbf{N j}$ & AJ & $\begin{array}{c}\text { ZATs } \\
\text { PUCAB }\end{array}$ & $\mathbf{N j}$ & AJ \\
\hline 171 & 104 & 28,49315068 & 224 & 98 & 26,84931507 & 596 & 91 & 24,93150685 \\
\hline 227 & 104 & 28,49315068 & 272 & 98 & 26,84931507 & 230 & 90 & 24,65753425 \\
\hline 232 & 104 & 28,49315068 & 382 & 98 & 26,84931507 & 424 & 90 & 24,65753425 \\
\hline 614 & 104 & 28,49315068 & 967 & 98 & 26,84931507 & 325 & 89 & 24,38356164 \\
\hline 326 & 103 & 28,21917808 & 168 & 97 & 26,57534247 & 216 & 88 & 24,10958904 \\
\hline 489 & 103 & 28,21917808 & 175 & 97 & 26,57534247 & 302 & 87 & 23,83561644 \\
\hline 490 & 103 & 28,21917808 & 237 & 97 & 26,57534247 & 319 & 87 & 23,83561644 \\
\hline 616 & 103 & 28,21917808 & 421 & 97 & 26,57534247 & 987 & 87 & 23,83561644 \\
\hline 965 & 103 & 28,21917808 & 602 & 97 & 26,57534247 & 996 & 87 & 23,83561644 \\
\hline 231 & 102 & 27,94520548 & 988 & 97 & 26,57534247 & 179 & 86 & 23,56164384 \\
\hline 284 & 102 & 27,94520548 & 951 & 96 & 26,30136986 & 320 & 86 & 23,56164384 \\
\hline 470 & 102 & 27,94520548 & 968 & 96 & 26,30136986 & 519 & 86 & 23,56164384 \\
\hline 492 & 102 & 27,94520548 & 599 & 95 & 26,02739726 & 600 & 86 & 23,56164384 \\
\hline 234 & 101 & 27,67123288 & 236 & 94 & 25,75342466 & 618 & 86 & 23,56164384 \\
\hline 969 & 101 & 27,67123288 & 601 & 94 & 25,75342466 & 266 & 84 & 23,01369863 \\
\hline 493 & 100 & 27,39726027 & 631 & 94 & 25,75342466 & 274 & 83 & 22,73972603 \\
\hline 615 & 100 & 27,39726027 & 275 & 93 & 25,47945205 & 180 & 82 & 22,46575342 \\
\hline 617 & 100 & 27,39726027 & 239 & 92 & 25,20547945 & 423 & 82 & 22,46575342 \\
\hline 481 & 99 & 27,12328767 & 603 & 92 & 25,20547945 & 254 & 81 & 22,19178082 \\
\hline 483 & 99 & 27,12328767 & 296 & 91 & 24,93150685 & 322 & 81 & 22,19178082 \\
\hline 634 & 99 & 27,12328767 & 425 & 91 & 24,93150685 & 605 & 81 & 22,19178082 \\
\hline
\end{tabular}




\begin{tabular}{|c|c|c|c|c|c|c|c|c|}
\hline $\begin{array}{c}\text { ZATs } \\
\text { PUCAB }\end{array}$ & $\mathbf{N j}$ & AJ & $\begin{array}{c}\text { ZATs } \\
\text { PUCAB }\end{array}$ & $\mathbf{N j}$ & AJ & $\begin{array}{c}\text { ZATs } \\
\text { PUCAB }\end{array}$ & $\mathbf{N j}$ & AJ \\
\hline 167 & 79 & 21,64383562 & 213 & 58 & 15,89041096 & 182 & 32 & 8,767123288 \\
\hline 233 & 79 & 21,64383562 & 211 & 55 & 15,06849315 & 199 & 32 & 8,767123288 \\
\hline 215 & 78 & 21,36986301 & 841 & 55 & 15,06849315 & 206 & 32 & 8,767123288 \\
\hline 301 & 78 & 21,36986301 & 955 & 55 & 15,06849315 & 954 & 32 & 8,767123288 \\
\hline 598 & 78 & 21,36986301 & 387 & 54 & 14,79452055 & 207 & 29 & 7,945205479 \\
\hline 297 & 76 & 20,82191781 & 185 & 51 & 13,97260274 & 204 & 28 & 7,671232877 \\
\hline 251 & 74 & 20,2739726 & 318 & 49 & 13,42465753 & 316 & 27 & 7,397260274 \\
\hline 181 & 72 & 19,7260274 & 323 & 49 & 13,42465753 & 201 & 25 & 6,849315068 \\
\hline 184 & 70 & 19,17808219 & 303 & 48 & 13,15068493 & 203 & 25 & 6,849315068 \\
\hline 324 & 70 & 19,17808219 & 209 & 47 & 12,87671233 & 397 & 22 & 6,02739726 \\
\hline 848 & 70 & 19,17808219 & 953 & 47 & 12,87671233 & 399 & 18 & 4,931506849 \\
\hline 253 & 68 & 18,63013699 & 210 & 45 & 12,32876712 & 400 & 18 & 4,931506849 \\
\hline 250 & 66 & 18,08219178 & 317 & 45 & 12,32876712 & 313 & 17 & 4,657534247 \\
\hline 214 & 63 & 17,26027397 & 208 & 44 & 12,05479452 & 315 & 16 & 4,383561644 \\
\hline 249 & 63 & 17,26027397 & 420 & 42 & 11,50684932 & 312 & 15 & 4,109589041 \\
\hline 255 & 61 & 16,71232877 & 183 & 36 & 9,863013699 & 403 & 13 & 3,561643836 \\
\hline 252 & 60 & 16,43835616 & 186 & 36 & 9,863013699 & 311 & 10 & 2,739726027 \\
\hline 321 & 60 & 16,43835616 & 205 & 36 & 9,863013699 & & & \\
\hline 388 & 60 & 16,43835616 & 200 & 34 & 9,315068493 & & & \\
\hline 842 & 59 & 16,16438356 & 202 & 34 & 9,315068493 & & & \\
\hline 212 & 58 & 15,89041096 & 314 & 34 & 9,315068493 & & & \\
\hline
\end{tabular}




\section{Apêndice 2}

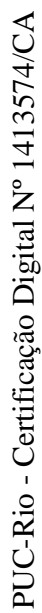

- Ranking ZAT de adensamento para percursos lar-trabalho-lar de até 20 minutos.

\section{-20 minutos.}

\begin{tabular}{|c|c|c|c|c|c|c|c|c|c|c|c|}
\hline $\begin{array}{c}\text { ZATs } \\
\text { PUCAB } \\
\text { NOMj }\end{array}$ & $\operatorname{Pj}(t)$ & $\mathrm{Aj}(\%)$ & peso_Pj & peso_Aj & soma & $\begin{array}{c}\text { ZATs } \\
\text { PUCAB } \\
\text { NOMj }\end{array}$ & $\operatorname{Pj}(t)$ & $A j(\%)$ & peso_Pj & peso_Aj & soma \\
\hline 173 & 12,43508619 & 46,02 & 3 & 5 & 8 & 439 & 12,87924467 & 36,37 & 3 & 4 & 7 \\
\hline 433 & 12,3789969 & 52,84 & 3 & 5 & 8 & 442 & 12,59349601 & 42,97 & 3 & 4 & 7 \\
\hline 168 & 12,55851153 & 38,35 & 3 & 4 & 7 & 443 & 12,41186309 & 36,25 & 3 & 4 & 7 \\
\hline 169 & 13,2181828 & 45,19 & 2 & 5 & 7 & 444 & 12,12279961 & 40,43 & 3 & 4 & 7 \\
\hline 170 & 12,46920453 & 38,10 & 3 & 4 & 7 & 445 & 12,47727272 & 44,96 & 3 & 4 & 7 \\
\hline 220 & 13,97208145 & 45,19 & 2 & 5 & 7 & 446 & 12,33365852 & 43,44 & 3 & 4 & 7 \\
\hline 223 & 12,78439571 & 42,17 & 3 & 4 & 7 & 447 & 12,85941125 & 40,06 & 3 & 4 & 7 \\
\hline 335 & 13,92933635 & 50,58 & 2 & 5 & 7 & 448 & 12,13858731 & 39,58 & 3 & 4 & 7 \\
\hline 336 & 13,27549651 & 50,45 & 2 & 5 & 7 & 449 & 12,0955034 & 39,63 & 3 & 4 & 7 \\
\hline 337 & 13,7042687 & 53,81 & 2 & 5 & 7 & 450 & 12,2726858 & 39,51 & 3 & 4 & 7 \\
\hline 338 & 13,63774019 & 51,47 & 2 & 5 & 7 & 451 & 12,42479924 & 37,99 & 3 & 4 & 7 \\
\hline 339 & 13,88805084 & 45,72 & 2 & 5 & 7 & 452 & 12,40772162 & 38,79 & 3 & 4 & 7 \\
\hline 370 & 12,90043331 & 40,82 & 3 & 4 & 7 & 453 & 12,57593999 & 39,31 & 3 & 4 & 7 \\
\hline 371 & 12,98919642 & 36,39 & 3 & 4 & 7 & 171 & 13,17517102 & 37,93 & 2 & 4 & 6 \\
\hline 430 & 12,5936614 & 36,61 & 3 & 4 & 7 & 172 & 13,67529099 & 38,48 & 2 & 4 & 6 \\
\hline 432 & 12,85018143 & 39,25 & 3 & 4 & 7 & 174 & 13,41896765 & 37,67 & 2 & 4 & 6 \\
\hline
\end{tabular}




\begin{tabular}{|c|c|c|c|c|c|c|c|c|c|c|c|}
\hline $\begin{array}{c}\text { ZATs } \\
\text { PUCAB } \\
\text { NOMj }\end{array}$ & $\operatorname{Pj}(t)$ & $\mathrm{Aj}(\%)$ & peso_Pj & peso_Aj & soma & $\begin{array}{c}\text { ZATs } \\
\text { PUCAB } \\
\text { NOMj }\end{array}$ & $\operatorname{Pj}(t)$ & $\mathrm{Aj}(\%)$ & peso_Pj & peso_Aj & soma \\
\hline 222 & 13,40647606 & 36,09 & 2 & 4 & 6 & 431 & 13,18236218 & 37,13 & 2 & 4 & 6 \\
\hline 224 & 12,22637572 & 33,65 & 3 & 3 & 6 & 434 & 12,99177659 & 33,58 & 3 & 3 & 6 \\
\hline 225 & 13,664543 & 35,12 & 2 & 4 & 6 & 460 & 12,96227074 & 33,03 & 3 & 3 & 6 \\
\hline 228 & 13,97024234 & 38,05 & 2 & 4 & 6 & 462 & 12,8134845 & 29,95 & 3 & 3 & 6 \\
\hline 233 & 12,66040143 & 28,37 & 3 & 3 & 6 & 463 & 12,69911016 & 30,36 & 3 & 3 & 6 \\
\hline 312 & 10,62613633 & 6,11 & 5 & 1 & 6 & 464 & 12,73950657 & 29,74 & 3 & 3 & 6 \\
\hline 327 & 13,87977721 & 39,96 & 2 & 4 & 6 & 466 & 12,42645298 & 26,74 & 3 & 3 & 6 \\
\hline 328 & 12,84029501 & 27,20 & 3 & 3 & 6 & 467 & 12,19202788 & 26,57 & 3 & 3 & 6 \\
\hline 329 & 12,80574858 & 33,80 & 3 & 3 & 6 & 495 & 11,97572978 & 16,33 & 4 & 2 & 6 \\
\hline 340 & 13,97838428 & 41,52 & 2 & 4 & 6 & 496 & 11,90564606 & 17,89 & 4 & 2 & 6 \\
\hline 341 & 13,63565868 & 36,67 & 2 & 4 & 6 & 497 & 11,80611108 & 19,73 & 4 & 2 & 6 \\
\hline 357 & 13,55325548 & 35,30 & 2 & 4 & 6 & 500 & 12,63172823 & 28,94 & 3 & 3 & 6 \\
\hline 361 & 12,86524284 & 30,93 & 3 & 3 & 6 & 501 & 13,05369461 & 38,54 & 2 & 4 & 6 \\
\hline 363 & 13,78607142 & 37,99 & 2 & 4 & 6 & 505 & 13,42462764 & 36,03 & 2 & 4 & 6 \\
\hline 364 & 13,20597508 & 44,07 & 2 & 4 & 6 & 507 & 12,97132715 & 34,09 & 3 & 3 & 6 \\
\hline 367 & 13,5354679 & 36,53 & 2 & 4 & 6 & 508 & 13,49802727 & 35,77 & 2 & 4 & 6 \\
\hline 368 & 13,9599125 & 38,38 & 2 & 4 & 6 & 509 & 12,52659636 & 31,97 & 3 & 3 & 6 \\
\hline 372 & 12,76343194 & 27,16 & 3 & 3 & 6 & 511 & 12,71095532 & 31,97 & 3 & 3 & 6 \\
\hline 376 & 12,00235759 & 27,74 & 3 & 3 & 6 & 512 & 12,90992591 & 30,89 & 3 & 3 & 6 \\
\hline 395 & 13,17741933 & 39,08 & 2 & 4 & 6 & 514 & 12,75784857 & 32,70 & 3 & 3 & 6 \\
\hline
\end{tabular}




\begin{tabular}{|c|c|c|c|c|c|c|c|c|c|c|c|}
\hline $\begin{array}{c}\text { ZATs } \\
\text { PUCAB } \\
\text { NOMj }\end{array}$ & $P j(t)$ & $\mathrm{Aj}(\%)$ & peso_Pj & peso_Aj & soma & $\begin{array}{c}\text { ZATs } \\
\text { PUCAB } \\
\text { NOMj }\end{array}$ & $P j(t)$ & $\mathrm{Aj}(\%)$ & peso_Pj & peso_Aj & soma \\
\hline 517 & 12,77440787 & 32,35 & 3 & 3 & 6 & 176 & 13,31518091 & 31,59 & 2 & 3 & 5 \\
\hline 539 & 12,64291665 & 29,22 & 3 & 3 & 6 & 180 & 13,64263565 & 26,22 & 2 & 3 & 5 \\
\hline 588 & 12,99923833 & 30,41 & 3 & 3 & 6 & 181 & 13,99560547 & 25,37 & 2 & 3 & 5 \\
\hline 589 & 12,54886441 & 30,43 & 3 & 3 & 6 & 184 & 13,9633272 & 25,83 & 2 & 3 & 5 \\
\hline 590 & 12,32825669 & 27,86 & 3 & 3 & 6 & 215 & 12,59784944 & 17,37 & 3 & 2 & 5 \\
\hline 591 & 12,97300735 & 30,55 & 3 & 3 & 6 & 217 & 13,7429142 & 32,02 & 2 & 3 & 5 \\
\hline 592 & 12,16233478 & 27,14 & 3 & 3 & 6 & 218 & 13,38337835 & 31,15 & 2 & 3 & 5 \\
\hline 593 & 12,12865296 & 26,39 & 3 & 3 & 6 & 221 & 13,98029938 & 33,21 & 2 & 3 & 5 \\
\hline 594 & 11,73877092 & 19,69 & 4 & 2 & 6 & 226 & 13,2676381 & 33,93 & 2 & 3 & 5 \\
\hline 598 & 10,98865699 & 8,89 & 5 & 1 & 6 & 227 & 13,76339014 & 25,61 & 2 & 3 & 5 \\
\hline 606 & 11,25619355 & 17,98 & 4 & 2 & 6 & 229 & 13,68080881 & 28,06 & 2 & 3 & 5 \\
\hline 610 & 11,66483983 & 17,91 & 4 & 2 & 6 & 231 & 13,66867239 & 30,01 & 2 & 3 & 5 \\
\hline 612 & 12,90387832 & 25,82 & 3 & 3 & 6 & 232 & 13,65726414 & 32,31 & 2 & 3 & 5 \\
\hline 966 & 12,91138119 & 31,27 & 3 & 3 & 6 & 234 & 13,64389061 & 32,90 & 2 & 3 & 5 \\
\hline 971 & 11,07486109 & 19,55 & 4 & 2 & 6 & 237 & 12,94076922 & 22,56 & 3 & 2 & 5 \\
\hline 975 & 11,66483983 & 17,89 & 4 & 2 & 6 & 238 & 13,94293795 & 26,00 & 2 & 3 & 5 \\
\hline 981 & 12,99426292 & 26,55 & 3 & 3 & 6 & 252 & 12,50767646 & 20,41 & 3 & 2 & 5 \\
\hline 992 & 13,73303167 & 37,64 & 2 & 4 & 6 & 268 & 14,61710754 & 40,67 & 1 & 4 & 5 \\
\hline 167 & 13,36424048 & 31,56 & 2 & 3 & 5 & 270 & 14,75061746 & 39,81 & 1 & 4 & 5 \\
\hline 175 & 13,87639285 & 30,37 & 2 & 3 & 5 & 274 & 13,7806653 & 26,50 & 2 & 3 & 5 \\
\hline
\end{tabular}




\begin{tabular}{|c|c|c|c|c|c|c|c|c|c|c|c|}
\hline $\begin{array}{c}\text { ZATs } \\
\text { PUCAB } \\
\text { NOMj }\end{array}$ & $P j(t)$ & $\mathrm{Aj}(\%)$ & peso_Pj & peso_Aj & soma & $\begin{array}{c}\text { ZATs } \\
\text { PUCAB } \\
\text { NOMj }\end{array}$ & $\operatorname{Pj}(t)$ & $\mathrm{Aj}(\%)$ & peso_Pj & peso_Aj & soma \\
\hline 276 & 14,36966346 & 35,77 & 1 & 4 & 5 & 342 & 14,73346873 & 37,45 & 1 & 4 & 5 \\
\hline 277 & 14,17283044 & 41,03 & 1 & 4 & 5 & 343 & 14,60953216 & 40,02 & 1 & 4 & 5 \\
\hline 279 & 14,15213414 & 37,78 & 1 & 4 & 5 & 344 & 14,04060846 & 37,54 & 1 & 4 & 5 \\
\hline 280 & 14,60010204 & 39,56 & 1 & 4 & 5 & 345 & 14,14960525 & 37,22 & 1 & 4 & 5 \\
\hline 282 & 13,24118055 & 27,23 & 2 & 3 & 5 & 346 & 14,93657574 & 36,74 & 1 & 4 & 5 \\
\hline 283 & 13,30301912 & 34,14 & 2 & 3 & 5 & 347 & 13,98073425 & 28,35 & 2 & 3 & 5 \\
\hline 285 & 14,3077073 & 37,73 & 1 & 4 & 5 & 348 & 13,60021471 & 30,25 & 2 & 3 & 5 \\
\hline 286 & 13,25844826 & 33,89 & 2 & 3 & 5 & 349 & 13,58734566 & 28,35 & 2 & 3 & 5 \\
\hline 288 & 13,88948828 & 33,34 & 2 & 3 & 5 & 350 & 13,85957627 & 29,11 & 2 & 3 & 5 \\
\hline 289 & 14,18609375 & 44,85 & 1 & 4 & 5 & 351 & 13,67274145 & 31,61 & 2 & 3 & 5 \\
\hline 291 & 14,02669998 & 37,44 & 1 & 4 & 5 & 352 & 13,60830924 & 30,12 & 2 & 3 & 5 \\
\hline 294 & 14,10708529 & 39,56 & 1 & 4 & 5 & 355 & 13,74826813 & 31,97 & 2 & 3 & 5 \\
\hline 295 & 13,84561685 & 29,38 & 2 & 3 & 5 & 356 & 13,32732142 & 34,47 & 2 & 3 & 5 \\
\hline 298 & 14,155 & 35,28 & 1 & 4 & 5 & 358 & 14,11299999 & 38,82 & 1 & 4 & 5 \\
\hline 300 & 13,67814453 & 27,35 & 2 & 3 & 5 & 359 & 13,29758168 & 28,96 & 2 & 3 & 5 \\
\hline 311 & 11,40805556 & 5,04 & 4 & 1 & 5 & 360 & 14,19747673 & 42,33 & 1 & 4 & 5 \\
\hline 313 & 11,98356245 & 7,56 & 4 & 1 & 5 & 362 & 13,49335714 & 28,40 & 2 & 3 & 5 \\
\hline 332 & 13,9475289 & 34,03 & 2 & 3 & 5 & 365 & 14,12098379 & 40,90 & 1 & 4 & 5 \\
\hline 333 & 14,18102161 & 40,82 & 1 & 4 & 5 & 369 & 13,61134714 & 32,82 & 2 & 3 & 5 \\
\hline 334 & 14,22572331 & 39,34 & 1 & 4 & 5 & 373 & 13,13870369 & 28,08 & 2 & 3 & 5 \\
\hline
\end{tabular}




\begin{tabular}{|c|c|c|c|c|c|c|c|c|c|c|c|}
\hline $\begin{array}{c}\text { ZATs } \\
\text { PUCAB } \\
\text { NOMj }\end{array}$ & $\operatorname{Pj}(t)$ & $\mathrm{Aj}(\%)$ & peso_Pj & peso_Aj & soma & $\begin{array}{c}\text { ZATs } \\
\text { PUCAB } \\
\text { NOMj }\end{array}$ & $\operatorname{Pj}(t)$ & $\mathrm{Aj}(\%)$ & peso_Pj & peso_Aj & soma \\
\hline 374 & 13,03481481 & 27,03 & 2 & 3 & 5 & 454 & 13,57202153 & 27,14 & 2 & 3 & 5 \\
\hline 375 & 13,6954212 & 34,65 & 2 & 3 & 5 & 457 & 13,26627879 & 28,64 & 2 & 3 & 5 \\
\hline 377 & 12,39364813 & 18,63 & 3 & 2 & 5 & 458 & 13,31073979 & 25,94 & 2 & 3 & 5 \\
\hline 380 & 13,2865309 & 32,55 & 2 & 3 & 5 & 459 & 13,26021126 & 29,34 & 2 & 3 & 5 \\
\hline 381 & 13,37010204 & 31,87 & 2 & 3 & 5 & 461 & 13,33902027 & 32,15 & 2 & 3 & 5 \\
\hline 384 & 13,56002975 & 31,07 & 2 & 3 & 5 & 465 & 13,2298549 & 30,27 & 2 & 3 & 5 \\
\hline 385 & 13,48871469 & 29,71 & 2 & 3 & 5 & 468 & 12,23484285 & 18,11 & 3 & 2 & 5 \\
\hline 386 & 13,74577939 & 27,65 & 2 & 3 & 5 & 469 & 12,12341132 & 20,03 & 3 & 2 & 5 \\
\hline 400 & 11,36427632 & 7,51 & 4 & 1 & 5 & 470 & 11,69270071 & 14,00 & 4 & 1 & 5 \\
\hline 403 & 11,63116667 & 5,41 & 4 & 1 & 5 & 471 & 12,66796472 & 17,57 & 3 & 2 & 5 \\
\hline 421 & 13,54721695 & 25,70 & 2 & 3 & 5 & 480 & 12,90411361 & 22,23 & 3 & 2 & 5 \\
\hline 422 & 13,60631646 & 26,69 & 2 & 3 & 5 & 488 & 13,54552702 & 25,81 & 2 & 3 & 5 \\
\hline 426 & 12,61993195 & 17,17 & 3 & 2 & 5 & 489 & 12,24010867 & 18,60 & 3 & 2 & 5 \\
\hline 427 & 12,37061148 & 16,36 & 3 & 2 & 5 & 490 & 12,22371375 & 18,45 & 3 & 2 & 5 \\
\hline 429 & 13,08654617 & 30,99 & 2 & 3 & 5 & 491 & 12,61281044 & 17,26 & 3 & 2 & 5 \\
\hline 435 & 13,13434474 & 32,98 & 2 & 3 & 5 & 492 & 11,69270071 & 14,02 & 4 & 1 & 5 \\
\hline 436 & 13,126714 & 34,91 & 2 & 3 & 5 & 493 & 11,51574597 & 11,68 & 4 & 1 & 5 \\
\hline 437 & 13,41773436 & 28,45 & 2 & 3 & 5 & 494 & 12,1236212 & 16,86 & 3 & 2 & 5 \\
\hline 438 & 13,55288546 & 30,85 & 2 & 3 & 5 & 498 & 12,11373579 & 17,59 & 3 & 2 & 5 \\
\hline 441 & 13,24417097 & 30,53 & 2 & 3 & 5 & 499 & 12,27692485 & 24,97 & 3 & 2 & 5 \\
\hline
\end{tabular}




\begin{tabular}{|c|c|c|c|c|c|c|c|c|c|c|c|}
\hline $\begin{array}{c}\text { ZATs } \\
\text { PUCAB } \\
\text { NOMj }\end{array}$ & $P j(t)$ & $\mathrm{Aj}(\%)$ & peso_Pj & peso_Aj & soma & $\begin{array}{c}\text { ZATs } \\
\text { PUCAB } \\
\text { NOMj }\end{array}$ & $\operatorname{Pj}(t)$ & $\mathrm{Aj}(\%)$ & peso_Pj & peso_Aj & soma \\
\hline 502 & 13,42087685 & 26,72 & 2 & 3 & 5 & 596 & 11,6867657 & 11,03 & 4 & 1 & 5 \\
\hline 503 & 13,29138886 & 30,13 & 2 & 3 & 5 & 597 & 12,10058656 & 21,17 & 3 & 2 & 5 \\
\hline 504 & 13,54244505 & 30,82 & 2 & 3 & 5 & 599 & 11,46592653 & 11,26 & 4 & 1 & 5 \\
\hline 506 & 13,48090995 & 33,90 & 2 & 3 & 5 & 600 & 11,44716415 & 10,06 & 4 & 1 & 5 \\
\hline 510 & 12,41961864 & 17,82 & 3 & 2 & 5 & 601 & 11,67360541 & 11,17 & 4 & 1 & 5 \\
\hline 513 & 12,43048386 & 19,75 & 3 & 2 & 5 & 602 & 11,53602822 & 12,16 & 4 & 1 & 5 \\
\hline 515 & 12,65007462 & 19,57 & 3 & 2 & 5 & 613 & 13,20253891 & 26,08 & 2 & 3 & 5 \\
\hline 518 & 13,62493859 & 34,65 & 2 & 3 & 5 & 615 & 11,23816326 & 12,36 & 4 & 1 & 5 \\
\hline 574 & 12,79872824 & 24,32 & 3 & 2 & 5 & 616 & 11,98706728 & 13,50 & 4 & 1 & 5 \\
\hline 575 & 13,19157472 & 33,04 & 2 & 3 & 5 & 617 & 11,81737863 & 13,44 & 4 & 1 & 5 \\
\hline 576 & 12,95021926 & 20,37 & 3 & 2 & 5 & 631 & 11,3473875 & 11,81 & 4 & 1 & 5 \\
\hline 577 & 12,2145168 & 15,30 & 3 & 2 & 5 & 632 & 12,12160087 & 19,95 & 3 & 2 & 5 \\
\hline 579 & 13,08615104 & 31,71 & 2 & 3 & 5 & 633 & 12,87029998 & 20,20 & 3 & 2 & 5 \\
\hline 580 & 13,22200729 & 31,16 & 2 & 3 & 5 & 843 & 13,68767856 & 26,25 & 2 & 3 & 5 \\
\hline 582 & 13,8289341 & 30,49 & 2 & 3 & 5 & 845 & 14,91194276 & 37,82 & 1 & 4 & 5 \\
\hline 583 & 12,32222467 & 16,81 & 3 & 2 & 5 & 846 & 14,09798077 & 40,92 & 1 & 4 & 5 \\
\hline 584 & 12,33815555 & 15,37 & 3 & 2 & 5 & 952 & 14,25560712 & 41,04 & 1 & 4 & 5 \\
\hline 586 & 12,60578193 & 19,25 & 3 & 2 & 5 & 967 & 11,92522057 & 8,98 & 4 & 1 & 5 \\
\hline 587 & 12,9493307 & 23,24 & 3 & 2 & 5 & 968 & 11,39551366 & 11,57 & 4 & 1 & 5 \\
\hline 595 & 12,04062849 & 19,51 & 3 & 2 & 5 & 969 & 11,28220483 & 13,21 & 4 & 1 & 5 \\
\hline
\end{tabular}




\begin{tabular}{|c|c|c|c|c|c|c|c|c|c|c|c|}
\hline $\begin{array}{c}\text { ZATs } \\
\text { PUCAB } \\
\text { NOMj }\end{array}$ & $P j(t)$ & $\mathrm{Aj}(\%)$ & peso_Pj & peso_Aj & soma & $\begin{array}{c}\text { ZATs } \\
\text { PUCAB } \\
\text { NOMj }\end{array}$ & $\operatorname{Pj}(t)$ & $\mathrm{Aj}(\%)$ & peso_Pj & peso_Aj & soma \\
\hline 982 & 12,92506996 & 22,97 & 3 & 2 & 5 & 255 & 13,28886598 & 22,82 & 2 & 2 & 4 \\
\hline 984 & 13,26459853 & 31,02 & 2 & 3 & 5 & 267 & 14,36827054 & 29,69 & 1 & 3 & 4 \\
\hline 985 & 13,34234488 & 31,13 & 2 & 3 & 5 & 269 & 14,72235915 & 32,21 & 1 & 3 & 4 \\
\hline 986 & 13,22973075 & 30,25 & 2 & 3 & 5 & 271 & 15,18566792 & 34,62 & 1 & 3 & 4 \\
\hline 987 & 11,93534756 & 10,94 & 4 & 1 & 5 & 272 & 14,13442164 & 33,31 & 1 & 3 & 4 \\
\hline 991 & 13,7803859 & 31,76 & 2 & 3 & 5 & 273 & 14,0901736 & 31,17 & 1 & 3 & 4 \\
\hline 182 & 12,89926281 & 12,11 & 3 & 1 & 4 & 275 & 14,0620709 & 27,76 & 1 & 3 & 4 \\
\hline 183 & 13,64404638 & 16,72 & 2 & 2 & 4 & 278 & 14,20164669 & 34,60 & 1 & 3 & 4 \\
\hline 186 & 13,96705724 & 17,68 & 2 & 2 & 4 & 281 & 14,63275166 & 28,68 & 1 & 3 & 4 \\
\hline 202 & 12,8088988 & 14,37 & 3 & 1 & 4 & 284 & 14,25622222 & 33,13 & 1 & 3 & 4 \\
\hline 212 & 12,95496792 & 12,29 & 3 & 1 & 4 & 287 & 13,09034782 & 22,39 & 2 & 2 & 4 \\
\hline 216 & 13,14504348 & 21,50 & 2 & 2 & 4 & 290 & 14,42048779 & 29,11 & 1 & 3 & 4 \\
\hline 219 & 13,87143836 & 23,68 & 2 & 2 & 4 & 292 & 14,10803459 & 25,64 & 1 & 3 & 4 \\
\hline 230 & 13,50404545 & 21,92 & 2 & 2 & 4 & 293 & 14,16503085 & 27,46 & 1 & 3 & 4 \\
\hline 235 & 14,57951257 & 31,34 & 1 & 3 & 4 & 299 & 14,25160303 & 27,63 & 1 & 3 & 4 \\
\hline 236 & 13,72441174 & 23,83 & 2 & 2 & 4 & 302 & 13,08614913 & 23,49 & 2 & 2 & 4 \\
\hline 240 & 14,27239527 & 34,87 & 1 & 3 & 4 & 303 & 12,89391026 & 13,18 & 3 & 1 & 4 \\
\hline 250 & 13,66322368 & 22,05 & 2 & 2 & 4 & 315 & 12,19527025 & 7,27 & 3 & 1 & 4 \\
\hline 253 & 13,25130629 & 21,56 & 2 & 2 & 4 & 320 & 13,81779997 & 20,87 & 2 & 2 & 4 \\
\hline 254 & 14,19709626 & 29,45 & 1 & 3 & 4 & 326 & 13,84435344 & 19,12 & 2 & 2 & 4 \\
\hline
\end{tabular}




\begin{tabular}{|c|c|c|c|c|c|c|c|c|c|c|c|}
\hline $\begin{array}{c}\text { ZATs } \\
\text { PUCAB } \\
\text { NOMj }\end{array}$ & $\operatorname{Pj}(t)$ & $\mathrm{Aj}(\%)$ & peso_Pj & peso_Aj & soma & $\begin{array}{c}\text { ZATs } \\
\text { PUCAB } \\
\text { NOMj }\end{array}$ & $P j(t)$ & $\mathrm{Aj}(\%)$ & peso_Pj & peso_Aj & soma \\
\hline 330 & 14,26907985 & 26,60 & 1 & 3 & 4 & 482 & 13,78893473 & 16,57 & 2 & 2 & 4 \\
\hline 331 & 14,00517379 & 33,27 & 1 & 3 & 4 & 484 & 13,77910251 & 16,60 & 2 & 2 & 4 \\
\hline 353 & 13,268866364 & 21,44 & 2 & 2 & 4 & 485 & 13,23892853 & 17,84 & 2 & 2 & 4 \\
\hline 354 & 13,66521959 & 23,71 & 2 & 2 & 4 & 486 & 13,35112284 & 17,84 & 2 & 2 & 4 \\
\hline 366 & 14,08683032 & 32,68 & 1 & 3 & 4 & 487 & 13,23892853 & 17,86 & 2 & 2 & 4 \\
\hline 378 & 13,35703226 & 24,54 & 2 & 2 & 4 & 516 & 13,72867977 & 18,84 & 2 & 2 & 4 \\
\hline 379 & 13,43461409 & 22,67 & 2 & 2 & 4 & 578 & 13,13291664 & 23,99 & 2 & 2 & 4 \\
\hline 383 & 13,12759934 & 20,45 & 2 & 2 & 4 & 581 & 12,69450704 & 14,85 & 3 & 1 & 4 \\
\hline 387 & 13,65470293 & 17,09 & 2 & 2 & 4 & 585 & 12,39248814 & 12,30 & 3 & 1 & 4 \\
\hline 399 & 12,35231699 & 7,03 & 3 & 1 & 4 & 603 & 12,45211538 & 7,62 & 3 & 1 & 4 \\
\hline 428 & 13,0384801 & 23,21 & 2 & 2 & 4 & 605 & 12,48141667 & 7,51 & 3 & 1 & 4 \\
\hline 440 & 14,12321428 & 33,48 & 1 & 3 & 4 & 614 & 12,09313397 & 12,78 & 3 & 1 & 4 \\
\hline 472 & 13,33664244 & 22,17 & 2 & 2 & 4 & 618 & 12,02451819 & 12,75 & 3 & 1 & 4 \\
\hline 473 & 13,79382042 & 19,84 & 2 & 2 & 4 & 634 & 12,26433938 & 12,27 & 3 & 1 & 4 \\
\hline 474 & 13,40475489 & 21,11 & 2 & 2 & 4 & 844 & 14,3947794 & 32,25 & 1 & 3 & 4 \\
\hline 475 & 13,7118524 & 20,82 & 2 & 2 & 4 & 965 & 13,90585766 & 16,01 & 2 & 2 & 4 \\
\hline 477 & 13,54031249 & 22,48 & 2 & 2 & 4 & 983 & 12,38049527 & 13,09 & 3 & 1 & 4 \\
\hline 478 & 13,02249997 & 22,22 & 2 & 2 & 4 & 993 & 14,28013613 & 33,05 & 1 & 3 & 4 \\
\hline 479 & 13,02249997 & 22,22 & 2 & 2 & 4 & 996 & 13,86528645 & 15,17 & 2 & 2 & 4 \\
\hline 481 & 13,59970582 & 15,00 & 2 & 2 & 4 & 997 & 13,51093749 & 22,51 & 2 & 2 & 4 \\
\hline
\end{tabular}




\begin{tabular}{|c|c|c|c|c|c|c|c|c|c|c|c|}
\hline $\begin{array}{c}\text { ZATs } \\
\text { PUCAB } \\
\text { NOMj }\end{array}$ & $\operatorname{Pj}(t)$ & $\mathrm{Aj}(\%)$ & peso_Pj & peso_Aj & soma & $\begin{array}{c}\text { ZATs } \\
\text { PUCAB } \\
\text { NOMj }\end{array}$ & $P j(t)$ & $\mathrm{Aj}(\%)$ & peso_Pj & peso_Aj & soma \\
\hline 179 & 14,02148436 & 22,13 & 1 & 2 & 3 & 314 & 13,26314815 & 10,56 & 2 & 1 & 3 \\
\hline 185 & 14,06488528 & 19,20 & 1 & 2 & 3 & 316 & 13,23343137 & 8,68 & 2 & 1 & 3 \\
\hline 199 & 13,89605258 & 13,31 & 2 & 1 & 3 & 318 & 13,37706081 & 14,44 & 2 & 1 & 3 \\
\hline 200 & 13,39317564 & 12,94 & 2 & 1 & 3 & 319 & 14,80435714 & 24,95 & 1 & 2 & 3 \\
\hline 201 & 13,34097454 & 10,88 & 2 & 1 & 3 & 321 & 13,12454858 & 14,96 & 2 & 1 & 3 \\
\hline 203 & 13,19742184 & 10,55 & 2 & 1 & 3 & 322 & 13,58450548 & 14,93 & 2 & 1 & 3 \\
\hline 205 & 13,02709091 & 9,02 & 2 & 1 & 3 & 323 & 13,61824404 & 13,80 & 2 & 1 & 3 \\
\hline 206 & 13,98533328 & 8,97 & 2 & 1 & 3 & 325 & 14,0861215 & 17,10 & 1 & 2 & 3 \\
\hline 207 & 13,83727612 & 9,96 & 2 & 1 & 3 & 382 & 14,13290697 & 15,44 & 1 & 2 & 3 \\
\hline 208 & 13,07678081 & 10,45 & 2 & 1 & 3 & 397 & 13,84619792 & 8,65 & 2 & 1 & 3 \\
\hline 209 & 13,98323075 & 9,39 & 2 & 1 & 3 & 424 & 13,94713815 & 13,85 & 2 & 1 & 3 \\
\hline 211 & 13,14390408 & 12,35 & 2 & 1 & 3 & 425 & 13,61329031 & 14,56 & 2 & 1 & 3 \\
\hline 213 & 13,48101563 & 11,22 & 2 & 1 & 3 & 455 & 14,28198224 & 20,09 & 1 & 2 & 3 \\
\hline 214 & 13,09760563 & 13,02 & 2 & 1 & 3 & 456 & 14,05466666 & 20,16 & 1 & 2 & 3 \\
\hline 239 & 14,25776515 & 24,63 & 1 & 2 & 3 & 476 & 14,11542339 & 21,56 & 1 & 2 & 3 \\
\hline 249 & 14,19971051 & 17,43 & 1 & 2 & 3 & 483 & 13,59970582 & 14,99 & 2 & 1 & 3 \\
\hline 251 & 14,14580433 & 22,90 & 1 & 2 & 3 & 519 & 13,656402 & 13,05 & 2 & 1 & 3 \\
\hline 266 & 14,19123784 & 23,34 & 1 & 2 & 3 & 841 & 13,265875 & 11,16 & 2 & 1 & 3 \\
\hline 296 & 14,17083333 & 15,27 & 1 & 2 & 3 & 842 & 13,00302468 & 13,57 & 2 & 1 & 3 \\
\hline 301 & 14,31232142 & 20,69 & 1 & 2 & 3 & 848 & 14,01110685 & 20,52 & 1 & 2 & 3 \\
\hline
\end{tabular}




\begin{tabular}{|c|c|c|c|c|c|c|c|c|c|c|c|}
\hline $\begin{array}{l}\text { ZATs } \\
\text { PUCAB } \\
\text { NOMj }\end{array}$ & $\operatorname{Pj}(t)$ & $\mathrm{Aj}(\%)$ & peso_Pj & peso_Aj & soma & $\begin{array}{l}\text { ZATs } \\
\text { PUCAB } \\
\text { NOMj }\end{array}$ & $P j(t)$ & $\mathrm{Aj}(\%)$ & peso_Pj & peso_Aj & soma \\
\hline 951 & 14,11646872 & 20,79 & 1 & 2 & 3 & & & & & & \\
\hline 954 & 13,22499996 & 10,97 & 2 & 1 & 3 & & & & & & \\
\hline 955 & 13,68293602 & 13,41 & 2 & 1 & 3 & & & & & & \\
\hline 988 & 13,99329041 & 14,04 & 2 & 1 & 3 & & & & & & \\
\hline 204 & 14,87596154 & 10,83 & 1 & 1 & 2 & & & & & & \\
\hline 210 & 14,32417967 & 9,76 & 1 & 1 & 2 & & & & & & \\
\hline 297 & 14,06170729 & 12,38 & 1 & 1 & 2 & & & & & & \\
\hline 317 & 14,82297295 & 12,83 & 1 & 1 & 2 & & & & & & \\
\hline 324 & 14,05467391 & 14,83 & 1 & 1 & 2 & & & & & & \\
\hline 388 & 14,25454817 & 14,62 & 1 & 1 & 2 & & & & & & \\
\hline 420 & 14,39224226 & 12,46 & 1 & 1 & 2 & & & & & & \\
\hline 423 & 14,47144365 & 12,21 & 1 & 1 & 2 & & & & & & \\
\hline 953 & 14,55618586 & 12,88 & 1 & 1 & 2 & & & & & & \\
\hline
\end{tabular}


- Ranking ZAT de adensamento par percursos lar-trabalho-lar de até 30 minutos. .

\section{-30 minutos.}

\begin{tabular}{|c|c|c|c|c|c|c|c|c|c|c|c|}
\hline $\begin{array}{c}\text { ZATs } \\
\text { PUCAB } \\
\text { NOMj }\end{array}$ & $\operatorname{Pj}(t)$ & $\mathrm{Aj}(\%)$ & peso_Pj & peso_Aj & soma & $\begin{array}{c}\text { ZATs } \\
\text { PUCAB } \\
\text { NOMj }\end{array}$ & $\operatorname{Pj}(t)$ & $\mathrm{Aj}(\%)$ & peso_Pj & peso_Aj & soma \\
\hline 501 & 16,75577381 & 60,37 & 5 & 5 & 10 & 173 & 18,45445401 & 74,69 & 3 & 5 & 8 \\
\hline 433 & 17,51951464 & 78,75 & 4 & 5 & 9 & 223 & 18,47357142 & 70,36 & 3 & 5 & 8 \\
\hline 443 & 17,62553062 & 63,44 & 4 & 5 & 9 & 224 & 18,6371225 & 61,58 & 3 & 5 & 8 \\
\hline 444 & 17,37767817 & 65,81 & 4 & 5 & 9 & 286 & 18,99139727 & 60,47 & 3 & 5 & 8 \\
\hline 445 & 17,49785087 & 70,79 & 4 & 5 & 9 & 336 & 18,34621782 & 74,42 & 3 & 5 & 8 \\
\hline 446 & 17,251841 & 66,55 & 4 & 5 & 9 & 337 & 18,40610395 & 74,42 & 3 & 5 & 8 \\
\hline 447 & 17,23883474 & 65,05 & 4 & 5 & 9 & 338 & 18,35359917 & 73,37 & 3 & 5 & 8 \\
\hline 448 & 17,12116596 & 65,83 & 4 & 5 & 9 & 340 & 18,90458038 & 65,77 & 3 & 5 & 8 \\
\hline 449 & 17,09509413 & 66,10 & 4 & 5 & 9 & 364 & 18,69703785 & 71,54 & 3 & 5 & 8 \\
\hline 450 & 17,11812631 & 65,38 & 4 & 5 & 9 & 367 & 18,92389864 & 60,35 & 3 & 5 & 8 \\
\hline 451 & 17,66702687 & 64,52 & 4 & 5 & 9 & 370 & 18,14243841 & 65,07 & 3 & 5 & 8 \\
\hline 452 & 17,7459728 & 65,51 & 4 & 5 & 9 & 395 & 18,4547519 & 60,86 & 3 & 5 & 8 \\
\hline 505 & 17,97752614 & 67,26 & 4 & 5 & 9 & 429 & 18,65564049 & 66,22 & 3 & 5 & 8 \\
\hline 511 & 17,84792173 & 62,42 & 4 & 5 & 9 & 430 & 18,73839999 & 69,65 & 3 & 5 & 8 \\
\hline 579 & 17,87377098 & 61,63 & 4 & 5 & 9 & 431 & 18,91508981 & 71,16 & 3 & 5 & 8 \\
\hline 169 & 18,96180813 & 73,64 & 3 & 5 & 8 & 432 & 18,66877716 & 69,35 & 3 & 5 & 8 \\
\hline 170 & 18,69141025 & 69,81 & 3 & 5 & 8 & 434 & 18,94479481 & 67,38 & 3 & 5 & 8 \\
\hline
\end{tabular}




\begin{tabular}{|c|c|c|c|c|c|c|c|c|c|c|c|}
\hline $\begin{array}{c}\text { ZATs } \\
\text { PUCAB } \\
\text { NOMj }\end{array}$ & $P j(t)$ & $\mathrm{Aj}(\%)$ & peso_Pj & peso_Aj & soma & $\begin{array}{c}\text { ZATs } \\
\text { PUCAB } \\
\text { NOMj }\end{array}$ & $P j(t)$ & $\mathrm{Aj}(\%)$ & peso_Pj & peso_Aj & soma \\
\hline 435 & 18,67478768 & 66,32 & 3 & 5 & 8 & 589 & 17,06178254 & 58,25 & 4 & 4 & 8 \\
\hline 436 & 18,40292267 & 68,12 & 3 & 5 & 8 & 590 & 17,17514018 & 55,86 & 4 & 4 & 8 \\
\hline 439 & 18,9737095 & 67,44 & 3 & 5 & 8 & 591 & 17,517845 & 58,68 & 4 & 4 & 8 \\
\hline 442 & 18,41562764 & 66,00 & 3 & 5 & 8 & 592 & 17,88069999 & 50,32 & 4 & 4 & 8 \\
\hline 453 & 18,29191017 & 65,89 & 3 & 5 & 8 & 612 & 17,38637731 & 52,41 & 4 & 4 & 8 \\
\hline 463 & 17,91013358 & 53,21 & 4 & 4 & 8 & 613 & 17,63903846 & 51,53 & 4 & 4 & 8 \\
\hline 502 & 17,41882812 & 52,56 & 4 & 4 & 8 & 846 & 18,93953552 & 65,01 & 3 & 5 & 8 \\
\hline 503 & 18,52181911 & 66,10 & 3 & 5 & 8 & 981 & 17,6394107 & 51,79 & 4 & 4 & 8 \\
\hline 504 & 18,20206568 & 65,04 & 3 & 5 & 8 & 982 & 17,68973589 & 50,75 & 4 & 4 & 8 \\
\hline 506 & 18,35609442 & 66,65 & 3 & 5 & 8 & 984 & 18,15526595 & 63,45 & 3 & 5 & 8 \\
\hline 507 & 18,6831968 & 67,41 & 3 & 5 & 8 & 985 & 18,17091738 & 62,97 & 3 & 5 & 8 \\
\hline 508 & 18,31975673 & 68,30 & 3 & 5 & 8 & 986 & 18,5527221 & 66,94 & 3 & 5 & 8 \\
\hline 509 & 18,38114164 & 64,73 & 3 & 5 & 8 & 167 & 19,65549702 & 60,44 & 2 & 5 & 7 \\
\hline 514 & 18,28315985 & 60,70 & 3 & 5 & 8 & 168 & 19,20618562 & 65,55 & 2 & 5 & 7 \\
\hline 517 & 17,85011563 & 55,56 & 4 & 4 & 8 & 171 & 19,07272725 & 66,54 & 2 & 5 & 7 \\
\hline 518 & 18,25667525 & 68,21 & 3 & 5 & 8 & 172 & 19,40124999 & 67,76 & 2 & 5 & 7 \\
\hline 575 & 17,94446936 & 56,53 & 4 & 4 & 8 & 174 & 19,21107234 & 69,90 & 2 & 5 & 7 \\
\hline 580 & 18,1353518 & 63,42 & 3 & 5 & 8 & 176 & 19,88436756 & 63,85 & 2 & 5 & 7 \\
\hline 582 & 18,72450749 & 65,19 & 3 & 5 & 8 & 220 & 19,09995 & 70,01 & 2 & 5 & 7 \\
\hline 588 & 17,29969169 & 58,01 & 4 & 4 & 8 & 221 & 19,99335194 & 62,44 & 2 & 5 & 7 \\
\hline
\end{tabular}




\begin{tabular}{|c|c|c|c|c|c|c|c|c|c|c|c|}
\hline $\begin{array}{c}\text { ZATs } \\
\text { PUCAB } \\
\text { NOMj }\end{array}$ & $\operatorname{Pj}(t)$ & $\mathrm{Aj}(\%)$ & peso_Pj & peso_Aj & soma & $\begin{array}{c}\text { ZATs } \\
\text { PUCAB } \\
\text { NOMj }\end{array}$ & $\operatorname{Pj}(t)$ & $A j(\%)$ & peso_Pj & peso_Aj & soma \\
\hline 222 & 19,60086035 & 69,23 & 2 & 5 & 7 & 360 & 19,5044904 & 66,26 & 2 & 5 & 7 \\
\hline 225 & 19,70257537 & 66,07 & 2 & 5 & 7 & 363 & 19,47373821 & 67,26 & 2 & 5 & 7 \\
\hline 226 & 19,45271262 & 65,41 & 2 & 5 & 7 & 365 & 19,55320938 & 70,08 & 2 & 5 & 7 \\
\hline 228 & 19,27248674 & 66,71 & 2 & 5 & 7 & 368 & 19,0356922 & 60,42 & 2 & 5 & 7 \\
\hline 279 & 19,56050486 & 64,18 & 2 & 5 & 7 & 369 & 19,29892856 & 60,93 & 2 & 5 & 7 \\
\hline 283 & 19,02657713 & 65,58 & 2 & 5 & 7 & 371 & 19,09497209 & 69,80 & 2 & 5 & 7 \\
\hline 285 & 19,27818298 & 63,62 & 2 & 5 & 7 & 381 & 18,80966438 & 55,50 & 3 & 4 & 7 \\
\hline 288 & 19,90722778 & 60,38 & 2 & 5 & 7 & 437 & 18,19452054 & 58,83 & 3 & 4 & 7 \\
\hline 289 & 19,00902174 & 70,88 & 2 & 5 & 7 & 438 & 19,24071188 & 61,60 & 2 & 5 & 7 \\
\hline 291 & 19,76643646 & 63,57 & 2 & 5 & 7 & 440 & 19,35030678 & 60,39 & 2 & 5 & 7 \\
\hline 294 & 19,81853006 & 73,12 & 2 & 5 & 7 & 441 & 18,44202585 & 56,49 & 3 & 4 & 7 \\
\hline 327 & 19,88771396 & 71,87 & 2 & 5 & 7 & 454 & 18,67336957 & 52,65 & 3 & 4 & 7 \\
\hline 329 & 18,79052205 & 55,51 & 3 & 4 & 7 & 457 & 18,38909438 & 52,33 & 3 & 4 & 7 \\
\hline 331 & 19,97147201 & 66,94 & 2 & 5 & 7 & 459 & 18,59275561 & 55,16 & 3 & 4 & 7 \\
\hline 333 & 19,94343048 & 72,30 & 2 & 5 & 7 & 460 & 18,47615752 & 58,04 & 3 & 4 & 7 \\
\hline 334 & 19,46144055 & 62,30 & 2 & 5 & 7 & 461 & 18,7845613 & 58,00 & 3 & 4 & 7 \\
\hline 335 & 19,00264413 & 73,04 & 2 & 5 & 7 & 462 & 18,10498036 & 52,37 & 3 & 4 & 7 \\
\hline 339 & 19,18188972 & 70,46 & 2 & 5 & 7 & 464 & 18,033444 & 52,16 & 3 & 4 & 7 \\
\hline 344 & 19,82787688 & 61,40 & 2 & 5 & 7 & 465 & 18,3582228 & 52,53 & 3 & 4 & 7 \\
\hline 358 & 19,44296319 & 62,08 & 2 & 5 & 7 & 466 & 17,37794386 & 48,22 & 4 & 3 & 7 \\
\hline
\end{tabular}




\begin{tabular}{|c|c|c|c|c|c|c|c|c|c|c|c|}
\hline $\begin{array}{c}\text { ZATs } \\
\text { PUCAB } \\
\text { NOMj }\end{array}$ & $P j(t)$ & $\mathrm{Aj}(\%)$ & peso_Pj & peso_Aj & soma & $\begin{array}{c}\text { ZATs } \\
\text { PUCAB } \\
\text { NOMj }\end{array}$ & $\operatorname{Pj}(t)$ & $\mathrm{Aj}(\%)$ & peso_Pj & peso_Aj & soma \\
\hline 467 & 17,25222512 & 48,16 & 4 & 3 & 7 & 952 & 19,5517597 & 66,39 & 2 & 5 & 7 \\
\hline 496 & 17,93806748 & 43,32 & 4 & 3 & 7 & 971 & 17,35556685 & 42,91 & 4 & 3 & 7 \\
\hline 497 & 17,57419909 & 43,68 & 4 & 3 & 7 & 975 & 17,33763264 & 44,65 & 4 & 3 & 7 \\
\hline 500 & 18,08130513 & 53,55 & 3 & 4 & 7 & 992 & 19,62344091 & 62,92 & 2 & 5 & 7 \\
\hline 512 & 18,15737233 & 56,20 & 3 & 4 & 7 & 175 & 19,99246688 & 56,99 & 2 & 4 & 6 \\
\hline 539 & 18,33548997 & 54,71 & 3 & 4 & 7 & 180 & 19,9411574 & 50,90 & 2 & 4 & 6 \\
\hline 574 & 18,40680973 & 52,03 & 3 & 4 & 7 & 181 & 19,94057765 & 51,22 & 2 & 4 & 6 \\
\hline 578 & 18,21344638 & 56,19 & 3 & 4 & 7 & 217 & 19,71889423 & 59,96 & 2 & 4 & 6 \\
\hline 583 & 17,03464092 & 40,85 & 4 & 3 & 7 & 219 & 19,85143312 & 54,78 & 2 & 4 & 6 \\
\hline 584 & 17,25067204 & 40,89 & 4 & 3 & 7 & 227 & 20,39415137 & 60,51 & 1 & 5 & 6 \\
\hline 586 & 17,894914 & 48,11 & 4 & 3 & 7 & 229 & 19,62704063 & 56,85 & 2 & 4 & 6 \\
\hline 587 & 17,54055555 & 48,81 & 4 & 3 & 7 & 231 & 19,71495113 & 56,33 & 2 & 4 & 6 \\
\hline 593 & 17,60509408 & 47,71 & 4 & 3 & 7 & 232 & 19,03636513 & 54,32 & 2 & 4 & 6 \\
\hline 594 & 17,49314924 & 42,19 & 4 & 3 & 7 & 233 & 19,04348992 & 52,89 & 2 & 4 & 6 \\
\hline 595 & 17,98603975 & 43,53 & 4 & 3 & 7 & 234 & 19,38524691 & 54,29 & 2 & 4 & 6 \\
\hline 597 & 17,03159011 & 41,04 & 4 & 3 & 7 & 235 & 19,98143867 & 54,35 & 2 & 4 & 6 \\
\hline 610 & 17,33763264 & 44,67 & 4 & 3 & 7 & 237 & 19,57357569 & 52,42 & 2 & 4 & 6 \\
\hline 615 & 17,74817763 & 40,95 & 4 & 3 & 7 & 240 & 20,14131674 & 61,41 & 1 & 5 & 6 \\
\hline 631 & 16,55232575 & 31,66 & 5 & 2 & 7 & 268 & 20,34897698 & 63,71 & 1 & 5 & 6 \\
\hline 633 & 17,93146946 & 45,11 & 4 & 3 & 7 & 270 & 20,43820963 & 62,42 & 1 & 5 & 6 \\
\hline
\end{tabular}




\begin{tabular}{|c|c|c|c|c|c|c|c|c|c|c|c|}
\hline $\begin{array}{c}\text { ZATs } \\
\text { PUCAB } \\
\text { NOMj }\end{array}$ & $\operatorname{Pj}(t)$ & $\mathrm{Aj}(\%)$ & peso_Pj & peso_Aj & soma & $\begin{array}{c}\text { ZATs } \\
\text { PUCAB } \\
\text { NOMj }\end{array}$ & $\operatorname{Pj}(t)$ & $\mathbf{A j}(\%)$ & peso_Pj & peso_Aj & soma \\
\hline 276 & 20,43527322 & 62,11 & 1 & 5 & 6 & 355 & 19,87549617 & 57,54 & 2 & 4 & 6 \\
\hline 277 & 20,13295219 & 63,58 & 1 & 5 & 6 & 356 & 19,36114116 & 57,97 & 2 & 4 & 6 \\
\hline 280 & 20,06560644 & 63,95 & 1 & 5 & 6 & 357 & 19,45208552 & 58,10 & 2 & 4 & 6 \\
\hline 282 & 19,82086207 & 56,06 & 2 & 4 & 6 & 359 & 19,46064641 & 52,81 & 2 & 4 & 6 \\
\hline 290 & 20,12619252 & 60,05 & 1 & 5 & 6 & 361 & 19,64615098 & 57,48 & 2 & 4 & 6 \\
\hline 292 & 19,80423423 & 54,91 & 2 & 4 & 6 & 362 & 19,25893372 & 53,71 & 2 & 4 & 6 \\
\hline 293 & 19,93240844 & 57,36 & 2 & 4 & 6 & 366 & 19,88685914 & 58,61 & 2 & 4 & 6 \\
\hline 298 & 20,01661649 & 63,49 & 1 & 5 & 6 & 372 & 19,18831883 & 56,91 & 2 & 4 & 6 \\
\hline 299 & 21,15840908 & 61,40 & 1 & 5 & 6 & 373 & 19,85743093 & 58,14 & 2 & 4 & 6 \\
\hline 300 & 21,1343644 & 60,67 & 1 & 5 & 6 & 374 & 19,69321325 & 55,27 & 2 & 4 & 6 \\
\hline 328 & 19,3456437 & 53,13 & 2 & 4 & 6 & 375 & 19,68416 & 57,50 & 2 & 4 & 6 \\
\hline 332 & 19,7751084 & 59,57 & 2 & 4 & 6 & 376 & 19,14869883 & 52,24 & 2 & 4 & 6 \\
\hline 341 & 20,16615625 & 62,40 & 1 & 5 & 6 & 378 & 19,68906061 & 50,90 & 2 & 4 & 6 \\
\hline 342 & 20,66298593 & 61,10 & 1 & 5 & 6 & 380 & 19,68363821 & 57,42 & 2 & 4 & 6 \\
\hline 343 & 20,23264285 & 60,71 & 1 & 5 & 6 & 384 & 19,94056473 & 56,71 & 2 & 4 & 6 \\
\hline 345 & 19,51536319 & 59,42 & 2 & 4 & 6 & 385 & 19,24262108 & 52,98 & 2 & 4 & 6 \\
\hline 348 & 19,47055881 & 53,84 & 2 & 4 & 6 & 428 & 19,84283078 & 54,18 & 2 & 4 & 6 \\
\hline 349 & 19,90210083 & 53,12 & 2 & 4 & 6 & 458 & 19,14678846 & 51,42 & 2 & 4 & 6 \\
\hline 351 & 19,32072801 & 55,71 & 2 & 4 & 6 & 468 & 18,37038226 & 41,85 & 3 & 3 & 6 \\
\hline 352 & 19,71781165 & 55,24 & 2 & 4 & 6 & 469 & 18,32542666 & 45,97 & 3 & 3 & 6 \\
\hline
\end{tabular}




\begin{tabular}{|c|c|c|c|c|c|c|c|c|c|c|c|}
\hline $\begin{array}{c}\text { ZATs } \\
\text { PUCAB } \\
\text { NOMj }\end{array}$ & $\operatorname{Pj}(t)$ & $\mathrm{Aj}(\%)$ & peso_Pj & peso_Aj & soma & $\begin{array}{c}\text { ZATs } \\
\text { PUCAB } \\
\text { NOMj }\end{array}$ & $\operatorname{Pj}(t)$ & $\mathbf{A j}(\%)$ & peso_Pj & peso_Aj & soma \\
\hline 470 & 17,75920362 & 30,33 & 4 & 2 & 6 & 634 & 17,37128811 & 32,37 & 4 & 2 & 6 \\
\hline 488 & 19,39516578 & 52,97 & 2 & 4 & 6 & 844 & 19,78990972 & 58,97 & 2 & 4 & 6 \\
\hline 490 & 17,897748 & 31,73 & 4 & 2 & 6 & 845 & 20,51793733 & 60,25 & 1 & 5 & 6 \\
\hline 492 & 17,75920362 & 30,35 & 4 & 2 & 6 & 966 & 19,5169027 & 58,36 & 2 & 4 & 6 \\
\hline 494 & 17,85702749 & 38,52 & 4 & 2 & 6 & 983 & 17,41992937 & 34,39 & 4 & 2 & 6 \\
\hline 495 & 17,71513249 & 39,07 & 4 & 2 & 6 & 987 & 17,28072754 & 30,49 & 4 & 2 & 6 \\
\hline 498 & 18,0527709 & 41,75 & 3 & 3 & 6 & 991 & 20,10388728 & 60,08 & 1 & 5 & 6 \\
\hline 499 & 18,13521371 & 49,01 & 3 & 3 & 6 & 993 & 19,84095965 & 57,23 & 2 & 4 & 6 \\
\hline 513 & 18,30199875 & 45,07 & 3 & 3 & 6 & 179 & 20,17567343 & 54,06 & 1 & 4 & 5 \\
\hline 515 & 18,92465686 & 44,26 & 3 & 3 & 6 & 184 & 19,48642592 & 49,33 & 2 & 3 & 5 \\
\hline 576 & 18,67268763 & 47,93 & 3 & 3 & 6 & 185 & 19,92461295 & 44,80 & 2 & 3 & 5 \\
\hline 577 & 18,04025463 & 47,71 & 3 & 3 & 6 & 215 & 19,7820169 & 40,23 & 2 & 3 & 5 \\
\hline 581 & 17,36687857 & 39,03 & 4 & 2 & 6 & 218 & 20,00346438 & 59,35 & 1 & 4 & 5 \\
\hline 585 & 17,41860481 & 33,77 & 4 & 2 & 6 & 230 & 19,74166304 & 47,91 & 2 & 3 & 5 \\
\hline 598 & 16,69727831 & 22,35 & 5 & 1 & 6 & 236 & 19,70472335 & 46,52 & 2 & 3 & 5 \\
\hline 606 & 17,54702381 & 39,60 & 4 & 2 & 6 & 238 & 20,29391509 & 54,97 & 1 & 4 & 5 \\
\hline 614 & 17,25997869 & 32,13 & 4 & 2 & 6 & 239 & 20,46139241 & 51,63 & 1 & 4 & 5 \\
\hline 616 & 17,11435458 & 31,27 & 4 & 2 & 6 & 250 & 20,61286607 & 53,83 & 1 & 4 & 5 \\
\hline 617 & 17,04580357 & 31,80 & 4 & 2 & 6 & 251 & 20,57872641 & 51,47 & 1 & 4 & 5 \\
\hline 632 & 18,06876769 & 47,95 & 3 & 3 & 6 & 253 & 20,01505791 & 50,24 & 1 & 4 & 5 \\
\hline
\end{tabular}




\begin{tabular}{|c|c|c|c|c|c|c|c|c|c|c|c|}
\hline $\begin{array}{c}\text { ZATs } \\
\text { PUCAB } \\
\text { NOMj }\end{array}$ & $P j(t)$ & $\mathrm{Aj}(\%)$ & peso_Pj & peso_Aj & soma & $\begin{array}{c}\text { ZATs } \\
\text { PUCAB } \\
\text { NOMj }\end{array}$ & $P j(t)$ & $\mathrm{Aj}(\%)$ & peso_Pj & peso_Aj & soma \\
\hline 254 & 20,64189373 & 56,94 & 1 & 4 & 5 & 347 & 20,00845611 & 51,61 & 1 & 4 & 5 \\
\hline 255 & 20,43339423 & 52,08 & 1 & 4 & 5 & 350 & 20,30455112 & 58,44 & 1 & 4 & 5 \\
\hline 266 & 21,13116964 & 53,52 & 1 & 4 & 5 & 353 & 20,32549689 & 50,49 & 1 & 4 & 5 \\
\hline 267 & 20,69483711 & 59,23 & 1 & 4 & 5 & 377 & 19,57877022 & 45,69 & 2 & 3 & 5 \\
\hline 269 & 20,79903571 & 58,07 & 1 & 4 & 5 & 379 & 19,84436533 & 48,21 & 2 & 3 & 5 \\
\hline 271 & 21,17992924 & 56,93 & 1 & 4 & 5 & 383 & 19,64283077 & 42,36 & 2 & 3 & 5 \\
\hline 272 & 20,73713557 & 59,15 & 1 & 4 & 5 & 386 & 20,15078628 & 51,73 & 1 & 4 & 5 \\
\hline 273 & 20,39502238 & 58,61 & 1 & 4 & 5 & 421 & 20,2526671 & 50,44 & 1 & 4 & 5 \\
\hline 274 & 20,36454777 & 55,42 & 1 & 4 & 5 & 422 & 19,20854556 & 49,95 & 2 & 3 & 5 \\
\hline 275 & 20,36383028 & 58,78 & 1 & 4 & 5 & 427 & 19,42283495 & 40,36 & 2 & 3 & 5 \\
\hline 278 & 20,18331817 & 58,84 & 1 & 4 & 5 & 455 & 19,79358848 & 47,63 & 2 & 3 & 5 \\
\hline 281 & 20,73716619 & 53,92 & 1 & 4 & 5 & 456 & 19,91367688 & 47,98 & 2 & 3 & 5 \\
\hline 284 & 20,84520773 & 59,65 & 1 & 4 & 5 & 471 & 18,43810525 & 39,26 & 3 & 2 & 5 \\
\hline 287 & 19,62581054 & 49,35 & 2 & 3 & 5 & 472 & 19,52481638 & 47,86 & 2 & 3 & 5 \\
\hline 295 & 20,12758977 & 57,73 & 1 & 4 & 5 & 473 & 19,81548589 & 46,44 & 2 & 3 & 5 \\
\hline 302 & 20,70755399 & 56,44 & 1 & 4 & 5 & 474 & 19,4164373 & 47,13 & 2 & 3 & 5 \\
\hline 319 & 21,78316154 & 56,10 & 1 & 4 & 5 & 475 & 19,39545904 & 48,53 & 2 & 3 & 5 \\
\hline 320 & 21,41163429 & 54,22 & 1 & 4 & 5 & 489 & 18,0881923 & 32,94 & 3 & 2 & 5 \\
\hline 330 & 20,20624218 & 53,31 & 1 & 4 & 5 & 491 & 18,56188379 & 39,23 & 3 & 2 & 5 \\
\hline 346 & 20,45661923 & 59,05 & 1 & 4 & 5 & 493 & 17,76584052 & 26,40 & 4 & 1 & 5 \\
\hline
\end{tabular}




\begin{tabular}{|c|c|c|c|c|c|c|c|c|c|c|c|}
\hline $\begin{array}{c}\text { ZATs } \\
\text { PUCAB } \\
\text { NOMj }\end{array}$ & $\operatorname{Pj}(t)$ & $\mathrm{Aj}(\%)$ & peso_Pj & peso_Aj & soma & $\begin{array}{c}\text { ZATs } \\
\text { PUCAB } \\
\text { NOMj }\end{array}$ & $P j(t)$ & $\mathrm{Aj}(\%)$ & peso_Pj & peso_Aj & soma \\
\hline 510 & 19,46772727 & 46,46 & 2 & 3 & 5 & 297 & 21,02360859 & 40,96 & 1 & 3 & 4 \\
\hline 596 & 17,50348789 & 28,33 & 4 & 1 & 5 & 301 & 21,4248177 & 48,39 & 1 & 3 & 4 \\
\hline 599 & 17,4166064 & 29,47 & 4 & 1 & 5 & 312 & 18,80888157 & 14,19 & 3 & 1 & 4 \\
\hline 600 & 17,71136362 & 26,80 & 4 & 1 & 5 & 326 & 20,37627306 & 42,06 & 1 & 3 & 4 \\
\hline 601 & 17,43663042 & 29,48 & 4 & 1 & 5 & 354 & 20,19687679 & 49,34 & 1 & 3 & 4 \\
\hline 602 & 17,95680379 & 25,56 & 4 & 1 & 5 & 426 & 19,63340342 & 39,35 & 2 & 2 & 4 \\
\hline 618 & 17,7332771 & 28,61 & 4 & 1 & 5 & 476 & 20,53470353 & 47,05 & 1 & 3 & 4 \\
\hline 843 & 21,04722633 & 54,89 & 1 & 4 & 5 & 477 & 20,35666403 & 49,17 & 1 & 3 & 4 \\
\hline 848 & 19,80298871 & 46,06 & 2 & 3 & 5 & 478 & 20,34122548 & 40,93 & 1 & 3 & 4 \\
\hline 951 & 19,49717124 & 42,01 & 2 & 3 & 5 & 479 & 20,34122548 & 40,93 & 1 & 3 & 4 \\
\hline 967 & 17,45648471 & 23,90 & 4 & 1 & 5 & 480 & 20,26176757 & 40,94 & 1 & 3 & 4 \\
\hline 968 & 17,12787447 & 27,43 & 4 & 1 & 5 & 484 & 19,92569547 & 36,12 & 2 & 2 & 4 \\
\hline 969 & 17,33856998 & 29,27 & 4 & 1 & 5 & 485 & 19,38929366 & 38,75 & 2 & 2 & 4 \\
\hline 997 & 19,24156914 & 46,30 & 2 & 3 & 5 & 486 & 19,46164177 & 38,75 & 2 & 2 & 4 \\
\hline 183 & 19,91637019 & 39,15 & 2 & 2 & 4 & 487 & 19,38929366 & 38,76 & 2 & 2 & 4 \\
\hline 202 & 18,92591614 & 26,14 & 3 & 1 & 4 & 516 & 19,50400145 & 38,23 & 2 & 2 & 4 \\
\hline 216 & 20,16366477 & 44,90 & 1 & 3 & 4 & 603 & 18,30881166 & 24,23 & 3 & 1 & 4 \\
\hline 249 & 21,2619305 & 49,31 & 1 & 3 & 4 & 605 & 18,44136261 & 21,09 & 3 & 1 & 4 \\
\hline 252 & 20,21193438 & 46,43 & 1 & 3 & 4 & 841 & 19,0931875 & 30,45 & 2 & 2 & 4 \\
\hline 296 & 21,50151341 & 44,68 & 1 & 3 & 4 & 842 & 19,98298342 & 35,73 & 2 & 2 & 4 \\
\hline
\end{tabular}




\begin{tabular}{|c|c|c|c|c|c|c|c|c|c|c|c|}
\hline $\begin{array}{c}\text { ZATs } \\
\text { PUCAB } \\
\text { NOMj }\end{array}$ & $\operatorname{Pj}(t)$ & $\mathrm{Aj}(\%)$ & peso_Pj & peso_Aj & soma & $\begin{array}{c}\text { ZATs } \\
\text { PUCAB } \\
\text { NOMj }\end{array}$ & $\operatorname{Pj}(t)$ & $\mathbf{A j}(\%)$ & peso_Pj & peso_Aj & soma \\
\hline 965 & 19,83405382 & 36,21 & 2 & 2 & 4 & 325 & 20,41179 & 36,46 & 1 & 2 & 3 \\
\hline 988 & 19,97399474 & 31,23 & 2 & 2 & 4 & 382 & 20,06537366 & 35,69 & 1 & 2 & 3 \\
\hline 996 & 19,86457908 & 31,17 & 2 & 2 & 4 & 387 & 20,85795815 & 34,73 & 1 & 2 & 3 \\
\hline 182 & 19,42424999 & 23,58 & 2 & 1 & 3 & 420 & 21,25757547 & 31,46 & 1 & 2 & 3 \\
\hline 186 & 20,03926615 & 39,49 & 1 & 2 & 3 & 423 & 19,69204063 & 24,12 & 2 & 1 & 3 \\
\hline 199 & 19,44524135 & 25,75 & 2 & 1 & 3 & 424 & 19,45893707 & 25,23 & 2 & 1 & 3 \\
\hline 200 & 19,18149998 & 24,50 & 2 & 1 & 3 & 425 & 19,67229876 & 28,82 & 2 & 1 & 3 \\
\hline 201 & 21,86047871 & 31,58 & 1 & 2 & 3 & 481 & 20,35848657 & 35,28 & 1 & 2 & 3 \\
\hline 203 & 19,68622179 & 19,96 & 2 & 1 & 3 & 482 & 20,00166351 & 36,12 & 1 & 2 & 3 \\
\hline 206 & 19,74818357 & 19,52 & 2 & 1 & 3 & 483 & 20,35848657 & 35,27 & 1 & 2 & 3 \\
\hline 208 & 19,78627358 & 29,62 & 2 & 1 & 3 & 519 & 19,05092333 & 24,80 & 2 & 1 & 3 \\
\hline 211 & 19,82910605 & 26,77 & 2 & 1 & 3 & 955 & 19,00123493 & 22,91 & 2 & 1 & 3 \\
\hline 212 & 19,17939348 & 28,33 & 2 & 1 & 3 & 204 & 20,4625 & 22,02 & 1 & 1 & 2 \\
\hline 213 & 20,43638365 & 31,42 & 1 & 2 & 3 & 205 & 21,26438291 & 25,26 & 1 & 1 & 2 \\
\hline 214 & 20,18106509 & 30,90 & 1 & 2 & 3 & 207 & 20,29934859 & 23,92 & 1 & 1 & 2 \\
\hline 303 & 21,44470528 & 38,12 & 1 & 2 & 3 & 209 & 20,43125827 & 26,49 & 1 & 1 & 2 \\
\hline 318 & 21,18632212 & 33,98 & 1 & 2 & 3 & 210 & 21,01934374 & 26,25 & 1 & 1 & 2 \\
\hline 321 & 20,59924744 & 32,95 & 1 & 2 & 3 & 311 & 20,30646104 & 13,86 & 1 & 1 & 2 \\
\hline 322 & 20,0750651 & 31,26 & 1 & 2 & 3 & 313 & 20,22854367 & 19,17 & 1 & 1 & 2 \\
\hline 323 & 19,36051204 & 23,23 & 2 & 1 & 3 & 314 & 20,32497951 & 23,14 & 1 & 1 & 2 \\
\hline
\end{tabular}




\begin{tabular}{|c|c|c|c|c|c|c|c|c|c|c|c|}
\hline $\begin{array}{l}\text { ZATs } \\
\text { PUCAB } \\
\text { NOMj }\end{array}$ & $\operatorname{Pj}(t)$ & $A j(\%)$ & peso_Pj & peso_Aj & soma & $\begin{array}{l}\text { ZATs } \\
\text { PUCAB } \\
\text { NOMj }\end{array}$ & $\operatorname{Pj}(t)$ & $A j(\%)$ & peso_Pj & peso_Aj & soma \\
\hline 315 & 21,10478971 & 16,67 & 1 & 1 & 2 & & & & & & \\
\hline 316 & 21,61712025 & 27,48 & 1 & 1 & 2 & & & & & & \\
\hline 317 & 20,33958859 & 22,76 & 1 & 1 & 2 & & & & & & \\
\hline 324 & 20,02844221 & 27,50 & 1 & 1 & 2 & & & & & & \\
\hline 388 & 20,01283045 & 26,89 & 1 & 1 & 2 & & & & & & \\
\hline 397 & 21,24925 & 17,82 & 1 & 1 & 2 & & & & & & \\
\hline 399 & 21,07079436 & 17,53 & 1 & 1 & 2 & & & & & & \\
\hline 400 & 20,84045045 & 17,97 & 1 & 1 & 2 & & & & & & \\
\hline 403 & 21,46441011 & 14,73 & 1 & 1 & 2 & & & & & & \\
\hline 953 & 20,69938919 & 23,75 & 1 & 1 & 2 & & & & & & \\
\hline 954 & 20,62889284 & 23,78 & 1 & 1 & 2 & & & & & & \\
\hline
\end{tabular}


- Ranking ZAT de adensamento para percursos lar-trabalho-lar de até 40 minutos.

\section{-40 minutos.}

\begin{tabular}{|c|c|c|c|c|c|c|c|c|c|c|c|}
\hline $\begin{array}{c}\text { ZATs } \\
\text { PUCAB } \\
\text { NOMj }\end{array}$ & $\operatorname{Pj}(t)$ & $\mathrm{Aj}(\%)$ & peso_Pj & peso_Aj & soma & $\begin{array}{c}\text { ZATs } \\
\text { PUCAB } \\
\text { NOMj }\end{array}$ & $\operatorname{Pj}(t)$ & $\mathrm{Aj}(\%)$ & peso_Pj & peso_Aj & soma \\
\hline 433 & 21,31034949 & 92,19 & 5 & 5 & 10 & 589 & 21,53075995 & 80,21 & 5 & 5 & 10 \\
\hline 445 & 20,66014659 & 84,69 & 5 & 5 & 10 & 590 & 21,57714726 & 76,54 & 5 & 5 & 10 \\
\hline 446 & 21,17931451 & 84,38 & 5 & 5 & 10 & 981 & 21,8393058 & 75,26 & 5 & 5 & 10 \\
\hline 447 & 21,6250873 & 85,23 & 5 & 5 & 10 & 982 & 21,8334481 & 75,27 & 5 & 5 & 10 \\
\hline 448 & 21,5013915 & 85,89 & 5 & 5 & 10 & 168 & 23,84217142 & 80,02 & 4 & 5 & 9 \\
\hline 449 & 21,45854231 & 86,20 & 5 & 5 & 10 & 169 & 22,70309821 & 83,89 & 4 & 5 & 9 \\
\hline 450 & 21,43335317 & 84,92 & 5 & 5 & 10 & 170 & 23,99771378 & 85,85 & 4 & 5 & 9 \\
\hline 451 & 21,9186939 & 84,06 & 5 & 5 & 10 & 171 & 23,61281249 & 78,61 & 4 & 5 & 9 \\
\hline 452 & 21,679424 & 81,89 & 5 & 5 & 10 & 173 & 22,82202702 & 87,83 & 4 & 5 & 9 \\
\hline 501 & 21,21734502 & 82,15 & 5 & 5 & 10 & 220 & 23,5041232 & 84,56 & 4 & 5 & 9 \\
\hline 504 & 21,90924267 & 82,42 & 5 & 5 & 10 & 223 & 22,41211824 & 80,72 & 4 & 5 & 9 \\
\hline 511 & 21,63208527 & 83,53 & 5 & 5 & 10 & 224 & 23,66738899 & 79,53 & 4 & 5 & 9 \\
\hline 512 & 21,75302892 & 80,06 & 5 & 5 & 10 & 226 & 23,97263711 & 82,90 & 4 & 5 & 9 \\
\hline 517 & 21,844234 & 79,47 & 5 & 5 & 10 & 285 & 23,97325488 & 78,48 & 4 & 5 & 9 \\
\hline 575 & 21,83609243 & 80,03 & 5 & 5 & 10 & 289 & 23,49070872 & 86,18 & 4 & 5 & 9 \\
\hline 579 & 21,9493425 & 83,45 & 5 & 5 & 10 & 327 & 23,81214108 & 87,95 & 4 & 5 & 9 \\
\hline 588 & 21,58936966 & 78,86 & 5 & 5 & 10 & 335 & 23,15154518 & 90,07 & 4 & 5 & 9 \\
\hline
\end{tabular}




\begin{tabular}{|c|c|c|c|c|c|c|c|c|c|c|c|}
\hline $\begin{array}{c}\text { ZATs } \\
\text { PUCAB } \\
\text { NOMj }\end{array}$ & $\operatorname{Pj}(t)$ & $\mathrm{Aj}(\%)$ & peso_Pj & peso_Aj & soma & $\begin{array}{c}\text { ZATs } \\
\text { PUCAB } \\
\text { NOMj }\end{array}$ & $\operatorname{Pj}(t)$ & $A j(\%)$ & peso_Pj & peso_Aj & soma \\
\hline 336 & 22,70997072 & 89,45 & 4 & 5 & 9 & 439 & 23,17303344 & 85,36 & 4 & 5 & 9 \\
\hline 337 & 22,67887334 & 87,82 & 4 & 5 & 9 & 442 & 22,36227236 & 82,72 & 4 & 5 & 9 \\
\hline 338 & 22,92385385 & 86,41 & 4 & 5 & 9 & 443 & 22,0326382 & 81,94 & 4 & 5 & 9 \\
\hline 339 & 23,24589936 & 82,04 & 4 & 5 & 9 & 444 & 22,02987864 & 85,37 & 4 & 5 & 9 \\
\hline 340 & 23,6245665 & 79,26 & 4 & 5 & 9 & 453 & 22,84927457 & 84,77 & 4 & 5 & 9 \\
\hline 345 & 23,36149641 & 75,03 & 4 & 5 & 9 & 459 & 23,71294643 & 76,72 & 4 & 5 & 9 \\
\hline 360 & 23,90126064 & 78,20 & 4 & 5 & 9 & 460 & 23,3821625 & 78,74 & 4 & 5 & 9 \\
\hline 364 & 23,73902542 & 89,18 & 4 & 5 & 9 & 461 & 23,39941553 & 76,99 & 4 & 5 & 9 \\
\hline 370 & 23,74911381 & 85,10 & 4 & 5 & 9 & 462 & 23,87094072 & 75,57 & 4 & 5 & 9 \\
\hline 371 & 23,88540458 & 88,70 & 4 & 5 & 9 & 463 & 23,63485244 & 76,41 & 4 & 5 & 9 \\
\hline 395 & 23,55987846 & 78,86 & 4 & 5 & 9 & 464 & 23,80415667 & 75,36 & 4 & 5 & 9 \\
\hline 429 & 22,66974922 & 86,23 & 4 & 5 & 9 & 502 & 22,23322231 & 78,64 & 4 & 5 & 9 \\
\hline 430 & 22,5549962 & 88,18 & 4 & 5 & 9 & 503 & 22,60393962 & 86,27 & 4 & 5 & 9 \\
\hline 431 & 22,67842943 & 88,65 & 4 & 5 & 9 & 505 & 22,02280756 & 86,09 & 4 & 5 & 9 \\
\hline 432 & 23,5127159 & 90,00 & 4 & 5 & 9 & 506 & 22,376408 & 84,96 & 4 & 5 & 9 \\
\hline 434 & 23,57191358 & 88,05 & 4 & 5 & 9 & 507 & 22,55966905 & 84,82 & 4 & 5 & 9 \\
\hline 435 & 22,86324803 & 84,39 & 4 & 5 & 9 & 508 & 22,23368359 & 85,75 & 4 & 5 & 9 \\
\hline 436 & 22,45567515 & 87,32 & 4 & 5 & 9 & 509 & 22,5769945 & 84,20 & 4 & 5 & 9 \\
\hline 437 & 22,60557142 & 78,17 & 4 & 5 & 9 & 514 & 22,26777102 & 81,83 & 4 & 5 & 9 \\
\hline 438 & 23,34268242 & 81,39 & 4 & 5 & 9 & 518 & 22,16029297 & 85,70 & 4 & 5 & 9 \\
\hline
\end{tabular}




\begin{tabular}{|c|c|c|c|c|c|c|c|c|c|c|c|}
\hline $\begin{array}{c}\text { ZATs } \\
\text { PUCAB } \\
\text { NOMj }\end{array}$ & $\operatorname{Pj}(t)$ & $\mathrm{Aj}(\%)$ & peso_Pj & peso_Aj & soma & $\begin{array}{c}\text { ZATs } \\
\text { PUCAB } \\
\text { NOMj }\end{array}$ & $\operatorname{Pj}(t)$ & $A j(\%)$ & peso_Pj & peso_Aj & soma \\
\hline 539 & 22,44278749 & 79,87 & 4 & 5 & 9 & 175 & 25,45085954 & 75,85 & 3 & 5 & 8 \\
\hline 574 & 22,56070997 & 76,15 & 4 & 5 & 9 & 176 & 25,02321918 & 79,36 & 3 & 5 & 8 \\
\hline 578 & 22,31439244 & 78,72 & 4 & 5 & 9 & 217 & 24,74062734 & 81,75 & 3 & 5 & 8 \\
\hline 580 & 22,36798489 & 83,76 & 4 & 5 & 9 & 218 & 25,09960371 & 79,92 & 3 & 5 & 8 \\
\hline 582 & 22,41348941 & 82,21 & 4 & 5 & 9 & 219 & 24,66587607 & 78,39 & 3 & 5 & 8 \\
\hline 587 & 22,43024869 & 76,99 & 4 & 5 & 9 & 221 & 24,71052581 & 81,97 & 3 & 5 & 8 \\
\hline 591 & 22,02301173 & 80,35 & 4 & 5 & 9 & 222 & 24,13827433 & 84,54 & 3 & 5 & 8 \\
\hline 612 & 21,23163357 & 74,51 & 5 & 4 & 9 & 225 & 24,03857464 & 82,71 & 3 & 5 & 8 \\
\hline 613 & 21,52886691 & 74,81 & 5 & 4 & 9 & 227 & 24,95059448 & 79,09 & 3 & 5 & 8 \\
\hline 632 & 21,38193809 & 67,00 & 5 & 4 & 9 & 228 & 24,12706342 & 83,76 & 3 & 5 & 8 \\
\hline 633 & 21,86074164 & 68,07 & 5 & 4 & 9 & 231 & 24,42200113 & 75,35 & 3 & 5 & 8 \\
\hline 846 & 23,78205323 & 80,76 & 4 & 5 & 9 & 240 & 24,88617647 & 79,41 & 3 & 5 & 8 \\
\hline 966 & 23,72767698 & 76,24 & 4 & 5 & 9 & 268 & 24,8613421 & 81,15 & 3 & 5 & 8 \\
\hline 984 & 22,37507539 & 83,89 & 4 & 5 & 9 & 270 & 24,95081261 & 80,37 & 3 & 5 & 8 \\
\hline 985 & 22,44322169 & 83,32 & 4 & 5 & 9 & 275 & 25,97823091 & 77,20 & 3 & 5 & 8 \\
\hline 986 & 22,55390866 & 86,31 & 4 & 5 & 9 & 276 & 25,42948582 & 80,58 & 3 & 5 & 8 \\
\hline 992 & 23,35925373 & 78,13 & 4 & 5 & 9 & 277 & 25,02091652 & 80,00 & 3 & 5 & 8 \\
\hline 167 & 24,55697708 & 76,03 & 3 & 5 & 8 & 278 & 24,66030125 & 76,54 & 3 & 5 & 8 \\
\hline 172 & 24,01903558 & 81,17 & 3 & 5 & 8 & 279 & 24,0876113 & 78,99 & 3 & 5 & 8 \\
\hline 174 & 24,40190434 & 85,58 & 3 & 5 & 8 & 280 & 25,00245499 & 80,24 & 3 & 5 & 8 \\
\hline
\end{tabular}




\begin{tabular}{|c|c|c|c|c|c|c|c|c|c|c|c|}
\hline $\begin{array}{c}\text { ZATs } \\
\text { PUCAB } \\
\text { NOMj }\end{array}$ & $\operatorname{Pj}(t)$ & $\mathrm{Aj}(\%)$ & peso_Pj & peso_Aj & soma & $\begin{array}{c}\text { ZATs } \\
\text { PUCAB } \\
\text { NOMj }\end{array}$ & $\operatorname{Pj}(t)$ & $\mathrm{Aj}(\%)$ & peso_Pj & peso_Aj & soma \\
\hline 283 & 24,16712736 & 80,57 & 3 & 5 & 8 & 343 & 24,82917996 & 80,26 & 3 & 5 & 8 \\
\hline 286 & 25,11922108 & 80,57 & 3 & 5 & 8 & 344 & 24,42229422 & 78,63 & 3 & 5 & 8 \\
\hline 288 & 25,01339353 & 77,63 & 3 & 5 & 8 & 346 & 24,91485046 & 78,29 & 3 & 5 & 8 \\
\hline 290 & 24,64674603 & 80,96 & 3 & 5 & 8 & 358 & 24,24215277 & 79,21 & 3 & 5 & 8 \\
\hline 291 & 24,14384429 & 81,77 & 3 & 5 & 8 & 361 & 23,76157257 & 74,09 & 4 & 4 & 8 \\
\hline 292 & 24,29167364 & 79,89 & 3 & 5 & 8 & 363 & 24,05556931 & 82,64 & 3 & 5 & 8 \\
\hline 293 & 24,706333 & 79,01 & 3 & 5 & 8 & 365 & 24,5697145 & 88,05 & 3 & 5 & 8 \\
\hline 294 & 24,02527999 & 88,16 & 3 & 5 & 8 & 366 & 25,40387745 & 78,21 & 3 & 5 & 8 \\
\hline 295 & 24,55945312 & 79,26 & 3 & 5 & 8 & 367 & 24,89189932 & 81,07 & 3 & 5 & 8 \\
\hline 298 & 24,43789982 & 80,57 & 3 & 5 & 8 & 368 & 24,81286082 & 81,12 & 3 & 5 & 8 \\
\hline 299 & 25,92143911 & 82,65 & 3 & 5 & 8 & 369 & 24,75699306 & 81,61 & 3 & 5 & 8 \\
\hline 300 & 25,37313592 & 79,41 & 3 & 5 & 8 & 372 & 25,48143653 & 80,60 & 3 & 5 & 8 \\
\hline 329 & 24,81837242 & 76,68 & 3 & 5 & 8 & 373 & 25,49428082 & 79,84 & 3 & 5 & 8 \\
\hline 330 & 25,79798133 & 76,12 & 3 & 5 & 8 & 374 & 25,79808436 & 77,80 & 3 & 5 & 8 \\
\hline 331 & 24,86165568 & 86,40 & 3 & 5 & 8 & 375 & 24,67509804 & 78,01 & 3 & 5 & 8 \\
\hline 332 & 25,63631292 & 83,25 & 3 & 5 & 8 & 380 & 24,54308608 & 76,79 & 3 & 5 & 8 \\
\hline 333 & 24,60865266 & 90,11 & 3 & 5 & 8 & 384 & 24,65110377 & 76,40 & 3 & 5 & 8 \\
\hline 334 & 25,06274541 & 84,61 & 3 & 5 & 8 & 428 & 24,63683708 & 77,24 & 3 & 5 & 8 \\
\hline 341 & 24,87695059 & 79,59 & 3 & 5 & 8 & 440 & 24,5204282 & 79,55 & 3 & 5 & 8 \\
\hline 342 & 25,09084642 & 80,07 & 3 & 5 & 8 & 441 & 24,58718581 & 75,22 & 3 & 5 & 8 \\
\hline
\end{tabular}




\begin{tabular}{|c|c|c|c|c|c|c|c|c|c|c|c|}
\hline $\begin{array}{c}\text { ZATs } \\
\text { PUCAB } \\
\text { NOMj }\end{array}$ & $\operatorname{Pj}(t)$ & $\mathrm{Aj}(\%)$ & peso_Pj & peso_Aj & soma & $\begin{array}{c}\text { ZATs } \\
\text { PUCAB } \\
\text { NOMj }\end{array}$ & $P j(t)$ & $\mathrm{Aj}(\%)$ & peso_Pj & peso_Aj & soma \\
\hline 454 & 23,470129 & 72,63 & 4 & 4 & 8 & 593 & 22,2932045 & 69,23 & 4 & 4 & 8 \\
\hline 457 & 23,59846938 & 74,67 & 4 & 4 & 8 & 594 & 22,74443814 & 65,87 & 4 & 4 & 8 \\
\hline 458 & 23,90436613 & 73,01 & 4 & 4 & 8 & 595 & 23,35457732 & 67,03 & 4 & 4 & 8 \\
\hline 465 & 23,97945026 & 74,91 & 4 & 4 & 8 & 597 & 23,6604849 & 65,40 & 4 & 4 & 8 \\
\hline 466 & 22,26131801 & 70,33 & 4 & 4 & 8 & 606 & 23,96690451 & 65,47 & 4 & 4 & 8 \\
\hline 467 & 22,20084896 & 70,31 & 4 & 4 & 8 & 610 & 22,56690915 & 67,74 & 4 & 4 & 8 \\
\hline 469 & 23,5075046 & 69,19 & 4 & 4 & 8 & 614 & 21,79429104 & 55,63 & 5 & 3 & 8 \\
\hline 496 & 23,25412526 & 65,55 & 4 & 4 & 8 & 616 & 21,9441274 & 57,46 & 5 & 3 & 8 \\
\hline 497 & 23,0296212 & 67,19 & 4 & 4 & 8 & 617 & 21,97935106 & 58,53 & 5 & 3 & 8 \\
\hline 499 & 22,63429642 & 71,18 & 4 & 4 & 8 & 844 & 25,56151293 & 82,30 & 3 & 5 & 8 \\
\hline 500 & 22,53766244 & 74,79 & 4 & 4 & 8 & 845 & 25,0599734 & 78,29 & 3 & 5 & 8 \\
\hline 510 & 23,79339947 & 70,42 & 4 & 4 & 8 & 952 & 24,75356736 & 85,39 & 3 & 5 & 8 \\
\hline 513 & 22,95413854 & 71,33 & 4 & 4 & 8 & 971 & 22,59099897 & 66,28 & 4 & 4 & 8 \\
\hline 515 & 23,0791259 & 67,71 & 4 & 4 & 8 & 975 & 22,56690915 & 67,72 & 4 & 4 & 8 \\
\hline 576 & 22,67049089 & 73,25 & 4 & 4 & 8 & 993 & 23,75271544 & 73,61 & 4 & 4 & 8 \\
\hline 577 & 22,24429253 & 73,57 & 4 & 4 & 8 & 179 & 26,27122601 & 75,48 & 2 & 5 & 7 \\
\hline 583 & 21,51208081 & 63,66 & 5 & 3 & 8 & 180 & 26,14146104 & 76,28 & 2 & 5 & 7 \\
\hline 584 & 21,65235858 & 64,75 & 5 & 3 & 8 & 181 & 25,90018581 & 74,97 & 3 & 4 & 7 \\
\hline 586 & 22,43712273 & 73,02 & 4 & 4 & 8 & 184 & 26,18825678 & 78,28 & 2 & 5 & 7 \\
\hline 592 & 22,00531904 & 71,24 & 4 & 4 & 8 & 229 & 24,49511056 & 72,66 & 3 & 4 & 7 \\
\hline
\end{tabular}




\begin{tabular}{|c|c|c|c|c|c|c|c|c|c|c|c|}
\hline $\begin{array}{c}\text { ZATs } \\
\text { PUCAB } \\
\text { NOMj }\end{array}$ & $\operatorname{Pj}(t)$ & $A j(\%)$ & peso_Pj & peso_Aj & soma & $\begin{array}{c}\text { ZATs } \\
\text { PUCAB } \\
\text { NOMj }\end{array}$ & $\operatorname{Pj}(t)$ & $A j(\%)$ & peso_Pj & peso_Aj & soma \\
\hline 230 & 25,18612606 & 65,57 & 3 & 4 & 7 & 301 & 25,85414746 & 66,30 & 3 & 4 & 7 \\
\hline 232 & 24,25620915 & 74,44 & 3 & 4 & 7 & 302 & 26,1465047 & 77,01 & 2 & 5 & 7 \\
\hline 233 & 24,48690475 & 72,44 & 3 & 4 & 7 & 328 & 25,24087263 & 74,56 & 3 & 4 & 7 \\
\hline 234 & 24,48258726 & 74,81 & 3 & 4 & 7 & 347 & 25,15431122 & 71,09 & 3 & 4 & 7 \\
\hline 235 & 25,25259694 & 73,11 & 3 & 4 & 7 & 348 & 24,79239423 & 73,20 & 3 & 4 & 7 \\
\hline 236 & 25,34614882 & 66,99 & 3 & 4 & 7 & 349 & 24,70256705 & 72,48 & 3 & 4 & 7 \\
\hline 237 & 24,70034182 & 67,95 & 3 & 4 & 7 & 350 & 24,16409926 & 74,73 & 3 & 4 & 7 \\
\hline 238 & 25,27023486 & 74,09 & 3 & 4 & 7 & 351 & 24,35595724 & 73,84 & 3 & 4 & 7 \\
\hline 239 & 25,05865751 & 69,36 & 3 & 4 & 7 & 352 & 24,57497668 & 73,19 & 3 & 4 & 7 \\
\hline 251 & 25,87472417 & 68,91 & 3 & 4 & 7 & 353 & 25,37337325 & 71,67 & 3 & 4 & 7 \\
\hline 254 & 25,50701905 & 74,76 & 3 & 4 & 7 & 354 & 24,91808654 & 71,09 & 3 & 4 & 7 \\
\hline 267 & 25,54302064 & 74,63 & 3 & 4 & 7 & 355 & 24,24401256 & 72,60 & 3 & 4 & 7 \\
\hline 269 & 25,25249031 & 72,99 & 3 & 4 & 7 & 356 & 24,03610655 & 73,94 & 3 & 4 & 7 \\
\hline 272 & 25,24610396 & 74,51 & 3 & 4 & 7 & 357 & 24,22396473 & 74,01 & 3 & 4 & 7 \\
\hline 273 & 25,52036679 & 73,85 & 3 & 4 & 7 & 359 & 25,46268796 & 72,02 & 3 & 4 & 7 \\
\hline 274 & 25,64791666 & 70,80 & 3 & 4 & 7 & 362 & 24,90157992 & 71,74 & 3 & 4 & 7 \\
\hline 281 & 25,09381372 & 73,33 & 3 & 4 & 7 & 376 & 25,19787088 & 70,94 & 3 & 4 & 7 \\
\hline 282 & 24,81734607 & 73,56 & 3 & 4 & 7 & 377 & 25,50164215 & 65,59 & 3 & 4 & 7 \\
\hline 284 & 25,44173704 & 74,50 & 3 & 4 & 7 & 378 & 25,21274614 & 69,17 & 3 & 4 & 7 \\
\hline 287 & 25,49279904 & 70,34 & 3 & 4 & 7 & 379 & 25,64068225 & 73,22 & 3 & 4 & 7 \\
\hline
\end{tabular}




\begin{tabular}{|c|c|c|c|c|c|c|c|c|c|c|c|}
\hline $\begin{array}{c}\text { ZATs } \\
\text { PUCAB } \\
\text { NOMj }\end{array}$ & $\operatorname{Pj}(t)$ & $\mathrm{Aj}(\%)$ & peso_Pj & peso_Aj & soma & $\begin{array}{c}\text { ZATs } \\
\text { PUCAB } \\
\text { NOMj }\end{array}$ & $\operatorname{Pj}(t)$ & $\mathrm{Aj}(\%)$ & peso_Pj & peso_Aj & soma \\
\hline 381 & 24,15091117 & 74,91 & 3 & 4 & 7 & 631 & 21,206875 & 54,68 & 5 & 2 & 7 \\
\hline 383 & 25,09009018 & 66,87 & 3 & 4 & 7 & 634 & 22,22947572 & 59,12 & 4 & 3 & 7 \\
\hline 385 & 24,14261187 & 72,65 & 3 & 4 & 7 & 843 & 26,26506505 & 76,37 & 2 & 5 & 7 \\
\hline 386 & 24,68850467 & 74,96 & 3 & 4 & 7 & 848 & 25,89284845 & 67,54 & 3 & 4 & 7 \\
\hline 421 & 24,6682062 & 73,75 & 3 & 4 & 7 & 983 & 22,16182098 & 59,63 & 4 & 3 & 7 \\
\hline 422 & 24,14483027 & 72,02 & 3 & 4 & 7 & 987 & 21,95029612 & 54,25 & 5 & 2 & 7 \\
\hline 455 & 24,64517175 & 67,94 & 3 & 4 & 7 & 991 & 24,4360172 & 74,72 & 3 & 4 & 7 \\
\hline 456 & 24,24023926 & 67,84 & 3 & 4 & 7 & 997 & 25,76043933 & 68,90 & 3 & 4 & 7 \\
\hline 468 & 23,58562369 & 63,81 & 4 & 3 & 7 & 183 & 27,18578914 & 65,65 & 2 & 4 & 6 \\
\hline 472 & 24,94613051 & 70,70 & 3 & 4 & 7 & 185 & 26,39570822 & 74,64 & 2 & 4 & 6 \\
\hline 474 & 24,14278072 & 65,78 & 3 & 4 & 7 & 215 & 25,90238269 & 62,35 & 3 & 3 & 6 \\
\hline 475 & 24,0349951 & 66,63 & 3 & 4 & 7 & 216 & 24,3246875 & 64,84 & 3 & 3 & 6 \\
\hline 476 & 25,86968688 & 72,37 & 3 & 4 & 7 & 249 & 26,45264251 & 66,20 & 2 & 4 & 6 \\
\hline 477 & 25,62667495 & 72,69 & 3 & 4 & 7 & 250 & 26,26795996 & 69,86 & 2 & 4 & 6 \\
\hline 488 & 24,17077696 & 72,66 & 3 & 4 & 7 & 252 & 27,95259159 & 72,81 & 2 & 4 & 6 \\
\hline 498 & 23,46257812 & 64,88 & 4 & 3 & 7 & 253 & 26,04853467 & 70,12 & 2 & 4 & 6 \\
\hline 581 & 22,53957329 & 63,56 & 4 & 3 & 7 & 255 & 27,09544087 & 74,88 & 2 & 4 & 6 \\
\hline 585 & 22,18165123 & 59,62 & 4 & 3 & 7 & 266 & 26,87852296 & 71,66 & 2 & 4 & 6 \\
\hline 615 & 22,19798638 & 62,29 & 4 & 3 & 7 & 271 & 26,28486166 & 74,54 & 2 & 4 & 6 \\
\hline 618 & 22,53268266 & 58,42 & 4 & 3 & 7 & 296 & 26,14051527 & 67,29 & 2 & 4 & 6 \\
\hline
\end{tabular}




\begin{tabular}{|c|c|c|c|c|c|c|c|c|c|c|c|}
\hline $\begin{array}{c}\text { ZATs } \\
\text { PUCAB } \\
\text { NOMj }\end{array}$ & $\operatorname{Pj}(t)$ & $\mathrm{Aj}(\%)$ & peso_Pj & peso_Aj & soma & $\begin{array}{c}\text { ZATs } \\
\text { PUCAB } \\
\text { NOMj }\end{array}$ & $P j(t)$ & $\mathrm{Aj}(\%)$ & peso_Pj & peso_Aj & soma \\
\hline 319 & 26,3985297 & 73,58 & 2 & 4 & 6 & 495 & 24,39404632 & 63,35 & 3 & 3 & 6 \\
\hline 320 & 26,03463617 & 73,71 & 2 & 4 & 6 & 516 & 24,31123752 & 59,04 & 3 & 3 & 6 \\
\hline 326 & 25,23530193 & 56,79 & 3 & 3 & 6 & 951 & 24,85037222 & 64,59 & 3 & 3 & 6 \\
\hline 426 & 25,13430417 & 60,92 & 3 & 3 & 6 & 965 & 25,88970312 & 59,37 & 3 & 3 & 6 \\
\hline 427 & 25,28087701 & 61,70 & 3 & 3 & 6 & 186 & 27,39437499 & 63,51 & 2 & 3 & 5 \\
\hline 471 & 24,47145089 & 60,32 & 3 & 3 & 6 & 212 & 26,64547468 & 56,96 & 2 & 3 & 5 \\
\hline 473 & 24,2342511 & 63,19 & 3 & 3 & 6 & 213 & 27,78718553 & 59,83 & 2 & 3 & 5 \\
\hline 478 & 25,81556295 & 63,17 & 3 & 3 & 6 & 214 & 27,01133871 & 56,33 & 2 & 3 & 5 \\
\hline 479 & 25,81556295 & 63,17 & 3 & 3 & 6 & 297 & 26,46026462 & 63,35 & 2 & 3 & 5 \\
\hline 480 & 25,75320651 & 63,19 & 3 & 3 & 6 & 303 & 27,28616253 & 60,31 & 2 & 3 & 5 \\
\hline 481 & 25,41501892 & 56,88 & 3 & 3 & 6 & 321 & 26,79408959 & 55,55 & 2 & 3 & 5 \\
\hline 482 & 25,07049497 & 57,55 & 3 & 3 & 6 & 322 & 27,36149324 & 58,93 & 2 & 3 & 5 \\
\hline 483 & 25,41501892 & 56,87 & 3 & 3 & 6 & 325 & 25,53072335 & 53,42 & 3 & 2 & 5 \\
\hline 484 & 25,00015036 & 57,55 & 3 & 3 & 6 & 382 & 26,0212013 & 57,89 & 2 & 3 & 5 \\
\hline 485 & 25,33079098 & 62,18 & 3 & 3 & 6 & 387 & 26,25695913 & 57,52 & 2 & 3 & 5 \\
\hline 486 & 25,38942707 & 62,18 & 3 & 3 & 6 & 425 & 24,02751655 & 47,96 & 3 & 2 & 5 \\
\hline 487 & 25,33079098 & 62,19 & 3 & 3 & 6 & 470 & 24,5157797 & 52,58 & 3 & 2 & 5 \\
\hline 489 & 23,93409721 & 52,39 & 4 & 2 & 6 & 490 & 24,44351367 & 53,49 & 3 & 2 & 5 \\
\hline 491 & 24,53961797 & 59,73 & 3 & 3 & 6 & 492 & 24,5157797 & 52,60 & 3 & 2 & 5 \\
\hline 494 & 24,13421225 & 62,70 & 3 & 3 & 6 & 493 & 25,06816919 & 50,59 & 3 & 2 & 5 \\
\hline
\end{tabular}




\begin{tabular}{|c|c|c|c|c|c|c|c|c|c|c|c|}
\hline $\begin{array}{c}\text { ZATs } \\
\text { PUCAB } \\
\text { NOMj }\end{array}$ & $\operatorname{Pj}(t)$ & $\mathrm{Aj}(\%)$ & peso_Pj & peso_Aj & soma & $\begin{array}{c}\text { ZATs } \\
\text { PUCAB } \\
\text { NOMj }\end{array}$ & $P j(t)$ & $\mathrm{Aj}(\%)$ & peso_Pj & peso_Aj & soma \\
\hline 596 & 24,42310072 & 51,73 & 3 & 2 & 5 & 208 & 27,02565254 & 50,08 & 2 & 2 & 4 \\
\hline 598 & 25,02184425 & 48,56 & 3 & 2 & 5 & 209 & 26,91873148 & 47,83 & 2 & 2 & 4 \\
\hline 599 & 24,3837983 & 52,28 & 3 & 2 & 5 & 210 & 27,04646139 & 48,86 & 2 & 2 & 4 \\
\hline 600 & 24,40151534 & 50,37 & 3 & 2 & 5 & 211 & 26,72790403 & 53,95 & 2 & 2 & 4 \\
\hline 601 & 24,37333531 & 52,36 & 3 & 2 & 5 & 318 & 27,19996518 & 51,99 & 2 & 2 & 4 \\
\hline 602 & 25,14660272 & 52,65 & 3 & 2 & 5 & 324 & 26,12725904 & 47,41 & 2 & 2 & 4 \\
\hline 603 & 25,85738889 & 53,73 & 3 & 2 & 5 & 388 & 27,10911993 & 47,23 & 2 & 2 & 4 \\
\hline 605 & 25,56573607 & 48,80 & 3 & 2 & 5 & 420 & 26,24968826 & 51,15 & 2 & 2 & 4 \\
\hline 842 & 26,40556349 & 59,03 & 2 & 3 & 5 & 423 & 24,52273981 & 40,76 & 3 & 1 & 4 \\
\hline 967 & 25,21573019 & 53,27 & 3 & 2 & 5 & 424 & 24,25217517 & 42,57 & 3 & 1 & 4 \\
\hline 968 & 24,2958313 & 50,89 & 3 & 2 & 5 & 519 & 24,03304834 & 41,47 & 3 & 1 & 4 \\
\hline 969 & 24,68235153 & 54,65 & 3 & 2 & 5 & 841 & 26,99125801 & 54,79 & 2 & 2 & 4 \\
\hline 988 & 25,12825842 & 52,64 & 3 & 2 & 5 & 201 & 28,57487944 & 54,98 & 1 & 2 & 3 \\
\hline 996 & 27,42285807 & 58,90 & 2 & 3 & 5 & 205 & 27,02953704 & 42,14 & 2 & 1 & 3 \\
\hline 182 & 26,99119672 & 50,70 & 2 & 2 & 4 & 206 & 27,05170453 & 40,07 & 2 & 1 & 3 \\
\hline 199 & 27,95822814 & 49,27 & 2 & 2 & 4 & 314 & 29,16057627 & 49,05 & 1 & 2 & 3 \\
\hline 200 & 27,65952748 & 45,60 & 2 & 2 & 4 & 316 & 28,67232988 & 54,27 & 1 & 2 & 3 \\
\hline 202 & 26,93849522 & 50,36 & 2 & 2 & 4 & 317 & 27,51287751 & 40,89 & 2 & 1 & 3 \\
\hline 203 & 27,63389679 & 46,61 & 2 & 2 & 4 & 323 & 26,52287337 & 44,65 & 2 & 1 & 3 \\
\hline 207 & 27,37143258 & 46,68 & 2 & 2 & 4 & 397 & 27,79061728 & 31,87 & 2 & 1 & 3 \\
\hline
\end{tabular}




\begin{tabular}{|c|c|c|c|c|c|c|c|c|c|c|c|}
\hline $\begin{array}{c}\text { ZATs } \\
\text { PUCAB } \\
\text { NOMj }\end{array}$ & $\operatorname{Pj}(t)$ & $\mathrm{Aj}(\%)$ & peso_Pj & peso_Aj & soma & $\begin{array}{c}\text { ZATs } \\
\text { PUCAB } \\
\text { NOMj }\end{array}$ & $\operatorname{Pj}(t)$ & $\mathrm{Aj}(\%)$ & peso_Pj & peso_Aj & soma \\
\hline 400 & 27,94443807 & 32,77 & 2 & 1 & 3 & & & & & & \\
\hline 953 & 27,03343059 & 38,99 & 2 & 1 & 3 & & & & & & \\
\hline 954 & 27,92504385 & 40,49 & 2 & 1 & 3 & & & & & & \\
\hline 955 & 26,24000838 & 42,00 & 2 & 1 & 3 & & & & & & \\
\hline 204 & 28,50610445 & 44,32 & 1 & 1 & 2 & & & & & & \\
\hline 311 & 29,33757772 & 31,16 & 1 & 1 & 2 & & & & & & \\
\hline 312 & 28,4550672 & 30,83 & 1 & 1 & 2 & & & & & & \\
\hline 313 & 29,12873999 & 40,35 & 1 & 1 & 2 & & & & & & \\
\hline 315 & 28,25170871 & 32,58 & 1 & 1 & 2 & & & & & & \\
\hline 399 & 28,24577101 & 35,40 & 1 & 1 & 2 & & & & & & \\
\hline 403 & 28,85765544 & 28,21 & 1 & 1 & 2 & & & & & & \\
\hline
\end{tabular}

\section{Apêndice 3}

-Ranking ZAT de adensamento no Cenário 2 de sensibilidade aos outros motivos de viagem para o Centro Ampliado. 


\begin{tabular}{|c|c|c|c|c|c|c|c|c|c|c|c|}
\hline \multirow{2}{*}{$\begin{array}{l}\begin{array}{c}\text { ZATs } \\
\text { PUCAB }\end{array} \\
20 \mathrm{~min}\end{array}$} & & \multicolumn{2}{|c|}{ Trabalho } & \multirow{2}{*}{\begin{tabular}{|l|} 
estudo \\
pucab
\end{tabular}} & \multirow[b]{2}{*}{ abrange \% } & \multirow{2}{*}{\begin{tabular}{|l} 
saude \\
pucab
\end{tabular}} & \multirow[b]{2}{*}{ abrange $\%$} & \multirow{2}{*}{$\begin{array}{l}\text { recreação } \\
\text { pucab }\end{array}$} & \multirow[b]{2}{*}{ abrange $\%$} & \multicolumn{2}{|c|}{ ponderação orden } \\
\hline & & pucab & abrange $\%$ & & & & & & & $\begin{array}{l}\text { ZATs } \\
\text { pucab }\end{array}$ & $\mathrm{P}$ \\
\hline 1 & 167 & 311 & 5,04350915 & 311 & 1,71843177 & 311 & 1,46308268 & 311 & 4,12725709 & 433 & 470669184 \\
\hline 2 & 168 & 403 & 5,41348488 & 403 & 2,03029532 & 312 & 2,58591358 & 403 & 4,98710232 & 337 & 468440116 \\
\hline 3 & 169 & 312 & 6,11199905 & 312 & 3,08681263 & 403 & 2,65396393 & 312 & 5,76096303 & 338 & 465621331 \\
\hline 4 & 170 & 399 & 7,02953886 & 315 & 3,53869654 & 315 & 3,57264376 & 397 & 6,62080825 & 445 & 463150255 \\
\hline 5 & 171 & 315 & 7,27224294 & 400 & 3,5959776 & 399 & 3,70874447 & 400 & 7,30868444 & 336 & 462949752 \\
\hline 6 & 172 & 605 & 7,5060676 & 313 & 4,36608961 & 400 & 3,84484519 & 315 & 7,39466896 & 335 & 462604256 \\
\hline 7 & 173 & 400 & 7,51198721 & 399 & 4,69704684 & 313 & 4,08302144 & 313 & 8,34049871 & 446 & 461077844 \\
\hline 8 & 174 & 313 & 7,5563843 & 397 & 5,06619145 & 397 & 4,89962572 & 399 & 8,6844368 & 442 & 455762120 \\
\hline 9 & 175 & 603 & 7,62445984 & 316 & 5,70264766 & 204 & 5,10377679 & 420 & 8,6844368 & 289 & 452628851 \\
\hline 10 & 176 & 397 & 8,64559285 & 207 & 5,94450102 & 203 & 5,81830555 & 954 & 9,88822012 & 339 & 452420521 \\
\hline 11 & 179 & 316 & 8,68407032 & 203 & 5,95086558 & 316 & 6,12453215 & 316 & 10,4901118 & 364 & 452116948 \\
\hline 12 & 180 & 598 & 8,89125673 & 201 & 6,50458248 & 207 & 6,22660769 & 207 & 11,0060189 & 444 & 449547275 \\
\hline 13 & 181 & 206 & 8,96525188 & 204 & 6,52367617 & 201 & 6,43075876 & 317 & 11,177988 & 447 & 448906913 \\
\hline 14 & 182 & 967 & 8,98005091 & 205 & 6,57459267 & 206 & 6,83906091 & 203 & 11,5219261 & 370 & 446642395 \\
\hline 15 & 183 & 205 & 9,02148819 & 420 & 6,67642566 & 202 & 7,04321198 & 182 & 12,8976784 & 449 & 445465350 \\
\hline 16 & 184 & 209 & 9,39442373 & 954 & 6,87372709 & 205 & 7,07723716 & 199 & 13,2416165 & 448 & 444173707 \\
\hline 17 & 185 & 210 & 9,76143965 & 206 & 6,92464358 & 182 & 7,21333787 & 183 & 13,327601 & 220 & 440561363 \\
\hline 18 & 186 & 207 & 9,95974664 & 199 & 7,23014257 & 199 & 7,9618918 & 206 & 13,8435082 & 450 & 440445986 \\
\hline 19 & 199 & 600 & 10,0574202 & 202 & 7,61201629 & 954 & 8,4382443 & 423 & 14,1014617 & 343 & 436270964 \\
\hline 20 & 200 & 208 & 10,4540342 & 182 & 7,68839104 & 200 & 8,9145968 & 605 & 14,2734308 & 501 & 436072889 \\
\hline 21 & 201 & 203 & 10,5517078 & 953 & 8,32484725 & 183 & 9,25484859 & 204 & 14,4453998 & 268 & 435591343 \\
\hline 22 & 202 & 314 & 10,5605872 & 208 & 8,33757637 & 209 & 10,0374277 & 186 & 14,5313844 & 453 & 434968138 \\
\hline
\end{tabular}




\begin{tabular}{|c|c|c|c|c|c|c|c|c|c|c|c|}
\hline \multirow{2}{*}{ 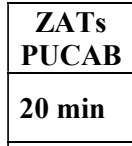 } & & \multicolumn{2}{|c|}{ Trabalho } & \multirow{2}{*}{\begin{tabular}{|l|} 
estudo \\
pucab
\end{tabular}} & \multirow[b]{2}{*}{ abrange \% } & \multirow{2}{*}{\begin{tabular}{|l|} 
saude \\
pucab
\end{tabular}} & \multirow[b]{2}{*}{ abrange $\%$} & \multirow{2}{*}{$\begin{array}{l}\text { recreação } \\
\text { pucab }\end{array}$} & \multirow{2}{*}{ abrange \% } & \multicolumn{2}{|c|}{ ponderação ordem } \\
\hline & & pucab & abrange $\%$ & & & & & & & $\begin{array}{l}\text { ZATs } \\
\text { pucab }\end{array}$ & $\mathrm{P}$ \\
\hline 23 & 203 & 204 & 10,8299296 & 210 & 8,33757637 & 186 & 10,4457298 & 323 & 14,6173689 & 294 & 433858963 \\
\hline 24 & 204 & 201 & 10,8772865 & 200 & 8,35667006 & 208 & 10,6158557 & 201 & 14,7033534 & 327 & 433809360 \\
\hline 25 & 205 & 987 & 10,9364826 & 314 & 8,64307536 & 210 & 10,6158557 & 255 & 14,961307 & 395 & 432785304 \\
\hline 26 & 206 & 954 & 10,9660806 & 317 & 8,70672098 & 953 & 10,854032 & 953 & 15,133276 & 340 & 432167256 \\
\hline 27 & 207 & 596 & 11,0341562 & 209 & 9,39409369 & 314 & 11,1942838 & 424 & 15,2192605 & 452 & 431828225 \\
\hline 28 & 208 & 841 & 11,1643876 & 183 & 9,57230143 & 420 & 11,43246 & 200 & 15,4772141 & 451 & 427466062 \\
\hline 29 & 209 & 601 & 11,1703072 & 323 & 9,80142566 & 317 & 11,5345356 & 202 & 15,5631986 & 270 & 427433812 \\
\hline 30 & 210 & 213 & 11,2176641 & 186 & 10,0305499 & 303 & 11,9428377 & 205 & \begin{tabular}{|l}
15,7351677 \\
\end{tabular} & 358 & 427066011 \\
\hline 31 & 211 & 599 & 11,2561416 & 303 & 10,2342159 & 323 & 12,5212657 & 603 & 15,9071367 & 173 & 426150181 \\
\hline 32 & 212 & 968 & 11,5669212 & 955 & 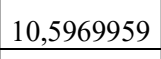 & 841 & 12,9976182 & 598 & 15,9931212 & 432 & 425960243 \\
\hline 33 & 213 & 493 & 11,676434 & 841 & 10,7688391 & 423 & 13,4399456 & 314 & 16,2510748 & 360 & 423194630 \\
\hline 34 & 214 & 631 & 11,8096253 & 211 & 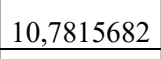 & 387 & 13,9162981 & 519 & 16,3370593 & 277 & 419987132 \\
\hline 35 & 215 & 182 & 12,1056059 & 423 & 11,1125255 & 318 & 15,1071793 & 634 & 16,5090284 & 333 & 419956274 \\
\hline 36 & 216 & 602 & 12,164802 & 212 & 11,11889 & 388 & 15,1412045 & 388 & 16,6809974 & 992 & 416236906 \\
\hline 37 & 217 & 423 & 12,2062393 & 318 & 11,3734725 & 212 & 15,1752297 & 252 & 16,7669819 & 368 & 415566507 \\
\hline 38 & 218 & 634 & 12,2654354 & 388 & 11,4816701 & 519 & 15,2092548 & 618 & 17,11092 & 846 & 414849280 \\
\hline 39 & 219 & 212 & 12,286154 & 519 & 11,8253564 & 185 & 15,5495066 & 210 & 17,1969046 & 169 & 412335022 \\
\hline 40 & 220 & 585 & 12,2979933 & 324 & 12,0672098 & 955 & 16,0598843 & 321 & 17,4548581 & 443 & 411716969 \\
\hline 41 & 221 & 211 & 12,34831 & 213 & 12,2199593 & 965 & 16,2980606 & 987 & \begin{tabular}{|l}
17,4548581 \\
\end{tabular} & 345 & 410311609 \\
\hline 42 & 222 & 615 & 12,3601492 & 325 & 12,3026986 & 988 & 16,570262 & 318 & 17,5408426 & 280 & 409442387 \\
\hline 43 & 223 & 297 & 12,3808678 & 842 & 12,3154277 & 382 & 16,7403879 & 967 & 17,9707653 & 223 & 408562087 \\
\hline 44 & 224 & 420 & 12,4607826 & 424 & 12,5381874 & 324 & 16,8084382 & 208 & 18,0567498 & 344 & 407947723 \\
\hline
\end{tabular}




\begin{tabular}{|c|c|c|c|c|c|c|c|c|c|c|c|}
\hline \multirow{2}{*}{$\begin{array}{l}\text { ZATs } \\
\text { PUCAB } \\
20 \text { min }\end{array}$} & & \multicolumn{2}{|c|}{ Trabalho } & \multirow{2}{*}{\begin{tabular}{|l|} 
estudo \\
pucab
\end{tabular}} & \multirow[b]{2}{*}{ abrange \% } & \multirow{2}{*}{\begin{tabular}{|l|} 
saude \\
pucab
\end{tabular}} & \multirow{2}{*}{ abrange \% } & \multirow{2}{*}{$\begin{array}{l}\text { recreação } \\
\text { pucab }\end{array}$} & \multirow[b]{2}{*}{ abrange $\%$} & \multicolumn{2}{|c|}{ ponderação ordem } \\
\hline & & pucab & abrange $\%$ & & & & & & & $\begin{array}{l}\text { ZATs } \\
\text { pucab }\end{array}$ & $\mathrm{P}$ \\
\hline 45 & 225 & 618 & 12,7538034 & 321 & 12,8691446 & 214 & 17,14869 & 387 & 18,0567498 & 365 & 404094641 \\
\hline 46 & 226 & 614 & 12,7834014 & 387 & 13,0282587 & 842 & 17,2507656 & 631 & 18,0567498 & 346 & 404027758 \\
\hline 47 & 227 & 317 & 12,8277985 & 618 & 13,110998 & 211 & 17,522967 & 615 & 18,1427343 & 505 & 403596417 \\
\hline 48 & 228 & 953 & 12,881075 & 987 & 13,3783096 & 424 & 17,5569922 & 249 & 18,2287188 & 952 & 401230801 \\
\hline 49 & 229 & 200 & 12,9373113 & 322 & 13,5437882 & 615 & 17,9993195 & 614 & 18,3147034 & 508 & 401119598 \\
\hline 50 & 230 & 214 & 13,0172261 & 988 & 14,0020367 & 321 & 18,101395 & 988 & 18,4866724 & 357 & 398500815 \\
\hline 51 & 231 & 519 & 13,0497839 & 631 & 14,1675153 & 598 & 18,101395 & 185 & \begin{tabular}{|l|}
18,5726569 \\
\end{tabular} & 431 & 396675222 \\
\hline 52 & 232 & 983 & 13,0882614 & 603 & 14,3711813 & 605 & 18,3395713 & 617 & \begin{tabular}{|l|}
18,5726569 \\
\end{tabular} & 371 & 396569676 \\
\hline 53 & 233 & 303 & 13,1800154 & 425 & 14,5175662 & 603 & 18,5096972 & 209 & 19,0025795 & 439 & 394959491 \\
\hline 54 & 234 & 969 & 13,2066536 & 605 & 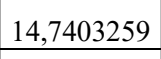 & 987 & 19,1221504 & 250 & 19,0025795 & 518 & 393170423 \\
\hline 55 & 235 & 199 & 13,307287 & 326 & 14,8294297 & 618 & 19,1902007 & 955 & 19,0025795 & 845 & 392886067 \\
\hline 56 & 236 & 955 & 13,4138401 & 996 & 14,9058045 & 213 & 19,3263015 & 951 & 19,6904557 & 334 & 392151553 \\
\hline 57 & 237 & 617 & 13,4434381 & 185 & 15,0521894 & 631 & 19,3943518 & 848 & 19,7764402 & 367 & 391122956 \\
\hline 58 & 238 & 616 & 13,4996744 & 617 & 15,5995418 & 325 & 19,4964274 & 253 & 20,1203783 & 356 & 385228238 \\
\hline 59 & 239 & 842 & 13,5736696 & 615 & 15,6377291 & 951 & 19,5304525 & 421 & 20,1203783 & 342 & 384699418 \\
\hline 60 & 240 & 323 & 13,7986148 & 965 & \begin{tabular}{|l}
15,7077393 \\
\end{tabular} & 634 & 20,2790065 & 616 & 20,1203783 & 279 & 383953652 \\
\hline 61 & 249 & 424 & 13,8518913 & 382 & 15,7395621 & 322 & 20,3130316 & 167 & 20,2063629 & 298 & 383849034 \\
\hline 62 & 250 & 470 & 13,9969218 & 214 & 15,8923116 & 516 & 20,4491324 & 382 & 20,4643164 & 430 & 383683810 \\
\hline 63 & 251 & 492 & 14,0176404 & 616 & 16,3314664 & 425 & 20,5171827 & 324 & 20,5503009 & 341 & 382264989 \\
\hline 64 & 252 & 988 & 14,0413189 & 383 & 16,4460285 & 383 & 20,7893841 & 600 & 20,6362855 & 506 & 380942502 \\
\hline 65 & 253 & 202 & 14,3668975 & 614 & 16,6306008 & 967 & 20,95951 & 251 & 20,8082545 & 170 & 380810898 \\
\hline 66 & 254 & 318 & 14,4379329 & 634 & 16,9679226 & 996 & 21,1976863 & 841 & 20,9802236 & 507 & 380266853 \\
\hline
\end{tabular}




\begin{tabular}{|c|c|c|c|c|c|c|c|c|c|c|c|}
\hline \multirow{2}{*}{$\begin{array}{l}\text { ZATs } \\
\text { PUCAB } \\
20 \mathrm{~min}\end{array}$} & & \multicolumn{2}{|c|}{ Trabalho } & \multirow{2}{*}{\begin{tabular}{|l|} 
estudo \\
pucab
\end{tabular}} & \multirow[b]{2}{*}{ abrange $\%$} & \multirow{2}{*}{\begin{tabular}{|l} 
saude \\
pucab
\end{tabular}} & \multirow[b]{2}{*}{ abrange $\%$} & \multirow{2}{*}{$\begin{array}{l}\text { recreação } \\
\text { pucab }\end{array}$} & \multirow[b]{2}{*}{ abrange $\%$} & \multicolumn{2}{|c|}{ ponderação ordem } \\
\hline & & pucab & abrange $\%$ & & & & & & & $\begin{array}{l}\text { ZATs } \\
\text { pucab }\end{array}$ & P \\
\hline 67 & 255 & 425 & 14,5563251 & 427 & 16,9806517 & 614 & 21,2657366 & 303 & 21,0662081 & 291 & 379344238 \\
\hline 68 & 266 & 388 & 14,6155212 & 585 & 17,878055 & 585 & 21,5379381 & 425 & 21,2381771 & 285 & 378710614 \\
\hline 69 & 267 & 324 & 14,8286272 & 598 & 18,139002 & 617 & 21,5719633 & 583 & 21,7540843 & 228 & 375664863 \\
\hline 70 & 268 & 581 & 14,8493459 & 426 & 18,3681263 & 493 & 21,6740388 & 842 & 21,8400688 & 436 & 375652939 \\
\hline 71 & 269 & 322 & 14,9322204 & 377 & 18,3935845 & 983 & 21,9802654 & 965 & 21,9260533 & 993 & 372532184 \\
\hline 72 & 270 & 321 & 14,9588587 & 983 & 18,8009165 & 249 & 22,4566179 & 596 & 22,0980224 & 172 & 370252645 \\
\hline 73 & 271 & 483 & 14,9943764 & 967 & 19,010947 & 616 & 22,6267438 & 585 & 22,1840069 & 460 & 369921352 \\
\hline 74 & 272 & 481 & 15,000296 & 297 & 20,4747963 & 600 & 22,8308949 & 601 & 22,3559759 & 168 & 369650276 \\
\hline 75 & 273 & 996 & 15,1690049 & 581 & 21,0794297 & 602 & 22,86492 & 983 & 22,3559759 & 363 & 368989064 \\
\hline 76 & 274 & 296 & 15,2666785 & 516 & 21,0857943 & 184 & 22,9669956 & 599 & 22,527945 & 375 & 361732581 \\
\hline 77 & 275 & 577 & 15,3021962 & 577 & 21,8049898 & 250 & 23,3072474 & 584 & 22,699914 & 171 & 360638357 \\
\hline 78 & 276 & 584 & 15,3702717 & 596 & 22,384165 & 968 & 23,6474991 & 383 & 22,7858985 & 351 & 360564963 \\
\hline 79 & 277 & 382 & 15,4442669 & 600 & 22,3905295 & 377 & 23,7155495 & 516 & 22,8718831 & 461 & 354476319 \\
\hline 80 & 278 & 965 & 16,0095898 & 951 & 22,6642057 & 297 & 23,817625 & 581 & 22,8718831 & 240 & 349942144 \\
\hline 81 & 279 & 495 & 16,3292488 & 215 & 22,689664 & 470 & 24,1238517 & 266 & 23,0438521 & 271 & 349827521 \\
\hline 82 & 280 & 427 & 16,3618067 & 601 & 22,7405804 & 301 & 24,1578768 & 427 & 23,2158212 & 283 & 348474556 \\
\hline 83 & 281 & 482 & 16,5749127 & 599 & 22,9569756 & 596 & 24,1578768 & 481 & 23,2158212 & 278 & 347928781 \\
\hline 84 & 282 & 484 & 16,5985911 & 301 & 23,154277 & 492 & 24,191902 & 181 & 23,3018057 & 331 & 347514492 \\
\hline 85 & 283 & 183 & 16,7199432 & 249 & 23,3070265 & 601 & 24,2259272 & 483 & 23,3018057 & 174 & 347015534 \\
\hline 86 & 284 & 583 & 16,8087373 & 584 & 23,5106925 & 581 & 24,3620279 & 297 & 23,3877902 & 575 & 346388208 \\
\hline 87 & 285 & 494 & 16,8620139 & 583 & 23,7652749 & 483 & 24,3960531 & 212 & 23,4737747 & 435 & 344489839 \\
\hline 88 & 286 & 387 & 17,0899189 & 302 & 24,0580448 & 481 & 24,4300783 & 214 & 23,6457438 & 589 & 344453063 \\
\hline
\end{tabular}




\begin{tabular}{|c|c|c|c|c|c|c|c|c|c|c|c|}
\hline \multirow{2}{*}{$\begin{array}{c}\text { ZATs } \\
\text { PUCAB } \\
20 \mathrm{~min} \\
\end{array}$} & & \multicolumn{2}{|c|}{ Trabalho } & \multirow{2}{*}{\begin{tabular}{|l} 
estudo \\
pucab
\end{tabular}} & \multirow[b]{2}{*}{ abrange $\%$} & \multirow{2}{*}{\begin{tabular}{|l|} 
saude \\
pucab
\end{tabular}} & \multirow[b]{2}{*}{ abrange $\%$} & \multirow{2}{*}{\begin{tabular}{|l} 
recreação \\
pucab
\end{tabular}} & \multirow[b]{2}{*}{ abrange $\%$} & \multicolumn{2}{|c|}{ ponderação ordem } \\
\hline & & pucab & abrange $\%$ & & & & & & & $\begin{array}{l}\text { ZATs } \\
\text { pucab }\end{array}$ & $\mathrm{P}$ \\
\hline 89 & 287 & 325 & 17,1017581 & 216 & 24,2680754 & 599 & 24,566179 & 602 & 23,7317283 & 514 & 343903236 \\
\hline 90 & 288 & 426 & 17,1698337 & 296 & 24,2935336 & 969 & 24,7363049 & 484 & 24,2476354 & 276 & 343125940 \\
\hline 91 & 289 & 491 & 17,2586278 & 481 & 24,2998982 & 302 & 24,9404559 & 211 & 24,3336199 & 591 & 342876156 \\
\hline 92 & 290 & 215 & 17,3651808 & 483 & 24,4017312 & 326 & 25,0425315 & 213 & 24,3336199 & 588 & 342590768 \\
\hline 93 & 291 & 249 & 17,4302966 & 320 & 24,6181263 & 215 & 25,723035 & 968 & 24,3336199 & 355 & 341799453 \\
\hline 94 & 292 & 471 & 17,5664476 & 250 & 24,694501 & 490 & 25,7910854 & 482 & 24,505589 & 434 & 341775153 \\
\hline 95 & 293 & 498 & 17,5901261 & 513 & 24,796334 & 485 & 26,1313372 & 486 & 24,505589 & 966 & 341096512 \\
\hline 96 & 294 & 186 & 17,6848399 & 968 & 25,0063646 & 486 & 26,1313372 & 493 & 24,505589 & 509 & 341068430 \\
\hline 97 & 295 & 510 & 17,8209909 & 515 & 25,2291242 & 489 & 26,1993875 & 422 & 24,677558 & 348 & 339766685 \\
\hline 98 & 296 & 486 & 17,8417096 & 184 & 25,2418534 & 487 & 26,3014631 & 487 & 24,677558 & 361 & 338900661 \\
\hline 99 & 297 & 485 & 17,8446694 & 848 & 25,4837067 & 266 & 26,4035386 & 485 & 25,0214961 & 517 & 337725006 \\
\hline 100 & 298 & 487 & 17,8565086 & 510 & 25,7001018 & 577 & 26,67574 & 456 & 25,5374033 & 463 & 337579650 \\
\hline 101 & 299 & 496 & 17,8861067 & 484 & 26,1901731 & 606 & 27,3222184 & 476 & 25,5374033 & 366 & 336264886 \\
\hline 102 & 300 & 975 & 17,8949861 & 482 & 26,3238289 & 584 & 27,4923443 & 184 & 25,6233878 & 369 & 334970293 \\
\hline 103 & 301 & 610 & 17,9127449 & 493 & 26,4574847 & 320 & 27,5603947 & 426 & 25,7093723 & 329 & 334253958 \\
\hline 104 & 302 & 606 & 17,9808205 & 602 & 26,5211303 & 427 & 27,5944199 & 470 & 25,7093723 & 440 & 333870910 \\
\hline 105 & 303 & 468 & 18,1080921 & 181 & 27,310336 & 632 & 27,6624702 & 492 & 25,7093723 & 511 & 333564981 \\
\hline 106 & 311 & 490 & 18,4484698 & 253 & 27,4439919 & 583 & 27,7305206 & 354 & 26,2252794 & 286 & 331644978 \\
\hline 107 & 312 & 489 & 18,6023797 & 428 & 27,6349287 & 971 & 27,7645458 & 274 & 26,311264 & 352 & 331212850 \\
\hline 108 & 313 & 377 & 18,6260581 & 470 & 28,0549898 & 515 & 27,8666213 & 267 & 26,483233 & 288 & 330611629 \\
\hline 109 & 314 & 516 & 18,8362043 & 969 & 28,0613544 & 216 & 27,9346717 & 477 & 26,8271711 & 580 & 329939767 \\
\hline 110 & 315 & 326 & 19,1233055 & 492 & 28,1313646 & 484 & 27,9686968 & 275 & 26,9131556 & 222 & 328809250 \\
\hline
\end{tabular}




\begin{tabular}{|c|c|c|c|c|c|c|c|c|c|c|c|}
\hline \multirow{2}{*}{$\begin{array}{c}\text { ZATs } \\
\text { PUCAB } \\
20 \text { min } \\
\end{array}$} & & \multicolumn{2}{|c|}{ Trabalho } & \multirow{2}{*}{\begin{tabular}{|l|} 
estudo \\
pucab
\end{tabular}} & \multirow[b]{2}{*}{ abrange $\%$} & \multirow{2}{*}{\begin{tabular}{|l|} 
saude \\
pucab
\end{tabular}} & \multirow[b]{2}{*}{ abrange $\%$} & \multirow{2}{*}{\begin{tabular}{|l} 
recreação \\
pucab
\end{tabular}} & \multirow[b]{2}{*}{ abrange $\%$} & \multicolumn{2}{|c|}{ ponderação ordem } \\
\hline & & pucab & abrange $\%$ & & & & & & & $\begin{array}{l}\text { ZATs } \\
\text { pucab }\end{array}$ & $\mathrm{P}$ \\
\hline 111 & 316 & 185 & 19,2002605 & 576 & 28,1377291 & 421 & 28,0367472 & 296 & 26,9131556 & 500 & 328625026 \\
\hline 112 & 317 & 586 & 19,2505772 & 376 & 28,430499 & 473 & 28,0367472 & 254 & 27,0851247 & 985 & 328176685 \\
\hline 113 & 318 & 595 & 19,5080803 & 219 & 28,7550916 & 482 & 28,0367472 & 239 & 27,1711092 & 234 & 327400376 \\
\hline 114 & 319 & 971 & 19,5495176 & 632 & 28,7741853 & 296 & 28,2068731 & 473 & 27,1711092 & 579 & 326878934 \\
\hline 115 & 320 & 515 & 19,573196 & 997 & 28,8441955 & 633 & 28,2068731 & 489 & 27,2570937 & 462 & 326352227 \\
\hline 116 & 321 & 594 & 19,694548 & 179 & 28,8696538 & 594 & 28,4790745 & 491 & 27,4290628 & 224 & 325518963 \\
\hline 117 & 322 & 497 & 19,7300657 & 255 & 28,9142057 & 491 & 28,7853011 & 515 & 27,5150473 & 465 & 325089222 \\
\hline 118 & 323 & 513 & 19,7507843 & 275 & 29,1051426 & 495 & 28,9894522 & 287 & 27,6010318 & 984 & 324894566 \\
\hline 119 & 324 & 473 & 19,8366187 & 251 & 29,1496945 & 510 & 29,1595781 & 325 & 27,6010318 & 582 & 323635613 \\
\hline 120 & 325 & 632 & 19,9520511 & 328 & 29,1815173 & 422 & 29,329704 & 495 & 27,6010318 & 225 & 322995472 \\
\hline 121 & 326 & 469 & 20,0290061 & 473 & 29,404277 & 468 & 29,4317795 & 490 & 27,6870163 & 504 & 321617514 \\
\hline 122 & 327 & 455 & 20,091162 & 421 & 29,4106415 & 426 & 29,6699558 & 969 & 27,6870163 & 464 & 321540578 \\
\hline 123 & 328 & 456 & 20,1592376 & 633 & 29,7479633 & 494 & 29,6699558 & 632 & 28,0309544 & 438 & 321072536 \\
\hline 124 & 329 & 633 & 20,2006748 & 379 & 29,7988798 & 386 & 29,9761824 & 377 & 28,116939 & 221 & 318717711 \\
\hline 125 & 330 & 576 & 20,366424 & 274 & 30,1934827 & 471 & 29,9761824 & 468 & 28,116939 & 429 & 318685808 \\
\hline 126 & 331 & 252 & 20,4137809 & 252 & 30,3844196 & 975 & 30,0102076 & 513 & 28,3748925 & 226 & 316166393 \\
\hline 127 & 332 & 383 & 20,4463387 & 490 & 30,4607943 & 274 & 30,0442327 & 577 & 28,3748925 & 350 & 314066212 \\
\hline 128 & 333 & 848 & 20,5232937 & 489 & 30,8235743 & 610 & 30,0782579 & 179 & 28,460877 & 512 & 313928101 \\
\hline 129 & 334 & 301 & 20,6920026 & 486 & 30,9699593 & 219 & 30,3164342 & 320 & 28,460877 & 349 & 312660465 \\
\hline 130 & 335 & 951 & 20,792636 & 487 & 31,0526986 & 576 & 30,9629126 & 379 & 28,6328461 & 272 & 311818220 \\
\hline 131 & 336 & 475 & 20,8192743 & 266 & 31,0908859 & 267 & 31,3031643 & 633 & 28,8048151 & 441 & 311731851 \\
\hline 132 & 337 & 320 & 20,8666311 & 180 & 31,2245418 & 181 & 31,3371895 & 586 & 29,0627687 & 235 & 311096976 \\
\hline
\end{tabular}




\begin{tabular}{|c|c|c|c|c|c|c|c|c|c|c|c|}
\hline \multirow{2}{*}{$\begin{array}{c}\begin{array}{c}\text { ZATs } \\
\text { PUCAB }\end{array} \\
20 \mathrm{~min} \\
\end{array}$} & & \multicolumn{2}{|c|}{ Trabalho } & \multirow{2}{*}{$\begin{array}{l}\text { estudo } \\
\text { pucab }\end{array}$} & \multirow[b]{2}{*}{ abrange $\%$} & \multirow{2}{*}{\begin{tabular}{|l|} 
saude \\
pucab
\end{tabular}} & \multirow[b]{2}{*}{ abrange $\%$} & \multirow{2}{*}{\begin{tabular}{|l} 
recreação \\
pucab
\end{tabular}} & \multirow[b]{2}{*}{ abrange $\%$} & \multicolumn{2}{|c|}{ ponderação ordem } \\
\hline & & pucab & abrange $\%$ & & & & & & & $\begin{array}{l}\text { ZATs } \\
\text { pucab }\end{array}$ & $\mathrm{P}$ \\
\hline 133 & 338 & 474 & 21,1063754 & 378 & 31,2309063 & 379 & 31,6774413 & 471 & 29,1487532 & 347 & 310070131 \\
\hline 134 & 339 & 597 & 21,1655715 & 485 & 31,2563646 & 848 & 31,6774413 & 576 & 29,1487532 & 284 & 309558992 \\
\hline 135 & 340 & 353 & 21,4437933 & 475 & 31,2690937 & 255 & 31,813542 & 510 & 29,2347377 & 380 & 309131891 \\
\hline 136 & 341 & 216 & 21,4970698 & 574 & 31,3072811 & 217 & 32,0857435 & 597 & 29,4067068 & 590 & 308771231 \\
\hline 137 & 342 & 253 & 21,5592257 & 474 & 31,3645621 & 252 & 32,1537938 & 353 & 29,7506449 & 437 & 307943322 \\
\hline 138 & 343 & 476 & 21,5621855 & 610 & 31,4091141 & 251 & 32,187819 & 494 & 29,7506449 & 332 & 306419653 \\
\hline 139 & 344 & 230 & 21,9232818 & 975 & 31,4091141 & 180 & 32,2218442 & 386 & 29,8366294 & 986 & 303877241 \\
\hline 140 & 345 & 250 & 22,0475937 & 292 & 32,0073829 & 179 & 32,4940456 & 455 & 29,8366294 & 503 & 302596531 \\
\hline 141 & 346 & 179 & 22,1304682 & 330 & 32,0455703 & 253 & 32,4940456 & 610 & 30,266552 & 454 & 301197731 \\
\hline 142 & 347 & 472 & 22,1689457 & 606 & 32,1474033 & 513 & 32,6981967 & 215 & 30,4385211 & 232 & 299792200 \\
\hline 143 & 348 & 478 & 22,2163026 & 422 & 32,3128819 & 982 & 32,6981967 & 322 & 30,5245056 & 457 & 299074568 \\
\hline 144 & 349 & 479 & 22,2163026 & 230 & 32,6056517 & 997 & 32,766247 & 498 & 30,5245056 & 269 & 297122476 \\
\hline 145 & 350 & 480 & 22,2281418 & 372 & 32,6183809 & 378 & 33,0724736 & 606 & 30,5245056 & 991 & 296577850 \\
\hline 146 & 351 & 287 & 22,3879713 & 287 & 32,790224 & 275 & 33,2085743 & 975 & 30,5245056 & 381 & 292607720 \\
\hline 147 & 352 & 477 & 22,4826851 & 332 & 32,8665988 & 574 & 33,4467506 & 273 & 30,6104901 & 592 & 290461158 \\
\hline 148 & 353 & 997 & 22,5122832 & 374 & 32,8729633 & 981 & 33,514801 & 302 & 30,6964746 & 459 & 290415718 \\
\hline 149 & 354 & 237 & 22,5596401 & 386 & 32,9302444 & 273 & 33,9231031 & 469 & 30,7824592 & 844 & 289922679 \\
\hline 150 & 355 & 379 & 22,6721127 & 578 & 32,9811609 & 474 & 34,1272542 & 996 & 30,7824592 & 384 & 289250079 \\
\hline 151 & 356 & 255 & 22,8171432 & 319 & 32,99389 & 475 & 34,1272542 & 180 & 30,8684437 & 176 & 288547674 \\
\hline 152 & 357 & 251 & 22,897058 & 273 & 33,1148167 & 376 & 34,5695815 & 168 & 31,0404127 & 359 & 285628991 \\
\hline 153 & 358 & 982 & 22,9651335 & 495 & 33,2357434 & 269 & 34,7737326 & 594 & 31,5563199 & 218 & 285364349 \\
\hline 154 & 359 & 428 & 23,2137572 & 236 & 33,3057536 & 498 & 34,7737326 & 233 & 31,6423044 & 295 & 284772831 \\
\hline
\end{tabular}




\begin{tabular}{|c|c|c|c|c|c|c|c|c|c|c|c|}
\hline \multirow{2}{*}{$\begin{array}{l}\begin{array}{c}\text { ZATs } \\
\text { PUCAB }\end{array} \\
20 \mathrm{~min}\end{array}$} & & \multicolumn{2}{|c|}{ Trabalho } & \multirow{2}{*}{\begin{tabular}{|l} 
estudo \\
pucab
\end{tabular}} & \multirow[b]{2}{*}{ abrange \% } & \multirow{2}{*}{\begin{tabular}{|l} 
saude \\
pucab
\end{tabular}} & \multirow[b]{2}{*}{ abrange $\%$} & \multirow{2}{*}{\begin{tabular}{|l|} 
recreação \\
pucab \\
\end{tabular}} & \multirow[b]{2}{*}{ abrange $\%$} & \multicolumn{2}{|c|}{ ponderação ordem } \\
\hline & & pucab & abrange $\%$ & & & & & & & $\begin{array}{l}\text { ZATs } \\
\text { pucab }\end{array}$ & $\mathrm{P}$ \\
\hline 155 & 360 & 587 & 23,2374356 & 217 & 33,3121181 & 292 & 34,8758081 & 301 & 31,6423044 & 466 & 282121405 \\
\hline 156 & 361 & 266 & 23,3351092 & 594 & 33,4203157 & 843 & 34,9438585 & 497 & 31,7282889 & 593 & 280583511 \\
\hline 157 & 362 & 302 & 23,4890191 & 267 & 33,7385438 & 612 & 35,1139843 & 595 & 31,8142734 & 217 & 278034796 \\
\hline 158 & 363 & 219 & 23,6843663 & 469 & 33,9740326 & 330 & 35,2160599 & 971 & 31,900258 & 467 & 277779010 \\
\hline 159 & 364 & 354 & 23,7139644 & 844 & 34,3304481 & 469 & 35,4542361 & 475 & 32,072227 & 502 & 275283957 \\
\hline 160 & 365 & 236 & 23,8323566 & 233 & 34,3877291 & 319 & 35,6924124 & 496 & 32,1582115 & 362 & 273736113 \\
\hline 161 & 366 & 578 & 23,9921861 & 254 & 34,6041242 & 284 & 35,7604627 & 326 & 32,3301806 & 167 & 273660879 \\
\hline 162 & 367 & 574 & 24,3177648 & 227 & 34,7886965 & 167 & 36,6451174 & 378 & 32,3301806 & 539 & 272371536 \\
\hline 163 & 368 & 378 & 24,5367904 & 494 & 34,7950611 & 578 & 36,7812181 & 284 & 32,5021496 & 290 & 271865849 \\
\hline 164 & 369 & 239 & 24,6315042 & 175 & 34,9096232 & 991 & 36,7812181 & 281 & 32,8460877 & 293 & 271846595 \\
\hline 165 & 370 & 319 & 24,9511632 & 491 & 34,9096232 & 496 & 36,8152433 & 574 & 32,9320722 & 273 & 267590420 \\
\hline 166 & 371 & 499 & 24,9748417 & 167 & 34,9732688 & 254 & 36,8832936 & 216 & 33,1900258 & 231 & 266430184 \\
\hline 167 & 372 & 181 & 25,3684958 & 971 & 35,1132892 & 227 & 37,0193944 & 224 & 33,3619948 & 175 & 265090834 \\
\hline 168 & 373 & 227 & 25,6052803 & 468 & 35,1514766 & 272 & 37,1554951 & 271 & 33,3619948 & 229 & 262458322 \\
\hline 169 & 374 & 292 & 25,6378382 & 237 & 35,2596741 & 595 & 37,7339231 & 319 & 33,3619948 & 281 & 261824328 \\
\hline 170 & 375 & 421 & 25,6999941 & 586 & 35,6797352 & 497 & 37,8019735 & 478 & 33,4479794 & 385 & 260145915 \\
\hline 171 & 376 & 488 & 25,8065471 & 471 & 35,8706721 & 613 & 37,8359986 & 479 & 33,4479794 & 299 & 258614055 \\
\hline 172 & 377 & 612 & 25,8213461 & 498 & 35,9024949 & 225 & 37,904049 & 480 & 33,4479794 & 373 & 258168519 \\
\hline 173 & 378 & 184 & 25,8331853 & 385 & 35,959776 & 287 & 37,904049 & 472 & 33,7919175 & 282 & 256675631 \\
\hline 174 & 379 & 458 & 25,9397384 & 231 & 36,1570774 & 428 & 37,904049 & 474 & 33,7919175 & 458 & 254597306 \\
\hline 175 & 380 & 238 & 26,0018943 & 456 & 36,2334521 & 222 & 38,1422252 & 230 & 33,877902 & 300 & 251480193 \\
\hline 176 & 381 & 613 & 26,0788492 & 239 & 36,2780041 & 226 & 38,278326 & 428 & 33,877902 & 499 & 250439260 \\
\hline
\end{tabular}




\begin{tabular}{|c|c|c|c|c|c|c|c|c|c|c|c|}
\hline \multirow{2}{*}{$\begin{array}{l}\text { ZATs } \\
\text { PUCAB } \\
20 \mathrm{~min}\end{array}$} & & \multicolumn{2}{|c|}{ Trabalho } & \multirow{2}{*}{\begin{tabular}{|l} 
estudo \\
pucab
\end{tabular}} & \multirow[b]{2}{*}{ abrange \% } & \multirow{2}{*}{\begin{tabular}{|l} 
saude \\
pucab
\end{tabular}} & \multirow[b]{2}{*}{ abrange $\%$} & \multirow{2}{*}{$\begin{array}{l}\text { recreação } \\
\text { pucab }\end{array}$} & \multirow[b]{2}{*}{ abrange $\%$} & \multicolumn{2}{|c|}{ ponderação ordem } \\
\hline & & pucab & abrange $\%$ & & & & & & & $\begin{array}{l}\text { ZATs } \\
\text { pucab }\end{array}$ & $\mathrm{P}$ \\
\hline 177 & 382 & 180 & 26,2209199 & 496 & 36,3098269 & 385 & 38,5845526 & 269 & 34,049871 & 254 & 249858671 \\
\hline 178 & 383 & 843 & 26,2475582 & 843 & 36,4052953 & 586 & 38,9588295 & 272 & 34,049871 & 613 & 245676328 \\
\hline 179 & 384 & 593 & 26,3925886 & 373 & 36,4307536 & 218 & 39,1289554 & 171 & 34,3078246 & 267 & 244831298 \\
\hline 180 & 385 & 274 & 26,5021015 & 176 & 36,8953666 & 539 & 39,231031 & 982 & 34,3078246 & 238 & 243786767 \\
\hline 181 & 386 & 981 & 26,5464985 & 222 & 36,9399185 & 233 & 39,2650561 & 236 & 34,6517627 & 233 & 243347566 \\
\hline 182 & 387 & 467 & 26,570177 & 225 & 36,9844705 & 455 & 39,2650561 & 232 & 34,7377472 & 488 & 243177181 \\
\hline 183 & 388 & 330 & 26,5997751 & 218 & 37,0226578 & 476 & 39,4011569 & 237 & 34,8237317 & 981 & 241903462 \\
\hline 184 & 395 & 422 & 26,6856094 & 300 & 37,0735743 & 175 & 39,7754338 & 843 & 34,9097163 & 612 & 239104574 \\
\hline 185 & 397 & 502 & 26,7152075 & 226 & 37,4681772 & 230 & 39,9455597 & 292 & 35,0816853 & 372 & 236257867 \\
\hline 186 & 399 & 466 & 26,7418457 & 381 & 37,5381874 & 239 & 40,0136101 & 231 & 35,1676698 & 354 & 231484583 \\
\hline 187 & 400 & 374 & 27,0289469 & 232 & 37,5891039 & 236 & 40,2177611 & 238 & 35,3396389 & 374 & 230310691 \\
\hline 188 & 403 & 454 & 27,1384597 & 595 & 37,9900713 & 353 & 40,2177611 & 613 & 35,3396389 & 843 & 227440695 \\
\hline 189 & 420 & 592 & 27,1414195 & 174 & 38,4037678 & 844 & 40,5580129 & 612 & 35,4256234 & 587 & 227391785 \\
\hline 190 & 421 & 372 & 27,1562186 & 472 & 38,7538187 & 328 & 40,7281388 & 381 & 35,683577 & 386 & 225765198 \\
\hline 191 & 422 & 328 & 27,1976558 & 497 & 38,836558 & 271 & 40,7961892 & 175 & 35,9415305 & 328 & 223427632 \\
\hline 192 & 423 & 282 & 27,2302137 & 982 & 39,084776 & 381 & 40,8302144 & 227 & 35,9415305 & 480 & 222235770 \\
\hline 193 & 424 & 300 & 27,3456461 & 384 & 39,4857434 & 477 & 40,9663151 & 234 & 36,1994841 & 478 & 221436830 \\
\hline 194 & 425 & 293 & 27,4581187 & 455 & 39,7212322 & 499 & 41,0003403 & 587 & 36,2854686 & 479 & 220944127 \\
\hline 195 & 426 & 299 & 27,6268277 & 290 & 39,7785132 & 456 & 41,0343654 & 217 & 36,4574377 & 477 & 220249001 \\
\hline 196 & 427 & 386 & 27,6475463 & 299 & 39,8930754 & 281 & 41,1024158 & 219 & 36,4574377 & 330 & 219869321 \\
\hline 197 & 428 & 376 & 27,7393003 & 281 & 39,9503564 & 221 & 41,136441 & 176 & 36,5434222 & 376 & 219650356 \\
\hline 198 & 429 & 275 & 27,7629787 & 229 & 40,2113035 & 332 & 41,136441 & 276 & 36,6294067 & 275 & 217973850 \\
\hline
\end{tabular}




\begin{tabular}{|c|c|c|c|c|c|c|c|c|c|c|c|}
\hline \multirow{2}{*}{ 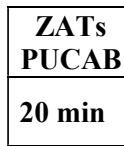 } & & \multicolumn{2}{|c|}{ Trabalho } & \multirow{2}{*}{\begin{tabular}{|l|} 
estudo \\
pucab \\
\end{tabular}} & \multirow[b]{2}{*}{ abrange \% } & \multirow{2}{*}{\begin{tabular}{|l} 
saude \\
pucab
\end{tabular}} & \multirow[b]{2}{*}{ abrange \% } & \multirow{2}{*}{$\begin{array}{l}\text { recreação } \\
\text { pucab }\end{array}$} & \multirow[b]{2}{*}{ abrange $\%$} & \multicolumn{2}{|c|}{ ponderação ordem } \\
\hline & & pucab & abrange $\%$ & & & & & & & $\begin{array}{l}\text { ZATs } \\
\text { pucab }\end{array}$ & $\mathrm{P}$ \\
\hline 199 & 430 & 590 & 27,8606523 & 587 & 40,2685845 & 232 & 41,2044913 & 991 & 36,7153912 & 239 & 217095071 \\
\hline 200 & 431 & 229 & 28,0589593 & 269 & 40,2813136 & 176 & 41,340592 & 373 & 36,8873603 & 227 & 215527169 \\
\hline 201 & 432 & 373 & 28,0767182 & 272 & 40,3831466 & 374 & 41,5447431 & 997 & 36,9733448 & 422 & 212385391 \\
\hline 202 & 433 & 349 & 28,3519801 & 380 & 40,421334 & 440 & 41,6468186 & 174 & 37,1453138 & 353 & 211561193 \\
\hline 203 & 434 & 347 & 28,3549399 & 282 & 40,5358961 & 237 & 41,9530453 & 499 & 37,1453138 & 982 & 211218540 \\
\hline 204 & 435 & 233 & 28,3726988 & 221 & 40,6186354 & 380 & 42,0210956 & 288 & 37,2312984 & 597 & 210213330 \\
\hline 205 & 436 & 362 & 28,399337 & 284 & 40,8159369 & 276 & 42,1571963 & 350 & 37,2312984 & 472 & 209821397 \\
\hline 206 & 437 & 437 & 28,4496537 & 286 & 41,0259674 & 478 & 42,1912215 & 385 & 37,4892519 & 236 & 208493141 \\
\hline 207 & 438 & 457 & 28,6361215 & 476 & 41,0641548 & 479 & 42,1912215 & 229 & 37,661221 & 319 & 207650302 \\
\hline 208 & 439 & 281 & 28,6834784 & 991 & 41,2996436 & 480 & 42,1912215 & 384 & 37,661221 & 237 & 207270619 \\
\hline 209 & 440 & 500 & 28,9350619 & 238 & 41,4460285 & 228 & 42,4293978 & 593 & 37,661221 & 476 & 207108449 \\
\hline 210 & 441 & 359 & 28,9617001 & 329 & 41,4587576 & 472 & 42,4634229 & 172 & 37,83319 & 180 & 207089623 \\
\hline 211 & 442 & 350 & 29,1067306 & 597 & 41,6178717 & 295 & 42,5654985 & 467 & 37,83319 & 292 & 206768420 \\
\hline 212 & 443 & 290 & 29,1096904 & 981 & 41,9997454 & 231 & 42,9057503 & 458 & 38,1771281 & 578 & 206355379 \\
\hline 213 & 444 & 539 & 29,2192032 & 539 & 42,1206721 & 597 & 43,041851 & 981 & 38,2631126 & 274 & 204020773 \\
\hline 214 & 445 & 459 & 29,3375955 & 488 & 42,1397658 & 278 & 43,3140524 & 362 & 38,6070507 & 574 & 198246179 \\
\hline 215 & 446 & 295 & 29,3849523 & 224 & 42,1588595 & 488 & 43,3140524 & 290 & 38,6930353 & 378 & 197613936 \\
\hline 216 & 447 & 254 & 29,4500681 & 354 & 42,3879837 & 384 & 43,3480776 & 349 & 38,6930353 & 421 & 191617347 \\
\hline 217 & 448 & 267 & 29,6927722 & 362 & 42,4643585 & 224 & 43,4161279 & 374 & 38,6930353 & 455 & 191152467 \\
\hline 218 & 449 & 385 & 29,710531 & 479 & 42,5852851 & 238 & 43,7223545 & 441 & 38,6930353 & 287 & 190930661 \\
\hline 219 & 450 & 464 & 29,740129 & 480 & 42,6489308 & 459 & 43,7563797 & 466 & 38,9509888 & 230 & 188096356 \\
\hline 220 & 451 & 462 & 29,9502753 & 477 & 42,6616599 & 171 & 43,9265056 & 488 & 39,2089424 & 181 & 186585229 \\
\hline
\end{tabular}




\begin{tabular}{|c|c|c|c|c|c|c|c|c|c|c|c|}
\hline \multirow{2}{*}{$\begin{array}{l}\text { ZATs } \\
\text { PUCAB } \\
20 \mathrm{~min}\end{array}$} & & \multicolumn{2}{|c|}{ Trabalho } & \multirow{2}{*}{\begin{tabular}{|l} 
estudo \\
pucab
\end{tabular}} & \multirow[b]{2}{*}{ abrange \% } & \multirow{2}{*}{\begin{tabular}{|l} 
saude \\
pucab
\end{tabular}} & \multirow[b]{2}{*}{ abrange $\%$} & \multirow{2}{*}{$\begin{array}{l}\text { recreação } \\
\text { pucab }\end{array}$} & \multirow[b]{2}{*}{ abrange $\%$} & \multicolumn{2}{|c|}{ ponderação ordem } \\
\hline & & pucab & abrange $\%$ & & & & & & & $\begin{array}{l}\text { ZATs } \\
\text { pucab }\end{array}$ & $\mathrm{P}$ \\
\hline 221 & 452 & 231 & 30,0065116 & 353 & 42,7125764 & 354 & 43,9265056 & 592 & 39,2089424 & 219 & 185757571 \\
\hline 222 & 453 & 352 & 30,121944 & 478 & 42,7253055 & 300 & 44,1646819 & 282 & 39,3809114 & 456 & 185407065 \\
\hline 223 & 454 & 503 & 30,1278636 & 612 & 42,8271385 & 282 & 44,5049337 & 359 & 39,5528805 & 428 & 185295148 \\
\hline 224 & 455 & 986 & 30,2462558 & 276 & 42,979888 & 372 & 44,572984 & 578 & 39,5528805 & 497 & 185252993 \\
\hline 225 & 456 & 348 & 30,2521755 & 434 & 43,0880855 & 359 & 44,6070092 & 347 & 39,810834 & 266 & 183175795 \\
\hline 226 & 457 & 465 & 30,2699343 & 171 & 43,1580957 & 467 & 44,8792106 & 286 & 39,8968186 & 184 & 182567800 \\
\hline 227 & 458 & 463 & 30,3646481 & 363 & 43,7945519 & 288 & 45,0153113 & 376 & 39,8968186 & 379 & 181742994 \\
\hline 228 & 459 & 175 & 30,3705677 & 613 & 43,9282077 & 466 & 45,0153113 & 464 & 40,3267412 & 595 & 180972778 \\
\hline 229 & 460 & 588 & 30,4090452 & 288 & 44,0364053 & 293 & 45,1854372 & 330 & 40,4127257 & 997 & 180653938 \\
\hline 230 & 461 & 589 & 30,426804 & 172 & 44,0745927 & 512 & 45,1854372 & 361 & 40,4987102 & 251 & 179976245 \\
\hline 231 & 462 & 582 & 30,4889599 & 458 & 44,1636965 & 299 & 45,2194624 & 355 & 40,7566638 & 255 & 176795051 \\
\hline 232 & 463 & 441 & 30,5303972 & 295 & 44,3546334 & 234 & 45,3215379 & 502 & 40,7566638 & 474 & 176635301 \\
\hline 233 & 464 & 591 & 30,5540757 & 235 & 44,3991853 & 235 & 45,4236135 & 235 & 40,8426483 & 469 & 175031041 \\
\hline 234 & 465 & 504 & 30,823418 & 293 & 44,5582994 & 172 & 45,8319156 & 240 & 40,8426483 & 586 & 174034243 \\
\hline 235 & 466 & 438 & 30,853016 & 168 & 44,6728615 & 517 & 45,8659408 & 437 & 40,9286328 & 475 & 173986143 \\
\hline 236 & 467 & 512 & 30,8914935 & 369 & 44,9656314 & 174 & 46,104117 & 352 & 41,0146174 & 179 & 172648517 \\
\hline 237 & 468 & 361 & 30,9270112 & 503 & 45,6275458 & 240 & 46,2061926 & 380 & 41,0146174 & 302 & 169855862 \\
\hline 238 & 469 & 429 & 30,9921269 & 986 & 45,6402749 & 229 & 46,3082681 & 966 & 41,0146174 & 496 & 167297023 \\
\hline 239 & 470 & 984 & 31,0158054 & 234 & 45,6657332 & 587 & 46,4103437 & 454 & 41,1006019 & 971 & 166767039 \\
\hline 240 & 471 & 384 & 31,0661221 & 440 & 45,7166497 & 375 & 46,6825451 & 170 & 41,44454 & 594 & 165329084 \\
\hline 241 & 472 & 985 & 31,1312378 & 429 & 45,8630346 & 362 & 46,7505954 & 223 & 41,44454 & 253 & 163764596 \\
\hline 242 & 473 & 218 & 31,1549162 & 240 & 45,8948574 & 458 & 46,7846206 & 465 & 41,7024936 & 252 & 161138297 \\
\hline
\end{tabular}




\begin{tabular}{|c|c|c|c|c|c|c|c|c|c|c|c|}
\hline \multirow{2}{*}{$\begin{array}{l}\text { ZATs } \\
\text { PUCAB } \\
20 \mathrm{~min}\end{array}$} & & \multicolumn{2}{|c|}{ Trabalho } & \multirow{2}{*}{\begin{tabular}{|l} 
estudo \\
pucab
\end{tabular}} & \multirow[b]{2}{*}{ abrange \% } & \multirow{2}{*}{\begin{tabular}{|l} 
saude \\
pucab
\end{tabular}} & \multirow[b]{2}{*}{ abrange $\%$} & \multirow{2}{*}{\begin{tabular}{|l|} 
recreação \\
pucab \\
\end{tabular}} & \multirow[b]{2}{*}{ abrange $\%$} & \multicolumn{2}{|c|}{ ponderação ordem } \\
\hline & & pucab & abrange $\%$ & & & & & & & $\begin{array}{l}\text { ZATs } \\
\text { pucab }\end{array}$ & $\mathrm{P}$ \\
\hline 243 & 474 & 580 & 31,1608358 & 952 & 45,9139511 & 168 & 47,0908472 & 463 & 41,8744626 & 468 & 160708628 \\
\hline 244 & 475 & 273 & 31,1726751 & 359 & 46,2830957 & 575 & 47,3970738 & 278 & 41,9604471 & 498 & 158966436 \\
\hline 245 & 476 & 966 & 31,2673889 & 170 & 46,6649695 & 290 & 47,4651242 & 462 & 42,1324162 & 633 & 158946006 \\
\hline 246 & 477 & 235 & 31,3443438 & 283 & 46,7095214 & 283 & 47,4991494 & 844 & 42,3903697 & 576 & 157363672 \\
\hline 247 & 478 & 167 & 31,5574498 & 459 & 46,9068228 & 342 & 47,5671997 & 375 & 42,4763543 & 216 & 156605832 \\
\hline 248 & 479 & 176 & 31,5870479 & 365 & 47,0595723 & 579 & 47,805376 & 590 & 42,4763543 & 471 & 153945699 \\
\hline 249 & 480 & 351 & 31,6107263 & 435 & 47,1550407 & 437 & 47,9414767 & 438 & 42,6483233 & 250 & 153923220 \\
\hline 250 & 481 & 579 & 31,7054401 & 366 & 47,3077902 & 441 & 48,0095271 & 300 & 42,7343078 & 473 & 153404233 \\
\hline 251 & 482 & 991 & 31,7616764 & 331 & 47,3587067 & 502 & 48,0435522 & 539 & 42,7343078 & 848 & 153360894 \\
\hline 252 & 483 & 381 & 31,8711892 & 278 & 47,3968941 & 984 & 48,2136781 & 440 & 42,8202923 & 320 & 152959984 \\
\hline 253 & 484 & 509 & 31,9688628 & 285 & 47,5178208 & 363 & 48,4178292 & 280 & 42,9062769 & 632 & 151134574 \\
\hline 254 & 485 & 355 & 31,9718226 & 499 & 47,5496436 & 373 & 48,4518544 & 348 & 43,3361995 & 610 & 149820693 \\
\hline 255 & 486 & 511 & 31,9747825 & 228 & 47,5941955 & 580 & 48,5879551 & 283 & 43,5941531 & 975 & 149319872 \\
\hline 256 & 487 & 217 & 32,0221393 & 334 & 48,25611 & 985 & 48,5879551 & 299 & 43,6801376 & 606 & 148883830 \\
\hline 257 & 488 & 461 & 32,1523708 & 169 & 48,2942974 & 511 & 48,6560054 & 328 & 43,6801376 & 491 & 147930262 \\
\hline 258 & 489 & 269 & 32,2145267 & 579 & 48,3070265 & 329 & 48,9282069 & 225 & 43,9380911 & 513 & 147383294 \\
\hline 259 & 490 & 844 & 32,2530042 & 512 & 48,313391 & 514 & 48,9962572 & 285 & 43,9380911 & 301 & 145718386 \\
\hline 260 & 491 & 232 & 32,3062807 & 502 & 48,3706721 & 277 & 49,1323579 & 295 & 44,0240757 & 494 & 145551085 \\
\hline 261 & 492 & 517 & 32,347718 & 441 & 48,4406823 & 438 & 49,1323579 & 279 & 44,1100602 & 489 & 144750908 \\
\hline 262 & 493 & 380 & 32,546025 & 511 & 48,4470468 & 590 & 49,1323579 & 169 & 44,2820292 & 490 & 143448056 \\
\hline 263 & 494 & 366 & 32,6762564 & 223 & 48,4788697 & 334 & 49,3024838 & 459 & 44,3680138 & 515 & 141331812 \\
\hline 264 & 495 & 514 & 32,7028947 & 457 & 48,5234216 & 845 & 49,3024838 & 226 & 44,7119518 & 485 & 139877546 \\
\hline
\end{tabular}




\begin{tabular}{|c|c|c|c|c|c|c|c|c|c|c|c|}
\hline \multirow{2}{*}{ 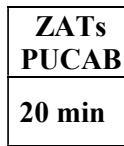 } & & \multicolumn{2}{|c|}{ Trabalho } & \multirow{2}{*}{\begin{tabular}{|l} 
estudo \\
pucab
\end{tabular}} & \multirow[b]{2}{*}{ abrange \% } & \multirow{2}{*}{\begin{tabular}{|l} 
saude \\
pucab
\end{tabular}} & \multirow[b]{2}{*}{ abrange $\%$} & \multirow{2}{*}{$\begin{array}{l}\text { recreação } \\
\text { pucab }\end{array}$} & \multirow[b]{2}{*}{ abrange $\%$} & \multicolumn{2}{|c|}{ ponderação ordem } \\
\hline & & pucab & abrange $\%$ & & & & & & & $\begin{array}{l}\text { ZATs } \\
\text { pucab }\end{array}$ & $\mathrm{P}$ \\
\hline 265 & 496 & 369 & 32,8242467 & 291 & 48,5361507 & 286 & 49,3705342 & 369 & 44,8839209 & 487 & 139561431 \\
\hline 266 & 497 & 234 & 32,8982419 & 279 & 48,7716395 & 593 & 49,6427356 & 173 & 44,9699054 & 951 & 139005271 \\
\hline 267 & 498 & 435 & 32,9811164 & 517 & 48,822556 & 504 & 49,9149371 & 591 & 44,9699054 & 486 & 137301939 \\
\hline 268 & 499 & 460 & 33,0343929 & 430 & 48,8989308 & 366 & 50,1190881 & 457 & 45,3138435 & 495 & 136098217 \\
\hline 269 & 500 & 575 & 33,0403126 & 504 & 48,9625764 & 341 & 50,3232392 & 588 & 45,3138435 & 383 & 132288888 \\
\hline 270 & 501 & 993 & 33,049192 & 271 & 49,0835031 & 298 & 50,3912896 & 589 & 45,5717971 & 510 & 130286922 \\
\hline 271 & 502 & 284 & 33,1261469 & 575 & 49,1153259 & 592 & 50,3912896 & 460 & 45,6577816 & 377 & 123302737 \\
\hline 272 & 503 & 221 & 33,2060617 & 514 & 49,1344196 & 509 & 50,5273903 & 500 & 45,9157352 & 516 & 122315736 \\
\hline 273 & 504 & 331 & 33,2711774 & 984 & 49,3062627 & 952 & 50,8676421 & 351 & 46,1736887 & 326 & 121955084 \\
\hline 274 & 505 & 272 & 33,3096549 & 438 & 49,3126273 & 582 & 50,9016672 & 372 & 46,3456578 & 482 & 117991747 \\
\hline 275 & 506 & 288 & 33,3392529 & 375 & 49,3635438 & 169 & 51,1738687 & 332 & 46,5176268 & 484 & 117918797 \\
\hline 276 & 507 & 440 & 33,4783638 & 985 & 49,4526477 & 360 & 51,4120449 & 363 & 46,6036113 & 215 & 116680695 \\
\hline 277 & 508 & 434 & 33,5849168 & 580 & 49,490835 & 223 & 51,5141204 & 293 & 46,6895959 & 426 & 113424243 \\
\hline 278 & 509 & 224 & 33,6500326 & 582 & 49,5162933 & 280 & 51,5141204 & 341 & 46,7755804 & 185 & 113378276 \\
\hline 279 & 510 & 329 & 33,7980228 & 436 & 49,8217923 & 291 & 51,6502212 & 331 & 47,033534 & 583 & 113303226 \\
\hline 280 & 511 & 286 & 33,8897768 & 846 & 49,9745418 & 503 & 51,7182715 & 461 & 47,1195185 & 249 & 113230649 \\
\hline 281 & 512 & 506 & 33,9016161 & 509 & 50,1845723 & 591 & 51,8203471 & 366 & 47,2914875 & 296 & 108930670 \\
\hline 282 & 513 & 226 & 33,9312141 & 355 & 50,4391548 & 986 & 51,8543722 & 342 & 47,4634566 & 584 & 106482854 \\
\hline 283 & 514 & 332 & 34,0259279 & 173 & 50,4582485 & 434 & 51,9904729 & 356 & 47,5494411 & 577 & 103901740 \\
\hline 284 & 515 & 507 & 34,0940034 & 467 & 50,7255601 & 457 & 52,1265737 & 514 & 47,6354256 & 481 & 103645167 \\
\hline 285 & 516 & 283 & 34,1413603 & 593 & 50,8974033 & 279 & 52,1605988 & 512 & 47,7214101 & 427 & 103231774 \\
\hline 286 & 517 & 356 & 34,466939 & 466 & 50,9355906 & 589 & 52,2286492 & 992 & 47,7214101 & 483 & 103166489 \\
\hline
\end{tabular}




\begin{tabular}{|c|c|c|c|c|c|c|c|c|c|c|c|}
\hline $\begin{array}{c}\text { ZATs } \\
\text { PUCAB }\end{array}$ & & Trabal & & estudo & & saude & & recreação & & ponder: & o ordem \\
\hline $20 \mathrm{~min}$ & & pucab & abrange \% & pucab & abrange \% & pucab & abrange \% & pucab & abrange \% & $\begin{array}{l}\text { ZATs } \\
\text { pucab }\end{array}$ & $P$ \\
\hline 287 & 518 & 278 & 34,60309 & 341 & 51,5529532 & 285 & 52,4328003 & 218 & 47,8073947 & 492 & 102084246 \\
\hline 288 & 519 & 271 & 34,6178891 & 592 & 51,8329939 & 170 & 52,6029262 & 277 & 47,8933792 & 470 & 100192996 \\
\hline 289 & 539 & 518 & 34,6474871 & 333 & 52,0557536 & 846 & 52,6029262 & 340 & 48,0653482 & 969 & 95994917 \\
\hline 290 & 574 & 375 & 34,6534067 & 342 & 52,0621181 & 369 & 52,9091528 & 228 & 48,3233018 & 325 & 95413157,8 \\
\hline 291 & 575 & 240 & 34,8724324 & 367 & 52,0621181 & 355 & 52,943178 & 579 & 48,4092863 & 581 & 94471983 \\
\hline 292 & 576 & 436 & 34,9109098 & 845 & 52,3803462 & 173 & 53,0792787 & 222 & 48,5812554 & 996 & 91481015,8 \\
\hline 293 & 577 & 225 & 35,1151364 & 465 & 52,4058045 & 500 & 53,147329 & 346 & 48,8392089 & 965 & 91162939,8 \\
\hline 294 & 578 & 298 & 35,2838454 & 360 & 52,412169 & 331 & 53,2153794 & 365 & 48,8392089 & 387 & 90699856 \\
\hline 295 & 579 & 357 & 35,3016042 & 431 & 52,4439919 & 588 & 53,2494046 & 221 & 49,011178 & 382 & 90684539 \\
\hline 296 & 580 & 508 & 35,7662937 & 966 & 52,5840122 & 220 & 53,2834297 & 291 & 49,0971625 & 186 & 89136783,8 \\
\hline 297 & 581 & 276 & 35,7692535 & 347 & 52,6094705 & 464 & 53,521606 & 952 & 49,2691316 & 322 & 85023243 \\
\hline 298 & 582 & 505 & 36,0267566 & 350 & 52,615835 & 465 & 53,521606 & 846 & 49,3551161 & 425 & 81091480 \\
\hline 299 & 583 & 222 & 36,0889126 & 280 & 52,6667515 & 350 & 53,7938074 & 511 & 49,4411006 & 321 & 79634257,5 \\
\hline 300 & 584 & 443 & 36,2546617 & 464 & 52,7813136 & 966 & 53,8618578 & 986 & 49,5270851 & 183 & 79431313,5 \\
\hline 301 & 585 & 439 & 36,3700941 & 371 & 52,8067719 & 435 & 54,2021096 & 993 & 49,5270851 & 616 & 78586299,8 \\
\hline 302 & 586 & 371 & 36,3937726 & 461 & 52,9849796 & 365 & 54,474311 & 345 & 49,7850387 & 983 & 77369542,3 \\
\hline 303 & 587 & 367 & 36,5269638 & 277 & 53,0868126 & 429 & 54,5083362 & 503 & 49,9570077 & 602 & 77252624,3 \\
\hline 304 & 588 & 430 & 36,6068786 & 361 & 53,0995418 & 461 & 54,5083362 & 845 & 49,9570077 & 324 & 75541447,3 \\
\hline 305 & 589 & 341 & 36,6690345 & 454 & 53,1313646 & 462 & 54,9166383 & 344 & 50,0429923 & 617 & 75271545 \\
\hline 306 & 590 & 346 & 36,7430297 & 437 & 53,4559572 & 463 & 54,9506635 & 357 & 50,2149613 & 988 & 74535773,5 \\
\hline 307 & 591 & 431 & 37,133724 & 462 & 53,5641548 & 349 & 55,4610412 & 575 & 50,3869304 & 493 & 74179451,3 \\
\hline 308 & 592 & 345 & 37,2225182 & 507 & 53,6023422 & 436 & 55,5290915 & 429 & 50,4729149 & 297 & 72516475,3 \\
\hline
\end{tabular}




\begin{tabular}{|c|c|c|c|c|c|c|c|c|c|c|c|}
\hline \multirow{2}{*}{$\begin{array}{l}\text { ZATs } \\
\text { PUCAB } \\
20 \mathrm{~min}\end{array}$} & & \multicolumn{2}{|c|}{ Trabalho } & \multirow{2}{*}{\begin{tabular}{|l|} 
estudo \\
pucab
\end{tabular}} & \multirow[b]{2}{*}{ abrange $\%$} & \multirow{2}{*}{\begin{tabular}{|l} 
saude \\
pucab
\end{tabular}} & \multirow[b]{2}{*}{ abrange \% } & \multirow{2}{*}{$\begin{array}{l}\text { recreação } \\
\text { pucab }\end{array}$} & \multirow[b]{2}{*}{ abrange $\%$} & \multicolumn{2}{|c|}{ ponderação ordem } \\
\hline & & pucab & abrange $\%$ & & & & & & & $\begin{array}{l}\text { ZATs } \\
\text { pucab }\end{array}$ & P \\
\hline 309 & 593 & 291 & 37,438584 & 439 & 53,6405295 & 340 & 55,5631167 & 270 & 50,6448839 & 388 & 72183388 \\
\hline 310 & 594 & 342 & 37,4474634 & 349 & 53,7105397 & 507 & 55,5631167 & 517 & 50,6448839 & 968 & 71772767 \\
\hline 311 & 595 & 344 & 37,5421772 & 993 & 54,0351324 & 454 & 55,6651922 & 329 & 50,7308684 & 318 & 70342945,3 \\
\hline 312 & 596 & 992 & 37,6398508 & 298 & 54,2133401 & 361 & 56,0734944 & 298 & 51,5907137 & 424 & 70021052,3 \\
\hline 313 & 597 & 174 & 37,6664891 & 352 & 54,3851833 & 460 & 56,2776455 & 509 & 51,9346518 & 214 & 69514575,8 \\
\hline 314 & 598 & 285 & 37,728645 & 368 & 55,1043788 & 506 & 56,3456958 & 984 & 52,0206363 & 842 & 69283033,8 \\
\hline 315 & 599 & 279 & 37,7789617 & 506 & 55,1616599 & 347 & 56,379721 & 358 & 52,1926053 & 614 & 68844046,8 \\
\hline 316 & 600 & 845 & 37,8174392 & 340 & 55,2571283 & 333 & 56,4817965 & 343 & 52,4505589 & 599 & 67125919,5 \\
\hline 317 & 601 & 171 & 37,926952 & 356 & 55,3716904 & 352 & 56,6859476 & 443 & 52,4505589 & 585 & 66147862,5 \\
\hline 318 & 602 & 363 & 37,9891079 & 590 & 55,4035132 & 439 & 57,1963253 & 580 & 52,4505589 & 601 & 64656765 \\
\hline 319 & 603 & 451 & 37,9920677 & 460 & 55,4862525 & 358 & 57,9448792 & 985 & 52,4505589 & 955 & 61792140,5 \\
\hline 320 & 605 & 228 & 38,0542236 & 220 & 55,6899185 & 344 & 58,1830555 & 334 & 52,6225279 & 323 & 61692109,3 \\
\hline 321 & 606 & 170 & 38,1015805 & 270 & 56,0972505 & 505 & 58,2170806 & 504 & 52,794497 & 634 & 61645644 \\
\hline 322 & 610 & 168 & 38,353164 & 432 & 56,7782587 & 508 & 58,8975842 & 268 & 53,1384351 & 596 & 61359742 \\
\hline 323 & 612 & 368 & 38,3798023 & 463 & 56,8355397 & 327 & 58,9316094 & 368 & 53,1384351 & 615 & 61330720,3 \\
\hline 324 & 613 & 172 & 38,4774759 & 346 & 56,9946538 & 518 & 58,9996597 & 294 & 53,6543422 & 202 & 60281608 \\
\hline 325 & 614 & 501 & 38,536672 & 348 & 57,1601324 & 430 & 59,1017353 & 435 & 53,6543422 & 618 & 59819814,5 \\
\hline 326 & 615 & 452 & 38,7912153 & 344 & 57,7138493 & 356 & 59,1357605 & 367 & 53,7403267 & 519 & 59451255,8 \\
\hline 327 & 616 & 358 & 38,8237732 & 351 & 57,8411405 & 270 & 59,2038108 & 333 & 54,1702494 & 303 & 58277498,8 \\
\hline 328 & 617 & 395 & 39,0783165 & 518 & 58,2039206 & 348 & 59,6801633 & 436 & 54,600172 & 600 & 54117053,8 \\
\hline 329 & 618 & 432 & 39,252945 & 268 & 58,6939919 & 346 & 59,7822389 & 360 & 54,6861565 & 631 & 53171016,8 \\
\hline 330 & 631 & 453 & 39,3121411 & 357 & 59,2668024 & 367 & 60,2245662 & 582 & 54,6861565 & 211 & 52841250 \\
\hline
\end{tabular}




\begin{tabular}{|c|c|c|c|c|c|c|c|c|c|c|c|}
\hline \multirow{2}{*}{$\begin{array}{l}\text { ZATs } \\
\text { PUCAB } \\
20 \text { min }\end{array}$} & & \multicolumn{2}{|c|}{ Trabalho } & \multirow{2}{*}{\begin{tabular}{|l|} 
estudo \\
pucab
\end{tabular}} & \multirow[b]{2}{*}{ abrange \% } & \multirow{2}{*}{\begin{tabular}{|l|} 
saude \\
pucab
\end{tabular}} & \multirow[b]{2}{*}{ abrange $\%$} & \multirow{2}{*}{$\begin{array}{l}\text { recreação } \\
\text { pucab }\end{array}$} & \multirow{2}{*}{ abrange \% } & \multicolumn{2}{|c|}{ ponderação ordem } \\
\hline & & pucab & abrange \% & & & & & & & $\begin{array}{l}\text { ZATs } \\
\text { pucab }\end{array}$ & $\mathrm{P}$ \\
\hline 331 & 632 & 334 & 39,3417392 & 591 & 59,3559063 & 294 & 60,3946921 & 327 & 54,772141 & 199 & 52055577,8 \\
\hline 332 & 633 & 450 & 39,5134079 & 339 & 59,4004582 & 431 & 60,564818 & 434 & 54,9441101 & 212 & 50648336 \\
\hline 333 & 634 & 294 & 39,5607648 & 345 & 59,4386456 & 357 & 60,5988431 & 452 & 55,0300946 & 200 & 50154463,8 \\
\hline 334 & 841 & 280 & 39,5637246 & 588 & 59,4386456 & 351 & 60,9731201 & 453 & 55,0300946 & 317 & 49903735 \\
\hline 335 & 842 & 448 & 39,5814835 & 508 & 59,4450102 & 268 & 61,3814223 & 220 & 55,5460017 & 953 & 48965592,5 \\
\hline 336 & 843 & 449 & 39,6258805 & 327 & 59,5086558 & 368 & 61,7556992 & 507 & 55,5460017 & 213 & 47881115,5 \\
\hline 337 & 844 & 270 & 39,8093885 & 343 & 59,5404786 & 993 & 61,9598503 & 506 & 55,7179708 & 967 & 46287287,3 \\
\hline 338 & 845 & 327 & 39,9603386 & 505 & 59,6041242 & 343 & 61,9938755 & 451 & 56,1478934 & 423 & 45996198,5 \\
\hline 339 & 846 & 343 & 40,0195347 & 500 & 59,7505092 & 345 & 62,1980265 & 439 & 56,2338779 & 987 & 44547965,8 \\
\hline 340 & 848 & 447 & 40,0550524 & 589 & 59,8205193 & 992 & \begin{tabular}{|l}
64,0353862 \\
\end{tabular} & 395 & 56,4918315 & 420 & 43383518,5 \\
\hline 341 & 951 & 444 & 40,4339075 & 364 & 61,3989308 & 451 & 64,2735624 & 518 & 57,0077386 & 598 & 41236153,8 \\
\hline 342 & 952 & 268 & \begin{tabular}{|l}
40,670692 \\
\end{tabular} & 992 & 61,787169 & 453 & 65,1922423 & 442 & \begin{tabular}{|l}
57,4376612 \\
\end{tabular} & 841 & 39692681 \\
\hline 343 & 953 & 333 & 40,8157225 & 289 & 61,8953666 & 289 & 65,2943178 & 364 & 57,5236457 & 182 & 37008296 \\
\hline 344 & 954 & 370 & 40,8246019 & 358 & 61,9717413 & 371 & 65,2943178 & 430 & 57,6096303 & 603 & 33038057,5 \\
\hline 345 & 955 & 365 & 40,9015569 & 294 & 62,1690428 & 443 & 65,7366451 & 370 & 57,8675838 & 605 & 30925609,5 \\
\hline 346 & 965 & 846 & 40,9193157 & 395 & 65,1349287 & 501 & 65,7366451 & 339 & 57,9535684 & 314 & 30457418,8 \\
\hline 347 & 966 & 277 & 41,0258687 & 370 & 65,2876782 & 395 & 65,7706703 & 505 & 58,383491 & 954 & 28635222,3 \\
\hline 348 & 967 & 952 & 41,0406677 & 452 & 66,3505601 & 452 & 66,1109221 & 508 & 58,55546 & 208 & 27825877 \\
\hline 349 & 968 & 340 & 41,5231161 & 335 & 66,3632892 & 339 & 66,5872746 & 431 & 58,8134136 & 209 & 26543848 \\
\hline 350 & 969 & 223 & 42,1683538 & 453 & 66,7706212 & 432 & 66,6212998 & 289 & 59,0713672 & 210 & 25797751,5 \\
\hline 351 & 971 & 360 & 42,3341029 & 443 & 66,8279022 & 447 & 68,186458 & 450 & 59,2433362 & 201 & 25381930,3 \\
\hline 352 & 975 & 442 & 42,9734209 & 336 & 67,8907841 & 450 & 68,6628105 & 501 & 59,2433362 & 204 & 24373767 \\
\hline
\end{tabular}




\begin{tabular}{|l|l|l|l|l|l|l|l|l|l|l|l|}
\hline $\begin{array}{c}\text { ZATs } \\
\text { PUCAB }\end{array}$ & \multicolumn{2}{|l|}{ Trabalho } & estudo & & saude & & recreação & \multicolumn{3}{|l|}{ ponderação ordem } \\
\hline $\mathbf{2 0}$ min & & pucab & abrange $\%$ & pucab & abrange $\%$ & pucab & abrange $\%$ & pucab & abrange $\%$ & $\begin{array}{l}\text { ZATs } \\
\text { pucab }\end{array}$ & P \\
\hline 353 & 981 & 446 & 43,4440301 & 451 & 68,5272403 & 364 & 69,0030623 & 448 & 60,6190886 & 203 & 21989212,3 \\
\hline 354 & 982 & 364 & 44,0715089 & 338 & 70,334776 & 370 & 69,8536917 & 449 & 60,6190886 & 205 & 19635270,3 \\
\hline 355 & 983 & 289 & 44,846978 & 442 & 70,5702648 & 442 & 70,2960191 & 371 & 60,7910576 & 207 & 19467944,5 \\
\hline 356 & 984 & 445 & 44,9564909 & 450 & 70,595723 & 444 & 70,6022457 & 444 & 62,2527945 & 206 & 18505575,3 \\
\hline 357 & 985 & 169 & 45,1873557 & 337 & 70,7293788 & 448 & 71,7591017 & 447 & 62,338779 & 316 & 13494329,5 \\
\hline 358 & 986 & 220 & 45,1932753 & 448 & 71,7158859 & 449 & 71,7591017 & 432 & 64,2304385 & 397 & 11761495,5 \\
\hline 359 & 987 & 339 & 45,7230806 & 449 & 71,8622709 & 335 & 72,0653283 & 445 & 66,8959587 & 313 & 9464957,25 \\
\hline 360 & 988 & 173 & 46,0190611 & 444 & 72,0277495 & 336 & 72,9159578 & 446 & 68,6156492 & 400 & 8140239,25 \\
\hline 361 & 991 & 336 & 50,4469307 & 501 & 74,0071283 & 446 & 73,902688 & 336 & 68,9595873 & 399 & 6490848,25 \\
\hline 362 & 992 & 335 & 50,5801219 & 447 & 74,2808045 & 445 & 74,4470908 & 338 & 69,6474635 & 315 & 6013049,75 \\
\hline 363 & 993 & 338 & 51,4680637 & 445 & 75,3755092 & 338 & 75,2636951 & 335 & 70,0773861 & 312 & 3753558,25 \\
\hline 364 & 996 & 433 & 52,835494 & 446 & 76,5593177 & 337 & 77,0670296 & 337 & 70,4213242 & 403 & 2704654,25 \\
\hline 365 & 997 & 337 & 53,8092701 & 433 & 79,2324338 & 433 & 85,6073494 & 433 & 79,4496991 & 311 & 1291642,5 \\
\hline
\end{tabular}

Tabela do Ranking no Cenário 2 em 20 minutos. 


\begin{tabular}{|c|c|c|c|c|c|c|c|c|c|c|c|}
\hline \multirow{2}{*}{\begin{tabular}{|l|} 
ZATs \\
PUCAB \\
$\mathbf{3 0}$ min \\
\end{tabular}} & & \multicolumn{2}{|c|}{ Trabalho } & \multirow{2}{*}{$\begin{array}{l}\text { estudo } \\
\text { pucab }\end{array}$} & \multirow[b]{2}{*}{ abrange $\%$} & \multirow{2}{*}{$\begin{array}{l}\text { saude } \\
\text { pucab }\end{array}$} & \multirow[b]{2}{*}{ abrange $\%$} & \multirow{2}{*}{$\begin{array}{l}\text { recreação } \\
\text { pucab }\end{array}$} & \multirow[b]{2}{*}{ abrange $\%$} & \multicolumn{2}{|l|}{ ponderação } \\
\hline & & pucab & abrange $\%$ & & & & & & & pucab prio & ponderado \\
\hline 1 & 167 & 311 & 13,8637305 & 311 & 7,46563136 & 311 & 11,9428377 & 311 & 14,7893379 & 433 & 317825404 \\
\hline 2 & 168 & 312 & 14,1893092 & 403 & 7,98752546 & 312 & 12,9295679 & 403 & 15,8211522 & 337 & 394387149 \\
\hline 3 & 169 & 403 & 14,7339135 & 312 & 8,68126273 & 203 & 13,4399456 & 312 & 16,0791058 & 336 & 459162578 \\
\hline 4 & 170 & 315 & 16,6666667 & 315 & 10,3933299 & 403 & 14,3586254 & 315 & 19,6044712 & 335 & 412725657 \\
\hline 5 & 171 & 399 & 17,5279702 & 206 & 10,5142566 & 206 & 14,7669275 & 399 & 20,3783319 & 294 & 396657467 \\
\hline 6 & 172 & 397 & 17,8180311 & 203 & 11,6153259 & 182 & 16,9105138 & 397 & 20,72227 & 327 & 405243775 \\
\hline 7 & 173 & 400 & 17,971941 & 397 & 12,5636456 & 315 & 17,1827152 & 313 & 20,894239 & 173 & 463092724 \\
\hline 8 & 174 & 313 & 19,1706624 & 399 & 12,9964358 & 399 & 17,8291936 & 954 & 21,4961307 & 338 & 402809415 \\
\hline 9 & 175 & 206 & 19,5169597 & 313 & 13,1555499 & 204 & 18,4416468 & 400 & 22,0120378 & 333 & 268660918 \\
\hline 10 & 176 & 203 & 19,9638904 & 400 & 13,4928717 & 313 & 18,8839741 & 317 & 22,4419604 & 431 & 359387936 \\
\hline 11 & 179 & 605 & 21,0945362 & 207 & 14,4857434 & 400 & 18,9179993 & 323 & 26,5692175 & 169 & 239132569 \\
\hline 12 & 180 & 204 & 22,0209554 & 204 & 14,5366599 & 397 & 19,4964274 & 203 & 26,8271711 & 289 & 191798345 \\
\hline 13 & 181 & 598 & 22,3524537 & 317 & 14,8994399 & 202 & 19,5644777 & 206 & 27,0851247 & 364 & 181916625 \\
\hline 14 & 182 & 317 & 22,7579471 & 182 & 15,1667515 & 954 & 20,8914597 & 314 & 27,0851247 & 445 & 20365658 \\
\hline 15 & 183 & 955 & 22,9148168 & 954 & 15,6950102 & 207 & 21,1296359 & 953 & 27,6010318 & 430 & 95110188,3 \\
\hline 16 & 184 & 314 & 23,1368022 & 202 & 15,9241344 & 317 & 21,2997618 & 207 & 28,6328461 & 508 & 164873611 \\
\hline 17 & 185 & 323 & 23,2285562 & 323 & 17,2034114 & 199 & 22,4906431 & 423 & 28,8048151 & 223 & 131869704 \\
\hline 18 & 186 & 182 & 23,5837329 & 953 & 17,3816191 & 200 & 23,239197 & 182 & 29,0627687 & 339 & 98327035,8 \\
\hline 19 & 199 & 953 & 23,749482 & 955 & 17,5089104 & 953 & 23,3412725 & 200 & 29,4067068 & 518 & 33371256,3 \\
\hline 20 & 200 & 954 & 23,7790801 & 199 & 19,0809572 & 955 & 23,9197006 & 519 & 30,1805675 & 432 & 29815548,8 \\
\hline 21 & 201 & 967 & 23,9033919 & 200 & 19,360998 & 209 & 25,1786322 & 955 & 30,4385211 & 331 & 74573475,8 \\
\hline 22 & 202 & 207 & 23,9152312 & 209 & 19,6155804 & 314 & 25,518884 & 204 & 30,6104901 & 220 & 32337858,5 \\
\hline 23 & 203 & 423 & 24,1194578 & 210 & 20,4111507 & 323 & 26,097312 & 199 & 30,8684437 & 371 & 10705515,3 \\
\hline
\end{tabular}




\begin{tabular}{|c|c|c|c|c|c|c|c|c|c|c|c|}
\hline $\begin{array}{c}\text { ZATs } \\
\text { PUCAB }\end{array}$ & & Trabalho & & estudo & & saude & & recreação & & ponderação & \\
\hline $30 \mathrm{~min}$ & & pucab & abrange $\%$ & pucab & abrange $\%$ & pucab & abrange $\%$ & pucab & abrange $\%$ & pucab prio & ponderado \\
\hline 24 & 204 & 603 & 24,2319304 & 388 & 20,9266802 & 316 & 28,2408983 & 420 & 31,0404127 & 505 & 15466357,3 \\
\hline 25 & 205 & 200 & 24,5042325 & 314 & 21,6267821 & 210 & 28,3429738 & 598 & 31,8142734 & 446 & 36761626,3 \\
\hline 26 & 206 & 519 & 24,7972533 & 423 & 22,9887984 & 841 & 29,7380061 & 202 & 32,244196 & 449 & 9844131,5 \\
\hline 27 & 207 & 424 & 25,229385 & 519 & 23,1733707 & 208 & 29,9761824 & 618 & 32,4161651 & 363 & 23442538,3 \\
\hline 28 & 208 & 205 & 25,2649026 & 205 & 23,415224 & 423 & 29,9761824 & 316 & 32,5021496 & 453 & 52140366,8 \\
\hline 29 & 209 & 602 & 25,563843 & 208 & 23,6443483 & 388 & 30,3844845 & 388 & 32,6741187 & 365 & 38187918,8 \\
\hline 30 & 210 & 199 & 25,747351 & 424 & 23,6443483 & 324 & 30,5886356 & 424 & 33,1040413 & 506 & 37238078,8 \\
\hline 31 & 211 & 202 & 26,1350855 & 324 & 24,0707739 & 205 & 30,6907111 & 210 & 33,7919175 & 442 & 45324608,3 \\
\hline 32 & 212 & 210 & 26,2475582 & 316 & 24,5735743 & 519 & 31,3371895 & 208 & 34,3938091 & 448 & 49859097,5 \\
\hline 33 & 213 & 493 & 26,3985083 & 212 & 26,4638493 & 212 & 33,6509017 & 841 & 35,0816853 & 429 & 66799841,5 \\
\hline 34 & 214 & 209 & 26,493222 & 211 & 27,1193992 & 211 & 34,5015311 & 614 & 35,683577 & 986 & 63620155,5 \\
\hline 35 & 215 & 211 & 26,7744036 & 841 & 27,4694501 & 424 & 34,6036067 & 205 & 36,027515 & 444 & 105162642 \\
\hline 36 & 216 & 600 & 26,8040017 & 988 & 30,3716904 & 213 & 36,3048656 & 617 & 36,1134996 & 370 & 139950935 \\
\hline 37 & 217 & 388 & 26,889836 & 425 & 30,435336 & 214 & 37,529772 & 605 & 36,3714531 & 436 & 296659565 \\
\hline 38 & 218 & 968 & 27,4314805 & 321 & 31,9246436 & 842 & 37,8700238 & 209 & 36,4574377 & 507 & 273651401 \\
\hline 39 & 219 & 316 & 27,4788374 & 618 & 32,4783605 & 618 & 38,1082001 & 425 & 36,8013758 & 222 & 235682244 \\
\hline 40 & 220 & 324 & 27,5025158 & 318 & 33,1657332 & 996 & 38,5165022 & 616 & 37,1453138 & 452 & 433309256 \\
\hline 41 & 221 & 212 & 28,3253419 & 322 & 33,7512729 & 605 & 38,5845526 & 214 & 37,3172829 & 447 & 348100421 \\
\hline 42 & 222 & 596 & 28,3253419 & 213 & 33,8467413 & 322 & 38,9928547 & 842 & 37,661221 & 298 & 415947637 \\
\hline 43 & 223 & 618 & 28,612443 & 996 & 34,884165 & 183 & 39,0268799 & 987 & 37,661221 & 170 & 442222058 \\
\hline 44 & 224 & 425 & 28,8196294 & 842 & 35,1260183 & 425 & 39,2650561 & 631 & 37,7472055 & 228 & 359097500 \\
\hline 45 & 225 & 969 & 29,2695199 & 420 & 35,5779022 & 321 & 39,4011569 & 603 & 37,83319 & 435 & 386184932 \\
\hline 46 & 226 & 599 & 29,4707867 & 214 & 36,8699084 & 614 & 39,435182 & 516 & 38,3490972 & 172 & 378808095 \\
\hline
\end{tabular}




\begin{tabular}{|c|c|c|c|c|c|c|c|c|c|c|c|}
\hline $\begin{array}{c}\text { ZATs } \\
\text { PUCAB }\end{array}$ & & Trabalho & & estudo & & saude & & recreação & & ponderação & \\
\hline $30 \mathrm{~min}$ & & pucab & abrange $\%$ & pucab & abrange $\%$ & pucab & abrange $\%$ & pucab & abrange $\%$ & pucab prio & ponderado \\
\hline 47 & 227 & 601 & 29,4826259 & 387 & 37,194501 & 186 & 39,7754338 & 967 & 38,7790198 & 503 & 316851363 \\
\hline 48 & 228 & 208 & 29,6217368 & 614 & 37,4936354 & 318 & 40,4559374 & 324 & 39,638865 & 174 & 410741057 \\
\hline 49 & 229 & 470 & 30,3261706 & 965 & 38,2191955 & 420 & 40,4559374 & 318 & 39,8968186 & 450 & 259658665 \\
\hline 50 & 230 & 492 & 30,3468892 & 516 & 38,7601833 & 493 & 41,6127935 & 215 & 40,6706793 & 451 & 166172431 \\
\hline 51 & 231 & 841 & 30,4475226 & 201 & 38,7983707 & 585 & 41,6127935 & 585 & 40,6706793 & 509 & 241542837 \\
\hline 52 & 232 & 987 & 30,4919197 & 325 & 38,8047352 & 602 & 41,9190201 & 983 & 41,0146174 & 360 & 231985141 \\
\hline 53 & 233 & 214 & 30,9003729 & 186 & 39,0911405 & 983 & 42,0551208 & 211 & 41,1865864 & 171 & 244751410 \\
\hline 54 & 234 & 996 & 31,1726751 & 183 & 39,4284623 & 988 & 42,3273222 & 602 & 41,1865864 & 984 & 255962360 \\
\hline 55 & 235 & 988 & 31,2289114 & 383 & 39,854888 & 600 & 42,5995236 & 321 & 41,5305245 & 443 & 233832831 \\
\hline 56 & 236 & 322 & 31,2644291 & 598 & 40,014002 & 516 & 42,9738006 & 387 & 41,9604471 & 168 & 156916852 \\
\hline 57 & 237 & 616 & 31,2673889 & 382 & 40,0203666 & 969 & 43,1779517 & 490 & 41,9604471 & 580 & 225440556 \\
\hline 58 & 238 & 213 & 31,4153792 & 605 & 40,4086049 & 598 & 43,2119769 & 186 & 42,1324162 & 985 & 237539012 \\
\hline 59 & 239 & 420 & 31,4597762 & 215 & 42,0506619 & 968 & 43,3140524 & 183 & 42,3043852 & 582 & 194614376 \\
\hline 60 & 240 & 201 & 31,5840881 & 615 & 42,6680244 & 325 & 43,8924804 & 969 & 42,4763543 & 952 & 340284362 \\
\hline 61 & 249 & 631 & 31,661043 & 602 & 42,8653259 & 201 & 44,2327322 & 493 & 42,5623388 & 225 & 163504906 \\
\hline 62 & 250 & 490 & 31,7261588 & 585 & 43,1326375 & 596 & 44,9812862 & 988 & 42,5623388 & 358 & 202970078 \\
\hline 63 & 251 & 617 & 31,8001539 & 987 & 43,4190428 & 965 & 45,4916638 & 212 & 42,9062769 & 511 & 183895047 \\
\hline 64 & 252 & 614 & 32,1286924 & 616 & 43,5145112 & 387 & 45,6277645 & 634 & 42,9922614 & 504 & 159452219 \\
\hline 65 & 253 & 634 & 32,3713964 & 983 & 43,5145112 & 599 & 45,7298401 & 201 & 43,0782459 & 579 & 178884545 \\
\hline 66 & 254 & 489 & 32,9396792 & 617 & 43,7881874 & 601 & 45,7298401 & 213 & 43,5081685 & 283 & 262986896 \\
\hline 67 & 255 & 321 & 32,9544782 & 631 & 44,0809572 & 382 & 46,0020415 & 470 & 44,3680138 & 226 & 191847894 \\
\hline 68 & 266 & 585 & 33,7684248 & 969 & 45,7421079 & 470 & 46,6144947 & 492 & 44,3680138 & 439 & 207349283 \\
\hline 69 & 267 & 318 & 33,9844906 & 968 & 46,3403768 & 615 & 46,6485199 & 382 & 44,5399828 & 368 & 265100599 \\
\hline
\end{tabular}




\begin{tabular}{|c|c|c|c|c|c|c|c|c|c|c|c|}
\hline $\begin{array}{c}\text { ZATs } \\
\text { PUCAB }\end{array}$ & & Trabalho & & estudo & & saude & & recreação & & ponderação & \\
\hline $30 \mathrm{~min}$ & & pucab & abrange $\%$ & pucab & abrange $\%$ & pucab & abrange $\%$ & pucab & abrange $\%$ & pucab prio & ponderado \\
\hline 70 & 268 & 983 & 34,3929438 & 513 & 46,6267821 & 492 & 46,6825451 & 581 & 44,7119518 & 299 & 365805913 \\
\hline 71 & 269 & 387 & 34,7333215 & 600 & 46,6840631 & 967 & 46,852671 & 965 & 44,7119518 & 501 & 249617315 \\
\hline 72 & 270 & 483 & 35,2720062 & 426 & 47,0086558 & 490 & 47,7033004 & 185 & 44,9699054 & 369 & 341305142 \\
\hline 73 & 271 & 481 & 35,2779258 & 493 & 47,4032587 & 185 & 49,336509 & 600 & 45,0558899 & 434 & 274314596 \\
\hline 74 & 272 & 382 & 35,6922986 & 470 & 48,2879328 & 249 & 49,9829874 & 489 & 45,4858126 & 395 & 267770858 \\
\hline 75 & 273 & 842 & 35,7307761 & 492 & 48,3643075 & 215 & 50,0510378 & 968 & 45,4858126 & 992 & 255094797 \\
\hline 76 & 274 & 482 & 36,1155508 & 515 & 48,4024949 & 426 & 50,7995917 & 951 & 45,9157352 & 340 & 225343782 \\
\hline 77 & 275 & 484 & 36,1155508 & 303 & 48,5679735 & 303 & 50,9697176 & 615 & 46,0877042 & 268 & 243824909 \\
\hline 78 & 276 & 965 & 36,2132244 & 596 & 49,0007637 & 427 & 51,1058183 & 596 & 46,9475494 & 334 & 302970737 \\
\hline 79 & 277 & 325 & 36,4559285 & 427 & 49,1471487 & 383 & 51,7522967 & 513 & 47,205503 & 514 & 331886712 \\
\hline 80 & 278 & 303 & 38,1163796 & 185 & 49,3635438 & 616 & 51,9564478 & 583 & 47,4634566 & 367 & 270104382 \\
\hline 81 & 279 & 516 & 38,2288522 & 603 & 49,898167 & 603 & 52,0585233 & 216 & 47,9793637 & 846 & 333050674 \\
\hline 82 & 280 & 494 & 38,5248328 & 634 & 50,0318228 & 617 & 52,0925485 & 601 & 48,4952709 & 176 & 325010892 \\
\hline 83 & 281 & 486 & 38,749778 & 599 & 50,3118635 & 631 & 52,0925485 & 599 & 48,6672399 & 224 & 216305301 \\
\hline 84 & 282 & 485 & 38,7527378 & 601 & 50,36278 & 987 & 52,1265737 & 515 & 49,183147 & 291 & 247225316 \\
\hline 85 & 283 & 487 & 38,764577 & 216 & 50,9992363 & 489 & 52,2626744 & 848 & 49,5270851 & 300 & 379910405 \\
\hline 86 & 284 & 581 & 39,0339194 & 490 & 51,0628819 & 848 & 52,3307247 & 996 & 49,5270851 & 295 & 273291043 \\
\hline 87 & 285 & 495 & 39,0723969 & 581 & 51,2219959 & 515 & 52,5008506 & 322 & 49,9570077 & 591 & 314728634 \\
\hline 88 & 286 & 183 & 39,1523116 & 967 & 51,4511202 & 275 & 53,0792787 & 584 & 50,2149613 & 344 & 293460127 \\
\hline 89 & 287 & 491 & 39,2263068 & 510 & 52,2466904 & 250 & 53,3174549 & 586 & 51,3327601 & 589 & 179120876 \\
\hline 90 & 288 & 471 & 39,2559048 & 377 & 52,8449593 & 326 & 53,5556312 & 184 & 52,1066208 & 588 & 311630590 \\
\hline 91 & 289 & 426 & 39,3535784 & 326 & 53,3095723 & 471 & 54,3382103 & 255 & 52,1926053 & 221 & 454879622 \\
\hline 92 & 290 & 186 & 39,4926893 & 184 & 53,3350305 & 491 & 54,3382103 & 252 & 52,2785899 & 293 & 296645549 \\
\hline
\end{tabular}




\begin{tabular}{|c|c|c|c|c|c|c|c|c|c|c|c|}
\hline $\begin{array}{c}\text { ZATs } \\
\text { PUCAB }\end{array}$ & & Trabalho & & estudo & & saude & & recreação & & ponderação & \\
\hline $30 \mathrm{~min}$ & & pucab & abrange $\%$ & pucab & abrange $\%$ & pucab & abrange $\%$ & pucab & abrange $\%$ & pucab prio & ponderado \\
\hline 93 & 291 & 606 & 39,5962825 & 489 & 53,6978106 & 494 & 54,4062606 & 471 & 52,2785899 & 375 & 357324466 \\
\hline 94 & 292 & 215 & 40,2326407 & 848 & 54,2897149 & 251 & 54,6104117 & 491 & 52,2785899 & 270 & 235759909 \\
\hline 95 & 293 & 427 & 40,3628722 & 951 & 54,4297352 & 495 & 55,3589656 & 426 & 52,966466 & 240 & 345915163 \\
\hline 96 & 294 & 583 & 40,8482804 & 494 & 54,4870163 & 581 & 55,8693433 & 478 & 52,966466 & 366 & 464171638 \\
\hline 97 & 295 & 584 & 40,8926774 & 249 & 54,665224 & 634 & 55,8693433 & 479 & 52,966466 & 343 & 353546903 \\
\hline 98 & 296 & 478 & 40,9281951 & 583 & 54,9643585 & 377 & 55,9033685 & 480 & 52,966466 & 350 & 170747814 \\
\hline 99 & 297 & 479 & 40,9281951 & 584 & 55,3716904 & 184 & 56,0394692 & 253 & 53,1384351 & 345 & 158569341 \\
\hline 100 & 298 & 480 & 40,9400343 & 275 & 55,4544297 & 468 & 57,1623001 & 494 & 53,5683577 & 461 & 413296264 \\
\hline 101 & 299 & 615 & 40,9518736 & 236 & 55,9317719 & 253 & 57,5706022 & 495 & 53,9122958 & 279 & 373967299 \\
\hline 102 & 300 & 297 & 40,960753 & 577 & 56,0590631 & 266 & 57,5706022 & 303 & 54,3422184 & 277 & 353785096 \\
\hline 103 & 301 & 597 & 41,0436275 & 181 & 56,3391039 & 274 & 58,0129296 & 325 & 54,600172 & 357 & 181650526 \\
\hline 104 & 302 & 498 & 41,7510211 & 495 & 56,7718941 & 281 & 58,0469547 & 468 & 54,6861565 & 460 & 310098669 \\
\hline 105 & 303 & 468 & 41,8516545 & 469 & 57,2874236 & 997 & 58,0469547 & 296 & 54,8581255 & 341 & 102624346 \\
\hline 106 & 311 & 951 & 42,0144439 & 491 & 57,2937882 & 510 & 58,5233072 & 597 & 55,0300946 & 280 & 1291642,5 \\
\hline 107 & 312 & 326 & 42,0558811 & 481 & 57,3892566 & 269 & 58,863559 & 251 & 55,2020636 & 966 & 2973229,5 \\
\hline 108 & 313 & 594 & 42,1861126 & 483 & 57,4910896 & 273 & 58,863559 & 476 & 55,2880482 & 361 & 10899672 \\
\hline 109 & 314 & 383 & 42,3577813 & 428 & 57,5356415 & 267 & 59,2038108 & 594 & 55,3740327 & 346 & 24540165,5 \\
\hline 110 & 315 & 971 & 42,9053454 & 250 & 57,7265784 & 951 & 59,2718612 & 249 & 55,4600172 & 167 & 5530677,75 \\
\hline 111 & 316 & 496 & 43,322678 & 468 & 57,8220468 & 230 & 59,3058864 & 297 & 55,4600172 & 227 & 45691605,3 \\
\hline 112 & 317 & 595 & 43,5269046 & 471 & 57,8411405 & 272 & 60,0204151 & 236 & 55,8039553 & 285 & 17836562,5 \\
\hline 113 & 318 & 497 & 43,6778547 & 484 & 57,8793279 & 255 & 60,0544403 & 587 & 55,8899398 & 288 & 75563867,3 \\
\hline 114 & 319 & 515 & 44,2579767 & 482 & 58,0129837 & 252 & 60,1565158 & 576 & 55,9759243 & 342 & 276764555 \\
\hline 115 & 320 & 975 & 44,648671 & 287 & 58,1466395 & 428 & 60,2585914 & 481 & 56,0619089 & 302 & 253013317 \\
\hline
\end{tabular}




\begin{tabular}{|c|c|c|c|c|c|c|c|c|c|c|c|}
\hline $\begin{array}{c}\text { ZATs } \\
\text { PUCAB }\end{array}$ & & Trabalho & & estudo & & saude & & recreação & & ponderação & \\
\hline $30 \mathrm{~min}$ & & pucab & abrange $\%$ & pucab & abrange $\%$ & pucab & abrange $\%$ & pucab & abrange $\%$ & pucab prio & ponderado \\
\hline 116 & 321 & 610 & 44,6664299 & 576 & 58,1466395 & 216 & 60,3946921 & 484 & 56,0619089 & 332 & 73123817 \\
\hline 117 & 322 & 296 & 44,6753093 & 251 & 58,2675662 & 586 & 60,6328683 & 250 & 56,1478934 & 380 & 66305116 \\
\hline 118 & 323 & 185 & 44,7996211 & 230 & 58,503055 & 513 & 60,9731201 & 483 & 56,1478934 & 844 & 22487685 \\
\hline 119 & 324 & 216 & 44,9002545 & 255 & 58,5857943 & 180 & 61,3814223 & 275 & 56,3198624 & 590 & 47504790,5 \\
\hline 120 & 325 & 513 & 45,0748831 & 372 & 58,764002 & 284 & 61,4494726 & 482 & 56,3198624 & 276 & 90892090,8 \\
\hline 121 & 326 & 633 & 45,107441 & 253 & 58,8403768 & 498 & 61,5515481 & 477 & 56,4918315 & 356 & 132946304 \\
\hline 122 & 327 & 377 & 45,6934825 & 266 & 59,171334 & 469 & 61,6876489 & 180 & 56,577816 & 384 & 463326843 \\
\hline 123 & 328 & 469 & 45,9657846 & 231 & 59,3304481 & 239 & 61,8917999 & 427 & 56,577816 & 459 & 255961122 \\
\hline 124 & 329 & 848 & 46,0575386 & 252 & 59,6677699 & 330 & 62,2660769 & 232 & 56,6638005 & 993 & 293358212 \\
\hline 125 & 330 & 997 & 46,3002427 & 269 & 59,680499 & 287 & 62,4021776 & 456 & 56,749785 & 438 & 220813804 \\
\hline 126 & 331 & 252 & 46,4275144 & 273 & 59,7250509 & 181 & 62,470228 & 383 & 56,9217541 & 351 & 433655232 \\
\hline 127 & 332 & 473 & 46,4363938 & 239 & 60,087831 & 583 & 62,8104798 & 606 & 56,9217541 & 217 & 309146179 \\
\hline 128 & 333 & 510 & 46,4571124 & 586 & 60,2914969 & 301 & 62,9465805 & 181 & 57,0937231 & 290 & 461255913 \\
\hline 129 & 334 & 236 & 46,5163085 & 274 & 60,7879328 & 278 & 63,1507315 & 510 & 57,0937231 & 578 & 364519615 \\
\hline 130 & 335 & 476 & 47,0549932 & 218 & 61,3289206 & 584 & 63,422933 & 287 & 57,7815993 & 845 & 464283921 \\
\hline 131 & 336 & 474 & 47,1319481 & 378 & 61,3925662 & 576 & 63,5250085 & 486 & 57,7815993 & 286 & 466139870 \\
\hline 132 & 337 & 455 & 47,6321553 & 997 & 61,729888 & 376 & 64,0694114 & 487 & 57,9535684 & 329 & 467552882 \\
\hline 133 & 338 & 593 & 47,7061505 & 301 & 61,7935336 & 485 & 64,6138142 & 971 & 58,0395529 & 441 & 462883588 \\
\hline 134 & 339 & 577 & 47,7091103 & 281 & 61,990835 & 486 & 64,6138142 & 485 & 58,2975064 & 437 & 441539169 \\
\hline 135 & 340 & 472 & 47,8571006 & 267 & 62,0608452 & 438 & 64,6478394 & 230 & 58,4694755 & 843 & 366118891 \\
\hline 136 & 341 & 230 & 47,9133369 & 379 & 62,239053 & 236 & 64,7158898 & 274 & 58,7274291 & 440 & 326585641 \\
\hline 137 & 342 & 576 & 47,9251761 & 292 & 62,4554481 & 487 & 64,7839401 & 498 & 58,8993981 & 981 & 310992536 \\
\hline 138 & 343 & 632 & 47,9458947 & 180 & 62,5509165 & 372 & 64,8519905 & 167 & 59,2433362 & 362 & 339867504 \\
\hline
\end{tabular}




\begin{tabular}{|c|c|c|c|c|c|c|c|c|c|c|c|}
\hline \begin{tabular}{|c|} 
ZATs \\
PUCAB
\end{tabular} & & Trabalho & & estudo & & saude & & recreação & & ponderação & \\
\hline $30 \mathrm{~min}$ & & pucab & abrange $\%$ & pucab & abrange $\%$ & pucab & abrange $\%$ & pucab & abrange $\%$ & pucab prio & ponderado \\
\hline 139 & 344 & 456 & 47,9843722 & 486 & 62,6973014 & 991 & 65,3623682 & 231 & 59,3293207 & 352 & 350460072 \\
\hline 140 & 345 & 586 & 48,1116439 & 487 & 62,7800407 & 594 & 65,4984689 & 377 & 59,3293207 & 374 & 335483582 \\
\hline 141 & 346 & 467 & 48,1649204 & 232 & 62,9009674 & 483 & 65,532494 & 422 & 59,3293207 & 355 & 319119229 \\
\hline 142 & 347 & 379 & 48,2093175 & 485 & 62,9837067 & 481 & 65,5665192 & 577 & 59,3293207 & 991 & 241506845 \\
\hline 143 & 348 & 466 & 48,2152371 & 272 & 62,9900713 & 437 & 65,7026199 & 266 & 59,5012898 & 463 & 281347124 \\
\hline 144 & 349 & 301 & 48,3928254 & 498 & 62,9964358 & 440 & 65,7026199 & 235 & 59,5872743 & 373 & 265941139 \\
\hline 145 & 350 & 475 & 48,5260167 & 284 & 63,0155295 & 484 & 65,7706703 & 254 & 59,5872743 & 348 & 337313172 \\
\hline 146 & 351 & 587 & 48,8101581 & 330 & 63,3401222 & 482 & 65,8387207 & 239 & 59,8452279 & 359 & 300038900 \\
\hline 147 & 352 & 499 & 49,0114249 & 219 & 63,4228615 & 502 & 65,9407962 & 469 & 59,9312124 & 500 & 287610542 \\
\hline 148 & 353 & 477 & 49,1742142 & 278 & 63,4292261 & 179 & 66,0088465 & 233 & 60,189166 & 612 & 231195852 \\
\hline 149 & 354 & 249 & 49,3103652 & 587 & 63,4674134 & 597 & 66,0768969 & 378 & 60,189166 & 613 & 218444426 \\
\hline 150 & 355 & 184 & 49,3281241 & 238 & 63,6647149 & 297 & 66,1109221 & 379 & 60,2751505 & 319 & 285505951 \\
\hline 151 & 356 & 354 & 49,3399633 & 296 & 63,7474542 & 271 & 66,2470228 & 354 & 60,4471195 & 539 & 302905847 \\
\hline 152 & 357 & 287 & 49,3547623 & 235 & 63,779277 & 577 & 66,7914257 & 349 & 60,6190886 & 575 & 329328590 \\
\hline 153 & 358 & 422 & 49,9526431 & 456 & 63,9956721 & 845 & 66,8254508 & 273 & 61,0490112 & 982 & 385477194 \\
\hline 154 & 359 & 253 & 50,2427041 & 286 & 64,1993381 & 606 & 66,8935012 & 502 & 61,3069647 & 512 & 280372454 \\
\hline 155 & 360 & 592 & 50,3226188 & 282 & 64,2948065 & 971 & 66,8935012 & 633 & 61,3069647 & 271 & 399190301 \\
\hline 156 & 361 & 421 & 50,4410111 & 285 & 64,3902749 & 282 & 66,9275264 & 238 & 61,3929493 & 218 & 321608759 \\
\hline 157 & 362 & 353 & 50,4854082 & 276 & 64,5684827 & 587 & 66,9955767 & 179 & 61,6509028 & 284 & 288115848 \\
\hline 158 & 363 & 982 & 50,7517907 & 385 & 65,0712831 & 285 & 67,2677782 & 234 & 61,7368874 & 381 & 428634109 \\
\hline 159 & 364 & 180 & 50,899781 & 991 & 65,160387 & 574 & 67,3358285 & 281 & 61,7368874 & 278 & 454493825 \\
\hline 160 & 365 & 378 & 50,899781 & 297 & 65,3004073 & 378 & 67,4719292 & 347 & 61,7368874 & 175 & 426512037 \\
\hline 161 & 366 & 181 & 51,2223998 & 440 & 65,4276986 & 235 & 67,6080299 & 352 & 62,2527945 & 454 & 340041411 \\
\hline
\end{tabular}




\begin{tabular}{|c|c|c|c|c|c|c|c|c|c|c|c|}
\hline $\begin{array}{l}\text { ZATs } \\
\text { PUCAB } \\
\end{array}$ & & Trabalho & & estudo & & saude & & recreação & & ponderação & \\
\hline $30 \mathrm{~min}$ & & pucab & abrange $\%$ & pucab & abrange $\%$ & pucab & abrange $\%$ & pucab & abrange $\%$ & pucab prio & ponderado \\
\hline 162 & 367 & 458 & 51,417747 & 229 & 65,8223014 & 238 & 67,6760803 & 175 & 62,9406707 & 272 & 363096643 \\
\hline 163 & 368 & 251 & 51,4739833 & 254 & 65,8795825 & 379 & 67,8462062 & 497 & 62,9406707 & 349 & 375384559 \\
\hline 164 & 369 & 613 & 51,5272598 & 376 & 65,9368635 & 276 & 67,9823069 & 276 & 63,0266552 & 267 & 372515380 \\
\hline 165 & 370 & 347 & 51,6071746 & 438 & 65,9686864 & 219 & 68,0503573 & 595 & 63,0266552 & 254 & 416802558 \\
\hline 166 & 371 & 239 & 51,630853 & 455 & 66,2296334 & 175 & 68,1524328 & 267 & 63,1986242 & 517 & 432088865 \\
\hline 167 & 372 & 386 & 51,7314864 & 237 & 66,2487271 & 167 & 68,4586594 & 269 & 63,1986242 & 229 & 242040393 \\
\hline 168 & 373 & 981 & 51,7877227 & 473 & 66,6751527 & 385 & 68,9350119 & 437 & 63,1986242 & 592 & 281966509 \\
\hline 169 & 374 & 574 & 52,03338666 & 217 & 66,7324338 & 279 & 69,0030623 & 455 & 63,3705933 & 458 & 287170712 \\
\hline 170 & 375 & 255 & 52,0837033 & 280 & 66,7833503 & 496 & 69,4113644 & 473 & 63,4565778 & 488 & 345716920 \\
\hline 171 & 376 & 464 & 52,1606583 & 574 & 66,9488289 & 595 & 69,4113644 & 284 & 63,6285469 & 234 & 216734998 \\
\hline 172 & 377 & 376 & 52,2376132 & 479 & 67,0188391 & 497 & 69,4794148 & 438 & 63,6285469 & 328 & 143843074 \\
\hline 173 & 378 & 457 & 52,332327 & 480 & 67,0824847 & 280 & 69,7856414 & 272 & 63,8005159 & 462 & 195949769 \\
\hline 174 & 379 & 462 & 52,3708045 & 478 & 67,1588595 & 229 & 69,9557673 & 496 & 63,8005159 & 273 & 184085379 \\
\hline 175 & 380 & 612 & 52,4122418 & 290 & 67,2797862 & 478 & 69,9897924 & 472 & 63,972485 & 386 & 307929772 \\
\hline 176 & 381 & 237 & 52,4152016 & 373 & 67,2988798 & 479 & 69,9897924 & 218 & 64,144454 & 457 & 270538839 \\
\hline 177 & 382 & 465 & 52,530634 & 496 & 67,3752546 & 480 & 69,9897924 & 997 & 64,144454 & 320 & 88499809,8 \\
\hline 178 & 383 & 502 & 52,5631919 & 502 & 67,3752546 & 342 & 70,0238176 & 292 & 64,2304385 & 465 & 118439313 \\
\hline 179 & 384 & 454 & 52,651986 & 476 & 67,4643585 & 237 & 70,091868 & 355 & 64,316423 & 269 & 301863601 \\
\hline 180 & 385 & 359 & 52,8147754 & 595 & 67,7125764 & 286 & 70,091868 & 227 & 64,7463457 & 464 & 225727540 \\
\hline 181 & 386 & 233 & 52,8887705 & 179 & 67,7189409 & 277 & 70,5341953 & 282 & 64,9183147 & 282 & 253888880 \\
\hline 182 & 387 & 488 & 52,9716451 & 845 & 67,8271385 & 296 & 70,5682205 & 632 & 65,0042992 & 233 & 81796044,3 \\
\hline 183 & 388 & 385 & 52,9834843 & 517 & 68,0180754 & 467 & 70,5682205 & 326 & 65,1762683 & 275 & 41915917,5 \\
\hline 184 & 395 & 349 & 53,1225952 & 475 & 68,1135438 & 466 & 70,6362708 & 217 & 65,2622528 & 372 & 367674221 \\
\hline
\end{tabular}




\begin{tabular}{|c|c|c|c|c|c|c|c|c|c|c|c|}
\hline \begin{tabular}{|c|} 
ZATs \\
PUCAB
\end{tabular} & & Trabalho & & estudo & & saude & & recreação & & ponderação & \\
\hline $30 \mathrm{~min}$ & & pucab & abrange $\%$ & pucab & abrange $\%$ & pucab & abrange $\%$ & pucab & abrange $\%$ & pucab prio & ponderado \\
\hline 185 & 397 & 328 & 53,125555 & 175 & 68,1644603 & 218 & 70,7383464 & 993 & 65,4342218 & 231 & 8834939,5 \\
\hline 186 & 399 & 463 & 53,2113893 & 342 & 68,2153768 & 292 & 70,7383464 & 385 & 65,5202064 & 347 & 7892927,25 \\
\hline 187 & 400 & 330 & 53,3149825 & 354 & 68,2471996 & 422 & 70,8744471 & 271 & 65,6921754 & 179 & 10663732,5 \\
\hline 188 & 403 & 266 & 53,5221689 & 497 & 68,4063136 & 473 & 70,9084723 & 353 & 65,6921754 & 421 & 3606352,25 \\
\hline 189 & 420 & 500 & 53,5488072 & 320 & 68,5781568 & 231 & 70,9765226 & 440 & 65,8641445 & 238 & 68839406,5 \\
\hline 190 & 421 & 362 & 53,7086367 & 597 & 68,6099796 & 232 & 71,0785982 & 301 & 65,950129 & 499 & 238710264 \\
\hline 191 & 422 & 250 & 53,8270289 & 477 & 68,6799898 & 517 & 71,4188499 & 593 & 65,950129 & 632 & 218480663 \\
\hline 192 & 423 & 348 & 53,8447878 & 355 & 68,8263747 & 844 & 71,7591017 & 219 & 66,2940671 & 292 & 31186777,8 \\
\hline 193 & 424 & 281 & 53,9247025 & 279 & 69,010947 & 341 & 71,8952024 & 467 & 66,2940671 & 219 & 37015135 \\
\hline 194 & 425 & 179 & 54,0638134 & 594 & 69,462831 & 512 & 72,1333787 & 475 & 66,5520206 & 235 & 54168809,5 \\
\hline 195 & 426 & 428 & 54,176286 & 575 & 69,5010183 & 254 & 72,1674039 & 421 & 66,6380052 & 232 & 109070720 \\
\hline 196 & 427 & 320 & 54,2177233 & 234 & 69,564664 & 575 & 72,4396053 & 348 & 66,8099742 & 353 & 115858970 \\
\hline 197 & 428 & 234 & 54,2857989 & 353 & 69,564664 & 381 & 72,5076557 & 176 & 66,8959587 & 593 & 212065373 \\
\hline 198 & 429 & 232 & 54,3213165 & 341 & 69,6855906 & 233 & 72,7458319 & 278 & 66,8959587 & 385 & 422460722 \\
\hline 199 & 430 & 235 & 54,3479548 & 277 & 69,7492363 & 373 & 73,1201089 & 464 & 66,8959587 & 237 & 444699911 \\
\hline 200 & 431 & 539 & 54,7090511 & 288 & 69,7492363 & 476 & 73,2221844 & 610 & 66,8959587 & 502 & 459838328 \\
\hline 201 & 432 & 219 & 54,7830462 & 422 & 69,9338086 & 290 & 73,4263355 & 465 & 67,1539123 & 274 & 434269514 \\
\hline 202 & 433 & 843 & 54,8866394 & 610 & 70,029277 & 434 & 73,4603607 & 975 & 67,1539123 & 466 & 471449513 \\
\hline 203 & 434 & 292 & 54,9073581 & 975 & 70,029277 & 439 & 73,4603607 & 229 & 67,6698194 & 467 & 371961693 \\
\hline 204 & 435 & 238 & 54,969514 & 512 & 70,0674644 & 328 & 73,4943858 & 286 & 67,8417885 & 330 & 406698337 \\
\hline 205 & 436 & 459 & 55,1648612 & 332 & 70,2265784 & 421 & 73,528411 & 237 & 68,0137575 & 574 & 416616069 \\
\hline 206 & 437 & 352 & 55,2418161 & 606 & 70,2520367 & 633 & 73,528411 & 381 & 68,0137575 & 422 & 292156836 \\
\hline 207 & 438 & 374 & 55,2714142 & 227 & 70,2647658 & 386 & 73,5964614 & 466 & 68,0137575 & 354 & 300229599 \\
\hline
\end{tabular}




\begin{tabular}{|c|c|c|c|c|c|c|c|c|c|c|c|}
\hline \begin{tabular}{|c|} 
ZATs \\
PUCAB
\end{tabular} & & Trabalho & & estudo & & saude & & recreação & & ponderação & \\
\hline $30 \mathrm{~min}$ & & pucab & abrange $\%$ & pucab & abrange $\%$ & pucab & abrange $\%$ & pucab & abrange $\%$ & pucab prio & ponderado \\
\hline 208 & 439 & 274 & 55,4164447 & 271 & 70,3029532 & 320 & 73,8006125 & 474 & 68,0137575 & 376 & 377456130 \\
\hline 209 & 440 & 381 & 55,4963594 & 233 & 70,5702648 & 288 & 73,8686628 & 290 & 68,4436801 & 477 & 288751798 \\
\hline 210 & 441 & 329 & 55,5141183 & 437 & 70,6911914 & 488 & 74,0047635 & 373 & 68,4436801 & 472 & 292472108 \\
\hline 211 & 442 & 517 & 55,5614752 & 971 & 70,697556 & 593 & 74,0047635 & 499 & 68,5296647 & 281 & 426145328 \\
\hline 212 & 443 & 351 & 55,7124253 & 319 & 70,9521385 & 319 & 74,0728139 & 351 & 68,7016337 & 474 & 395151286 \\
\hline 213 & 444 & 590 & 55,8604156 & 434 & 71,0285132 & 332 & 74,2089146 & 428 & 68,7016337 & 475 & 417237486 \\
\hline 214 & 445 & 282 & 56,0557627 & 474 & 71,0667006 & 975 & 74,2429398 & 454 & 68,7016337 & 428 & 453422325 \\
\hline 215 & 446 & 319 & 56,0972 & 381 & 71,1430754 & 347 & 74,3109901 & 462 & 68,7016337 & 266 & 431395450 \\
\hline 216 & 447 & 578 & 56,188954 & 328 & 71,3212831 & 610 & 74,3109901 & 277 & 68,7876182 & 633 & 413621534 \\
\hline 217 & 448 & 512 & 56,1978334 & 465 & 71,410387 & 227 & 74,4470908 & 574 & 68,7876182 & 250 & 423072168 \\
\hline 218 & 449 & 231 & 56,3251051 & 457 & 71,4422098 & 499 & 74,5491664 & 966 & 68,7876182 & 455 & 429368258 \\
\hline 219 & 450 & 302 & 56,4434973 & 472 & 71,6586049 & 456 & 74,855393 & 441 & 68,9595873 & 378 & 401862211 \\
\hline 220 & 451 & 441 & 56,4908542 & 270 & 71,7668024 & 176 & 74,9914937 & 500 & 69,0455718 & 610 & 401201871 \\
\hline 221 & 452 & 575 & 56,5263719 & 844 & 71,9959267 & 500 & 75,0255189 & 592 & 69,2175408 & 975 & 413880522 \\
\hline 222 & 453 & 384 & 56,7098798 & 633 & 72,1104888 & 240 & 75,22967 & 285 & 69,3035254 & 239 & 428601676 \\
\hline 223 & 454 & 229 & 56,8519505 & 356 & 72,135947 & 234 & 75,2636951 & 320 & 69,3895099 & 456 & 268637059 \\
\hline 224 & 455 & 372 & 56,905227 & 464 & 72,2123218 & 472 & 75,3317455 & 174 & 69,4754944 & 476 & 196112444 \\
\hline 225 & 456 & 271 & 56,9348251 & 488 & 72,23778 & 632 & 75,3317455 & 346 & 69,4754944 & 255 & 193780957 \\
\hline 226 & 457 & 254 & 56,9437045 & 439 & 72,2696029 & 171 & 75,5699217 & 361 & 69,5614789 & 180 & 253336756 \\
\hline 227 & 458 & 175 & 56,9881016 & 539 & 72,3650713 & 441 & 76,182375 & 345 & 69,8194325 & 587 & 256322845 \\
\hline 228 & 459 & 993 & 57,2278459 & 347 & 72,5369145 & 340 & 76,3184757 & 356 & 69,8194325 & 473 & 301317418 \\
\hline 229 & 460 & 293 & 57,3580773 & 291 & 72,5496436 & 475 & 76,5226267 & 463 & 69,905417 & 971 & 327067115 \\
\hline 230 & 461 & 380 & 57,4202332 & 993 & 72,6005601 & 174 & 76,5566519 & 319 & 70,1633706 & 379 & 334107657 \\
\hline
\end{tabular}




\begin{tabular}{|c|c|c|c|c|c|c|c|c|c|c|c|}
\hline $\begin{array}{c}\text { ZATs } \\
\text { PUCAB }\end{array}$ & & Trabalho & & estudo & & saude & & recreação & & ponderação & \\
\hline $30 \mathrm{~min}$ & & pucab & abrange $\%$ & pucab & abrange $\%$ & pucab & abrange $\%$ & pucab & abrange $\%$ & pucab prio & ponderado \\
\hline 231 & 462 & 361 & 57,4764695 & 462 & 72,9951629 & 590 & 76,6587275 & 342 & 70,2493551 & 251 & 255788856 \\
\hline 232 & 463 & 375 & 57,4971882 & 221 & 73,1160896 & 217 & 76,7267778 & 372 & 70,2493551 & 181 & 282046309 \\
\hline 233 & 464 & 355 & 57,5356657 & 340 & 73,1988289 & 455 & 76,760803 & 991 & 70,2493551 & 301 & 248600040 \\
\hline 234 & 465 & 295 & 57,728053 & 467 & 73,2242872 & 474 & 76,760803 & 330 & 70,4213242 & 497 & 251578296 \\
\hline 235 & 466 & 356 & 57,9737169 & 167 & 73,2433809 & 843 & 76,7948282 & 457 & 70,4213242 & 287 & 225343535 \\
\hline 236 & 467 & 461 & 58,0003552 & 846 & 73,2624745 & 464 & 76,8288534 & 386 & 70,5073087 & 253 & 222127844 \\
\hline 237 & 468 & 588 & 58,0121944 & 466 & 73,3324847 & 539 & 76,8628785 & 240 & 70,6792777 & 595 & 137123755 \\
\hline 238 & 469 & 460 & 58,0417925 & 346 & 73,3897658 & 354 & 76,8969037 & 458 & 70,9372313 & 496 & 153120828 \\
\hline 239 & 470 & 269 & 58,0654709 & 349 & 73,4915988 & 477 & 76,8969037 & 359 & 71,0232158 & 594 & 75113582,3 \\
\hline 240 & 471 & 357 & 58,095069 & 421 & 73,5934318 & 384 & 76,9309289 & 380 & 71,1951849 & 586 & 124319539 \\
\hline 241 & 472 & 373 & 58,1394661 & 441 & 73,8289206 & 355 & 76,9649541 & 376 & 71,2811694 & 296 & 216473617 \\
\hline 242 & 473 & 589 & 58,2519387 & 343 & 73,9689409 & 465 & 76,9989792 & 279 & 71,3671539 & 597 & 187495997 \\
\hline 243 & 474 & 966 & 58,3584917 & 458 & 74,0389511 & 270 & 77,0330044 & 350 & 71,3671539 & 606 & 213873141 \\
\hline 244 & 475 & 350 & 58,4384064 & 374 & 74,0580448 & 966 & 77,2031303 & 171 & 71,539123 & 576 & 213021770 \\
\hline 245 & 476 & 366 & 58,6100752 & 352 & 74,287169 & 374 & 77,339231 & 288 & 71,539123 & 230 & 193168293 \\
\hline 246 & 477 & 273 & 58,613035 & 240 & 74,3062627 & 302 & 77,5093569 & 172 & 71,6251075 & 184 & 216660020 \\
\hline 247 & 478 & 591 & 58,6840703 & 578 & 74,3126273 & 592 & 77,5433821 & 224 & 71,7970765 & 480 & 162982290 \\
\hline 248 & 479 & 275 & 58,7847037 & 454 & 74,4017312 & 346 & 78,0537598 & 612 & 71,883061 & 577 & 163203326 \\
\hline 249 & 480 & 437 & 58,8291008 & 329 & 74,6244908 & 172 & 78,1898605 & 221 & 72,0550301 & 249 & 164494968 \\
\hline 250 & 481 & 278 & 58,8350204 & 499 & 74,7199593 & 329 & 78,2238857 & 845 & 72,0550301 & 997 & 116187098 \\
\hline 251 & 482 & 844 & 58,9652519 & 268 & 74,7454175 & 462 & 78,2238857 & 982 & 72,1410146 & 479 & 121677022 \\
\hline 252 & 483 & 346 & 59,0451666 & 380 & 74,9236253 & 380 & 78,3259612 & 578 & 72,2269991 & 478 & 115741495 \\
\hline 253 & 484 & 272 & 59,1546795 & 952 & 74,9490835 & 170 & 78,3940116 & 225 & 72,3989682 & 252 & 121846810 \\
\hline
\end{tabular}




\begin{tabular}{|c|c|c|c|c|c|c|c|c|c|c|c|}
\hline $\begin{array}{c}\text { ZATs } \\
\text { PUCAB }\end{array}$ & & Trabalho & & estudo & & saude & & recreação & & ponderação & \\
\hline $30 \mathrm{~min}$ & & pucab & abrange $\%$ & pucab & abrange $\%$ & pucab & abrange $\%$ & pucab & abrange $\%$ & pucab prio & ponderado \\
\hline 254 & 485 & 267 & 59,2257148 & 386 & 75,0445519 & 348 & 78,4620619 & 488 & 72,5709372 & 297 & 136797240 \\
\hline 255 & 486 & 218 & 59,3500266 & 384 & 75,2545825 & 504 & 78,4960871 & 613 & 72,5709372 & 236 & 134968447 \\
\hline 256 & 487 & 345 & 59,421062 & 226 & 75,4837067 & 846 & 78,5981626 & 280 & 72,7429063 & 469 & 137283157 \\
\hline 257 & 488 & 332 & 59,5720121 & 344 & 75,509165 & 463 & 78,6321878 & 384 & 72,7429063 & 498 & 256204077 \\
\hline 258 & 489 & 284 & 59,648967 & 176 & 75,6046334 & 952 & 78,7002382 & 170 & 73,0008598 & 510 & 97454487,8 \\
\hline 259 & 490 & 217 & 59,9597466 & 225 & 75,7064664 & 578 & 78,7342634 & 270 & 73,0008598 & 377 & 89695006 \\
\hline 260 & 491 & 290 & 60,045581 & 593 & 75,7637475 & 221 & 78,8023137 & 992 & 73,0008598 & 848 & 121552441 \\
\hline 261 & 492 & 991 & 60,0810987 & 283 & 75,8655804 & 343 & 78,8023137 & 517 & 73,0868444 & 216 & 76526594 \\
\hline 262 & 493 & 845 & 60,2527674 & 345 & 76,0565173 & 224 & 78,8703641 & 362 & 73,2588134 & 487 & 59888353,8 \\
\hline 263 & 494 & 367 & 60,3474812 & 351 & 76,3301935 & 459 & 78,9043892 & 291 & 73,4307825 & 468 & 112841272 \\
\hline 264 & 495 & 501 & 60,3741195 & 348 & 76,3938391 & 349 & 78,9384144 & 283 & 73,688736 & 485 & 119873682 \\
\hline 265 & 496 & 288 & 60,3829989 & 843 & 76,482943 & 353 & 78,9384144 & 168 & 73,8607051 & 513 & 176170214 \\
\hline 266 & 497 & 440 & 60,3918783 & 460 & 76,6102342 & 612 & 79,0064648 & 343 & 73,8607051 & 486 & 181535338 \\
\hline 267 & 498 & 368 & 60,4244362 & 632 & 76,8011711 & 356 & 79,04049 & 374 & 73,8607051 & 326 & 151760349 \\
\hline 268 & 499 & 167 & 60,442195 & 300 & 76,8329939 & 361 & 79,0745151 & 843 & 73,8607051 & 951 & 237363003 \\
\hline 269 & 500 & 286 & 60,4658734 & 966 & 76,8966395 & 582 & 79,3126914 & 846 & 73,8607051 & 185 & 280077192 \\
\hline 270 & 501 & 227 & 60,5102705 & 362 & 76,9411914 & 457 & 79,4828173 & 512 & 74,1186586 & 584 & 373796895 \\
\hline 271 & 502 & 300 & 60,6730598 & 174 & 77,0112016 & 168 & 79,6529432 & 226 & 74,4625967 & 515 & 225356106 \\
\hline 272 & 503 & 514 & 60,7026579 & 992 & 77,0621181 & 283 & 79,7209935 & 575 & 74,7205503 & 583 & 404730681 \\
\hline 273 & 504 & 343 & 60,7144971 & 334 & 77,1066701 & 982 & 79,7209935 & 590 & 74,7205503 & 471 & 383269757 \\
\hline 274 & 505 & 395 & 60,8565678 & 359 & 77,1894094 & 357 & 79,7550187 & 981 & 74,8925193 & 484 & 431684686 \\
\hline 275 & 506 & 369 & 60,9335228 & 463 & 77,456721 & 454 & 79,9251446 & 344 & 75,0644884 & 482 & 426278909 \\
\hline 276 & 507 & 342 & 61,1022317 & 500 & 77,5458248 & 344 & 80,0952705 & 539 & 75,322442 & 491 & 415973399 \\
\hline
\end{tabular}




\begin{tabular}{|c|c|c|c|c|c|c|c|c|c|c|c|}
\hline $\begin{array}{c}\text { ZATs } \\
\text { PUCAB } \\
\end{array}$ & & Trabalho & & estudo & & saude & & recreação & & ponderação & \\
\hline $30 \mathrm{~min}$ & & pucab & abrange $\%$ & pucab & abrange $\%$ & pucab & abrange $\%$ & pucab & abrange $\%$ & pucab prio & ponderado \\
\hline 277 & 508 & 344 & 61,3952525 & 592 & 77,5649185 & 268 & 80,2313712 & 588 & 75,5803955 & 495 & 442785639 \\
\hline 278 & 509 & 299 & 61,4041319 & 459 & 77,5840122 & 351 & 80,2313712 & 439 & 75,7523646 & 383 & 399364032 \\
\hline 279 & 510 & 240 & 61,4070917 & 357 & 77,660387 & 365 & 80,2313712 & 357 & 75,8383491 & 481 & 148775301 \\
\hline 280 & 511 & 224 & 61,5758006 & 302 & 77,7494908 & 503 & 80,2994216 & 228 & 76,5262253 & 427 & 385374348 \\
\hline 281 & 512 & 438 & 61,5965193 & 350 & 77,7494908 & 352 & 80,5035726 & 268 & 76,6122098 & 483 & 274608634 \\
\hline 282 & 513 & 579 & 61,6290771 & 224 & 77,8704175 & 359 & 80,571623 & 341 & 76,7841788 & 494 & 135554816 \\
\hline 283 & 514 & 358 & 62,0848872 & 366 & 77,8895112 & 436 & 80,6396734 & 589 & 77,1281169 & 581 & 364474138 \\
\hline 284 & 515 & 276 & 62,1115255 & 361 & 77,921334 & 360 & 80,7757741 & 222 & 77,2141015 & 615 & 129416988 \\
\hline 285 & 516 & 334 & 62,3039129 & 360 & 77,9849796 & 993 & 80,7757741 & 302 & 77,3860705 & 426 & 89368229,8 \\
\hline 286 & 517 & 341 & 62,3956668 & 612 & 78,0995418 & 345 & 80,8097993 & 299 & 77,472055 & 215 & 261770626 \\
\hline 287 & 518 & 511 & 62,4163855 & 222 & 78,328666 & 362 & 80,9799251 & 340 & 77,7300086 & 303 & 440644263 \\
\hline 288 & 519 & 270 & 62,4223051 & 461 & 78,5132383 & 981 & 81,0139503 & 223 & 77,8159931 & 186 & 34469336,5 \\
\hline 289 & 539 & 221 & 62,4430237 & 172 & 78,5832485 & 334 & 81,150051 & 293 & 77,8159931 & 489 & 274968363 \\
\hline 290 & 574 & 992 & 62,9195525 & 170 & 78,5959776 & 992 & 81,2181014 & 332 & 77,8159931 & 183 & 219375252 \\
\hline 291 & 575 & 985 & 62,972829 & 504 & 78,7869145 & 458 & 81,2861518 & 334 & 77,9879622 & 634 & 274827018 \\
\hline 292 & 576 & 580 & 63,4167999 & 590 & 78,8187373 & 514 & 81,2861518 & 501 & 77,9879622 & 325 & 167971822 \\
\hline 293 & 577 & 443 & 63,4375185 & 582 & 79,0796843 & 589 & 81,3542021 & 504 & 77,9879622 & 490 & 164109538 \\
\hline 294 & 578 & 984 & 63,4463979 & 613 & 79,2260692 & 225 & 81,4903028 & 514 & 77,9879622 & 516 & 296467315 \\
\hline 295 & 579 & 298 & 63,4937548 & 507 & 79,4551935 & 226 & 81,4903028 & 328 & 78,1599312 & 382 & 381733614 \\
\hline 296 & 580 & 291 & 63,56775 & 435 & 79,4933809 & 291 & 81,5583532 & 591 & 78,1599312 & 965 & 392681868 \\
\hline 297 & 581 & 277 & 63,582549 & 171 & 79,6015784 & 613 & 81,5923784 & 844 & 78,2459157 & 983 & 112122609 \\
\hline 298 & 582 & 285 & 63,6210265 & 228 & 79,8625255 & 591 & 81,6264035 & 451 & 78,5038693 & 617 & 388321330 \\
\hline 299 & 583 & 268 & 63,7098206 & 395 & 79,9198065 & 300 & 81,6604287 & 460 & 78,5038693 & 585 & 127944657 \\
\hline
\end{tabular}




\begin{tabular}{|c|c|c|c|c|c|c|c|c|c|c|c|}
\hline $\begin{array}{l}\text { ZATs } \\
\text { PUCAB } \\
\end{array}$ & & Trabalho & & estudo & & saude & & recreação & & ponderação & \\
\hline $30 \mathrm{~min}$ & & pucab & abrange $\%$ & pucab & abrange $\%$ & pucab & abrange $\%$ & pucab & abrange $\%$ & pucab prio & ponderado \\
\hline 300 & 584 & 176 & 63,8548511 & 514 & 79,9389002 & 395 & 81,6604287 & 503 & 78,5038693 & 631 & 129710566 \\
\hline 301 & 585 & 280 & 63,9495649 & 436 & 80,1043788 & 460 & 81,8305546 & 295 & 78,9337919 & 387 & 83064915,3 \\
\hline 302 & 586 & 279 & 64,17747 & 369 & 80,2825866 & 375 & 82,0687309 & 582 & 79,0197764 & 842 & 172069179 \\
\hline 303 & 587 & 451 & 64,5178476 & 299 & 80,3398676 & 435 & 82,3409323 & 434 & 79,3637145 & 616 & 189893982 \\
\hline 304 & 588 & 509 & 64,7339135 & 168 & 80,3907841 & 450 & 82,3409323 & 986 & 79,4496991 & 601 & 348177719 \\
\hline 305 & 589 & 846 & 65,0091754 & 367 & 80,5053462 & 461 & 82,477033 & 358 & 79,5356836 & 492 & 349029801 \\
\hline 306 & 590 & 504 & 65,0358137 & 365 & 80,5180754 & 451 & 82,5450834 & 366 & 79,5356836 & 599 & 307481680 \\
\hline 307 & 591 & 447 & 65,0506127 & 503 & 80,5308045 & 222 & 82,6471589 & 461 & 79,5356836 & 318 & 353254535 \\
\hline 308 & 592 & 370 & 65,0713313 & 982 & 80,537169 & 588 & 82,6811841 & 360 & 79,7076526 & 470 & 257091560 \\
\hline 309 & 593 & 582 & 65,1897236 & 509 & 80,6517312 & 358 & 82,8172848 & 459 & 79,9656062 & 987 & 228495996 \\
\hline 310 & 594 & 450 & 65,3761913 & 371 & 80,9254073 & 228 & 82,85131 & 952 & 80,0515907 & 201 & 174105016 \\
\hline 311 & 595 & 226 & 65,4087492 & 220 & 81,1290733 & 366 & 83,0894862 & 329 & 80,1375752 & 614 & 177844839 \\
\hline 312 & 596 & 452 & 65,5123424 & 579 & 81,2245418 & 501 & 83,1235114 & 436 & 80,1375752 & 321 & 70714372 \\
\hline 313 & 597 & 168 & 65,5537797 & 511 & 81,2754582 & 507 & 83,1915618 & 220 & 80,2235598 & 596 & 169768993 \\
\hline 314 & 598 & 283 & 65,5774581 & 985 & 81,3200102 & 293 & 83,3276625 & 300 & 80,3095443 & 420 & 37995241,8 \\
\hline 315 & 599 & 340 & 65,7728053 & 450 & 81,3454684 & 295 & 83,3957128 & 506 & 80,3095443 & 969 & 76149517,3 \\
\hline 316 & 600 & 444 & 65,8053632 & 986 & 81,3581976 & 986 & 83,804015 & 169 & 80,6534824 & 213 & 62519354,3 \\
\hline 317 & 601 & 448 & 65,8320014 & 981 & 81,4345723 & 367 & 83,9741409 & 173 & 80,6534824 & 322 & 77375008,8 \\
\hline 318 & 602 & 453 & 65,8911975 & 580 & 82,0455703 & 350 & 84,1102416 & 507 & 80,6534824 & 996 & 52495820,8 \\
\hline 319 & 603 & 442 & 65,9977505 & 432 & 82,1155804 & 447 & 84,1782919 & 367 & 80,7394669 & 988 & 58953585,8 \\
\hline 320 & 605 & 225 & 66,0747055 & 984 & 82,1346741 & 511 & 84,2803675 & 369 & 80,8254514 & 968 & 35481951 \\
\hline 321 & 606 & 449 & 66,0983839 & 591 & 82,1601324 & 223 & 84,3143927 & 375 & 80,8254514 & 214 & 168977041 \\
\hline 322 & 610 & 503 & 66,1013438 & 368 & 82,2746945 & 985 & 84,382443 & 450 & 80,9974205 & 600 & 195436531 \\
\hline
\end{tabular}




\begin{tabular}{|c|c|c|c|c|c|c|c|c|c|c|c|}
\hline $\begin{array}{l}\text { ZATs } \\
\text { PUCAB } \\
\end{array}$ & & Trabalho & & estudo & & saude & & recreação & & ponderação & \\
\hline $30 \mathrm{~min}$ & & pucab & abrange $\%$ & pucab & abrange $\%$ & pucab & abrange $\%$ & pucab & abrange $\%$ & pucab prio & ponderado \\
\hline 323 & 612 & 429 & 66,219736 & 589 & 82,4083503 & 444 & 84,5185437 & 435 & 81,255374 & 493 & 279109010 \\
\hline 324 & 613 & 360 & 66,2611733 & 443 & 82,5165479 & 579 & 84,7226948 & 505 & 81,255374 & 603 & 277374321 \\
\hline 325 & 614 & 435 & 66,3174096 & 339 & 82,5992872 & 299 & 84,75672 & 395 & 81,4273431 & 967 & 73778304,5 \\
\hline 326 & 615 & 952 & 66,3884449 & 363 & 82,6247454 & 369 & 84,75672 & 429 & 81,8572657 & 841 & 111146636 \\
\hline 327 & 616 & 171 & 66,5423548 & 588 & 82,6820265 & 446 & 84,9268459 & 363 & 81,9432502 & 425 & 78350914,8 \\
\hline 328 & 617 & 446 & 66,5512342 & 358 & 82,7138493 & 443 & 85,0629466 & 509 & 82,1152193 & 618 & 83857061,8 \\
\hline 329 & 618 & 506 & 66,645948 & 375 & 82,732943 & 580 & 85,0969718 & 511 & 82,2012038 & 602 & 53098466,5 \\
\hline 330 & 631 & 228 & 66,7110638 & 451 & 82,7584012 & 339 & 85,2330725 & 442 & 82,4591574 & 208 & 83039246,5 \\
\hline 331 & 632 & 331 & 66,9389688 & 429 & 82,9429735 & 984 & 85,2330725 & 298 & 82,5451419 & 212 & 236297213 \\
\hline 332 & 633 & 986 & 66,9419286 & 452 & 82,9684318 & 506 & 85,5733243 & 331 & 82,6311264 & 324 & 203773465 \\
\hline 333 & 634 & 363 & 67,255668 & 506 & 82,9684318 & 220 & 85,6413746 & 579 & 82,6311264 & 316 & 93874276 \\
\hline 334 & 841 & 505 & 67,2615876 & 505 & 83,7576375 & 371 & 85,7434502 & 294 & 82,8030954 & 211 & 56534273,3 \\
\hline 335 & 842 & 434 & 67,3829397 & 293 & 84,2413442 & 452 & 85,7774753 & 443 & 83,061049 & 388 & 80228094,8 \\
\hline 336 & 843 & 507 & 67,4125377 & 444 & 84,2986253 & 368 & 85,8115005 & 365 & 83,2330181 & 209 & 289582700 \\
\hline 337 & 844 & 439 & 67,439176 & 501 & 84,4959267 & 432 & 85,9476012 & 518 & 83,4049871 & 598 & 307856885 \\
\hline 338 & 845 & 172 & 67,7558752 & 223 & 84,5913951 & 509 & 86,0156516 & 448 & 83,7489252 & 210 & 2962346661 \\
\hline 339 & 846 & 436 & 68,1228911 & 518 & 84,7441446 & 505 & 86,2198027 & 446 & 83,8349097 & 424 & 362189190 \\
\hline 340 & 848 & 518 & 68,2087255 & 370 & 84,8077902 & 331 & 86,2538278 & 430 & 84,3508169 & 205 & 143555624 \\
\hline 341 & 951 & 508 & 68,3034393 & 430 & 84,8714358 & 445 & 86,287853 & 452 & 84,3508169 & 605 & 132481758 \\
\hline 342 & 952 & 222 & 69,2268987 & 448 & 84,9796334 & 429 & 86,3899285 & 985 & 84,3508169 & 519 & 386241701 \\
\hline 343 & 953 & 432 & 69,3452909 & 508 & 85,0114562 & 363 & 86,7642055 & 368 & 84,4368014 & 199 & 24052036,5 \\
\hline 344 & 954 & 430 & 69,650151 & 295 & 85,0941955 & 169 & 86,7982307 & 449 & 84,4368014 & 202 & 22923383,5 \\
\hline 345 & 955 & 371 & 69,8040609 & 331 & 85,1260183 & 289 & 87,0364069 & 580 & 84,4368014 & 423 & 21607412,8 \\
\hline
\end{tabular}




\begin{tabular}{|c|c|c|c|c|c|c|c|c|c|c|c|}
\hline \begin{tabular}{|c|} 
ZATs \\
PUCAB
\end{tabular} & & Trabalho & & estudo & & saude & & recreação & & ponderação & \\
\hline $30 \mathrm{~min}$ & & pucab & abrange $\%$ & pucab & abrange $\%$ & pucab & abrange $\%$ & pucab & abrange $\%$ & pucab prio & ponderado \\
\hline 346 & 965 & 170 & 69,8129403 & 364 & 85,2087576 & 453 & 87,1725077 & 508 & 84,6087704 & 200 & 88346846,8 \\
\hline 347 & 966 & 174 & 69,9046943 & 447 & 85,3551426 & 442 & 87,3766587 & 984 & 84,6087704 & 314 & 322442203 \\
\hline 348 & 967 & 220 & 70,0082875 & 442 & 85,552444 & 173 & 87,7169105 & 447 & 84,866724 & 953 & 57963141 \\
\hline 349 & 968 & 365 & 70,076363 & 446 & 85,5842668 & 364 & 87,818986 & 444 & 85,038693 & 207 & 63917901,8 \\
\hline 350 & 969 & 223 & 70,3634642 & 449 & 85,6351833 & 448 & 87,818986 & 289 & 85,5546002 & 954 & 68284463 \\
\hline 351 & 971 & 339 & 70,4581779 & 169 & 86,1889002 & 449 & 87,8870364 & 339 & 85,8985383 & 323 & 184346797 \\
\hline 352 & 975 & 445 & 70,7867164 & 445 & 86,1952648 & 338 & 88,1592378 & 364 & 86,844368 & 955 & 194836484 \\
\hline 353 & 981 & 289 & 70,8755106 & 289 & 86,3352851 & 508 & 88,1592378 & 370 & 86,9303525 & 182 & 288239734 \\
\hline 354 & 982 & 431 & 71,1566921 & 173 & 86,4753055 & 298 & 88,3974141 & 371 & 87,1883061 & 317 & 274643350 \\
\hline 355 & 983 & 364 & 71,5355473 & 453 & 86,5007637 & 294 & 88,6355903 & 445 & 87,7042132 & 204 & 85971993,8 \\
\hline 356 & 984 & 327 & 71,8670455 & 333 & 87,3663442 & 518 & 88,6696155 & 453 & 88,2201204 & 313 & 395265153 \\
\hline 357 & 985 & 333 & 72,2962174 & 338 & 87,5254582 & 430 & 89,3841443 & 327 & 88,3920894 & 203 & 389525252 \\
\hline 358 & 986 & 335 & 73,0361688 & 431 & 88,1173625 & 370 & 89,4862198 & 338 & 88,650043 & 400 & 420247384 \\
\hline 359 & 987 & 294 & 73,1190434 & 336 & 88,5565173 & 336 & 89,6903709 & 432 & 88,9079966 & 206 & 74677105,5 \\
\hline 360 & 988 & 338 & 73,3676671 & 337 & 88,7983707 & 333 & 90,47295 & 431 & 89,2519347 & 397 & 64369985,8 \\
\hline 361 & 991 & 169 & 73,6399692 & 335 & 89,5112016 & 337 & 90,9152773 & 333 & 89,9398108 & 399 & 284984892 \\
\hline 362 & 992 & 336 & 74,4243178 & 298 & 89,5175662 & 431 & 91,1874787 & 336 & 90,455718 & 315 & 367160418 \\
\hline 363 & 993 & 337 & 74,4243178 & 327 & 90,6377291 & 335 & 91,3576046 & 337 & 90,7136715 & 403 & 300704029 \\
\hline 364 & 996 & 173 & 74,6907003 & 294 & 91,0196029 & 327 & 91,6638312 & 335 & 92,3473775 & 312 & 65182382,5 \\
\hline 365 & 997 & 433 & 78,7485941 & 433 & 92,674389 & 433 & 96,18918 & 433 & 95,9587274 & 311 & 163245937 \\
\hline
\end{tabular}

Tabela do Ranking no Cenário 2 em 30 minutos. 


\begin{tabular}{|c|c|c|c|c|c|c|c|c|c|c|c|}
\hline \multirow{2}{*}{$\begin{array}{l}\text { ZATs } \\
\text { PUCAB } \\
\mathbf{4 0} \mathbf{m i n} \\
\end{array}$} & & \multicolumn{2}{|l|}{ Trabalho } & \multirow{2}{*}{$\begin{array}{l}\text { estudo } \\
\text { pucab } \\
\end{array}$} & \multirow[b]{2}{*}{ abrange $\%$} & \multirow{2}{*}{$\begin{array}{l}\text { saude } \\
\text { pucab } \\
\end{array}$} & \multirow{2}{*}{ abrange $\%$} & \multirow{2}{*}{$\begin{array}{c}\text { recreação } \\
\text { pucab }\end{array}$} & \multirow[b]{2}{*}{ abrange $\%$} & \multicolumn{2}{|l|}{ ponderação } \\
\hline & & pucab & abrange $\%$ & & & & & & & pucab prio & ponderado \\
\hline 1 & 167 & 403 & 28,2069496 & 403 & 20,1247454 & 403 & 28,2068731 & 403 & 33,1040413 & 433 & 292753403 \\
\hline 2 & 168 & 312 & 30,8293376 & 397 & 27,1321283 & 397 & 34,2973801 & 400 & 34,2218401 & 333 & 347936206 \\
\hline 3 & 169 & 311 & 31,1608358 & 315 & 30,0280041 & 315 & 37,2915958 & 311 & 36,6294067 & 364 & 405428012 \\
\hline 4 & 170 & 397 & 31,8652696 & 311 & 30,0407332 & 311 & 38,7887036 & 312 & 36,8873603 & 371 & 441263023 \\
\hline 5 & 171 & 315 & 32,575623 & 312 & 30,6453666 & 312 & 38,9248044 & 315 & 36,8873603 & 327 & 346962478 \\
\hline 6 & 172 & 400 & 32,7650506 & 206 & 31,7082485 & 206 & 39,7414086 & 397 & 37,7472055 & 294 & 392995296 \\
\hline 7 & 173 & 399 & 35,4022376 & 400 & 33,1148167 & 400 & 41,8509697 & 399 & 40,6706793 & 331 & 441800344 \\
\hline 8 & 174 & 953 & 38,9895223 & 317 & 33,9358452 & 317 & 42,1231711 & 206 & 42,2184007 & 431 & 411811475 \\
\hline 9 & 175 & 206 & 40,0698514 & 954 & 34,6232179 & 954 & 43,0758761 & 207 & 46,7755804 & 432 & 271250669 \\
\hline 10 & 176 & 313 & 40,3539928 & 953 & 36,5707739 & 207 & 43,7563797 & 954 & 48,0653482 & 335 & 316230735 \\
\hline 11 & 179 & 954 & 40,487184 & 204 & 38,2828411 & 399 & 44,0966315 & 208 & 49,3551161 & 336 & 271694675 \\
\hline 12 & 180 & 423 & 40,7594862 & 207 & 38,3592159 & 953 & 44,8451854 & 423 & 49,3551161 & 337 & 291183619 \\
\hline 13 & 181 & 317 & 40,8926774 & 205 & 39,1229633 & 203 & 45,6277645 & 210 & 49,4411006 & 449 & 274752241 \\
\hline 14 & 182 & 519 & 41,4698396 & 399 & 39,3648167 & 210 & 45,8319156 & 203 & 49,6130696 & 430 & 40635634,3 \\
\hline 15 & 183 & 955 & 41,996685 & 209 & 39,3711813 & 205 & 46,5804695 & 205 & 49,7850387 & 365 & 149999378 \\
\hline 16 & 184 & 205 & 42,1417155 & 203 & 40,3958758 & 209 & 46,852671 & 209 & 49,9570077 & 370 & 333297318 \\
\hline 17 & 185 & 424 & 42,5738472 & 210 & 40,9623218 & 204 & 48,1456278 & 200 & 50,2149613 & 173 & 237897613 \\
\hline 18 & 186 & 204 & 44,3201326 & 423 & 42,0824847 & 323 & 48,4858796 & 317 & 50,4729149 & 170 & 124282329 \\
\hline 19 & 199 & 323 & 44,6457112 & 200 & 42,9989817 & 182 & 49,5406601 & 953 & 50,9028375 & 448 & 38352531,5 \\
\hline 20 & 200 & 200 & 45,5987687 & 519 & 43,1644603 & 200 & 49,710786 & 313 & 51,1607911 & 338 & 25376754,5 \\
\hline 21 & 201 & 203 & 46,6110223 & 323 & 44,4437373 & 423 & 50,289214 & 519 & 51,1607911 & 952 & 77816213,3 \\
\hline 22 & 202 & 207 & 46,676138 & 208 & 44,5773931 & 202 & 51,4120449 & 424 & 51,5047291 & 429 & 39696287,3 \\
\hline 23 & 203 & 388 & 47,2296217 & 424 & 44,9019857 & 519 & 51,4120449 & 841 & 52,1066208 & 503 & 24137665 \\
\hline
\end{tabular}




\begin{tabular}{|c|c|c|c|c|c|c|c|c|c|c|c|}
\hline $\begin{array}{c}\text { ZATs } \\
\text { PUCAB }\end{array}$ & & Trabalho & & estudo & & saude & & recreação & & ponderação & \\
\hline $40 \mathrm{~min}$ & & pucab & abrange $\%$ & pucab & abrange $\%$ & pucab & abrange $\%$ & pucab & abrange $\%$ & pucab prio & ponderado \\
\hline 24 & 204 & 324 & 47,4101699 & 318 & 45,2393075 & 955 & 51,5141204 & 323 & 52,7085125 & 986 & 20861641,3 \\
\hline 25 & 205 & 209 & 47,8304623 & 955 & 46,7413442 & 318 & 51,9564478 & 204 & 52,966466 & 434 & 19441228,3 \\
\hline 26 & 206 & 425 & 47,9636536 & 182 & 47,9124236 & 208 & 52,6369513 & 842 & 53,4823732 & 220 & 10156992,3 \\
\hline 27 & 207 & 598 & 48,5585746 & 841 & 48,0015275 & 199 & 52,7730521 & 199 & 53,7403267 & 334 & 22961032,5 \\
\hline 28 & 208 & 605 & 48,8012786 & 199 & 48,0715377 & 424 & 52,943178 & 202 & 53,8263113 & 508 & 36341069 \\
\hline 29 & 209 & 210 & 48,8575149 & 202 & 48,2433809 & 614 & 54,7465124 & 182 & 54,600172 & 511 & 27332369,8 \\
\hline 30 & 210 & 314 & 49,0469425 & 313 & 48,3388493 & 313 & 55,6651922 & 425 & 55,3740327 & 505 & 30825457,8 \\
\hline 31 & 211 & 199 & 49,2748476 & 425 & 51,7247963 & 425 & 56,8220483 & 631 & 55,9759243 & 579 & 58119474,8 \\
\hline 32 & 212 & 208 & 50,0799148 & 211 & 53,0168024 & 615 & 58,0809799 & 987 & 56,0619089 & 518 & 68113275 \\
\hline 33 & 213 & 202 & 50,3640561 & 212 & 54,9516293 & 388 & 58,2511058 & 617 & 56,1478934 & 984 & 110226068 \\
\hline 34 & 214 & 600 & 50,3699757 & 516 & 55,5689919 & 585 & 58,9996597 & 212 & 57,1797077 & 363 & 75869644 \\
\hline 35 & 215 & 493 & 50,5890014 & 420 & 55,9572301 & 983 & 58,9996597 & 215 & 57,4376612 & 453 & 100812872 \\
\hline 36 & 216 & 182 & 50,701474 & 388 & 56,5745927 & 324 & 59,3399115 & 420 & 57,9535684 & 444 & 117438860 \\
\hline 37 & 217 & 968 & 50,8879418 & 614 & 56,7528004 & 212 & 60,564818 & 214 & 58,0395529 & 299 & 347213852 \\
\hline 38 & 218 & 420 & 51,1454449 & 324 & 57,7074847 & 841 & 60,8029942 & 318 & 58,1255374 & 580 & 300686957 \\
\hline 39 & 219 & 596 & 51,7344462 & 387 & 60,1705703 & 211 & 61,7556992 & 618 & 58,1255374 & 332 & 284207586 \\
\hline 40 & 220 & 318 & 51,9949091 & 842 & 60,2342159 & 988 & 63,2868323 & 614 & 58,2975064 & 985 & 429411035 \\
\hline 41 & 221 & 599 & 52,2849701 & 988 & 60,9406823 & 493 & 65,906771 & 616 & 58,2975064 & 174 & 361568778 \\
\hline 42 & 222 & 601 & 52,3589653 & 585 & 61,4052953 & 516 & 66,2129976 & 211 & 58,55546 & 367 & 393303059 \\
\hline 43 & 223 & 489 & 52,3885633 & 983 & 61,4880346 & 631 & 66,2470228 & 955 & 59,8452279 & 369 & 365870711 \\
\hline 44 & 224 & 470 & 52,5839105 & 615 & 61,5134929 & 987 & 66,4171487 & 216 & 60,9630267 & 447 & 340067498 \\
\hline 45 & 225 & 492 & 52,6046291 & 987 & 61,526222 & 968 & 66,5532494 & 983 & 61,2209802 & 368 & 375805458 \\
\hline 46 & 226 & 988 & 52,637187 & 631 & 62,0990326 & 420 & 66,7914257 & 585 & 61,4789338 & 509 & 390316623 \\
\hline
\end{tabular}




\begin{tabular}{|c|c|c|c|c|c|c|c|c|c|c|c|}
\hline $\begin{array}{c}\text { ZATs } \\
\text { PUCAB }\end{array}$ & & Trabalho & & estudo & & saude & & recreação & & ponderação & \\
\hline $40 \mathrm{~min}$ & & pucab & abrange $\%$ & pucab & abrange $\%$ & pucab & abrange $\%$ & pucab & abrange $\%$ & pucab prio & ponderado \\
\hline 47 & 227 & 602 & 52,651986 & 316 & 62,239053 & 600 & 67,0976523 & 516 & 61,6509028 & 228 & 300277189 \\
\hline 48 & 228 & 967 & 53,2735453 & 321 & 62,4618126 & 321 & 67,1657026 & 316 & 62,7687016 & 289 & 406529420 \\
\hline 49 & 229 & 325 & 53,4156159 & 314 & 62,5190937 & 602 & 67,1657026 & 605 & 63,1986242 & 169 & 194299911 \\
\hline 50 & 230 & 490 & 53,4925709 & 215 & 64,4030041 & 969 & 67,1657026 & 581 & 64,5743766 & 445 & 131904794 \\
\hline 51 & 231 & 603 & 53,7323152 & 968 & 64,7085031 & 491 & 67,6760803 & 634 & 64,5743766 & 436 & 235604606 \\
\hline 52 & 232 & 211 & 53,9513408 & 493 & 64,7976069 & 489 & 67,7441307 & 314 & 64,9183147 & 298 & 237172407 \\
\hline 53 & 233 & 987 & 54,2502812 & 214 & 65,0394603 & 249 & 67,812181 & 388 & 64,9183147 & 450 & 231692582 \\
\hline 54 & 234 & 316 & 54,2650802 & 616 & 65,2240326 & 596 & 68,0503573 & 493 & 65,2622528 & 844 & 264737393 \\
\hline 55 & 235 & 969 & 54,649855 & 201 & 65,2558554 & 470 & 68,4586594 & 598 & 65,2622528 & 446 & 204298887 \\
\hline 56 & 236 & 631 & 54,6824128 & 325 & 65,5358961 & 599 & 68,4586594 & 490 & 65,5202064 & 451 & 139921567 \\
\hline 57 & 237 & 841 & 54,7919256 & 617 & 65,5422607 & 601 & 68,4586594 & 602 & 65,5202064 & 222 & 162887842 \\
\hline 58 & 238 & 201 & 54,9783934 & 216 & 65,9814155 & 314 & 68,4926846 & 603 & 65,6921754 & 172 & 222839297 \\
\hline 59 & 239 & 321 & 55,5525957 & 969 & 66,4905804 & 492 & 68,5267098 & 615 & 65,6921754 & 506 & 158493376 \\
\hline 60 & 240 & 614 & 55,6325105 & 602 & 66,6751527 & 325 & 68,6287853 & 489 & 66,2080825 & 439 & 304630309 \\
\hline 61 & 249 & 214 & 56,3251051 & 470 & 66,7069756 & 605 & 68,6628105 & 969 & 66,5520206 & 226 & 124907891 \\
\hline 62 & 250 & 326 & 56,7897946 & 492 & 66,7833503 & 471 & 69,0030623 & 600 & 66,6380052 & 442 & 153577873 \\
\hline 63 & 251 & 483 & 56,8697093 & 515 & 66,9679226 & 382 & 69,2072133 & 296 & 66,8959587 & 514 & 151600946 \\
\hline 64 & 252 & 481 & 56,875629 & 489 & 67,4452648 & 515 & 69,4453896 & 387 & 66,8959587 & 507 & 263350154 \\
\hline 65 & 253 & 212 & 56,9614633 & 490 & 67,5916497 & 281 & 69,4794148 & 583 & 67,3258813 & 435 & 175588205 \\
\hline 66 & 254 & 616 & 57,4616705 & 596 & 67,8016802 & 490 & 69,5474651 & 968 & 67,5838349 & 501 & 225548498 \\
\hline 67 & 255 & 387 & 57,5208666 & 600 & 67,9862525 & 214 & 69,6835658 & 324 & 67,8417885 & 300 & 271502045 \\
\hline 68 & 266 & 482 & 57,5475049 & 599 & 68,3744908 & 267 & 69,717591 & 988 & 67,927773 & 225 & 163472332 \\
\hline 69 & 267 & 484 & 57,5475049 & 601 & 68,4254073 & 275 & 69,8196666 & 515 & 68,0137575 & 591 & 195315499 \\
\hline
\end{tabular}




\begin{tabular}{|c|c|c|c|c|c|c|c|c|c|c|c|}
\hline $\begin{array}{c}\text { ZATs } \\
\text { PUCAB }\end{array}$ & & Trabalho & & estudo & & saude & & recreação & & ponderação & \\
\hline $40 \mathrm{~min}$ & & pucab & abrange $\%$ & pucab & abrange $\%$ & pucab & abrange $\%$ & pucab & abrange $\%$ & pucab prio & ponderado \\
\hline 70 & 268 & 382 & 57,8878826 & 510 & 68,546334 & 316 & 69,8877169 & 470 & 68,1857266 & 366 & 323909062 \\
\hline 71 & 269 & 618 & 58,4236074 & 491 & 68,6545316 & 842 & 70,0238176 & 492 & 68,1857266 & 589 & 173649857 \\
\hline 72 & 270 & 617 & 58,5301604 & 249 & 68,7754582 & 617 & 70,091868 & 297 & 68,6156492 & 443 & 299317434 \\
\hline 73 & 271 & 996 & 58,903096 & 275 & 68,8581976 & 266 & 70,1258932 & 491 & 68,6156492 & 375 & 226189611 \\
\hline 74 & 272 & 322 & 58,9297342 & 581 & 68,8645621 & 387 & 70,3640694 & 471 & 68,7016337 & 452 & 208180920 \\
\hline 75 & 273 & 842 & 59,0303676 & 605 & 69,2209776 & 618 & 70,670296 & 596 & 68,7016337 & 223 & 186952052 \\
\hline 76 & 274 & 516 & 59,0362872 & 634 & 69,4246436 & 634 & 71,0785982 & 601 & 68,9595873 & 339 & 162354766 \\
\hline 77 & 275 & 634 & 59,1191618 & 618 & 69,4819246 & 273 & 71,5549507 & 599 & 69,1315563 & 512 & 220165015 \\
\hline 78 & 276 & 965 & 59,3737051 & 471 & 69,5392057 & 269 & 71,5889758 & 321 & 69,6474635 & 221 & 284055281 \\
\hline 79 & 277 & 585 & 59,6164092 & 269 & 70,595723 & 616 & 72,0313032 & 201 & 69,9914015 & 575 & 289181449 \\
\hline 80 & 278 & 983 & 59,6252886 & 322 & 70,7357434 & 510 & 72,1674039 & 186 & 70,2493551 & 539 & 228995266 \\
\hline 81 & 279 & 491 & 59,725922 & 236 & 70,8630346 & 250 & 72,4736305 & 967 & 70,4213242 & 380 & 265691445 \\
\hline 82 & 280 & 213 & 59,8295152 & 273 & 71,3149185 & 303 & 72,6437564 & 213 & 70,5932932 & 293 & 277374484 \\
\hline 83 & 281 & 303 & 60,3119635 & 230 & 71,3976578 & 581 & 72,9840082 & 584 & 70,5932932 & 504 & 181862492 \\
\hline 84 & 282 & 471 & 60,3178831 & 996 & 71,5631365 & 996 & 73,0180333 & 848 & 70,9372313 & 302 & 207121462 \\
\hline 85 & 283 & 426 & 60,9157639 & 267 & 71,7031568 & 201 & 73,0860837 & 236 & 71,3671539 & 295 & 347383917 \\
\hline 86 & 284 & 427 & 61,7001125 & 266 & 72,2759674 & 278 & 73,1541341 & 183 & 71,711092 & 517 & 201838861 \\
\hline 87 & 285 & 486 & 62,179601 & 250 & 72,3332485 & 322 & 73,2902348 & 586 & 72,9148753 & 374 & 251333946 \\
\hline 88 & 286 & 485 & 62,1825608 & 603 & 72,7023931 & 274 & 73,4943858 & 510 & 73,1728289 & 168 & 326641211 \\
\hline 89 & 287 & 487 & 62,1944 & 186 & 72,7596741 & 215 & 73,5624362 & 473 & 73,6027515 & 582 & 183302833 \\
\hline 90 & 288 & 615 & 62,2891138 & 213 & 72,7660387 & 426 & 74,1068391 & 437 & 73,9466896 & 283 & 291508387 \\
\hline 91 & 289 & 215 & 62,3453501 & 251 & 72,8806008 & 284 & 74,2429398 & 587 & 73,9466896 & 217 & 406102392 \\
\hline 92 & 290 & 494 & 62,697567 & 281 & 72,8806008 & 239 & 74,855393 & 249 & 74,1186586 & 171 & 333353224 \\
\hline
\end{tabular}




\begin{tabular}{|c|c|c|c|c|c|c|c|c|c|c|c|}
\hline $\begin{array}{c}\text { ZATs } \\
\text { PUCAB }\end{array}$ & & Trabalho & & estudo & & saude & & recreação & & ponderação & \\
\hline $40 \mathrm{~min}$ & & pucab & abrange \% & pucab & abrange $\%$ & pucab & abrange $\%$ & pucab & abrange $\%$ & pucab prio & ponderado \\
\hline 93 & 291 & 478 & 63,1740958 & 583 & 72,8933299 & 251 & 74,855393 & 495 & 74,1186586 & 358 & 344664838 \\
\hline 94 & 292 & 479 & 63,1740958 & 274 & 73,1670061 & 213 & 74,9234433 & 951 & 74,2046432 & 291 & 310092713 \\
\hline 95 & 293 & 473 & 63,185935 & 303 & 73,2242872 & 598 & 75,0255189 & 275 & 74,4625967 & 384 & 354293460 \\
\hline 96 & 294 & 480 & 63,185935 & 848 & 73,4534114 & 285 & 75,0935692 & 498 & 74,5485813 & 224 & 455082209 \\
\hline 97 & 295 & 297 & 63,3516841 & 584 & 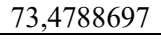 & 326 & 75,433821 & 486 & 74,6345658 & 329 & 350712742 \\
\hline 98 & 296 & 495 & 63,3546439 & 278 & 73,6570774 & 586 & 75,5358966 & 239 & 74,8065348 & 395 & 165912007 \\
\hline 99 & 297 & 186 & 63,5085538 & 598 & 73,8480143 & 848 & 75,6379721 & 251 & 74,8065348 & 846 & 148481239 \\
\hline 100 & 298 & 581 & 63,5647901 & 951 & 73,8734725 & 845 & 75,7400476 & 487 & 74,8065348 & 588 & 404848921 \\
\hline 101 & 299 & 583 & 63,6565441 & 326 & 73,9052953 & 965 & 75,7740728 & 230 & 75,0644884 & 290 & 418103516 \\
\hline 102 & 300 & 468 & 63,8134138 & 239 & 74,0962322 & 427 & 75,9101735 & 484 & 75,0644884 & 184 & 378911696 \\
\hline 103 & 301 & 951 & 64,5918428 & 426 & 74,1025967 & 272 & 76,0802994 & 485 & 75,1504729 & 578 & 171207497 \\
\hline 104 & 302 & 584 & 64,7457527 & 382 & 74,1216904 & 186 & 76,182375 & 481 & 75,2364574 & 843 & 351197574 \\
\hline 105 & 303 & 216 & 64,8404665 & 284 & 74,1471487 & 583 & 76,3525009 & 482 & 75,322442 & 440 & 112624255 \\
\hline 106 & 311 & 498 & 64,8789439 & 456 & 74,1471487 & 428 & 76,4205512 & 483 & 75,322442 & 381 & 4353165,75 \\
\hline 107 & 312 & 597 & 65,39691 & 428 & 74,4717413 & 280 & 76,4545764 & 513 & 75,494411 & 286 & 4084150,75 \\
\hline 108 & 313 & 606 & 65,4709051 & 427 & 74,4781059 & 230 & 76,5566519 & 438 & 75,5803955 & 373 & 22811945 \\
\hline 109 & 314 & 496 & 65,5508199 & 237 & 74,63722 & 991 & 76,5906771 & 494 & 75,7523646 & 268 & 49655786 \\
\hline 110 & 315 & 230 & 65,5715385 & 473 & 74,739053 & 216 & 77,1010548 & 576 & 75,7523646 & 386 & 5501736 \\
\hline 111 & 316 & 377 & 65,5922571 & 455 & 74,7708758 & 603 & 77,1691051 & 456 & 75,9243336 & 360 & 68994067 \\
\hline 112 & 317 & 183 & 65,6484935 & 272 & 74,9554481 & 279 & 77,2371555 & 325 & 76,0103181 & 981 & 14565538,8 \\
\hline 113 & 318 & 474 & 65,7757651 & 285 & 75,1463849 & 282 & 77,8155835 & 469 & 76,0963027 & 343 & 44069106,3 \\
\hline 114 & 319 & 594 & 65,8734387 & 577 & 75,2800407 & 473 & 77,9176591 & 577 & 76,0963027 & 176 & 238387789 \\
\hline 115 & 320 & 249 & 66,204937 & 280 & 75,3182281 & 584 & 77,9176591 & 281 & 76,1822872 & 982 & 261523682 \\
\hline
\end{tabular}




\begin{tabular}{|c|c|c|c|c|c|c|c|c|c|c|c|}
\hline $\begin{array}{c}\text { ZATs } \\
\text { PUCAB }\end{array}$ & & Trabalho & & estudo & & saude & & recreação & & ponderação & \\
\hline $40 \mathrm{~min}$ & & pucab & abrange $\%$ & pucab & abrange $\%$ & pucab & abrange $\%$ & pucab & abrange $\%$ & pucab prio & ponderado \\
\hline 116 & 321 & 971 & 66,2759723 & 276 & 75,4200611 & 183 & 77,9857094 & 478 & 76,1822872 & 613 & 71574721, \\
\hline 117 & 322 & 301 & 66,2996507 & 965 & 75,4200611 & 437 & 78,1218101 & 479 & 76,1822872 & 292 & 101582769 \\
\hline 118 & 323 & 475 & 66,6341088 & 586 & 75,5473523 & 277 & 78,9724396 & 480 & 76,1822872 & 438 & 25298953,8 \\
\hline 119 & 324 & 383 & 66,8679335 & 991 & 75,7255601 & 341 & 78,9724396 & 382 & 76,2682717 & 328 & 38874263, \\
\hline 120 & 325 & 236 & 66,9892855 & 845 & 75,8019348 & 236 & 79,244641 & 426 & 76,2682717 & 463 & 69207383,8 \\
\hline 121 & 326 & 632 & 66,9981649 & 229 & 75,8210285 & 587 & 79,244641 & 303 & 76,4402408 & 240 & 102745918 \\
\hline 122 & 327 & 595 & 67,0307228 & 513 & 75,8910387 & 271 & 79,4487921 & 502 & 76,4402408 & 330 & 459040958 \\
\hline 123 & 328 & 497 & 67,1905523 & 481 & 76,0246945 & 287 & 79,4487921 & 965 & 76,4402408 & 372 & 305929010 \\
\hline 124 & 329 & 296 & 67,2941455 & 483 & 76,1265275 & 502 & 79,4828173 & 468 & 76,6122098 & 218 & 338559460 \\
\hline 125 & 330 & 848 & 67,5398094 & 484 & 76,1456212 & 276 & 79,5848928 & 475 & 76,6981943 & 346 & 304519809 \\
\hline 126 & 331 & 515 & 67,7144379 & 482 & 76,279277 & 253 & 79,618918 & 237 & 76,8701634 & 227 & 452968292 \\
\hline 127 & 332 & 975 & 67,7173977 & 475 & 76,4638493 & 967 & 79,9591698 & 274 & 77,300086 & 344 & 415002376 \\
\hline 128 & 333 & 610 & 67,7351566 & 183 & 76,584776 & 577 & 80,0272201 & 250 & 77,3860705 & 460 & 466394848 \\
\hline 129 & 334 & 456 & 67,8446694 & 279 & 76,5975051 & 485 & 80,3334468 & 496 & 77,3860705 & 270 & 428781504 \\
\hline 130 & 335 & 455 & 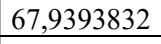 & 231 & 76,8711813 & 486 & 80,3334468 & 253 & \begin{tabular}{|l|}
77,9879622 \\
\end{tabular} & 574 & 448957512 \\
\hline 131 & 336 & 237 & 67,9512224 & 253 & 77,6412933 & 487 & 80,5035726 & 497 & 77,9879622 & 461 & 446631870 \\
\hline 132 & 337 & 633 & 68,0696146 & 587 & 77,9658859 & 342 & 81,0479755 & 175 & \begin{tabular}{|l|}
78,0739467 \\
\end{tabular} & 340 & 446465064 \\
\hline 133 & 338 & 997 & 68,9013201 & 254 & 78,0422607 & 438 & 81,0479755 & 595 & 78,0739467 & 167 & 438265569 \\
\hline 134 & 339 & 251 & 68,9101995 & 486 & 78,2968432 & 235 & 81,0820007 & 231 & 78,1599312 & 342 & 365486728 \\
\hline 135 & 340 & 378 & 69,1736222 & 282 & 78,3350305 & 513 & 81,3201769 & 427 & 78,1599312 & 612 & 293377294 \\
\hline 136 & 341 & 469 & 69,191381 & 474 & 78,3350305 & 951 & 81,3882273 & 633 & 78,3319003 & 459 & 283374842 \\
\hline 137 & 342 & 593 & 69,2268987 & 487 & 78,3795825 & 185 & 81,4562776 & 266 & 78,4178848 & 590 & 292563999 \\
\hline 138 & 343 & 239 & 69,3630498 & 993 & 78,4368635 & 296 & 81,4903028 & 267 & 78,4178848 & 288 & 316403116 \\
\hline
\end{tabular}




\begin{tabular}{|c|c|c|c|c|c|c|c|c|c|c|c|}
\hline $\begin{array}{l}\text { ZATs } \\
\text { PUCAB }\end{array}$ & & Trabalho & & estudo & & saude & & recreação & & ponderação & \\
\hline $40 \mathrm{~min}$ & & pucab & abrange $\%$ & pucab & abrange \% & pucab & abrange \% & pucab & abrange $\%$ & pucab prio & ponderado \\
\hline 139 & 344 & 250 & 69,863257 & 235 & 78,5705193 & 301 & 81,5583532 & 597 & 78,5038693 & 180 & 300236970 \\
\hline 140 & 345 & 253 & 70,1237199 & 485 & 78,5832485 & 254 & 81,8645798 & 454 & 78,9337919 & 992 & 259381652 \\
\hline 141 & 346 & 467 & 70,3072278 & 296 & 78,6468941 & 372 & 81,8645798 & 455 & 79,0197764 & 441 & 300574732 \\
\hline 142 & 347 & 466 & 70,3309063 & 469 & 78,7041752 & 297 & 82,0687309 & 229 & 79,1917455 & 277 & 225606776 \\
\hline 143 & 348 & 287 & 70,3397857 & 287 & 78,7678208 & 377 & 82,0687309 & 322 & 79,1917455 & 219 & 258747850 \\
\hline 144 & 349 & 510 & 70,4197005 & 341 & 78,837831 & 383 & 82,102756 & 273 & 79,27773 & 276 & 234852172 \\
\hline 145 & 350 & 472 & 70,6979222 & 342 & 79,0605906 & 237 & 82,1708064 & 996 & 79,27773 & 341 & 272785777 \\
\hline 146 & 351 & 274 & 70,8044752 & 270 & 79,2387984 & 576 & 82,6811841 & 179 & 79,4496991 & 966 & 259001969 \\
\hline 147 & 352 & 376 & 70,9376665 & 496 & 79,4551935 & 488 & 82,7152093 & 355 & 79,4496991 & 280 & 239860320 \\
\hline 148 & 353 & 347 & 71,0886166 & 238 & 79,4679226 & 238 & 82,8853351 & 269 & 79,7936371 & 462 & 210711194 \\
\hline 149 & 354 & 354 & 71,0915764 & 297 & 79,4679226 & 340 & 83,1915618 & 292 & 79,9656062 & 181 & 202528252 \\
\hline 150 & 355 & 499 & 71,1833304 & 355 & 79,4870163 & 483 & 83,2255869 & 176 & 80,0515907 & 350 & 206114581 \\
\hline 151 & 356 & 592 & 71,2366069 & 457 & 79,5952138 & 481 & 83,2596121 & 235 & 80,1375752 & 502 & 238642158 \\
\hline 152 & 357 & 513 & 71,3342805 & 354 & 79,6270367 & 229 & 83,3276625 & 254 & 80,1375752 & 421 & 249537318 \\
\hline 153 & 358 & 266 & 71,6628189 & 458 & 79,7797862 & 231 & 83,3616876 & 284 & 80,2235598 & 179 & 346956694 \\
\hline 154 & 359 & 353 & 71,6657787 & 271 & 79,8434318 & 484 & 83,3616876 & 276 & 80,3955288 & 255 & 237495996 \\
\hline 155 & 360 & 362 & 71,7397739 & 372 & 80,0852851 & 482 & 83,429738 & 227 & 80,4815133 & 175 & 319462763 \\
\hline 156 & 361 & 359 & 72,0150358 & 967 & 80,0916497 & 469 & 83,6679143 & 185 & 80,6534824 & 385 & 257847535 \\
\hline 157 & 362 & 422 & 72,0179956 & 277 & 80,1807536 & 498 & 83,8380401 & 217 & 80,6534824 & 437 & 249411949 \\
\hline 158 & 363 & 476 & 72,3731723 & 353 & 80,5498982 & 292 & 83,9060905 & 301 & 80,9114359 & 500 & 420051135 \\
\hline 159 & 364 & 233 & 72,4412479 & 498 & 80,5626273 & 456 & 83,9741409 & 474 & 80,9114359 & 464 & 465590908 \\
\hline 160 & 365 & 349 & 72,4797253 & 476 & 80,8108452 & 495 & 84,4504934 & 232 & 81,083405 & 279 & 442968114 \\
\hline 161 & 366 & 355 & 72,5951578 & 477 & 80,9826884 & 455 & 84,4845185 & 377 & 81,083405 & 234 & 370230598 \\
\hline
\end{tabular}




\begin{tabular}{|c|c|c|c|c|c|c|c|c|c|c|c|}
\hline $\begin{array}{c}\text { ZATs } \\
\text { PUCAB }\end{array}$ & & Trabalho & & estudo & & saude & & recreação & & ponderação & \\
\hline $40 \mathrm{~min}$ & & pucab & abrange $\%$ & pucab & abrange $\%$ & pucab & abrange $\%$ & pucab & abrange $\%$ & pucab prio & ponderado \\
\hline 162 & 367 & 454 & 72,6277156 & 301 & 81,0845214 & 496 & 84,5185437 & 238 & 81,255374 & 252 & 410500590 \\
\hline 163 & 368 & 385 & 72,6513941 & 502 & 81,4218432 & 219 & 84,5865941 & 458 & 81,255374 & 320 & 407856167 \\
\hline 164 & 369 & 229 & 72,6602735 & 495 & 81,5491344 & 475 & 84,8247703 & 167 & 81,3413586 & 345 & 408935772 \\
\hline 165 & 370 & 488 & 72,6602735 & 488 & 81,5809572 & 468 & 85,1650221 & 500 & 81,4273431 & 351 & 442177953 \\
\hline 166 & 371 & 477 & 72,6898715 & 438 & 81,657332 & 494 & 85,2670977 & 181 & 81,5133276 & 348 & 459130909 \\
\hline 167 & 372 & 252 & 72,805304 & 576 & 81,6764257 & 270 & 85,5733243 & 378 & 81,8572657 & 361 & 302316108 \\
\hline 168 & 373 & 269 & 72,9858521 & 383 & 81,6955193 & 474 & 85,7774753 & 354 & 81,9432502 & 465 & 326322152 \\
\hline 169 & 374 & 458 & 73,0095306 & 454 & 81,8228106 & 465 & 85,9476012 & 476 & 81,9432502 & 845 & 348485479 \\
\hline 170 & 375 & 586 & 73,0213698 & 218 & 81,9819246 & 472 & 85,9476012 & 319 & 82,0292347 & 285 & 368883122 \\
\hline 171 & 376 & 235 & 73,1131238 & 345 & 82,0901222 & 500 & 85,9476012 & 233 & 82,1152193 & 357 & 248588377 \\
\hline 172 & 377 & 352 & 73,1930385 & 268 & 82,1155804 & 232 & 86,0156516 & 290 & 82,1152193 & 362 & 172106394 \\
\hline 173 & 378 & 348 & 73,1989581 & 356 & 82,325611 & 440 & 86,0156516 & 594 & 82,1152193 & 592 & 208477575 \\
\hline 174 & 379 & 379 & 73,2226366 & 494 & 82,3510692 & 464 & 86,1177271 & 287 & 82,2012038 & 376 & 246171282 \\
\hline 175 & 380 & 576 & 73,2492748 & 340 & 82,4147149 & 378 & 86,1517523 & 632 & 82,2012038 & 379 & 354611076 \\
\hline 176 & 381 & 281 & 73,3321494 & 377 & 82,427444 & 240 & 86,3899285 & 271 & 82,2871883 & 587 & 327592974 \\
\hline 177 & 382 & 282 & 73,5600545 & 185 & 82,4974542 & 582 & 86,4239537 & 428 & 82,2871883 & 499 & 103319636 \\
\hline 178 & 383 & 577 & \begin{tabular}{|l}
73,5689339 \\
\end{tabular} & 232 & 82,5674644 & 997 & 86,4239537 & 272 & 82,4591574 & 466 & 176640781 \\
\hline 179 & 384 & 319 & \begin{tabular}{|l}
73,5807731 \\
\end{tabular} & 437 & 82,6756619 & 286 & 86,4579789 & 993 & 82,4591574 & 457 & 342578793 \\
\hline 180 & 385 & 993 & 73,6074114 & 468 & 82,99389 & 454 & 86,4920041 & 472 & 82,5451419 & 467 & 270314310 \\
\hline 181 & 386 & 320 & 73,7110046 & 343 & 83,0066191 & 590 & 86,5600544 & 180 & 82,6311264 & 428 & 321352780 \\
\hline 182 & 387 & 421 & 73,7465222 & 472 & 83,0448065 & 355 & 86,6961552 & 320 & 82,8030954 & 352 & 77298073,8 \\
\hline 183 & 388 & 351 & 73,8353164 & 595 & 83,1275458 & 290 & 86,7642055 & 477 & 82,9750645 & 356 & 36553032 \\
\hline 184 & 395 & 273 & 73,8530752 & 352 & 83,1657332 & 218 & 86,9003062 & 219 & 83,061049 & 319 & 338349488 \\
\hline
\end{tabular}




\begin{tabular}{|c|c|c|c|c|c|c|c|c|c|c|c|}
\hline $\begin{array}{l}\text { ZATs } \\
\text { PUCAB }\end{array}$ & & Trabalho & & estudo & & saude & & recreação & & ponderação & \\
\hline $40 \mathrm{~min}$ & & pucab & abrange $\%$ & pucab & abrange $\%$ & pucab & abrange $\%$ & pucab & abrange $\%$ & pucab prio & ponderado \\
\hline 185 & 397 & 356 & 73,9418694 & 319 & 83,2612016 & 441 & 86,9003062 & 353 & 83,061049 & 185 & 4276244,5 \\
\hline 186 & 399 & 357 & 74,0069851 & 219 & 83,3630346 & 439 & 86,9343314 & 234 & 83,3190026 & 422 & 12025057,5 \\
\hline 187 & 400 & 361 & 74,0868999 & 465 & 83,3821283 & 504 & 86,9343314 & 966 & 83,3190026 & 359 & 8095791,25 \\
\hline 188 & 403 & 238 & 74,0898597 & 479 & 83,6303462 & 975 & 86,9343314 & 218 & 83,4049871 & 232 & 1291642,5 \\
\hline 189 & 420 & 232 & 74,4391168 & 349 & 83,6748982 & 597 & 86,9683566 & 488 & 83,4049871 & 231 & 48916611 \\
\hline 190 & 421 & 284 & 74,5012727 & 480 & 83,6939919 & 610 & 87,0023818 & 359 & 83,4909716 & 349 & 271952139 \\
\hline 191 & 422 & 612 & 74,5071923 & 460 & 83,7130855 & 357 & 87,0364069 & 379 & 83,4909716 & 233 & 237588999 \\
\hline 192 & 423 & 272 & 74,5131119 & 478 & 83,7703666 & 422 & 87,0364069 & 383 & 83,4909716 & 593 & 18733247,3 \\
\hline 193 & 424 & 271 & 74,5397502 & 227 & 83,7958248 & 379 & 87,2065328 & 610 & 83,5769561 & 278 & 25599575,8 \\
\hline 194 & 425 & 328 & 74,557509 & 497 & 83,8212831 & 595 & 87,2745832 & 280 & 83,6629407 & 606 & 36106198,3 \\
\hline 195 & 426 & 267 & 74,6285444 & 346 & 83,8340122 & 458 & 87,3086084 & 278 & 83,8349097 & 271 & 117977743 \\
\hline 196 & 427 & 185 & 74,6403836 & 992 & 83,8721996 & 497 & 87,3426335 & 422 & 83,8349097 & 347 & 122494981 \\
\hline 197 & 428 & 457 & 74,6699816 & 240 & 84,0376782 & 966 & 87,3426335 & 975 & 83,8349097 & 254 & 240281743 \\
\hline 198 & 429 & 991 & 74,7173385 & 610 & 84,0885947 & 344 & 87,3766587 & 326 & 83,9208942 & 997 & 437315532 \\
\hline 199 & 430 & 350 & 74,7321376 & 975 & 84,0885947 & 179 & 87,4447091 & 277 & 84,0068788 & 238 & 443094624 \\
\hline 200 & 431 & 254 & 74,7646954 & 347 & 84,1331466 & 361 & 87,4447091 & 285 & 84,0068788 & 477 & 452523705 \\
\hline 201 & 432 & 500 & 74,7883739 & 288 & 84,1904277 & 175 & 87,5127594 & 499 & 84,4368014 & 993 & 451906704 \\
\hline 202 & 433 & 234 & 74,8120523 & 464 & 84,3240835 & 181 & 87,5127594 & 593 & 84,4368014 & 275 & 471092644 \\
\hline 203 & 434 & 613 & 74,8120523 & 344 & 84,3686354 & 356 & 87,5127594 & 372 & 84,6947549 & 991 & 430009528 \\
\hline 204 & 435 & 255 & 74,8771681 & 234 & 84,3877291 & 462 & 87,5127594 & 349 & 84,7807395 & 971 & 383277510 \\
\hline 205 & 436 & 381 & 74,9126857 & 175 & 84,4322811 & 233 & 87,5467846 & 225 & 85,1246776 & 576 & 405241706 \\
\hline 206 & 437 & 465 & 74,9126857 & 350 & 84,5659369 & 459 & 87,5467846 & 606 & 85,1246776 & 458 & 268335448 \\
\hline 207 & 438 & 386 & 74,9630024 & 357 & 84,782332 & 436 & 87,6828853 & 223 & 85,2106621 & 476 & 308371171 \\
\hline
\end{tabular}




\begin{tabular}{|c|c|c|c|c|c|c|c|c|c|c|c|}
\hline $\begin{array}{c}\text { ZATs } \\
\text { PUCAB } \\
\end{array}$ & & Trabalho & & estudo & & saude & & recreação & & ponderação & \\
\hline $40 \mathrm{~min}$ & & pucab & abrange $\%$ & pucab & abrange $\%$ & pucab & abrange $\%$ & pucab & abrange $\%$ & pucab prio & ponderado \\
\hline 208 & 439 & 181 & 74,9748417 & 291 & 84,8459776 & 180 & 87,7169105 & 291 & 85,2106621 & 454 & 390682940 \\
\hline 209 & 440 & 345 & 75,0251583 & 255 & 84,8714358 & 343 & 87,7849609 & 457 & 85,2106621 & 633 & 329236160 \\
\hline 210 & 441 & 441 & 75,2205055 & 179 & 84,985998 & 993 & 87,7849609 & 224 & 85,2966466 & 488 & 290212963 \\
\hline 211 & 442 & 981 & 75,2560232 & 292 & 85,0369145 & 268 & 87,818986 & 465 & 85,2966466 & 632 & 386261184 \\
\hline 212 & 443 & 982 & 75,2678624 & 462 & 85,1069246 & 227 & 87,8870364 & 578 & 85,5546002 & 594 & 368934150 \\
\hline 213 & 444 & 231 & 75,3477772 & 351 & 85,1132892 & 463 & 87,9210616 & 582 & 85,5546002 & 353 & 418289072 \\
\hline 214 & 445 & 464 & 75,3596164 & 378 & 85,1260183 & 359 & 87,9891119 & 279 & 85,7265692 & 378 & 405281261 \\
\hline 215 & 446 & 179 & 75,4780086 & 286 & 85,1578411 & 288 & 88,0231371 & 282 & 85,7265692 & 272 & 394611724 \\
\hline 216 & 447 & 462 & 75,5697626 & 233 & 85,1769348 & 167 & 88,0911875 & 255 & 85,8125537 & 282 & 408413834 \\
\hline 217 & 448 & 175 & 75,853904 & 846 & 85,1832994 & 846 & 88,0911875 & 504 & 85,8985383 & 355 & 439417385 \\
\hline 218 & 449 & 167 & 76,0285325 & 633 & 85,2724033 & 354 & 88,193263 & 350 & 85,9845228 & 472 & 445712608 \\
\hline 219 & 450 & 330 & 76,1173267 & 459 & 85,3169552 & 460 & 88,193263 & 590 & 85,9845228 & 235 & 400717100 \\
\hline 220 & 451 & 574 & 76,1498846 & 461 & 85,3996945 & 633 & 88,193263 & 592 & 85,9845228 & 354 & 393558985 \\
\hline 221 & 452 & 966 & 76,2416385 & 597 & 85,4060591 & 217 & 88,3293637 & 347 & 86,0705073 & 284 & 366366209 \\
\hline 222 & 453 & 180 & 76,2830758 & 966 & 85,4824338 & 992 & 88,3293637 & 357 & 86,0705073 & 610 & 419928665 \\
\hline 223 & 454 & 843 & 76,3748298 & 361 & 85,8706721 & 319 & 88,4314393 & 971 & 86,0705073 & 975 & 213201154 \\
\hline 224 & 455 & 384 & 76,3955485 & 290 & 85,8961303 & 376 & 88,6696155 & 168 & 86,2424764 & 577 & 165259291 \\
\hline 225 & 456 & 463 & 76,4103475 & 176 & 86,0106925 & 176 & 88,7376659 & 373 & 86,2424764 & 267 & 161459614 \\
\hline 226 & 457 & 590 & 76,5376191 & 379 & 86,0106925 & 345 & 88,8057162 & 992 & 86,2424764 & 229 & 243532013 \\
\hline 227 & 458 & 278 & 76,5435387 & 320 & 86,1825356 & 632 & 88,8397414 & 184 & 86,3284609 & 497 & 215534826 \\
\hline 228 & 459 & 329 & 76,6826496 & 348 & 86,3352851 & 373 & 88,9077918 & 845 & 86,4144454 & 597 & 291972763 \\
\hline 229 & 460 & 459 & 76,7240869 & 582 & 86,3543788 & 461 & 88,9077918 & 352 & 86,5004299 & 586 & 299752791 \\
\hline 230 & 461 & 380 & 76,7892026 & 373 & 86,4498473 & 451 & 88,9418169 & 464 & 86,5004299 & 595 & 294564951 \\
\hline
\end{tabular}




\begin{tabular}{|c|c|c|c|c|c|c|c|c|c|c|c|}
\hline $\begin{array}{c}\text { ZATs } \\
\text { PUCAB }\end{array}$ & & Trabalho & & estudo & & saude & & recreação & & ponderação & \\
\hline $40 \mathrm{~min}$ & & pucab & abrange $\%$ & pucab & abrange $\%$ & pucab & abrange $\%$ & pucab & abrange $\%$ & pucab prio & ponderado \\
\hline 231 & 462 & 461 & 76,9904694 & 181 & 86,4943992 & 353 & 89,0098673 & 222 & 86,5864144 & 273 & 277367742 \\
\hline 232 & 463 & 587 & 76,9904694 & 221 & 86,6598778 & 234 & 89,0438925 & 270 & 86,5864144 & 287 & 305706178 \\
\hline 233 & 464 & 302 & 77,0082283 & 504 & 86,6662424 & 476 & 89,1119428 & 295 & 86,672399 & 513 & 267803505 \\
\hline 234 & 465 & 275 & 77,1976558 & 359 & 86,6789715 & 477 & 89,1119428 & 240 & 86,844368 & 281 & 254972559 \\
\hline 235 & 466 & 428 & 77,2390931 & 632 & 86,7235234 & 478 & 89,1799932 & 467 & 87,1883061 & 469 & 243547390 \\
\hline 236 & 467 & 288 & 77,6268277 & 217 & 86,787169 & 479 & 89,1799932 & 575 & 87,1883061 & 383 & 241262502 \\
\hline 237 & 468 & 374 & 77,7955366 & 594 & 86,7935336 & 480 & 89,1799932 & 345 & 87,3602752 & 253 & 167957241 \\
\hline 238 & 469 & 375 & 78,0145622 & 500 & 87,0863035 & 362 & 89,2140184 & 997 & 87,3602752 & 480 & 179471243 \\
\hline 239 & 470 & 992 & 78,1329545 & 422 & 87,398167 & 457 & 89,2140184 & 356 & 87,5322442 & 269 & 65094067, \\
\hline 240 & 471 & 437 & 78,171432 & 574 & 87,4236253 & 466 & 89,2140184 & 421 & 87,5322442 & 478 & 103355878 \\
\hline 241 & 472 & 360 & 78,20103 & 590 & 87,4363544 & 467 & 89,2140184 & 466 & 87,5322442 & 479 & 204684189 \\
\hline 242 & 473 & 366 & 78,2128692 & 593 & 87,4490835 & 289 & 89,2480436 & 461 & 87,7042132 & 377 & 130166635 \\
\hline 243 & 474 & 184 & 78,277985 & 180 & 87,5127291 & 593 & 89,2480436 & 348 & \begin{tabular}{|l}
87,7901978 \\
\end{tabular} & 301 & 162360371 \\
\hline 244 & 475 & 346 & 78,2898242 & 252 & 87,7354888 & 360 & 89,3501191 & 361 & 87,7901978 & 468 & 161440150 \\
\hline 245 & 476 & 845 & 78,292784 & 283 & 87,8245927 & 330 & 89,3841443 & 846 & 87,7901978 & 296 & 214259777 \\
\hline 246 & 477 & 219 & 78,3874978 & 971 & 87,8309572 & 283 & 89,4181694 & 286 & 87,8761823 & 455 & 221443703 \\
\hline 247 & 478 & 285 & 78,476292 & 507 & 87,8436864 & 446 & 89,4181694 & 512 & 87,8761823 & 266 & 173447954 \\
\hline 248 & 479 & 171 & 78,6094832 & 339 & 88,0346232 & 447 & 89,4181694 & 435 & 87,9621668 & 237 & 172955251 \\
\hline 249 & 480 & 344 & 78,6272421 & 421 & 88,0473523 & 452 & 89,4862198 & 171 & 88,0481513 & 474 & 175384091 \\
\hline 250 & 481 & 502 & 78,6361215 & 499 & 88,1810081 & 450 & 89,520245 & 439 & 88,2201204 & 274 & 115602536 \\
\hline 251 & 482 & 578 & 78,718996 & 592 & 88,212831 & 507 & 89,520245 & 506 & 88,2201204 & 498 & 120313010 \\
\hline 252 & 483 & 460 & 78,7426745 & 997 & 88,212831 & 255 & 89,5542702 & 221 & 88,3061049 & 456 & 115123858 \\
\hline 253 & 484 & 588 & 78,8610667 & 224 & 88,3210285 & 443 & 89,7584212 & 460 & 88,3061049 & 496 & 120515874 \\
\hline
\end{tabular}




\begin{tabular}{|c|c|c|c|c|c|c|c|c|c|c|c|}
\hline $\begin{array}{c}\text { ZATs } \\
\text { PUCAB }\end{array}$ & & Trabalho & & estudo & & saude & & recreação & & ponderação & \\
\hline $40 \mathrm{~min}$ & & pucab & abrange $\%$ & pucab & abrange $\%$ & pucab & abrange $\%$ & pucab & abrange $\%$ & pucab prio & ponderado \\
\hline 254 & 485 & 395 & 78,8640265 & 362 & 88,4610489 & 346 & 89,8264716 & 462 & 88,3061049 & 475 & 137694000 \\
\hline 255 & 486 & 279 & 78,9883384 & 167 & 88,5374236 & 445 & 89,9285471 & 507 & 88,3061049 & 239 & 134695373 \\
\hline 256 & 487 & 293 & 79,0120168 & 506 & 88,6838086 & 339 & 89,9625723 & 293 & 88,3920894 & 494 & 137547234 \\
\hline 257 & 488 & 227 & 79,0948914 & 435 & 88,7347251 & 225 & 90,0646478 & 514 & 88,4780739 & 495 & 211730178 \\
\hline 258 & 489 & 358 & 79,2103238 & 440 & 88,9511202 & 435 & 90,0646478 & 991 & \begin{tabular}{|l}
88,4780739 \\
\end{tabular} & 250 & 64689483, \\
\hline 259 & 490 & 295 & \begin{tabular}{|l}
79,2576807 \\
\end{tabular} & 360 & 89,0338595 & 347 & 90,1326982 & 174 & \begin{tabular}{|l|l|}
88,5640585 \\
\end{tabular} & 251 & 72075521 \\
\hline 260 & 491 & 340 & 79,2606405 & 168 & 89,1102342 & 351 & 90,1326982 & 440 & 88,5640585 & 183 & 97148671 \\
\hline 261 & 492 & 176 & 79,3642337 & 330 & 89,1802444 & 499 & 90,1326982 & 351 & 88,650043 & 510 & 66749818 \\
\hline 262 & 493 & 300 & 79,4115906 & 452 & 89,2120672 & 291 & 90,1667234 & 588 & 88,650043 & 297 & 52630910 \\
\hline 263 & 494 & 240 & 79,4145504 & 588 & 89,4093686 & 501 & 90,1667234 & 252 & 88,822012 & 848 & 157637976 \\
\hline 264 & 495 & 517 & 79,4678269 & 467 & 89,5175662 & 594 & 90,2007486 & 343 & 89,1659501 & 236 & 157493835 \\
\hline 265 & 496 & 224 & 79,5329426 & 443 & 89,5366599 & 444 & 90,2347737 & 517 & 89,1659501 & 485 & 161444135 \\
\hline 266 & 497 & 440 & 79,5507015 & 441 & 89,5430244 & 385 & 90,4048996 & 289 & 89,2519347 & 487 & 193334286 \\
\hline 267 & 498 & 341 & \begin{tabular}{|l}
79,5862191 \\
\end{tabular} & 463 & 89,5684827 & 352 & 90,47295 & 226 & 89,3379192 & 951 & 161687239 \\
\hline 268 & 499 & 373 & 79,8378026 & 466 & 89,6003055 & 578 & 90,5410003 & 436 & 89,3379192 & 486 & 244592112 \\
\hline 269 & 500 & 539 & 79,8703605 & 395 & 89,6066701 & 223 & 90,5750255 & 574 & 89,3379192 & 584 & 267992500 \\
\hline 270 & 501 & 292 & 79,894039 & 517 & 89,6830448 & 295 & 90,6430759 & 362 & 89,4239037 & 230 & 382018104 \\
\hline 271 & 502 & 218 & 79,9177174 & 225 & 89,6957739 & 574 & 90,6771011 & 441 & 89,5098882 & 515 & 272336833 \\
\hline 272 & 503 & 277 & 79,9976322 & 376 & 89,7976069 & 971 & 90,6771011 & 463 & 89,5098882 & 473 & 431459309 \\
\hline 273 & 504 & 168 & 80,0183508 & 539 & 89,7976069 & 421 & 90,7111262 & 169 & 89,5958727 & 583 & 351804508 \\
\hline 274 & 505 & 575 & 80,0272302 & 578 & 89,8167006 & 320 & 90,7791766 & 268 & 89,5958727 & 249 & 424184729 \\
\hline 275 & 506 & 512 & 80,0627479 & 436 & 89,8676171 & 442 & 90,8472269 & 501 & 89,5958727 & 186 & 391568513 \\
\hline 276 & 507 & 342 & 80,0745871 & 575 & 89,8867108 & 395 & 90,9833277 & 385 & 89,6818573 & 427 & 383772736 \\
\hline
\end{tabular}




\begin{tabular}{|c|c|c|c|c|c|c|c|c|c|c|c|}
\hline $\begin{array}{l}\text { ZATs } \\
\text { PUCAB }\end{array}$ & & Trabalho & & estudo & & saude & & recreação & & ponderação & \\
\hline $40 \mathrm{~min}$ & & pucab & abrange \% & pucab & abrange \% & pucab & abrange \% & pucab & abrange $\%$ & pucab prio & ponderado \\
\hline 277 & 508 & 589 & 80,2077784 & 222 & 90,2494908 & 506 & 91,0854032 & 446 & 89,9398108 & 484 & 427783895 \\
\hline 278 & 509 & 280 & 80,2373764 & 439 & 90,2813136 & 612 & 91,0854032 & 341 & 90,1117799 & 482 & 407622244 \\
\hline 279 & 510 & 343 & 80,2580951 & 612 & 90,3067719 & 171 & 91,1874787 & 173 & 90,3697334 & 965 & 149968354 \\
\hline 280 & 511 & 591 & 80,3528089 & 512 & 90,3449593 & 222 & 91,1874787 & 283 & 90,3697334 & 426 & 425697276 \\
\hline 281 & 512 & 270 & 80,3676079 & 289 & 90,3895112 & 184 & 91,2215039 & 381 & 90,3697334 & 216 & 362249750 \\
\hline 282 & 513 & 286 & 80,5659149 & 606 & 90,3895112 & 358 & 91,2555291 & 452 & 90,3697334 & 581 & 182071915 \\
\hline 283 & 514 & 283 & 80,5688747 & 442 & 90,6695519 & 348 & 91,2895543 & 360 & 90,455718 & 481 & 385852147 \\
\hline 284 & 515 & 298 & 80,5688747 & 358 & 90,7204684 & 592 & 91,3235794 & 299 & 90,627687 & 483 & 130854011 \\
\hline 285 & 516 & 276 & 80,5807139 & 385 & 90,8795825 & 591 & 91,3576046 & 342 & 90,7136715 & 303 & 78090588 \\
\hline 286 & 517 & 372 & 80,5984727 & 184 & 90,885947 & 168 & 91,425655 & 344 & 90,7996561 & 967 & 349600480 \\
\hline 287 & 518 & 223 & 80,7198248 & 223 & 90,9050407 & 982 & 91,425655 & 539 & 90,7996561 & 213 & 423736805 \\
\hline 288 & 519 & 846 & 80,7583023 & 450 & 90,9241344 & 226 & 91,4937053 & 288 & 90,8856406 & 471 & 21548060,8 \\
\hline 289 & 539 & 290 & 80,9625289 & 174 & 91,134165 & 293 & 91,4937053 & 443 & 91,0576096 & 382 & 355664499 \\
\hline 290 & 574 & 367 & 81,0720417 & 982 & 91,2423625 & 589 & 91,4937053 & 451 & 91,0576096 & 326 & 299109261 \\
\hline 291 & 575 & 368 & 81,1164388 & 226 & 91,2614562 & 981 & 91,4937053 & 376 & 91,1435942 & 996 & 359799484 \\
\hline 292 & 576 & 268 & 81,1460368 & 446 & 91,3187373 & 328 & 91,5617557 & 505 & 91,1435942 & 322 & 217512870 \\
\hline 293 & 577 & 172 & 81,1697153 & 501 & 91,3696538 & 221 & 91,5957809 & 429 & 91,2295787 & 215 & 198887455 \\
\hline 294 & 578 & 438 & 81,3917007 & 613 & 91,4332994 & 843 & 91,5957809 & 294 & 91,3155632 & 634 & 333183587 \\
\hline 295 & 579 & 369 & 81,6136861 & 509 & 91,4651222 & 349 & 91,6298061 & 346 & 91,3155632 & 491 & 423956777 \\
\hline 296 & 580 & 217 & 81,7498372 & 434 & 91,5542261 & 381 & 91,6298061 & 374 & 91,3155632 & 618 & 416181911 \\
\hline 297 & 581 & 291 & 81,7705559 & 591 & 91,5542261 & 224 & 91,7318816 & 843 & 91,5735168 & 615 & 116168604 \\
\hline 298 & 582 & 514 & 81,8267922 & 451 & 91,598778 & 503 & 91,7659068 & 434 & 91,7454858 & 603 & 347470380 \\
\hline 299 & 583 & 452 & 81,8859883 & 514 & 91,6560591 & 986 & 91,7659068 & 518 & 91,7454858 & 617 & 126895700 \\
\hline
\end{tabular}




\begin{tabular}{|c|c|c|c|c|c|c|c|c|c|c|c|}
\hline $\begin{array}{l}\text { ZATs } \\
\text { PUCAB }\end{array}$ & & Trabalho & & estudo & & saude & & recreação & & ponderação & \\
\hline $40 \mathrm{~min}$ & & pucab & abrange $\%$ & pucab & abrange $\%$ & pucab & abrange $\%$ & pucab & abrange $\%$ & pucab prio & ponderado \\
\hline 300 & 584 & 443 & 81,9422246 & 981 & 91,6687882 & 386 & 91,9360327 & 300 & 91,8314703 & 983 & 132473213 \\
\hline 301 & 585 & 221 & 81,965903 & 447 & 91,6878819 & 588 & 91,9360327 & 340 & 91,8314703 & 585 & 82282496,8 \\
\hline 302 & 586 & 339 & 82,042858 & 589 & 91,8151731 & 453 & 92,2762845 & 442 & 91,8314703 & 842 & 189538185 \\
\hline 303 & 587 & 501 & 82,1464512 & 295 & 91,8851833 & 350 & 92,3103096 & 612 & 91,8314703 & 616 & 245838528 \\
\hline 304 & 588 & 582 & 82,2115669 & 328 & 91,9233707 & 606 & 92,3443348 & 358 & 91,9174549 & 516 & 336477646 \\
\hline 305 & 589 & 844 & 82,3033209 & 445 & 91,9297352 & 338 & 92,4123852 & 450 & 91,9174549 & 201 & 370136726 \\
\hline 306 & 590 & 504 & 82,4246729 & 228 & 91,961558 & 174 & 92,6505614 & 459 & 91,9174549 & 387 & 291571095 \\
\hline 307 & 591 & 363 & 82,6436986 & 518 & 92,0124745 & 252 & 92,752637 & 228 & 92,0034394 & 214 & 370450351 \\
\hline 308 & 592 & 299 & 82,652578 & 844 & 92,0124745 & 505 & 92,752637 & 508 & 92,0034394 & 490 & 249149237 \\
\hline 309 & 593 & 225 & 82,7117741 & 505 & 92,0188391 & 434 & 92,8206873 & 986 & 92,0894239 & 969 & 229441316 \\
\hline 310 & 594 & 442 & 82,7176937 & 169 & 92,0252037 & 169 & 93,0248384 & 339 & 92,2613929 & 321 & 211298974 \\
\hline 311 & 595 & 226 & 82,8982419 & 293 & 92,0952138 & 329 & 93,0588636 & 386 & 92,2613929 & 598 & 188451811 \\
\hline 312 & 596 & 332 & 83,2504588 & 171 & 92,107943 & 844 & 93,0928887 & 445 & 92,2613929 & 325 & 63020777,3 \\
\hline 313 & 597 & 985 & 83,3185343 & 843 & 92,1397658 & 173 & 93,1269139 & 982 & 92,2613929 & 316 & 189899508 \\
\hline 314 & 598 & 579 & 83,445806 & 172 & 92,165224 & 514 & 93,2289895 & 503 & 92,5193465 & 212 & 69748138,5 \\
\hline 315 & 599 & 511 & 83,5316403 & 329 & 92,2352342 & 384 & 93,2630146 & 613 & 92,5193465 & 601 & 65604062,3 \\
\hline 316 & 600 & 580 & 83,7565856 & 508 & 92,2415988 & 336 & 93,2970398 & 170 & 92,605331 & 492 & 58196436,3 \\
\hline 317 & 601 & 228 & 83,7595454 & 386 & 92,3434318 & 517 & 93,2970398 & 329 & 92,605331 & 631 & 66829553,8 \\
\hline 318 & 602 & 169 & 83,8927366 & 430 & 92,4452648 & 335 & 93,3650902 & 444 & 92,605331 & 602 & 65919988 \\
\hline 319 & 603 & 984 & 83,8927366 & 986 & 92,5343686 & 365 & 93,3650902 & 172 & 92,6913156 & 599 & 86591604 \\
\hline 320 & 605 & 451 & 84,0584858 & 444 & 92,572556 & 539 & 93,6032664 & 302 & 92,8632846 & 470 & 57638603,8 \\
\hline 321 & 606 & 509 & 84,1975966 & 374 & 92,5916497 & 380 & 93,6713168 & 328 & 92,8632846 & 614 & 228622368 \\
\hline 322 & 610 & 446 & 84,375185 & 503 & 92,674389 & 613 & 93,6713168 & 395 & 92,8632846 & 489 & 199985871 \\
\hline
\end{tabular}




\begin{tabular}{|c|c|c|c|c|c|c|c|c|c|c|c|}
\hline $\begin{array}{c}\text { ZATs } \\
\text { PUCAB }\end{array}$ & & Trabalho & & estudo & & saude & & recreação & & ponderação & \\
\hline $40 \mathrm{~min}$ & & pucab & abrange $\%$ & pucab & abrange $\%$ & pucab & abrange $\%$ & pucab & abrange $\%$ & pucab prio & ponderado \\
\hline 323 & 612 & 435 & 84,3870242 & 336 & 92,7253055 & 374 & 93,705342 & 220 & 92,9492691 & 987 & 292371770 \\
\hline 324 & 613 & 222 & 84,5379743 & 335 & 92,7698574 & 448 & 93,8074175 & 384 & 93,0352537 & 596 & 312825903 \\
\hline 325 & 614 & 220 & 84,5557331 & 453 & 92,8207739 & 294 & 93,8754678 & 330 & 93,1212382 & 841 & 64866606,3 \\
\hline 326 & 615 & 334 & 84,6060498 & 365 & 92,8398676 & 512 & 93,8754678 & 985 & 93,3791917 & 600 & 91767094 \\
\hline 327 & 616 & 445 & 84,694844 & 432 & 92,8716904 & 575 & 93,909493 & 580 & 93,5511608 & 211 & 81716889,8 \\
\hline 328 & 617 & 453 & 84,7658794 & 985 & 92,9226069 & 228 & 94,0115686 & 298 & 93,6371453 & 605 & 86355280,5 \\
\hline 329 & 618 & 507 & 84,8191559 & 302 & 92,9862525 & 429 & 94,0115686 & 448 & 93,7231298 & 988 & 93274892,5 \\
\hline 330 & 631 & 450 & 84,9168295 & 338 & 93,0626273 & 430 & 94,0455937 & 380 & 93,8091144 & 968 & 66358602,3 \\
\hline 331 & 632 & 506 & 84,9582667 & 580 & 93,139002 & 985 & 94,0455937 & 984 & 93,8091144 & 493 & 211623026 \\
\hline 332 & 633 & 370 & 85,1003374 & 429 & 93,2981161 & 508 & 94,0796189 & 430 & 93,8950989 & 314 & 212000340 \\
\hline 333 & 634 & 447 & 85,2305689 & 384 & 93,3490326 & 449 & 94,2157196 & 589 & 93,9810834 & 420 & 98118271,3 \\
\hline 334 & 841 & 439 & 85,3608003 & 332 & 93,3617617 & 518 & 94,2157196 & 447 & 94,0670679 & 318 & 59486969,8 \\
\hline 335 & 842 & 444 & \begin{tabular}{|l}
85,3696797 \\
\end{tabular} & 337 & 93,3999491 & 580 & 94,2157196 & 509 & 94,1530525 & 182 & 82276596 \\
\hline 336 & 843 & 952 & \begin{tabular}{|l}
85,3933582 \\
\end{tabular} & 173 & 93,444501 & 509 & 94,2497448 & 844 & 94,1530525 & 202 & 331219291 \\
\hline 337 & 844 & 174 & 85,5827858 & 984 & 93,4763238 & 332 & 94,28377 & 338 & 94,239037 & 324 & 396896495 \\
\hline 338 & 845 & 518 & 85,7041378 & 431 & 93,5972505 & 432 & 94,4198707 & 981 & 94,411006 & 199 & 253682963 \\
\hline 339 & 846 & 508 & 85,7455751 & 334 & 93,6927189 & 984 & 94,4198707 & 327 & 94,5829751 & 388 & 336615878 \\
\hline 340 & 848 & 170 & 85,8491683 & 300 & 93,7118126 & 431 & 94,5899966 & 449 & 94,5829751 & 208 & 146594416 \\
\hline 341 & 951 & 448 & 85,8906056 & 952 & 93,8072811 & 302 & 94,6240218 & 431 & 94,6689596 & 425 & 135676076 \\
\hline 342 & 952 & 505 & 86,0948322 & 170 & 93,9473014 & 337 & 94,6240218 & 336 & 94,8409286 & 210 & 437452697 \\
\hline 343 & 953 & 289 & 86,1777067 & 381 & 93,9663951 & 952 & 94,6240218 & 453 & 94,8409286 & 209 & 11896185,5 \\
\hline 344 & 954 & 449 & 86,2013852 & 220 & 94,1191446 & 172 & 94,7941477 & 591 & 94,8409286 & 424 & 13218515,5 \\
\hline 345 & 955 & 429 & 86,2250636 & 448 & 94,3355397 & 334 & 94,8281728 & 331 & 94,9269132 & 200 & 24961764,8 \\
\hline
\end{tabular}




\begin{tabular}{|c|c|c|c|c|c|c|c|c|c|c|c|}
\hline $\begin{array}{c}\text { ZATs } \\
\text { PUCAB }\end{array}$ & & Trabalho & & estudo & & saude & & recreação & & ponderação & \\
\hline $40 \mathrm{~min}$ & & pucab & abrange $\%$ & pucab & abrange $\%$ & pucab & abrange $\%$ & pucab & abrange $\%$ & pucab prio & ponderado \\
\hline 346 & 965 & 503 & 86,2724205 & 579 & 94,4882892 & 363 & 94,8281728 & 332 & 95,0128977 & 323 & 118945896 \\
\hline 347 & 966 & 986 & 86,3079382 & 369 & 94,5837576 & 327 & 94,862198 & 335 & 95,0988822 & 955 & 281772433 \\
\hline 348 & 967 & 331 & 86,402652 & 299 & 94,6537678 & 375 & 94,8962232 & 337 & 95,0988822 & 203 & 111220354 \\
\hline 349 & 968 & 338 & 86,4144912 & 511 & 94,9719959 & 220 & 95,0323239 & 334 & 95,1848667 & 207 & 54717082 \\
\hline 350 & 969 & 436 & 87,3231516 & 371 & 94,9910896 & 371 & 95,1684246 & 369 & 95,1848667 & 313 & 72059420,3 \\
\hline 351 & 971 & 337 & 87,8233588 & 380 & 94,9910896 & 331 & 95,2024498 & 371 & 95,18486667 & 519 & 218696182 \\
\hline 352 & 975 & 173 & 87,8292784 & 449 & 95,0101833 & 333 & 95,2705002 & 579 & 95,3568358 & 204 & 199451975 \\
\hline 353 & 981 & 327 & 87,9476706 & 368 & 95,13111 & 298 & 95,4406261 & 365 & 95,5288048 & 205 & 318208037 \\
\hline 354 & 982 & 365 & 88,048304 & 366 & 95,4493381 & 368 & 95,5086764 & 432 & 95,7007739 & 423 & 314107311 \\
\hline 355 & 983 & 434 & 88,0512638 & 363 & 95,8439409 & 366 & 95,5427016 & 375 & 95,7867584 & 317 & 83507988,3 \\
\hline 356 & 984 & 294 & 88,1578168 & 370 & 96,2194501 & 300 & 95,6447771 & 511 & 95,8727429 & 954 & 421281891 \\
\hline 357 & 985 & 430 & 88,1844551 & 331 & 96,2830957 & 369 & 95,7468527 & 363 & 95,9587274 & 399 & 412251766 \\
\hline 358 & 986 & 431 & 88,6461848 & 333 & 96,6013238 & 170 & 95,9169786 & 368 & 96,38865 & 953 & 431125023 \\
\hline 359 & 987 & 371 & 88,6994613 & 294 & 96,7922607 & 511 & 96,18918 & 333 & 96,5606191 & 206 & 63815191,8 \\
\hline 360 & 988 & 364 & 89,1848695 & 367 & 96,8240835 & 367 & 96,4273562 & 364 & 97,3344798 & 400 & 57630655,5 \\
\hline 361 & 991 & 336 & 89,4453324 & 364 & 97,0277495 & 579 & 96,4273562 & 952 & 97,5924334 & 315 & 218735231 \\
\hline 362 & 992 & 432 & 89,9988161 & 375 & 97,3141548 & 364 & 96,8016332 & 366 & 97,7644024 & 311 & 290863932 \\
\hline 363 & 993 & 335 & 90,0668916 & 298 & 97,6705703 & 370 & 97,720313 & 370 & 98,022356 & 397 & 221115154 \\
\hline 364 & 996 & 333 & 90,1112887 & 433 & 97,9887984 & 299 & 97,8904389 & 367 & 98,194325 & 312 & 101931959 \\
\hline 365 & 997 & 433 & 92,194992 & 327 & 98,3070265 & 433 & 99,1153454 & 433 & 98,5382631 & 403 & 223190407 \\
\hline
\end{tabular}

Tabela do Ranking no Cenário 2 em 40 minutos. 
Apêndice 4

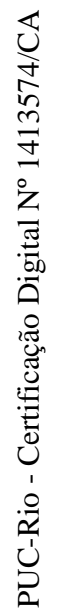
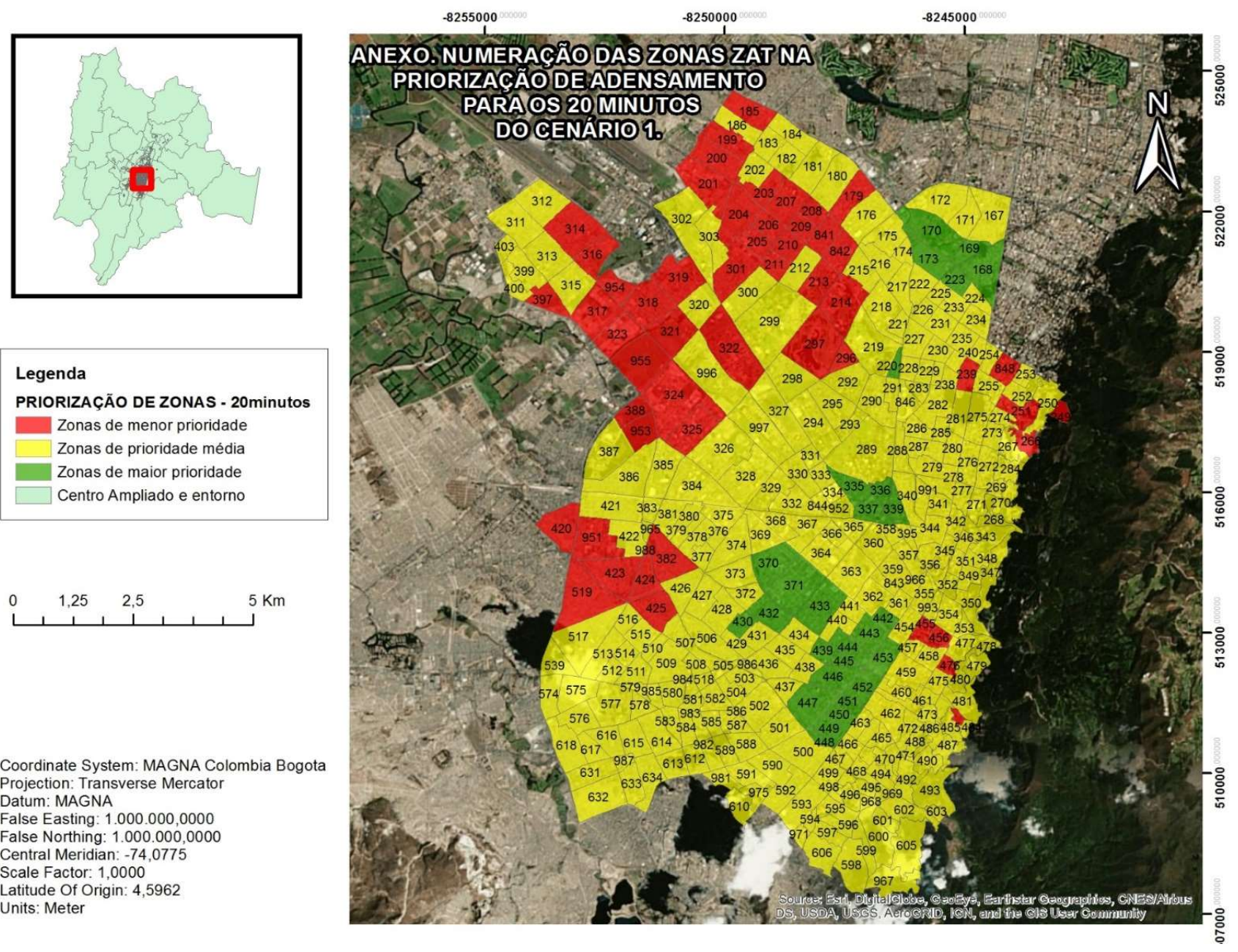

Coordinate System: MAGNA Colombia Bogota Projection: Transverse Mercator Datum: MAGNA
False Easting: $1.000 .000,0000$ False Northing: $1.000 .000,0000$ Central Meridian: - 74,0775 Scale Factor: 1,0000 Latitude Of Origin: 4,5962 Units: Meter

Legenda
PRIORIZAÇÃO DE ZONAS - 20minutos Zonas de menor prioridade Zonas de prioridade média Zonas de maior prioridade Centro Ampliado e entorno

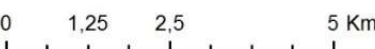




\section{Anexos}

\section{- 1. Endereços dos limites geográficos do centro ampliado de Bogotá}

Norte de occidente a oriente, con la avenida calle 80 , desde la avenida longitudinal de occidente hasta la avenida 68 . Con la avenida calle 100, desde la avenida 68 hasta la autopista norte. $\mathrm{Y}$ con la calle 64 , desde la avenida $\mathrm{Ca}-$ racas hasta el limite urbario contra los cerros orientales subiendo por la carrera $1 \mathrm{~A}$.

Oriente: de norte a sur, con ba autopista norte, desde la calle 100 , hasta la calle 64 . Con los cerros orientales, desde la calle 64 hasta la calle 3 . $Y$ con ha carrera $3 E$ y $5 \mathrm{E}$, desde la calle 3 hasta la calle 22 sur.

Sur: de oriente a occidente, con la calle 22 sur desde la transwersal 5 E hasta la carrena 6 . Con la calie 27 sur, desde la carreta 6 hasta la avenida Caracas, Con la avenida Caracas, desde el cruce con la carrera 6 hasta la diagonal 48 sur. Con la diagonal 48 sur, desde el cruce con la avenida Caracas hasta el cruce con la calle 48 sur. Con la carrera $19 \mathrm{C}$, desde el cruce con la calle 48 sur hasta ha avenida Boyacá.

Occidente: de sur a norte, con la avenida Boyaca, desde la carrera $19 \mathrm{C}$ hasta ha avenida Centenario. Con la avenida Centenario, rodeando el centto de Fontibón, hasta la avenida longitudinal de occidente. $Y$ con la avenida longitudinal de occidente, dende Fontibòn hasta la avenida calle 80 . 
- 2. Listas UPZ:

\begin{tabular}{|c|c|c|c|}
\hline Nú mero & Nombre UPZ & Nú mero & Nombre UPZ \\
\hline 1 & Paseo De Los Libertadores & 63 & El Mochuelo \\
\hline 2 & La Academia & 64 & Monte Blanco \\
\hline 3 & Guaymaral & 65 & Arborizadora \\
\hline 9 & Verbenal & 66 & San Francisco \\
\hline 10 & La Uribe & 67 & Lucero \\
\hline 11 & San Cristobal Norte & 68 & El Tesoro \\
\hline 12 & Toberín & 69 & Ismael Perdomo \\
\hline 13 & Los Cedros & 70 & Jerusalem \\
\hline 14 & Usaquen & 71 & Tibabuyes \\
\hline 15 & Country Club & 72 & Bolivia \\
\hline 16 & Santa Barbara & 73 & Garces Navas \\
\hline 17 & San José de Bavaria & 74 & Engativá \\
\hline 18 & Britalia & 75 & Fontibó n \\
\hline 19 & El Prado & 76 & Fontibó n San Pablo \\
\hline 20 & La Alhambra & 77 & Zona Franca \\
\hline 21 & Los Andes & 78 & Tintal Norte \\
\hline 22 & Doce De Octubre & 79 & Calandaima \\
\hline 23 & Casa Blanca Suba & 80 & Corabastos \\
\hline 24 & Niza & 81 & Gran Britalia \\
\hline 25 & La Floresta & 82 & Patio Bonito \\
\hline 26 & Las Ferias & 83 & Las Margaritas \\
\hline 27 & Suba & 84 & Bosa Occidental \\
\hline 28 & El Rincón & 85 & Bosa Central \\
\hline 29 & Minuto De Dios & 86 & El Porvenir \\
\hline 30 & Boyaca Real & 87 & Tintal Sur \\
\hline 31 & Santa Cecilia & 88 & El Refugio \\
\hline 32 & San Blas & 89 & San Isidro - Patios \\
\hline 33 & Sosiego & 90 & Pardo Rubio \\
\hline 34 & 20 de Julio & 91 & Sagrado Corazó n \\
\hline 35 & Ciudad Jardin & 92 & La Macarena \\
\hline 36 & San Jose & 93 & Las Nieves \\
\hline 37 & Santa Isabel & 94 & La Candelaria \\
\hline 38 & Restrepo & 95 & Las Cruces \\
\hline 39 & Quiroga & 96 & Lourdes \\
\hline 40 & Ciudad Montes & 97 & Chicó Lago \\
\hline 41 & Muzu & 98 & Los Alcá zares \\
\hline 42 & Venecia & 99 & Chapinero \\
\hline 43 & San Rafael & 100 & Galerías \\
\hline 44 & Amé ricas & 101 & Teusaquillo \\
\hline 45 & Carvajal & 102 & La Sabana \\
\hline 46 & Castilla & 103 & Parque Salitre \\
\hline 47 & Kennedy Central & 104 & Parque Simón Bolivar - Can \\
\hline 48 & Timiza & 105 & Jardin Botánico \\
\hline 49 & Apogeo & 106 & La Esmeralda \\
\hline 50 & La Gloria & 107 & Quinta Paredes \\
\hline 51 & Los Libertadores & 108 & Zona Industrial \\
\hline 52 & La Flora & 109 & Ciudad Salitre Oriental \\
\hline 53 & Marco Fidel Suárez & 110 & Ciudad Salitre Occidental \\
\hline 54 & Marruecos & 111 & Puente Aranda \\
\hline 55 & Diana Turbay & 112 & Granjas De Techo \\
\hline 56 & Danubio & 113 & Bavaria \\
\hline 57 & Gran Yomasa & 114 & Modelia \\
\hline 58 & Comuneros & 115 & Capellanía \\
\hline 59 & Alfonso López & 116 & Alamos \\
\hline 60 & Parque Entrenubes & 117 & Aeropuerto El Dorado \\
\hline 61 & Ciudad Usme & & \\
\hline 62 & Tunjuelito & & \\
\hline
\end{tabular}

Fonte: Diana Gutiérrez (2011). 


\section{- 3. Equipamentos por setor, população e equipamentos por cada 10.000}

\section{habitantes 2011:}

\begin{tabular}{|c|c|c|c|c|c|c|c|c|c|c|c|c|c|c|c|}
\hline No & Localidad & 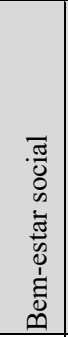 & $\begin{array}{l}\mathscr{E} \\
\mathscr{E} \\
\mathscr{n}\end{array}$ & 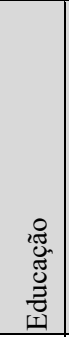 & $\frac{\widetilde{\widetilde{E}}}{\stackrel{\mathrm{E}}{\mathrm{J}}}$ & $\stackrel{\ominus}{3}$ & 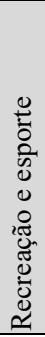 & 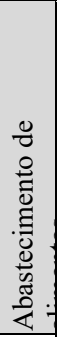 & 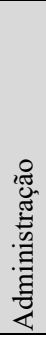 & 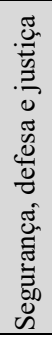 & 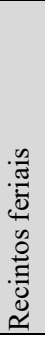 & 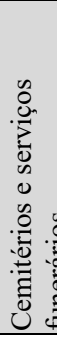 & 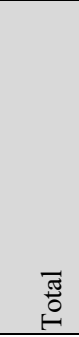 & 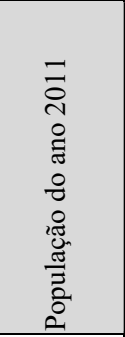 & 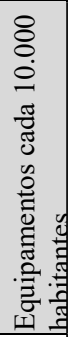 \\
\hline 1 & Usaquen & 380 & 38 & 233 & 42 & 98 & 12 & 5 & 10 & 12 & & 5 & 835 & 474773 & 18 \\
\hline 2 & Chapinero & 233 & 10 & 176 & 74 & 43 & 7 & 2 & 19 & 13 & & 4 & 581 & 133778 & 43 \\
\hline 3 & Santa Fe & 286 & 14 & 110 & 69 & 41 & 5 & 6 & 23 & 33 & 1 & 12 & 600 & 109993 & 55 \\
\hline 4 & San Cristobal & 563 & 25 & 174 & 63 & 60 & 6 & 3 & 6 & 12 & & 2 & 914 & 409799 & 22 \\
\hline 5 & Usme & 598 & 18 & 110 & 63 & 32 & 3 & 3 & 6 & 10 & & 3 & 846 & 382876 & 22 \\
\hline 6 & Tunjuelito & 103 & 19 & 97 & 10 & 48 & 1 & 4 & 6 & 11 & & 4 & 303 & 201843 & 15 \\
\hline 7 & Bosa & 430 & 27 & 178 & 45 & 41 & 2 & 2 & 6 & 12 & & 5 & 748 & 583056 & 13 \\
\hline 8 & Kennedy & 464 & 33 & 372 & 87 & 109 & 6 & 6 & 16 & 19 & & 4 & 1116 & 1019949 & 11 \\
\hline 9 & Fontibón & 163 & 17 & 167 & 35 & 58 & 4 & 5 & 14 & 12 & & 3 & 478 & 345909 & 14 \\
\hline 10 & Engativá & 681 & 29 & 402 & 47 & 147 & 12 & 9 & 16 & 19 & & 5 & 1367 & 843722 & 16 \\
\hline 11 & Suba & 532 & 21 & 429 & 78 & 130 & 21 & 3 & 18 & 19 & & 5 & 1256 & 1069114 & 12 \\
\hline 12 & Barrios Unidos & 370 & 14 & 132 & 10 & 80 & 10 & 3 & 9 & 6 & 1 & 6 & 641 & 233781 & 27 \\
\hline 13 & Teusaquillo & 179 & 12 & 179 & 48 & 73 & 3 & 2 & 27 & 10 & 1 & 9 & 543 & 146583 & 37 \\
\hline 14 & Los Martires & 130 & 24 & 64 & 10 & 25 & 1 & 3 & 4 & 16 & & 4 & 281 & 97926 & 29 \\
\hline 15 & \begin{tabular}{|l|} 
Antonio \\
Nariño \\
\end{tabular} & 53 & 8 & 72 & 12 & 27 & 1 & 2 & 7 & 7 & & 3 & 192 & 108307 & 18 \\
\hline 16 & Puente Aranda & 168 & 15 & 158 & 23 & 54 & 5 & 4 & 11 & 14 & & 1 & 453 & 258441 & 18 \\
\hline 17 & La Candelaria & 116 & 8 & 102 & 40 & 16 & 0 & 1 & 28 & 12 & & & 323 & 24144 & 134 \\
\hline 18 & Rafael Uribe & 525 & 21 & 183 & 38 & 72 & 6 & 2 & 8 & 10 & & 3 & 868 & 377615 & 23 \\
\hline 19 & Ciudad Bolívar & 823 & 37 & 174 & 85 & 74 & 3 & 4 & 7 & 14 & & 4 & 1225 & 639937 & 19 \\
\hline 20 & Sumapaz & & 3 & 4 & 7 & 2 & & & & & & 3 & 19 & 6258 & 30 \\
\hline & $\begin{array}{l}\text { Fuera de } \\
\text { Bogotá }\end{array}$ & & & 1 & 2 & 26 & & 2 & 7 & 1 & & & 39 & & \\
\hline
\end{tabular}

Equipamentos por setor, população e equipamentos por cada 10.000 habitantes 2011. FONTE: SDP, Dirección de Planes Maestros y Complementarios. 
- 4. Fig. Proximidade aos equipamentos 2015.

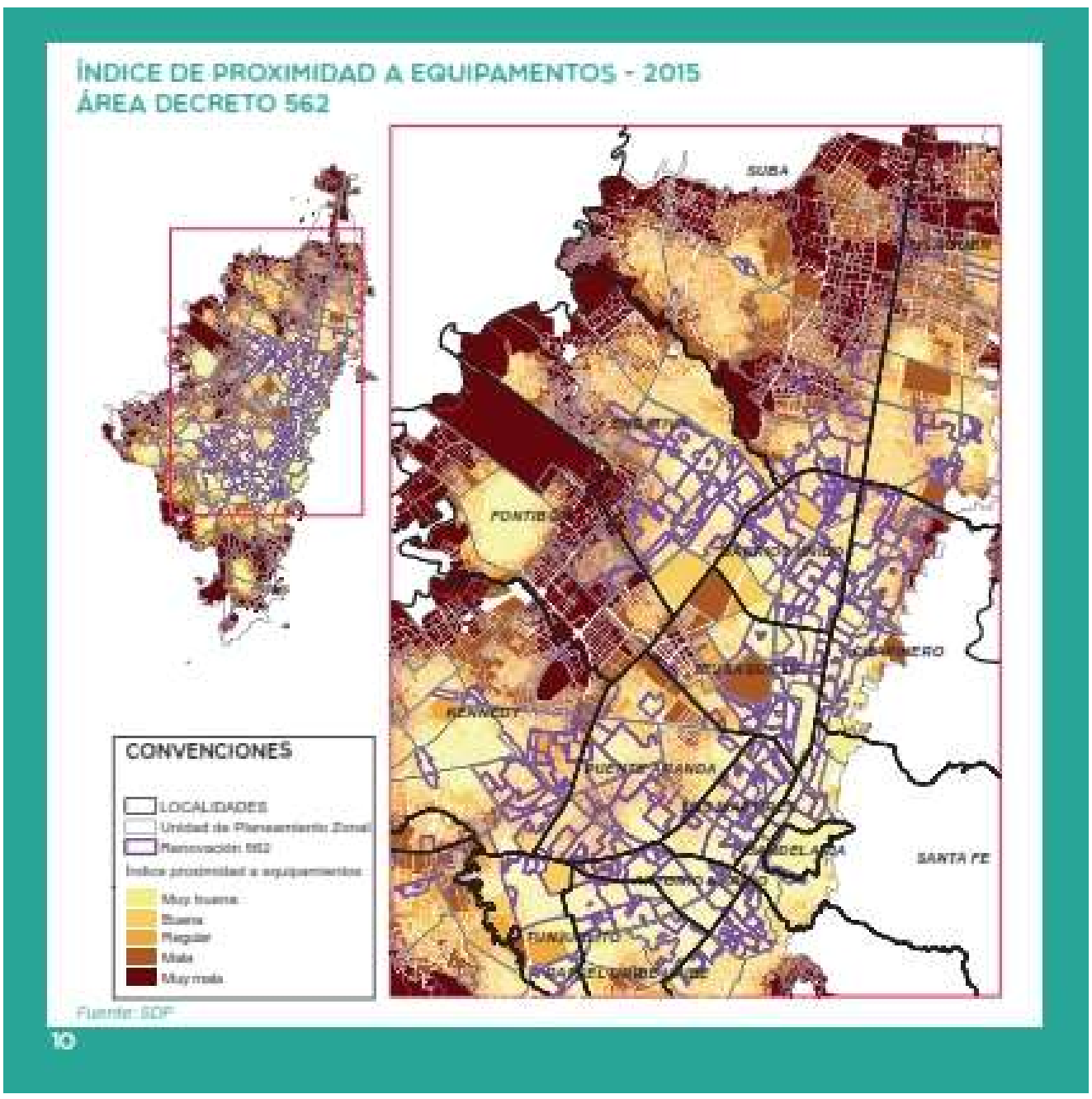

